\title{
Cooperation, Convertibility, and Compatibility Among
}

\section{Information Systems: A Literature Review}

\author{
Madeline M. Henderson, John S. Moats, \\ and Mary Elizabeth Stevens \\ Institute for Applied Technology \\ National Bureau of Standards \\ Washington, D.C.
}

and

Simon M. Newman

Office of Documentation

National Academy of Sciences

National Research Council

National Bureau of Standards Miscellaneous Publication 276

Issued June 15, 1966 
Library of Congress Catalog Card Number: 66-60028 


\section{Contents}

1. Introduction - .

Page

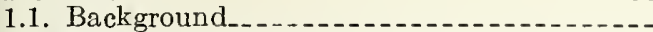

1.2. Scope of this report

1.3. Definition of documentation

1.4. Definitions of cooperation, compatibility, and convertibility

1.5. Increased growth and complexity of information resources

2. Early developments in coordination and cooperation _._. 2.1. Historical background 2.2. Role of the Federal Government_....... 2.3. Role of national organizations 2.4. Role of international groups 2.5. Role of conferences and meetings on documentation _..................

3. Current operations and proposed activities 3.1. Background 3.2. Current activities in Federal agencies.-.3.3. Traditional cooperative activities......... 3.4. Dissemination and publication of secondary 4.1. Listings of monographic publications

3.4.2. Listings of periodicals and periodical articles

3.4.3. Listings of reports of Government agencies

3.4.4. Abstracting and indexing services and publications..............

3.4.5. Clearinghouses

3.4.6. Copyright and translation problems-

3.5. Acquisition and exchange of publications.-3.5.1. Interlibrary loans

3.5.2. The Farmington and other exchange plans .....-

3.5.3. Photo duplication services

3.5.4. Depository libraries

3.5.5. Cooperative exchange of data

3.6. Analysis and identification

3.6.1. Phys i cal identification-descriptive cataloging

3.6.2. Content identification-subject cataloging - . . . .
3. Current operations and proposed activities-Con. 3.6. Analysis and identification-Continued

3.6.3. Cooperative and centralized cataloging . .

3.6.4. Cataloging rules and guidelines....

3.6.5. Use of machines for description and

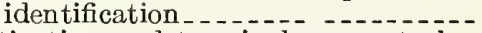

3.7. Systematization and terminology control -3.7.1. Thesauri._._.

3.7.2. Classification schemes $\ldots \ldots$

3.7.3. Interchange of indexing languages...

3.8. Storage, search, and selective dissemination_

3.9. Standardization

3.9.1. Programs of Federal Government agencies

3.9.2. Programs of the American Standards Association (ASA)

3.9.3. Programs of the International Standards Organization.........

3.9.4. Programs of other organizations...

4. Problem areas .

4.1. General problem areas.

4.1.1. Difficulties of problem definition...-

4.1.2. Problems of language.

4.1.3. Consistency, reliability, and relevancy

in indexing
4.1.4. Problems of user acceptance and
human factors

4.2. Special problems raised by changes in the nature of the materials to be handled...-

4.3. Special problems raised by the prospects for mechanization

4.3.1. Machine language and bibliographic information ......

4.3.2. Storage requirements 4.3.3. Problems of input.....

4.3.4. Character sets for machine processing . . .

4.3.5. Internal processing and programming languages . . .

5. Implications for further progress Appendix: List of references cited and selective bibliography
Pago

60

61

63

66

67

72

77

84

87

88

91

93

95

95

96

98

102

104

107

110

111

113

114

116

117

118

124 



\title{
Cooperation, Convertibility, and Compatibility Among Information Systems: A Literature Review
}

\author{
Madeline M. Henderson, John S. Moats, Mary Elizabeth \\ Stevens, and Simon M. Newman
}

\begin{abstract}
The purpose of the study of the literature on which this report is based was to examine those problems in the field of documentation and in the operation of information systems which could possibly be solved or alleviated by some greater measure of cooperation, convertibility, or compatibility among systems, particularly those systems for handling scientific and technical information supported in whole or in part by the United States Government. An account is given of early developments and general background information about organizations active in cooperative documentation efforts. Current cooperative activities are then discussed in terms of dissemination and publication of secondary sources, acquisition and exchange of publications, analysis and identification, systematization and terminology control, storage and search, and standardization. General problem areas, special problems created by changes in the nature of the documentary materials to be handled and special problems raised by the prospects for mechanization are then discussed. A final section raises questions with regard to the implications for future progress.
\end{abstract}

Key words: Documentation, scientific and technical information, information centers, libraries, mechanized information systems, convertibility, abstracting, indexing, cataloging, technical reports, translations, cooperative acquisitions, information exchange, standardization.

\section{Introduction}

\subsection{Background}

There are two principal developments that have converged, since the close of World War II, to influence the promotion of and participation in greater cooperation, collaboration, and coordination in the handling of recorded scientific and technical information. These two developments have made the problems of such cooperation an area of sharply increased need and of challenging new opportunities to the U.S. Government, the scientific community and its professional societies, and business and industry. The first development is the large-scale involvement of the Government itself both in sponsoring and in supporting research and development efforts, with accompanying recognition of its responsibility to make public, as promptly and widely as possible, the results of such efforts.

The second development is the technological advance that has occurred in information processing, with enormous potentialities for radically new systems and techniques. New opportunities arise from the successful use of machines to assemble, process, list, store, retrieve, and display records of various sorts; from the development of techniques for handling scientific and technical literature by clerical and machine manipulation, and from the development of nerv, unconventional, and less formal means for publication and dissemination.
A major reason for the increasing concern about possibilities for improved cooperation, convertibility, and compatibility among information systems is the problem of the so-called information explosion. Despite controversy as to the nature and extent of the steadily growing volume of scientific and technical information, it is indisputable that today the amount of literature that must be checked for possible pertinency far exceeds the the capacity of individuals to maintain awareness or to make full use of potentially related work.

The number of scientists and engineers falls short of meeting demands; this means that there is a heavy premium on reducing duplication of efforts and conserving the technical man's time to the maximum extent possible. More effective utilization of information resources in science and technology can contribute to more effective use of scientific manpower. Such improved use of information is indeed a major concern of the Committee on Scientific and Technical Information (COSATI) of the Federal Council for Science and Technology (FCST), The Office of the President.

The present report is the outgrowth of suggestions advanced by the Ad Hoc Interagency Study Group on Language Compatibility in Mechanized Storage and Retrieval Systems. At the instigation of the National Science Foundation, this Study Group was established in 1961 to provide, on an informal working-level basis, a mechanism 
for investigation and interchange of information among representatives of agencies already in process of mechanizing their information handling operations, contemplating such action in the near future, or heavily involved in the interchange of information with agencies that have such mechanized systems. During the course of early deliberations of the Study Group it was decided that it would be well to undertake, for the guidance of the Group's members and as a source of clues to problem areas and possible solutions, a review of the present state of cooperation, convertibility and compatibility among information centers.

Subsequently, following FCST's establishment of a Committee on Scientific Information (precursor of COSATI) its members reviewed the objectives and activities of the Study Group. In a letter dated April 19, 1963, addressed to the members of the Study Group, Admiral Martell, Chairman of the Committee, stated in part: "I am impressed not only with the importance of the need for cooperation, convertibilty and, if possible, ultimate compatibility among the many federal information systems, but also with the need for speed in isolating the many detailed problems which will need resolution as we attempt these necessary steps. I have asked Dr. Alexander to continue his chairmanship and have included your committee as a technical subcommittee of the Committee on Information." 1

In addition to thus co-opting the original Study Group, the Chairman approved the task of assembling a bibliography and preparing a report on the state of cooperation, convertibility, and compatibility among information retrieval systems in the Government. However, the literature is not easily divided between Government and non-Government activities. "The communication problems of Government are inextricably intertwined with those outside the Government. Both the Government and the non-Government communities are concerned with the same total body of information; the progress made in each contributes vitally to the other." 2

Since the lessons to be learned from a study of past actions in either case should be equally applicable to present problems, a mutually acceptable arrangement was made to cover information systems in general. Under this arrangement, the National Science Foundation supported the intraGovernment review by the National Bureau of Standards and the Office of Documentation, National Academy of Sciences-National Research Council, made provision for coverage of the extraGovernment activities.

A review of the literature has therefore been undertaken to determine what precedents for improved cooperation, convertibility, and compati-

\footnotetext{
1.Alexander and Newman, 1963 ( $[10]$, Appendix H. Note :
bibliographic citations are listed in the order of the number shown in brackets in the appendix, p. $124 \mathrm{ff}$ ).

${ }^{2}$ President's Scientific Advisory Committee, 1962 [465], p. 33.
}

bility have occurred, to identify typical problems and difficulties, and to provide a realistic perspective for attacks on current problems.

\subsection{Scope of This Report}

The motivation for organization of and the name adopted by the original Ad Hoc Study Group emphasize its primary interest in machine language compatibility and, by extension, in the possibilities for cooperation, convertibility, and compatibility between mechanized systems, particularly those in operation or planned by the Government agencies engaged in large-scale operations of information dissemination. There are three major reasons, however, why these primary interests have needed to be broadened.

First is the recognition that the problems of mechanization are but one aspect of the whole complex cycle of the generation, dissemination, and use of scientific and technical information. This recognition implies that language compatibility at many levels (initial recording, language of announcement of availability, cataloging, classifying or indexing, encoding for storage, transmission via communication links, and the like) affects and is affected by many different operations in the broad area of documentation. Also implied is the high probability that the problems of handling the report literature, with which the majority of the Government's informationhandling agencies are most directly concerned, cannot safely be divorced from the problems of handling the traditional literature: books, serials, and monographs.

In particular, the question of Government responsibility for the preparation, announcement, and dissemination of information on the results of Government-sponsored research cannot be divorced from the missions of the three great Government-supported National Libraries: The Library of Congress (LC), The National Agricultural Library (NAL), and The National Library of Medicine (NLM). Obviously, in these three libraries, the techniques for handling the traditional and the newer forms must be blended. Similarly, the network aspects of the overall problem should not be neglected, which involves many small special-purpose information centers, offices, and libraries as well as the large organizations and national centers and services.

The second major reason has to do with the characteristics of machines used to date and the fact that currently there are very few instances of fully mechanized systems of any considerable size or with more than quite limited operational experience. In terms of machine characteristics, there is a wide variety of machines available for prospective as well as present applications, but beyond the punched card stage, machines are seldom compatible even within the "family" of a single manufacturer. There is a true Babel of 
programming and machine languages; there is little or no compatibility between words or record lengths and formats; and auxiliary equipment to achieve conversions between one type of machineusable record and another is limited as to availability, is often costly and is cumbersome and slow in performance.

With respect to the limited number of mechanized systems from which practical lessons might be learned, it should be noted that despite the emphasis placed upon the potentialities of machine techniques over the past decade, very little real advantage has as yet been achieved. With rare exceptions, search and retrieval systems that have been mechanized in whole or in part are simply ". . scaled up and computerized versions of punched card searching systems based on index term matching. The overall performance of such systems, in terms of the generally used precision and recall measures, appears to be very low, and not adequate to provide a thorough searching capability." 3

Large-scale integrated machine systems such as MEDLARS (Medical Literature Analysis and $R$ etrieval System) or STAR (Scientific and Technical Aerospace $R$ eports) are still in various stages of development and have yet to prove their comparative efficiency in overall operation, despite the promise and challenge they offer. Thus, the opinions expressed by Jahoda in 1958, Adkinson in 1960, Herbert in 1962, and an Arthur D. Little team in 1963 have almost equal pertinence today:

"Mr. Gerald Jahoda reported on the results of a questionnaire survey of some 39 correlative or coordinate indexing systems now in operation, mostly located in the United States. These systems are relatively small. Over 80 percent of the installations participating in the survey reported collections of 20,000 or fewer documents. The systems are not extensively used, since 60 percent reported 200 or less inquiries per year. Finally, there was a strong indication from the questionnaire responses that in the large majority of the installations more traditional methods such as alphabetical subject indexing or conventional classifications systems might have been used to equal advantage." 4

"Thus far a large majority of the operating systems that make use of some mechanized procedures are located within individual industrial organizations. The subject matter encompassed by any one system is fairly homogeneous and for the most part it is chemical or biochemical in nature, fields in which the information itself has a more apparent structure and is more easily coded for mechanized systems than is information in other fields ... . Very few of the operating systems cover more than 25,000 documents, and only two or three cover more than 100,000 documentsall very small systems compared with the problem

8 Arthur D. Little, Inc., 1963 [344], p. 2.

4 Stevens and de Grolier 1959 [544], p. 809. of handling all scientific literature, or even all the literature of one discipline. Experience with such systems may be needed to handle very large volumes of material." 5

"The fact is that relatively few information retrieval systems have been put to work. There are very few data available to show how various IR systems significantly excel each other, or even do better than a resourceful librarian." 6

"It may be possible to scale up a punched card searching system originally designed to work on a digital computer with perhaps 30,000 documents without too much difficulty. But scaling it up an order of magnitude further, to 300,000 documents, will in all probability so magnify and distort the existing difficulties that the feasibility of the procedure becomes uncertain." 7

The third of the major reasons for extending the scope of this report beyond the "present state of cooperation, convertibility, and compatibility among information retrieval systems in the Government" 8 was the paucity of examples found in the literature search that would directly pertain to the problems of machine language compatibility. The small number of examples of cooperation, convertibility, and compatibility, in the special terms of machine language and machine application compatibility, has led to a preponderance of coverage in other areas of cooperation, especially those where future needs for greater compatibility and convertibility can be foreseen in terms of machine potentialities. For this reason, the coverage of more traditional library techniques and requirements may seem at first glance to be out of balance; yet it well may be that improvement in the handling of scientific and technical information can be achieved as much by extended efforts in these areas as in specific agreements between mechanized systems. It is important to remember how interdependent the information generating, processing, and utilization processes are.

The organization of material for this report has also been difficult in other respects. It has seemed desirable first to give a relatively general background with respect to agencies, national and international organizations, formal and informal groups and individuals active in efforts which may improve cooperation, convertibility, or compatibility, leading toward the ultimate goal of standardization. Next, we have attempted to discuss these and similar efforts in the framework of the typical documentation and information handling operations. We have included consideration of the present and potential effects of mechanization and of typical problems and difficulties in each of these sections. However, we have also attempted to reemphasize problem areas and difficulties in a separate section, at the risk of some repetition and redundancy.

\footnotetext{
${ }^{5}$ U.S. Senate, 1960 [592], p. 104-105, report by B. W. Adkinson.

${ }^{6}$ Herbert, 1962 [253], p. 22.

7 Arthur D. Little. Inc., 1963 [344], p. 16-17.

8 Alexander and Newman, 1963 [9], Appendix $\mathrm{B}$ (italic sup-
} plied). 
In the concluding section on implications for future progress, certain somewhat controversial points have undoubtedly been raised. These reflect points which have been made in the literature and which, in the opinion of the reviewers merit some consideration in terms of continuing concern for cooperation, convertibility, and compatibility. The authors, however, are responsible for selecting the quotations which have been included. The material covered in this report represents primarily information from a selective survey of the literature published through December 1963. In a few instances, however, pertinent material published later has also been included.

Interesting anomalies of viewpoint, procedure and knowledge of other (but often collateral) practices run through the literature we have scanned, selected, and assembled. It is always difficult, even when teaming together authors of several different backgrounds but all with some specialized experience in the field, to avoid inadvertent omissions and misplaced emphases in coverage and treatment.

The present report was circulated in draft form to the members of the Ad Hoc Committee in February 1965 , with a request for their criticisms and comments to be submitted by March 31. Wherever possible, those suggestions received for correction and improvement have been incorporated. Other inaccuracies may nevertheless remain. It should be noted also that the inclusion of information on various specific activities and the omission of others is not intended to reflect an endorsement as such of those that are included nor in any sense an adverse evaluation of those that are not mentioned.

The purpose of the study on which this report is based was to examine those problems in the field of documentation and in the operation of information systems which could possibly be solved or alleviated by some greater measure of cooperation, convertibility, or compatibility between systems. It might be valuable to start by defining documentation and by delineating what we mean by cooperation, convertibility, and compatibility among information systems. We can then enumerate the various activities pertinent to the field, pointing out which documentation activities are susceptible to cooperation and therefore are pertinent to the scope of this report.

\subsection{Definition of Documentation}

The term "documentation" is considerably older than its present-day implications. It is reported that the delegates to the Congress of Archivists and Librarians held in Brussels in 1910 "admitted confusion regarding the use of the word documention." 9 The confusion persists despite the mushrooming of the field and many new additional facets. As a result little agreement on standard meanings for terms has yet been reached.

\footnotetext{
${ }^{9}$ Ludington, 1954 [351], p. 196.
}

Individuals and professional societies have published glossaries of terms in documentation and data processing, but little if any agreement on the use of such terms has found its way into the literature of the field. However, we can quote several definitions to illustrate what is generally meant by the term "documentation."

Ranganathan has traced the genesis of the term as follows: "From the turn of the present century, bibliographers began to pay attention to microthought (i.e., articles in current periodicals) and not merely to macro-thought (i.e., whole books). This was necessitated by large-scale promotion of research work 'in-series' and the need for communicating nascent thought to all workers in the field as and when each little quantum of it got created. . . Micro-bibliography and economical service of articles by photographic methods started to attract active attention about a generation ago. At that time a generic name was needed to cover these two activities. . . . This genesis of the term 'Documentation' makes it clear that the materials coming within its purview are printed and published ones arising in the course of the creation of new thought by persons working in the forefront of knowledge. . . " 10

The letterhead of the Federation Internationale de Documentation (FID) carries the message "Documentation égal collection et conservation, classification et selection, dissemination et utilisation de toute information." The term classification, while ambiguous, most often refers to the step of indexing or tagging a document with some representation of its subject content. Two additional steps, those of systematization and recording, are of particular interest from the standpoint of cooperation, convertibility, and compatibility among information handling systems. Systematization is the construction, organization and maintenance of some form of schedule or authority list setting forth the tags or indexes, while recording is the construction and maintenance of transcriptions which relate the documents to the index tags. These are operations especially sensitive to the introduction of new techniques and mechanization which have given new emphases to the field of documentation since World War II.

The new status of the field is reflected in the definition of documentation in Webster's New International Dictionary, Third Edition, as "the assembling, coding, and disseminating of recorded knowledge comprehensively treated as an integral procedure utilizing semantics, psychological and mechanical aids, and techniques of reproduction including microcopy for giving documentary information maximum accessibility and usability."

Another definition, by Helen L. Brownson, calls documentation the "art of facilitating the use of recorded, specialized knowledge through the presentation, reproduction, publication, dissemination, collection, storage, subject analysis, organi-

${ }^{10}$ Ranganathan, 1952 [470], p. 105-106. 
zation and retrieval." 11 In their textbook on information storage and retrieval, Becker and Hayes define documentation by pointing out what it is not: it is not concerned with librarianship so much as with the systems and tools of librarianship; it is not concerned with the operation of information systems so much as with their analysis and design. ${ }^{12}$

Again, Allen Kent in his book on mechanical information retrieval considers documentation activities as the unit operations which comprise an information system: (1) acquisition of source materials; (2) analysis of these documents to serve as a basis for orderly organization to facilitate the identification of wanted information on demand; (3) terminology and subject heading control to facilitate search by the use of language based information retrieval systems; (4) recording the results of the analysis on a searchable

11 As contributed to the American Documentation Institute, see Wagner, 1960 [618], p. 108.

12 Becker and Hayes, 1963 [ [4], p. 43-44. medium; (5) storage of source documents, extracts of documents, abstracts and bibliographic references; (6) analysis of questions put to the information retrieval system and development of search strategy; ( $\tau$ ) conducting a search; and (8) delivery of the results of a search. ${ }^{13}$

If the above definitions of documentation are of service in delineating the field, then the activities of particular interest to this report are as follows: (1) dissemination, including publication of secondary sources such as abstract journals, announcement bulletins and indexes; (2) acquisition and exchange of publications; (3) analysis, leading to descriptive cataloging and subject cataloging; (4) systematization, including terminology control and standardization; (5) storage, at least in some aspects such as standardization of formats, maintenance of cooperative deposits, ability to convert from one form of storage medium to another, ease of adding or deleting items, system modifications based on storage capacities and the

${ }^{13}$ Kent, 1962 [312], 76-78; see also [309], p. 110.

TABLE 1. Documentation Processes

\section{Process 1. COMMUNICATE}

A. Direct:

Basic data

Primary publication

B. Indirect:

Tables, Compendia

Secondary publication

Information about sources

Subprocesses :

1. Identify-Select

2. Transcribe-Encode

3. Issue-Publish

Process 3. ACQUIRE
A. Basic data
B. Primary references
C. Secondary references
D. Information about sources

Subprocesses :
1. Identify need
2. Locate sources
3. Order
4. Receive

Process 5. SEARCH

A. Basic data

B. Primary references

C. Secondary sources

D. Information about needs

Subprocesses :

1. Specify selection criteria

2. Define scope, relationships of selection criteria, strategy

3. Conduct search

4. Reformulate specification, iterate as necessary

5. Reject-select
Process 2. ROU'TE

A. Basic data

B. Primary reference

C. Secondary reference

Subprocesses :

1. Identify

2. Select addressees

3. Disseminate

Process 4. STORE

A. Basic data

B. Primary references

C. Secondary references

D. Information about sources

E. Information about needs

F. Information about searches

Subprocesses :

1. Organize for search

2. Organize for storage

3. Prepare and store

4. Maintain-revise-restore

Process 6. RE'TRIEVE

A. Selected items or values of basic data

B. Selected primary references

C. Selected secondary references

D. Selected information about needs

Subprocesses:

1. Locate

2. Remove-reproduce

3. Prepare for use

4. Distribute 
like; and (6) searching for documents, in the sense of "where to find what." Since the product of searching can be facts, references, or documents themselves, the interest of this report lies with what is obtained and the degree of its compatibility with the products of other systems, rather than the detailed techniques of how the product is obtained.

We might portray documentation activities as shown in table 1 . Those activities of special interest here, as shown by italics, are susceptible to some degree of cooperation, convertibility, or compatibility. We can now define these terms for the purposes of this report.

\subsection{Definitions of Cooperation, Compatibility, and Convertibility}

Cooperation involves collaborative effort or sharing between organizations in actual processing of materials for information systems or in exchange of the products of such processing. Cooperation ranges from sharing of the load of coverage of a particular subject field by means of interorganization loans, through sharing the $a b$ stracting coverages and workloads, to joint effort in the establishment of word lists, thesauri, and indexing standards. An especially important area of cooperation is in the coordination of information about sources-what is available and where.

Systems are considered to be compatible when the results of processing in one system are immediately and directly usable by other organizations having similar but not necessarily identical systems. Where the products of systems in collaborating organizations can be used interchangeably by those organizations without special efforts or conventions, the systems are compatible. An obvious and early example of such compatibility is the practice of adding directly to an existing card catalog the cards supplied by the Library of Congress. However, it should be noted that "the most challenging problems for company, as well as for society, government, or commercial services, are those of compatibility between systems for indexing, retrieving, and disseminating information and between the languages of those systems. There is yet, however, no meeting of the minds even as to the meaning and purpose of such compatibility." 14

Where results and products of processing in one system are usable in another system, but not immediately or directly, the systems may or may not be convertible one to another. Various operations of transcription, transliteration, re-recording, re-encoding or rearrangement have to be achieved, particularly by clerical or mechanical means, in the maintenance of convertible systems. An example of convertibility is the mechanized

It Anderson, 1962 [29], p. 114. rearrangement of a classified index listing into an alphabetized listing.

Compatiblity and convertibility may apply either mutually or in only one direction between and among information systems.

\subsection{Increased Growth and Complexity of Information Resources}

Interest in applying some measure of cooperation or coordination to the activities of documentation has been quickened, as noted earlier, by the growing volume of publication. In addition, the increasing specialization and yet interdisciplinary nature of research areas have combined to augment this same interest. In the case of scientific and techuical developments, the volume of new materials is beyond the capacity of most organizations to acquire, issue prompt notice of accession, classify or index, disseminate, store, and subsequently select and retrieve documents within the time scale, economics and precision necessary for efficient service and effective use. Patent offices and the legal profession compound these problems with pressures for immediate detailed documentation of all past publications which, in these areas, do not lose pertinency because of age.

There have been expressions of doubt as to the size and nature of the increased flow of information, and the possible extent of application of computer technology to the handling of this flow. ${ }^{15} \mathrm{~A}$ particularly provocative reaction is that of Yehoshua Bar-Hillel, who has summarized his opinion as follows: "The geometrical rate of increase in scientific and technological publications ... is commensurate with the increase in scientific and technological manpower and is in fact, nothing more than its direct result. . . . The only areas in which the [information] retrieval situation is intrinsically worsening are those which exhibit the 'cumulative effect' especially the areas of law, patent searching, and library acquisitions. But in these areas the natural remedy lies in a change of policy and practices rather than in a revolutionary change of the retrieval operations." 16

Reactions to this forthright opinion ranged from argument about the complexity of the information flow and the crisis which it engenders for librarians and information specialists to statements of belief that information handling facilities were generally keeping pace with the increased volume. An interesting point was made by Philip Abelson, editor of Science, who wrote that in leading areas of scientific discovery, information retrieval presents no problem, and there is fast and complete interchange of information by personal visit, telephone, postal correspondence, and exchange of mimeographed preprints of papers. For

15 A varlety of views with respect to the information "crisis" are Incorporated in the report on the hearing before the Senate Subcommittee on Reorganization and Internal Organlzations, 1962 [594], p. 41-49.

16 Bar-Hillel, 1963 [45], p. 98. 
those engaged in technology, who wish to apply the results of basic research, and especially for those concerned with patents, the problem is quite different and a more serious difficulty exists. ${ }^{17}$

But given the problem of the volume and interdisciplinary nature of scientific and technical information, whether we tag it as a crisis or an explosion or not, the fact remains that interest has been aroused in the possibilities for increased cooperation, compatibility, and convertibility in and among information systems. We shall review here the early steps in these directions, before discuss. ing more fully the current operations and proposed activities in these areas.

\section{Early Developments in Coordination and Cooperation}

\subsection{Historical Background}

The need for cooperation by governments, industry, professional societies, and individual scientists in the handling of scientific and technical information is not a new problem. The history of the development of science is all too abundantly marked by instances of communication failures, barriers to communication effectiveness and consequent replications of effort and rediscoveries of the same inventions and ideas. Disclosure of the results of research and development efforts has always been prerequisite to progress in scholarship, basic scientific understanding and technological applications of the results of new knowledge.

Originally, disclosure involved principally the scholarly obligations of the individual investigator. The Royal Society, founded in England in the 17th Century, included among its functions the responsibility for communication and disclosure of scientific information. It is the prototype for responsibilities of professional societies and of the scientific community, then and since. Thus, until approximately the last two decades, the handling of scientific and technical information continued to be generally subsumed under obligations assumed by individual and professional societies to publish and disseminate disclosures of research and development results and under responsibilities for the collection and (at least to some extent) the cataloging of published literature, as assumed by libraries, museums, universities, and other institutions.

Interest and concern for the effective disclosure of scientific information has had a relatively long history in the United States. We might go back to Washington's Farewell Address, in which the injunction is laid down "to promote knowledge." The Smithsonian Institution was created in 1846 as a result of a bequest from James Smithson to the United States for the establishment of a center "for the increase and diffusion of knowledge." Joseph Henry, America's most distinguished

\footnotetext{
${ }^{17}$ Abelson, 1963 [1], p. 319
}

scientist at the time, served as Secretary for the Smithsonian for 32 years. His principles still govern it; ". . . to facilitate in every way the promotion of science. ... and enlarging the bounds of human thought." No branch of knowledge is excluded from the Smithsonian's attention. Some 10,000 scholarly books and monographs bear the Institution's imprint. Scientists and scholars in increasing numbers use its library of more than a million titles, many of them now on deposit at the Library of Congress.

That venerable institution was founded at the beginning of the 19th century, when the original library-"shipped, by the Grace of God," as a bill of lading reads-arrived from London in 1801, a year after the books had been ordered by Congress. The Act of 1800 establishing the Library provided for the "purchase of such books as may be necessary for the use of Congress at the said city of Washington and for fitting up an apartment for containing them. The first significant material of a scientific nature came with the purchase by Collgress in 1815 of the 7,000 volume personal library of Thomas Jefferson." 1

Today the Library of Congress includes far more than books. It houses newspapers on microfilm, motion pictures, historical items such as election posters and photographs, the finest surviving Gutenberg Bible, and the like. In all, the library is full to the bursting point with $43,500,000$ items. Of particular interest to this report is the collection of scientific and technical material which was started at the Smithsonian and transferred to the Library of Congress in 1866.

An additional example of attempts at cooperation and collaboration by the Smithsonian and the Library of Congress involved library catalogs of holdings. Charles C. Jewett, librarian at the Institution in its early years, saw a need for a method by which catalogs, at that time issued in book form, might be issued cheaply and promptly and without endless duplication by separate libraries. If a technique based on the "stereotype" could be developed, it would be possible to assemble a national collection of stereotypes, each representing a separate book, and to combine these as desired for printing the catalogs of individual libraries.

"The title of every book and of each distinct edition is stereotyped upon a separate plate. The author's name also stands by itself. Each plate shows at a glance the heading to which it belongs. It is obvious that these plates may be placed together in alphabetical or other order, as may be desired. They are mounted on blocks, for printing like other stereotype plates. It is proposed to preserve the plates or blocks in alphabetical order of the titles, so as to be able readily to insert additional titles, in their proper places, and then to reprint the whole catalogue. By these means, the chief cost of republication (that of composition) together with the trouble of revision and

1 Sherrod, 1962 [528], p. 35. 
correction of the press, would, except for new titles, be avoided." 2

"Congress, on the recommendation of the Library Committee, made an appropriation for the practical testing of the plan in its application to the Library of Congress." 3 The resulting sample catalog, printed in 1854, constitutes a handsome piece of 19th century printing. Unfortunately, the plates warped in storage and the information on them was lost. Not until some 50 years later did American libraries get the benefit of a central source of bibliographic information with standardized printed catalog cards based on very large collections. ${ }^{4}$

Jewett was also instrumental in calling and presiding over a convention of librarians in New York in 1853 , "the first convention of the kind, not only in this country, but, so far as I know, in the world." 5 We shall mention some of the actions of this 1853 Convention in section 2.5 , but because the International Exchange Service also involved, historically, the collaboration of the Smithsonian Institution and the Library of Congress, we note here a communication from Mons. $\mathbf{A}$. Vattemare on the subject of international exchanges and the chronology and coverage of cooperative efforts in this area from 1832 to that date.

Several of his remarks are of particular interest: "What I aim at is, the establishment of a regular and permanent system of exchange between governments, of not only the useless duplicates of their public libraries, but everything emanating from the genius of a nation, so as to form in the capitals of the civilized nations, public international libraries that would become a permanent exhibition of the intellectual power of each of them, a lasting World's Fair of the genius of nations. . . . Let us have a central agency on each Continent, which shall be in connection with each other to negotiate these exchanges; let us have a monthly publication in English, French, and German, which shall publish the proceedings of the agency, and the titles of the books or objects exchanged. . . . Let me close this letter by expressing my grateful acknowledgment towards the States and institutions of the Union, that have so readily and so nobly given a helping hand to my efforts, and tell them that, in my conviction, the time is not distant when they will reap the advantages of that generous and persevering support; that the little that has been done to this time is only the earnest of what is yet to come. As for the private individuals who have seconded my labors, the number is too great to mention them here, and they have already found in their conscience and patriotism the reward of their acts." 6

a "Proceedings of the Librarians' Convention . . 1853," 1915 [466], p. 26 .

5 "Proceedings of the Librarians' Convention . . . 1853," 1915 [466] p. 13 .
Ibid, pp. $53-55$.
Under the guidance of Joseph Henry, the Smithsonian Institution made early provision for the international exchange of publications. Since the scientific literature collection was transferred to the Library of Congress the program has been steadily extended, until today there exist some 17,000 or more agreements with other governments, research centers, laboratories, academic and other institutions (including more than a hundred in the Soviet Union) for exchanges of holdings. ${ }^{7}$ Libraries throughout the world have been enriched by the publications received through this exchange service from many institutions in the United States and, in turn, the libraries of the United States have benefited from the publications received from the institutions in foreign countries. ${ }^{8}$ Publications are sent to foreign countries on exchange or as gifts by libraries, scientific societies, educational institutions, and individuals. Shipments of publications are received from foreign exchange bureaus for distribution in the United States.

This International Exchange Service, supported by appropriations of the U.S. Congress from 1881 onward, became the official United States Agency under the terms of the Brussels Convention of 1886 for the exchange of governmental, scientific, and literary publications. ${ }^{9}$

A final example from Smithsonian history is of interest both with respect to U.S. Government participation in international cooperation in documentation and with respect to compatibility through the adoption of uniform practices. Langley, discussing the sending of U.S. delegates to the International Conference on a Catalogue of Scientific Literature (July 1895, Royal Society, London) remarked that "as to the propriety and feasibility of the United States taking part, through the Smithsonian Institution, in the proposed work by providing for the continuous cataloguing of scientific literature published in the United States ... I fully concur in the view of the delegates ..... 10

Other 19th century developments included the establishment of the libraries that have become, respectively, the National Library of Medicine and the National Agricultural Library. The National Library of Medicine "dates back to 1836 , when its predecessor, the Library of the Surgeon General's Office was established." "11 (An interesting historical account of NLM, including details of early exchanges with other libraries and the earliest predecessor of today's Index Medicus, the 1840 'Catalogue' - "quaintly inscribed on ruled paper in roughly alphabetical order"-is given by Schullian and Rogers, 1958 [507].)

At least some commentators, however, suggest that "the history of the Army Medical Library

\footnotetext{
${ }^{7}$ C.S. House, 1959 [586], p. 2, statement of L. Q. Mumford.

8 Smithsonian Institution, 1964 [538], p. 65 .

8 True, $1946[572]$, p. 53-54.

10 Rhees, 1901 [479], p. 1772 .

11 National Library of Medicine, 1963 [412], p. 1.
} 
as a great research institution dates back, not to its founding in 1836 , but to 1865 when John Shaw Billings was an assistant to the Surgeon General." 12 Billings is noteworthy not only for his accomplishments in the Library itself and for the Index-Catalogue but for his early appreciation of the need for union catalogs ${ }^{13}$ and his pleas for author accuracy and specificity in the writing of titles. ${ }^{14}$

It is of interest, especially with respect to machine language compatibility, that Billings has been credited as the co-father, with Hollerith, of the notion of recording information into punched cards, which can then be sorted mechanically, and that the size of the Hollerith (IBM-type) punched card was based, at Billings' suggestion, on the then size of the U.S. dollar bill. ${ }^{15}$ Larkey has commented on the Billings-Hollerith colloboration as follows: "It is not known if Billings ever thought of applying the principle to bibliographic work, but it would seem eminently fitting that it might be so utilized." 16

Another early 19th century library, involving both Government support and scientific and technical information interests, is that of the U.S. Military Academy at West Point, New York. As Captain Henry Coppee remarked in 1853, "The institution which I have the honor to represent is certainly peculiar and unique-both sui juris and suigeneris - in that it is under the control of the general government and that its special character is military and scientific." 17

The U.S. Department of Agriculture Library has, since its establishment in 1862 , "emphasized direct service to users . . . [ the organic act states] that it shall be the duty of the Commissioner of Agriculture to acquire and preserve in his Department all information which he can obtain by means of books and correspondence." 18 In addition, he is to "diffuse useful information on subjects connected with agxiculture in the most general and comprehensive sense of that word." 19

The 19th century also saw the first development of an abstracting service, the assumption by professional societies of responsibilities for bibliographic services, the founding of library associations, and the first international activities in the field of documentation. For example, "As early as 1807 in the field of geology and mineralogy ... the first abstracting service was established in Germany." 20 In 1858, the Royal Society began preparation of a "Manuscript Catalogue of the Titles of Scientific Periodicals in All Languages," 21 and in 1877 the Library Association of

12 Metcalf et al., 1944 [380], p. vii.

13 Schullian and Rogers, 1958 [507], p. 16

14 Rogers, 1962 [490], p. 704.

15 Larkey, 1953 [322], private communication, Scott Adams.

10 Larkey, 1953 [332], p. 34.

17 "Proceedings of the Librarians' Convention . . . 1853", 1915

$[466], \mathrm{p} .16$.

18 U.S. Senate, 1960 [592], p. 144, statement by F. E. Mohrhardt.

19 U.S. House, 1964 [589], p. 5.

${ }^{20}$ U.S. House, 1959 [586], p. 99, statement of G. M. Conrad.

21 Murra, 1951 [401], p. 29-30.
Great Britain was founded. ${ }^{22}$ In 1882, The American Association for the Advancement of Science appointed a Committee on Indexing Chemical Literature and in 1893 a Congress of Chemists held in Chicago proposed an International Committee on Chemical Bibliography to investigate cooperative international indexing. ${ }^{23}$

In the remainder of this section on early developments and organizational background, we shall discuss 20 th century developments up to about 1960 , and in a few cases we shall include even later instances as of general background interest with respect to organizations active in cooperative documentation efforts.

\subsection{Role of the Federal Government}

Burgeoning activities in scientific research and development brought about a need for extension of the responsibility for disclosure of research results from that of the scholar, the professional society, and the learned institution. There was, and is, the need for disclosure as a necessary condition for proprietary rights to private industrial exploitation, involving patent laws and copyright requirements; disclosure as a responsibility of a publicly supported agency for dissemination to its supporters and the public; disclosure as required by contractual provisions or in return for financial support; and disclosure as necessary to technological advancement in terms of special interests, ranging from the defense and security of a national government, through governmental concerns for public welfare, to the mutual advantages of commercial and private interests.

The importance of effective handling of disclosures of research results has received increased recognition throughout the world since World War II. In the United States, this period has been marked by:

(a) Prompt assumption of Governmental responsibilities for the announcement of a vailability of scientific and technical information stemming directly from Government-acquired material or Government-reporting of research and development progress;

(b) creation of information processing operations and organizations within U.S. Government agencies to handle the information output of these agencies and their contractors;

(c) continuing concern on the part of both Congressional and Executive branches of the U.S. Government with the problems of achieving more effective coordination and support of both conventional and newer methods of information control; and

(d) continuing concern with the effects of possible mechanization or automation of information handling operations upon improved utilization of recorded knowledge.

22 Bonn, 1959 [68], p. 1445

23 Murra, 1951 [401], p. 31-33. 
During the years of World War II, the research and development programs of the Federal Government, especially those of the Office of Scientific Research and Development (OSRD) and The Manhattan Project, included provision for the release and interchange of classified information "among a veritable army of civilian scientists, but the dissemination was cumbersome because little effort was spent toward establishing and maintaining bibliographic control." 24

As early as 1944, President Roosevelt requested Dr. Vannevar Bush, Director of OSRD, to prepare recommendations for postwar continuation of the "unique experiment of team-work and cooperation in coordinating scientific research and in applying existing scientific knowledge to the solution of technical problems" which OSRD represented. In particular, the first of four major questions was, "What can be done, consistent with military security, and with the prior approval of the military authority, to make known to the world as soon as possible the contributions which have been made during our war effort to scientific knowledge?" 25

The resulting report, "Science-the Endless Frontier," was submitted in July 1945 and served as the impetus for the organization of new information processing activities, for consideration in the Congress and elsewhere of the desirability of a Department of Science and Technology, and for many of the functions now carried by the Office of Science and Technology, The Federal Council for Science and Technology, The National Science Foundation, the Clearinghouse for Federal Scientific and Technical Information, and others.

Examples of specific recommendations which continue to be reflected in present activities or concerns are as follows: "The Government should take an active role in promoting the international flow of scientific information." 26

"Much of the information and experience acquired during the war is confined to the agencies that gathered it. Except to the extent that military security dictates otherwise, such knowledge should be spread upon the record for the benefit of the general public." ${ }^{27}$

"It is recommended that measures which will encourage and facilitate the preparation and publication of reports be adopted forthwith by all agencies, governmental and private, possessing scientific information released from security control." 28

More generally, the recommendations for a $\mathrm{Na}$ tional Research Foundation foreshadow much of the structure and operations of NSF. Specifically, with respect to scientific and technical information:

${ }^{24}$ Heald, 1952 [244], p. 138.

${ }^{25}$ Letter of President Roosevelt, November 17, 1944, Bush, 1945 [91], p. vil.

${ }_{20}$ Bush, 1945 [91], p. 17.

$2 \pi$ Ibld, p. 22 .
"Division of Publications and Scientific Collaboration-this Division should be charged with encouraging the publication of scientific knowledge and promoting international exchange of scientific information." 29

"The Foundation should take all necessary and proper steps :

"(d) To provide for and assure the most com. prehensive collection and dissemination of scientific and technical knowledge and information by aids to libraries, bibliographic services, translating activities, etc. ...

"(i) To cooperate with the Army, Navy, and civilian military research organizations for the rapid interchange of information on basic scientific problems of use in national defense. It should coordinate its activities wherever possible with these organizations to prevent unnecessary duplication ...

"(j) To assist industry and business, particularly small enterprises ... in obtaining scientific and technical information and guidance ...

"(1) To represent the United States of America in effecting better international cooperation in scientific activities, to assist in the freer international exchange of scentific and technical knowledge. . to help sponsor and finance international scientific: congresses or associations." 30

The work leading to "Science-the Endless Erontier" was accomplished with the aid of four committees of consultants. The reports of two of these committees are of special interest, that of the Committee on Science and the Public Welfare, Dr. Isaiah Bowman, Chairman, and that of the Committee on Publication of Scientific Information, Dr. Irvin Stewart, Chairman.

The Bowman report includes as an appendix a discussion of library aids and a summary of the Committee's views on interlibrary cooperation, abstracting and translating services and bibliographic and reference services. With respect to the first, the Committee concluded that "pending the widespread adoption of really revolutionary technical aids, it will be necessary to make comprehensive arrangements for interlibrary cooperation." ${ }^{31}$ Particular problems discussed include inadequate coverage with respect to library holdings and the problem of reproducing European literature not available during the war, the question of translation and republication of Russian language materials, the need for cumulative indexes to periodicals in various fields, and the like. While the Committee did not offer specific recommendations, it wished "to call attention to the existence of problems which, because of their magnitude and the large measure of centralization necessary for solution, appear to be proper subjects of federal concern." 32

\footnotetext{
29 Ibld, p. 29.

${ }^{80} 1$ bid, pp. 110-111

a Bush, 1945 [91], p. 112

22 Ibid, p. 115.
} 
The Stewart Committee report, however, noting the developments already in progress in OSRD toward the establishment of a publication board, specifically recommended "the prompt establishment and adequate staffing within the National Academy of Sciences of the proposed board to control the release and promote publication of certain scientific information. This is essential." 33

Then, in June of 1945, an Executive Order (9568) turned over to the Secretary of Commerce "operational responsibilities with respect to the declassification and distribution of government research reports kept under wraps during the war years." 34 This Executive Order was followed by a second (9604) concerning the reporting of the scientific and technical accomplishments of Axis Nations. Out of these orders came the Office of Technical Services (OTS), recently renamed the Clearinghouse for Federal Scientific and Technical Information. From the original order creating a "Publication Board," derives the so-called "PB" number still in use today. The Clearinghouse was endorsed by the Federal Council for Science and Technology and is building on existing activities of OTS.

Shaw reports on some of the early objectives as follows: "The work of the board is so designed as to make maximum use of all cooperating bodies and it welcomes offers of cooperation from any group which can carry responsibilities for abstracting and disseminating knowledge on a nonprofit basis. ... The concept of publication under which the board operates is the broad concept of 'announcing or making known' rather than the narrower concept of printing and distribution of multiple copies. ... The publication itself will ... be sent to the cooperating library covering its subject-matter field. Initially the cooperating libraries are Library of Congress, Army Medical Library, and the Department of Agriculture Library ... these libraries will file the publication by the number assigned to them by the publication board." 35

In September 1950, the 81st Congress passed Public Law 776, Section 2 of which is concerned with the operation of the OTS as follows: "... the purpose of this Act is to make the results of technological research and development more readily available to industry and business, and to the general public, by clarifying and defining the functions and responsibilities of the Department of Commerce as a central clearinghouse for technical information which is useful to American industry and business ...

"The Secretary of Commerce . . . is hereby directed :

"(a) To search for, collect, classify, coordinate, integrate, record, and catalog such information

83 Ibid, p. 184.

84 Green, 1963 [225], p. 1

s5 Shaw [52], p. 106-107. from whatever sources, foreign and domestic, that may be available.

"(b) To make such information available ... through tho preparation of abstracts, digests, translations, bibliographies, indexes, and microfilm and other reproductions . . ." 36

For the next several years O'TS collected and processed unclassified reports supplied by cooperating government agencies. Then, in 1957, after Sputnik, a greater interest in Soviet scientific and technical achievements led to the establishment of a clearinghouse for translations. OTS has also expanded its coverage of reports from non-Government sources, particularly those resulting from research "indirectly supported by the Government .... (such as) grants or percentage allowances (which enable) improvements or developments of research facilities ..." 37

From its initial establishment, OTS has provided many examples of cooperation in the processing of scientific and technical informationintra-Governmental, between Government and industry, with professional society or commercial publishers. A specific example is the program whereby American scientists and technologists visited Europe to uncover for themselves information about wartime developments there. "Victory opened the doors and the files of German factories and laboratories to American investigators. ... The cost is trivial, no more than the salaries and expenses of investigators-they travel at no cost to the Government. . . . We are dependent on the military for billets, food, transportation, and a hundred other things, all of which they have efficiently provided. ... The Office of Technical Services opens the way. ... We impose but one major condition on investigators: they must report their findings fully, in writing, in the form of technical reports. All reports are made publicly available for the benefit of all industry." 38

Another example: "To get important documents into circulation more effectively, OTS persuaded a number of commercial publishers to issue some of them. Once every two or three weeks, a selective 'Bulletin of OTS Reports Suitable for Commercial Publication' goes to 75 publishers, inviting them to order copies of items considered publishable." 39

Something of the scope of the "technological reparations" program of OTS may be appreciated in terms of 1947 comments: "To date over four million pages covering all fields of sciences and technology have been put on microfilm." 40

Turning back to the immediate post-war period, the Atomic Energy Commission was directed by the Atomic Energy Act of 1946 (and that of 1954), to conduct the following program: "(1) records

\footnotetext{
36 U.S. Senate, 1961 [591], p. 13.

эт Hamrick, 1963 [237], p. 219.

28 Green, 1947 [224], p. 24.

39 "Distribution", 1947 [175], p. 10

"Technological Reparations", 1947 [567], p. 8.
} 
and reproduces as rapidly as possible the scientific and technological data developed in its research and technological programs; (2) maintains acquisition and exchange programs with nuclear research centers throughout the world; (3) compiles the world's most comprehensive scientific information in the field of nuclear science; (4) bibliographically organizes, packages, and distributes for the use of all peoples this body of knowledge of the atom and its application to peaceful purposes." 41

The Department of Defense was also, of course, through the predecessor separate Departments, active in this period. The Central Air Documents Office, with a large punched card processing installation, had been established at Dayton, the Navy Research Section had been established in the Division of Science and Technology of the Library of Congress, and a variety of information activities in specialized subject fields were in operation. Then, "in 1948, the Research and Development Board chartered a Committee on Technical Information. The principal act of this committee was to establish the Armed Services Technical Information Agency (ASTIA) in 1951 by consolidating the activities of the Navy at the Library of Congress, known as the Navy Research Section, and a similar Air Force operation at Dayton, Ohio, known as the Central Air Documents Office (CADO)." 42

The interests of the Congress in documentation and library matters, as previously noted, reach back to the beginning of the 19th century and the founding of the Library of Congress. Again, ". . . previous to the passage of the act of Congress establishing the Smithsonian Institution, various propositions were from time to time made to Congress, for the appropriation of the fund bequeathed to the United States ... No one of the many plans suggested met the approval of Congress, until Mr. Choate proposed, and in one of his most brilliant and effective speeches advocated, the establishment of a great central library of reference and research. His bill met with general approval and passed the Senate, but was lost among other unfinished business in the lower House." 43

In 1906, the Keep Commission distributed a questionnaire on the organization and use of government libraries, to which the Army Medical Library responded to some of the specific inquiries as follows: "On why printed cards were not used: 'About 20 languages are represented in the indexing work of this library to several of the less known of which translations are appended. The space required can suit each caso on a written card'... On whether the ALA list of subject headings was followed: 'For a highly specialized collection the subject headings of the A.L.A.,

41 U.S. Senate, 1960 [592], p. 36.

42 U.S. House 1959 [586], p. 43 , statement of B. G. Huff. 43 "Proceedings of the Iibrarians' Convention . . . 1853," 1915 [466], p. 19. though excellent for a general library, would be inadequate." " 44

The interest of the Senate Committee on Government Operations in the development of a coordinated program for dissemination of scientific information began when the committee was first established in the 80th Congress. "Immediately after its creation ... the committee ... held hearings on a bill ( $\mathrm{S} 493$ ) . . . to provide for the coordination of agencies disseminating technological and scientific information and for the more efficient administration of an information exchange program." 45 But instead of S. 493, a bill was passed which created the National Science Foundation (NSF). This 1950 act (P.L. 81-507), reflected recognition by the Congress "of a new and enchanced role of science and technology in public affairs-recognition by an expressed intent: to promote the progress of science; to advance the national health, prosperity, and welfare; to secure the national defense." "46 Paragraph 5 of the act is especially significant: "To foster the interchange of scientific information among scientists in the United States and foreign countries . . . ."47

In 1958, the National Defense Education Act provided for the establishment of the Science Information Service in the NSF, as follows: "The National Science Foundation, through ... (the Science Information Service) . . . shall (1) provide, or arrange for the provision of, indexing, abstracting, translating, and other services leading to a more effective dissemination of scientific information; and (2) undertake programs to develop new or improved methods, including mechanized systems, for making scientific information available." 48

On December 30, 1958, the Science Information Council advisory to the Office of Science Information Service (OSIS) was established. The Council included the Librarian of Congress, the Director of the National Library of Medicine, the Director of the National Agricultural Library, the head of OSIS, and 15 members from the fields of science, librarianship, and documentation, and from the lay public. NSF also established the Federal Advisory Committee on Scientific Information, which held its first meeting in January 1959 , and considered the problem of dissemination of unpublished research reports and the need for expanded indexing services for foreign technical literature.

Executive Order No. 10807 of March 13, 1959 established the Federal Council for Science and Technology "to promote closer cooperation among Federal agencies in planning their research and development programs, and to recommend ways in which the Federal Government can assist in ad-

\footnotetext{
44 Schullian and Rogers, 1958 [567], p. 29.

45 U.S. Senate, 1960 [592], p. 1.

40 U.S. Senate, 1961 [591], p. 10

${ }^{47}$ Par. 5, The National Science Foundation Act of 1950 (P.L. $81-507)$.

${ }_{48}$ Title IX, National Defense Education Act of 1958 (P.L. $85-864)$.
} 
vancing and strengthening the Nation's scientific effort as a whole".49 The Order called specifically for the National Science Foundation to provide leadership in the effective coordination of the scientific information activities of the Federal Government and to improve the availability and dissemination of scientific information.

In carrying out the various tasks and responsibilities assigned to it, the NSF "is generally proceeding on the assumption that more can be gained by close cooperation with, and in support of, existing scientific information services in the United States, both public and private, where they are functioning effectively, than by direct Federal operation of such services. The scientific information services rendered by many of the scientific socities and professional institutions to the scientific community are world famous for their quality. We believe it is essential that the Federal Government continue to cooperate with, and assist, such private groups in the achievement of long-range solutions to scientific information problems." "50

In summarizing the activities of OSIS in its first several years of operation, Adkinson reports that a six-point program has been developed by the National Science Foundation for improving the dissemination of scientific information, particularly among U.S. scientists and engineers:

"First, improvement in policy making, program planning, and coordination in scientific information activities is being fostered both within and between Government agencies.

"Second, a sizable research and study program is being supported looking toward the development of new and better methods of processing, disseminating, storage, and retrieving scientific information ...

"Third, scientific societies are being encouraged and supported by the Federal Government in assuming greater responsibility for the effective dissemination of scientific information within their own disciplines ...

"Fourth, closer cooperation and coordination is being fostered among Government agencies having like or similar scientific information programs ...

"Fifth, better coordination is being fostered in American participation in international organizations that are oriented to documentation activities ...

"Sixth, action is being undertaken to stimulate effective educational and training programs in scientific documentation." 51

As a result of these and other programs, it has been claimed that "O.S.I.S has probably served as the most influential single force for progress in scientific and technical information throughout the world." 52

49 U.S. Senate, 1961 [591], p. 15

50 U.S. Senate, 1960 [592], p. 25, comments bJ A. T. Waterman.

$511962[5]$. p. 50.

52 Cahn, 1962 [94], p. 28.
Other examples of the U.S. Govemment activities during the first 15 years succeeding the close of World War II include the "financial sponsorship by agencies of the publication of new research journals by appropriate learned societies," such as the Air Force Office of Scientific Research in the field of fluid mechanics and the AEC in the field of reactor technology, ${ }^{53}$ the DOD Directive of March 4, 1952 establishing the Armed Forces Medical Library as a national library for medicine and related sciences, and the subsequent transferrence of the latter to the Department of Health, Education, and Welfare with the name change appropriate to its mission.

To cope with its information handling problems, the Central Intelligence Agency has since the late 1940 's developed an information processing center which "comprehensively indexes and stores that information which is collected and, as a service of common concern, renders daily support to analysts at work in all parts of the U.S. Government's intelligence community." 54

In 1954, in its consideration of a Department of Commerce budget request, the U.S. Senate Appropriations Committee had directed that the Department ". . make an aggressive, thorough investigation as to the possibility of mechanizing the searching operations ... [of the U.S. Patent Office]." 55 This directive resulted in the convening of a committee headed by Dr. Vannevar Bush which recommended in part that a research unit be established in the Patent Office and that it undertake a joint program with the National Bureau of Standards to develop techniques specifically for patent searching operations (1954 [596]).

Turning now to cooperative efforts among the various Government agencies, we note first that during the period 1946-1948 the Army Medical Library entered into a cooperative cataloging agreement with the Library of Congress whereby "the cards for all medical titles cataloged by the two libraries were published in a medical card series." 56 Far more extensive, however, were the pre-VE Day concerns of the defense-intelligence communities with problems of acquisition of additional and declassification of previously acquired material relating to foreign scientific and technological information. "The burden of federal procurement throughout the war . . . was placed upon two principal sources of supply-the foreign service and an interdepartmental committee created for the express purpose of acquiring foreign publications." 57

Further, "during the past few years the government has itself, through the Office of Strategic Services, the Interdepartmental Committee for the Acquisition of Foreign Publications, the Department of State, and the Library of Congress, been

\footnotetext{
53 Herner and Herner, 1959 [254], p. 195

64 U.S. Senate, 1960 [592], p. 63 .

${ }^{55}$ Ibid. p. 75.

56 MacDonald, 1953 [364], p. 67.

57 Humphrey, 1946 [276], p. 99.
} 
the principal promoter of the acquisition of European (as well as other) book materials, and has made, through the Alien Property Custodian's republication program, many important foreign publications available in photofacsimile to libraries generally

"At the June [1945] meeting of the Association of Research Libraries, the question was raised whether libraries generally might not share the use of the channels enjoyed by the Library of Congress. On August 4, 1945, Mr. MacLeish wrote to Dr. Evans stating that: 'The Department of Stats agrees with the Library of Congress's view that the national interest is directly affected by the holdings of the many private research libraries. It would, therefore, interpose no objection in principle to the employment of federal government facilities to assist in maintaining their specialized collections where normal channels of acquisition are inoperative. It is believed, however, that certain basic understandings should be made clear at the outset. The department would wish to be assured that the private libraries had agreed upon and carefully planned a program of cooperative buying .... 58

Shortly after the war, then, the Department of State requested the Librarian of Congress to explore new means for coordination of the foreign acquisitions activities.

As a result, it was recommended to the Secretary of State that consideration be given to "the establishment of a permanent Interdepartmental Committee on the Acquisition of Library Materials within the framework of the interagency intelligence group which the President had requested him to form." 59

In late 1946, the area of cooperative acquisition was the topic of a conference of college librarians. Clapp, in his introduction, said: "As a sort of precursor of a general plan, there has been developed a special project which has had as its object the procurement and distribution of recent European library materials," "60 and Peiss reported on the Library of Congress Mission, stating that "the number of volumes shipped from Germany and Austria ... now exceeds one million." 61

Boyd, who was a co-father of what would emerge as the Farmington Plan, remarked at the same conference that "some of us have been privileged to inspect the vast mechanism of the cooperative acquisitions project. More than six thousand wooden packing cases full of books, gathered from many repositories in Europe, transported to America, opened, divided into categories, correlated with the system of priorities established by the committee and dispatched to 115 participating libraries, makes an impressing spectacle." 62

The Downs committee, which established these

E8 Clapp, 1946 [115] p. 130-131.

so Humphrey, 1946 [276], p. 103

${ }^{\circ}$ Clapp, 1947 [113], p. 100

61 Peiss, 1947 [452], 116.

62 Boyd, 1947 [75], p. 109. priorities among participating libraries for the distribution of materials found by the Cooperative Acquisitions Project, was composed of representatives of ALA, the Association of Research Libraries, the American Council of Learned Societies, the Joint Committee on Importations, the National Research Council, the Social Science Research Council, and the American Council on Education.

The Interdepartmental Committee itself was of interest in several ways. First, it provided an instructive example with respect to the roles of members of such interagency groups: "For members of the committee to conceive of themselves, or for their agencies to conceive of them, solely as representatives of the interests of the governmental bodies to which they are attached, would render most difficult the primary task of attaining broad consideration of federal acquisition policy. The situation demands, instead, the continuous deliberation of individuals whose responsibility and chief interest lies in substantive fields of knowledge not necessarily encompassed by the rigid framework of governmental administrative structures." 63

Second, the Committee provided a stimulus to other more or less formal mechanisms for interchange of information and for cooperation among Government agencies. Taube, for example, from 1948 onward promoted collaboration between The Science and Technology Division, LC, and the information divisions of other agencies. Taube (1952 [560]) also has described arrangements made by $\mathrm{AEC}$ to receive photostats of all articles on selected subjects abstracted by either the U.S. Department of Agriculture Libiary or the Army Medical Library.

Such efforts bore fruit in these and other government agencies, in the Group for the Standardization of Information Services (GSIS) which was organized in the early 1950 's. The agencies represented in the Group included the Technical Information Service of the Atomic Energy Commission (AEC); the Division of Research Information of the National Advisory Committee for Aeronautics (NACA), now a part of the National Aeronautical and Space Agency (NASA); the Central Air Documents Office (CADO) of the Air Materiel Command; and the Navy Research Section of the Library of Congress (IC) the latter two being eventually merged as ASTIA.

Working-level personnel of the agencies represented in the Group agreed upon a common format for catalog cards in the hope that they might be interchangeable among and directly usable by the agencies in their respective card catalogs. The card, which had been devised at LC by Taube, was a marginal-type $3 \times 5$ card having a vertical line about two inches from the right edge; the citation and an abstract appeared in the body of the card, and subject headings and other filing points in the

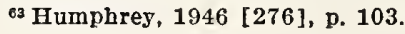


right-hand margin. The cards could also be employed in the preparation of abstract bulletins, bibliographies, and cumulated indexes; pasted into sheets, with the margins covered, they formed twocolumn pages of entries, each of which consisted of a citation and an abstract. This technique was in fact used in the preparation of Technical Information Pilot (TIP), of the Navy Research Section. "The TIP ... utilizes the left half of the GSIS catalog card for each entry and makes additional typing for the journal unnecessary except for the typing of source and subject indexes for each issue."

Other GSIS activities, for example, with respect to possibilities for standard practice in the citing of corporate authors and for the development of a common set of subject headings, were significantly less successful. ${ }^{65}$ The interesting point in these attempts at cooperative processing was that the working-level personnel got together, established common aims and at least some common goals and tried to operate in a cooperative and coordinated manner. It is also interesting to note that several non-Governmental agencies, the editorial office of Meteorological and Geoastrophysical Abstracts and a number of Department of Defense contractors, adopted the right-hand margin card.

Another early example of cooperative Governmental agency cooperation to improve the dissemination of information about research accomplishments and research progress was the short-lived periodical, Federal Science Progress. The first issue, for February, 1947, stated in a foreword that: "This is a magazine for the businessman. It is published to bring him, each month, a report on the scientific and technical activities of his Government ... Government research files are bulging with reports. They contain millions of pages of scientific and technical information seized in enemy countries, as well as information given us by friendly foreign governments. Federal Science Progress proposes to skim the cream from this mass of material and to report to the businessman what is available, and where." 66

After a relatively small number of issues, publication of Federal Science Progress was discontinued. As the endpiece of its last issue, there is a facsimile of a Department of Commerce press release dated March 7, 1947, stating in part: "Federal Science Progress' was started with the February issue as a medium to review and to call attention to the nonsecret scientific reports available in the Government of work being carried on with federal funds... The magazine ... was regarded after three month's experience as not being adapted to the purely service functions of the Department ... Criticism developed from publishers with general circulation in the scientific field on the ground that the magazine represented

\footnotetext{
64 Jackson, 1952 [291], p. 96 .

os Faube, 1952 [560], p. $22-23$.
}

potential competition, and overlapped the field of private publications. Although early Department surveys had indicated that direct competition would not develop, the views of publisher groups were taken into consideration in making the decision." 67

In the first issue of this ill-fated periodical, the ill-fated Chemical-Biological Coordination Center received early appreciation: "Now there is a central clearinghouse to record all new substances, as well as those already discovered, to keep a systematic file on their most important properties, and to point the way to further research on their potentalities. This tremendous job has been undertaken by the Chemical-Biological Coordinating Center, recently set up by the National Research Council ...." 68

During the war years, OSRD had sponsored the testing of chemical compounds for biological activity, especially for effectiveness against insects and rodents. After the war, its Insect Control Committee was transferred to the National Research Council, where with financial support from the Army, the Navy and the American Cancer Society it emerged in 1946 as the ChemicalBiological Coordination Center. The initial objectives were: "to make information accessible to scientists and to facilitate the study of relationships between chemical structure and biological activity . . to to sponsor a screening program to facilitate testing of chemicals on a variety of plants and animals ... to prepare and publish reviews, and to sponsor symposia." 69 The essential first steps were to develop codes for both the chemical and the biological information.

In a study made for the Air Force Office of Scientific Research, Dougherty has explored the "rise and fall" of this organization. The experiment was an interesting one, especially in the develop. ment of the codes. However, many of the reasons for failure are instructive in terms of the general problems of improving utilization of scientific and technical information through cooperation, convertibility, and compatibility.

First, the questions of funding. By the end of CBCC's first five years, budget requirements were in excess of the planned financial support. "In the beginning of the Center apparently the sponsors believed in its value; now, however, it has become more expensive than had originally been estimated, therefore, the NRC wants to reappraise its value and cost. The Research Council is interested in furnishing a home for the CBCC as an interesting and perhaps very important experiment but only as long as there is adequate support and interest." 70

There was, second, the problem of alternate or supplemental sources for stable financing. At a

\footnotetext{
6t Federal Science Progress 1, No. 5 (1947).

68 "Chemlcal Center," 1947 [110], p. 15.

69 Dougherty, 1963 [177], p. 4-5.

70 Minutes, 1952 meeting of representatives of sponsoring agencles, quoted, Dougherty, 1963 [177]) p. 9.
} 
1952 meeting, "a number of those present suggested the possibility of approaching industry for support ... Others ... pointed out that companies would not want to cooperate until they found something they could utilize, or, that industry would not be willing to support the Center until provisions had been made to insure individual companies that their patent rights would be protected." 71

A third problem was that of relative breadth and depth of coverage, especially as CBCC moved more in the direction of emphasizing service functions. In 1955 a special committee considered, among other problems, the scope of the activities. "The term 'scope' was used to denote two concepts. First, that the amount of literature coverage be increased, that is, the number of journals coded in the various disciplines be increased, and second, that the size of the organization, itself, be expanded in order to broaden the scope of services offered. There were several people who advocated expansion. On the other hand, there were others who recommended that instead of attempting to cover so many disciplines that the center should concentrate its efforts and restrict coverage to only a few disciplines in order to achieve depth. Finally there were a few who believed that the Center needed both breadth and depth of coverage in order to achieve its objective ...." 72

Finally, in 1957, NAS/NRC terminated the CBCC operations. Dougherty reports representative reactions as follows: "Sentiment ran the gamut from thorough disgust with the Academy's decision to complete approval. ... The Center received a number of letters from scientists and organizations that had received information from the Center . . . Although the letters, about thirty in number, could not be termed a representative sample, they indicated that some scientists had benefited from the Center's services and regretted its passing." "73

Further "some scientists believed that . . . if activities were terminated somebody else would have to restart a similar operation," "the center was ahead of its time," "the center had demonstrated that given adequate financial support and scientifically qualified personnel large masses of published and unpublished data could be controlled by machine methods," "the nature of the objectives had forced the staff to spread itself so thinly in its efforts that the ultimate result was over-all dilution of programs." ${ }^{44}$ The most sig: nificant achievement was generally felt to be the development of the NRC Chemistry and Biology Codes.

"An important early contribution to information retrieval was made by the Chemical-Biological Coordination Center ... There were several outgrowths as a result of the early pioneer-

\footnotetext{
71 Dougherty, 1963 [177], p. 9.

72 Ibid, pp. 10-11

73 Ibid, pp. 13-14.

74 Ibid, pp. 15-16.
}

ing work of the CBCC . . Among them was the work of Maloney, at Fort Detrick, who developed a medical and chemical system patterned after the CBCC work. Welt developed one of the CBCC ramifications which has subsequently become the Cardiovascular Literature Project. A somewhat related project dealing with carcinogenic effects of chemical compounds is being carried out at The Cancer Chemotherapy National Service Center ...." 75

This example has been reported at some length because the CBCC involved a cooperative venture in information services in terms of both Governmental and non-Governmental sponsorship, it enlisted the collaboration of outside scientists in various subcommittees which dealt with the development of the codes, it attempted to develop an integrated system for storage, search, and retrieval using machine techniques. Moreover, it is possible that instructive lessons may be learned from the reasons for failure.

Dougherty summarizes the four points considered to be the major reasons as follows: "The first, as stated by the NRC-NAS, was an inability to attract adequate and stable financial support.. The second, according to a number of scientists, was the failure to limit its objectives and scope of operation . . . The third point was that the Center had not been able to develop an integrated storage and retrieval system. While they had demonstrated an ability to code and store data, the retrieval portion of the system had been neglected. As a consequence the Center had not been able to show a capacity to retrieve stored data. Finally, one scientist stated that the Center had not been able to demonstrate the uniqueness of its services. In his opinion, the only unique features produced were the two codes and the design of a variety of code sheets." 76

\subsection{Role of National Organizations}

In addition to early Government activities leading to cooperation and coordination of scientific information activities, other steps have been taken by organizations interested in such developments. Associations of librarians; professional societies in fields related to library science and in fields related to science, technology, law and communications; industrial organizations, and formal and informal groupings of many of these bodies have individually and in mutual cooperation contributed to the development of documentation practices.

For example, "the Joint Libraries Committee on Fair Use in Photocopying . . . which represents the American Library Association, the Association of Research Libraries, and the Special Libraries Association, was established in 1957 to work on copyright problems which arise when libraries

\footnotetext{
75 Marden \& Koller, 1961 [370], p. 11.

"Dougherty, 1963 [177], p. 17.
} 
photocopy materials in their collections for their users. .." 77

Among the librarians particularly active in documentation matters have been the members of the Special Libraries Association (SLA), "formed in 1909 by librarians of business, professional, governmental, and industrial organizations to promote the collection, organization and dissemination of information in specialized fields and to improve the usefulness of special libraries and information services." 78 One instance of SLA's interest in cooperation in documentation was the session held in conjunction with the annual convention of 1959 , which had the theme "International Cooperation in Documentation." Papers were presented on documentation services in Great Britain, the Netherlands, West Germany, South Africa, Japan, Canada, and Latin America, as well as on two documentation agencies in the United States.

Other instances of cooperative activities on the part of SLA are the maintenance of a collection of specialized classification schedules, contributed from other groups in the United States and abroad and the establishment, in 1953, of a national "pool" of translations at the John Crerar Library which, in 1959 , entered into a cooperative program with O'TS. ${ }^{79}$

The American Documentation Institute (ADI) was formed in 1937 as a society of organizations rather than of individuals. Its original major interests were "in techniques for more effective use of microfilm and questions related to copyright . . . based on the goal which ADI had set for itself . . . to make scholarly material readily available to researchers . . . .80 As steps to implement the goal, a network of microfilm laboratories, a coordinated interlibrary loan system, and an auxiliary publication program were envisioned. The latter program, which began in the U.S. Department of Agriculture Library in 1934, ${ }^{81}$ still operates through the Photoduplication Service of the Library of Congress.

In 1952, ADI changed from an institute of societies to an organization composed mainly of individual members, although institutional membership is still also allowed. The interests of the society and the activities to which it has turned its attention have broadened considerably. By 195\%, ADI had working committees on Bibliography, on Research and Development, on Education of Documentalists, and on Cataloging and Classification.

Until 1959, ADI also served as the U.S. representative to the International Federation for Documentation (FID). When that international organization was incorporated under Belgian law, in August 1959, and increased the financial obli-

$7 \pi$ Scientific Information Notes, Vol. 3, No. 4, p. 20 (1961).

78 Towner, 1953 [571]. title page.

${ }^{79}$ Gingold, 1961 [217] ], p. 15 ; U.S. House, 1959 [586], p. 19.

${ }^{80}$ Adkinson, 1964 [4] p. 388.

81 Mohrhardt, 1959 [391], p. 30. gations of national and international members, ADI requested the National Academy of SciencesNational Research Council to undertake the responsibility. The Office of Documentation, NAS/ NRC, was assigned the task of establishing the U.S. National Committee for FID, and "a tiny membership organization ... was thus relieved of the burden of this representation." 82

An example of the continuing drive of ADI to explore and to apply new techniques for coping with documentation problems was shown in the preparation for its 1963 annual meeting. Each registrant for the meeting was given two volumes of preprints of "short papers" (not exceeding two printed pages), the text of which had been printed from type set automatically with the aid of electronic information processing equipment, in an interval of three weeks or less before the meeting. (Luhn, 1963 (354) : Figure 1 is a facsimile of the frontispiece of a special edition of Volume I).

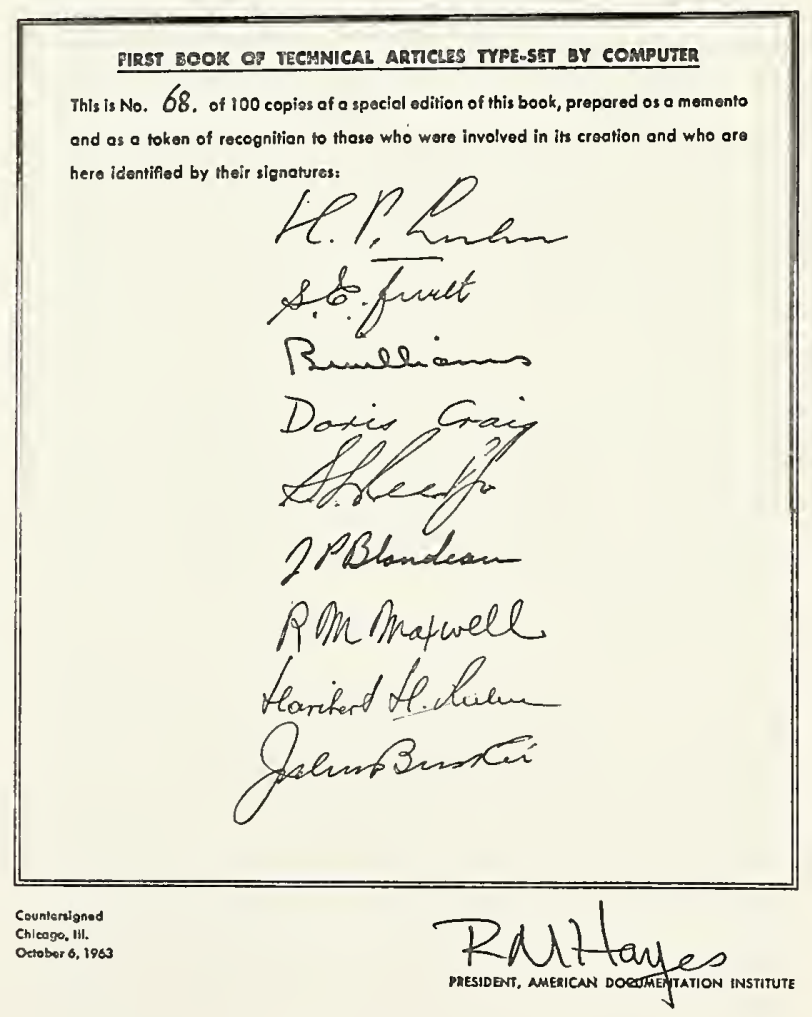

The bibliographic information for the approximately 600 papers was keypunched and processed on an IBM-1401 computer to produce (1) the table of contents, (2) a permuted title or key word-incontext (KWIC) index, (3) an author index to the short papers, (4) a citation index to the bibliographic references cited in the papers, (5) a KWIC index to the titles of these references, (6) a "bibliography" or listing by the codes assigned

\footnotetext{
82 Council on Library Resources, 1960 [142], p. 6.
} 
to the citations, and (7) an author index to the citations. The machine-readable form of the text is available for research purposes.

In appointing the U.S. National Committee for FID, the Office of Documentation, NAS/NRC, provides representation not only for documentation and scientific information specialists, but also for scientific societies. Many of these societies have their own groups and programs in the scientific information field.

The Division of Chemical Literature of the American Chemical Society (ACS) dates at least informally from the society's meeting in the Spring of 1943. At that meeting a paper by Egloff, Alexander and Van Arsdell, "Problems of the Scientific Literatmre Survey" (1949 [184]), was presented before the Division of Chemical Education. The presentation inspired the organization of symposia on technical library techniques, the first of which was held at the ACS Fall meeting in 1943.

This activity in turn led to the formation of the Chemical Literature Group of the Division of Chemical Education. 'The Group sponsored sessions at subsequent national meetings, dealing with the subjects of technical library operation, chemical nomenclature, translation of foreign publications, and the like. In September 1948, the ACS Council approved the petition of the Group to be given the status of a division, and the Division of Chemical Literature came into existence. Its first official program was presented at the Society's Spring 1949 meeting. The Division continues to devote itself to documentation problems in the field of chemistry, sponsors technical sessions, maintains operating committees for various special areas and is responsible for technical content of the ACS publication Journal of Chemical Documentation.

In addition to its sponsorship of the Gordon Research Conferences, the American Association for the Advancement of Science (AAAS) has established the Section on Information and Communication (Section $\mathrm{T}$ ), which developed from a series of information conferences which had been held during the Association's annual meetings beginning in 1951. The conferences were variously called Operation Knowledge (1951), Conference on Scientific Editorial Problems (1952-56), and Conference on Scientific Communication (19571961). The Section was organized formally in 1962. It has provided a forum where interested societies and individuals may "discuss documentation problems and work toward their solution." 83

The Special Interest Group on Information Retrieval (SIGIR) of the Association for Computing Machinery (ACM) was organized in 1962 to satisfy certain specialized needs of the professional community served by ACM. These include, (1) advancement of the application of machines to the storage, retrieval, and dissemination of informa-

${ }^{83}$ Parkins, 1962 [447], p. 536. tion; (2) advancement of information retrieval theory, programming, file preparation, searching strategy, output schemes, information retrieval system evaluation, and development of equipment best suited for these tasks; and (3) the exchange of information on new developments in these areas.

Two groups actively engaged in cooperative and coordinating studies of documentation problems are the National Federation of Science Abstracting and Indexing Services (NFSAIS), and the Classification Research Study Group (CRSG). The NFSAIS was established in 1958, when the National Science Foundation "provided funds and staff work for a conference of major U.S. scientific abstracting and indexing services. The major accomplishment of the conference was the formation of the National Federation of Science Abstracting and Indexing Services which strives to coordinate and improve the work of the various: services and to encourage the development of abstracting and indexing services for those specialized subject fields not at present covered by such services." 84

The Federation now numbers 14 major abstracting and indexing service organizations. Its activities include the preparation of a union list of periodicals covered by the cooperating services, analysis of the scientific periodicals produced around the world, and the like. Its working groups are the Index Editorial, Management Services, Manufacture and Production, Material Procurement, and Research Groups.

The Classification Research Study Group is an organization of persons interested in the development of classification schemes and often actively engaged in research or studies of classification systems and applications. The group usually meets, in conjunction with meetings of related societies, and conducts cooperative projects dealing with the theory and structure of classification schemes. It collaborates also in the maintenance of the SLA Special Classifications Center.

In addition to these specialized groups, the following organizations are actively interested in certain aspects of cooperative documentation: the American Institute of Physics, with its Documentation Research Project; the American Chemical Society which in addition to the Division of Chemical Literature has an active research program on abstracting and indexing and the total publication process and which "since its inception in $1876 \ldots$ has been deeply concerned with the need to handle effectively the mass of chemical knowledge generated by American scientists," 85 and the American Institute of Biological Sciences. The Biological Sciences Communication Project, for example, studies the flow of information from producer to user, the extent of use of the foreign literature, citation practices, and the like. One of

84 U.S. House, 1959 [591], p. 67, statement by A. T. Waterman. ss U.S. Senate, $1962[594]$, p. 24 , statement of A. H. Emery. 
its most important tasks is the "identification, examination, and classification of all the world's journals in the field of biomedicine." 86

Still other organizations interested in cooperative efforts in documentation include the National Microfilm Association, concerned with all aspects of microfilm reprography; the Association of Research Libraries, whose Automation Committee proposes to take a major role in developing a national system of bibliographic automation; the American Society for Metals with its Documentation Committee and its collaboration with Western Reserve; the Engineers Joint Council and its Information System Committee, and the American Library Association which in 1922 established a Committee on Bibliography that would participate "in the growing movement to get together all going enterprises in biblography for practical cooperation," 87 and which has sponsored since 1959 a Library Technology Project "designed to provide librarians with authoritative information and guidance of all phases of equipment, supplies, machines, and systems used in library operations." 88

An example of early interindustry cooperative concern in the technical documentation area is the American Petroleum Institute: ". . . In the 1940's the considerable amount of duplicate work going on in processing a central core of published petroleum information, and in developing the methods needed for this processing, caused much concern. It seemed logical that much of this work could be done more economically, and on an even larger scale, by a central operation. Each company would still have to cover a residue of documents of particular interest to itself. Interest was aroused among petroleum research managements, and a proposal to begin centralized abstracting was eventually put before the American Petroleum Institute ....."

"[In 1954] the API Central Abstracting Service began its operations by publishing a weekly abstract bulletin covering the literature reported in the 100 sources deemed basic to petroleum refining. Classified sets of abstract cards were soon made available, following development of an acceptable classification system." 89

The interests of some of the nonprofit organizations and private foundations in the United States should also be noted. In his 1945 report to the President, Bush pointed out that "both the Library of Congress and the Army Medical Library occupy leading positions in their fields. Yet those two Government institutions still have to look to private sources for much of their support, especially for projects involving experimentation with new methods. Two foundations alone have contributed over half a million dollars to the Library of Congress in the past few years." 90

\footnotetext{
${ }^{80}$ Shilling, 1963 [531], p. 206.

87 Richardson, 1928 [480], p. 43 .

85 Sclentific Information Notes 2 , No. 2,3 (1960).

${ }^{89}$ Weil et al., $1961[635]$, p. 57

${ }^{80}$ Bush, $1945[91]$, p. 113 .
}

First and foremost among such organizations, partly because of its quasi-Governmental yet independent character, partly because of its sponsorship of work involved in the preparation of this report, and partly because of its explicit assumption of responsibilities for international collaboration in the field, is the National Academy of Sciences/National Research Council. NAS/NRC has been instrumental in such other activities as the planning and support of the International Conference on Scientific Information, the establishment of the Office of Critical Tables, and provision of financial support and/or "homes" for specialized information centers such as CBCC and the Prevention of Deterioration Center which "is a nonprofit, scientific organization maintained jointly by the three United States armed services, by means of an Office of Naval Research contract, under the operating supervision of the National Academy of Science-National Research Council." 91

Another example of NAS/NRC service in U.S. representation to international groups was the U.S. National Committee for the International Geophysical Year. We might note in passing that IGY had been preceded by an International Polar Year "in which several countries interested in the compilation of scientific data of the Arctic regions, pooled information and techniques. This cooperation gave added value to the methods of the observation and presentation of the data collected." 92

IGY activities are also to be noted in terms of uses of advanced documentation techniques. Thus, computer programs were prepared to compile a "Tabledex" index for the IGY bibliography compiled by the Library of Congress (Zusman et al., 1962 [660]) and the World Meteorological Organization published the meteorological data obtained in the form of micro-cards (Günther, 1962 [232]).

In addition to its contributions over the years to the Library of Congress, Army Medical Library, and others, the Rockefeller Foundation's interests are exemplified by its initial financial support for the American Book Center, (now the U.S. Book Exchange) and the establishment of the Scientific Information Service of the Inter-American Institute of Agricultural Services for the purposes of promoting "the betterment of scientific communication facilities among technicians working in research, education and agricultural extension." 93

A special example of an independent privately supported organization devoted to the advancement of libraries and documentation is the Council on Library Resources established by the Ford Foundation and incorporated in 1956 in the District of Columbia. The Council has as its prin-

p1 Wessel and Bejuk:, 1959 [642], p. 731.

${ }^{92}$ Bush, 1945 [91], p. 107.

93 Murra, 1962 [402], p. 173. 
cipal objectives: to aid in the solution of library problems; to conduct research and develop and demonstrate new techniques and methods and to disseminate the results. It conducts its work chiefly through grants or contracts to other organizations or to individuals.

Over the years, then, there have been many instances of cooperative interplay and interaction with respect to scientific documentation among professional societies, industrial and commercial interests, nonprofit institutions, and other national organizations. Two further examples illustrate cooperative relationships in which Government agencies have also participated.

First, "The Index Medicus began its career under a commercial publisher, F. Teypoldt, in 1879 ... From [1900] . . . until 1903, when Billings was able to secure a grant from the Carnegie Institution of Washington, there was a gap.... With Carnegie funds the Index Medicus continued its publication based on the Army Medical Library until 1927, when it merged with the Quarterly Cumulative Index. . . From 1927 to 1931 the Quarterly Cumulative Index Medicus was a cooperative production of the Army Medical Library and The American Medical Association." 94

Second, "Making readily available the research information of the world literature in its field is the task of the Alloys of Iron Research Committee which is in process of preparing monographs on the important iron-alloy systems. This useful, expensive, and still unfinished project was financed in part by Engineering Foundation, the National Bureau of Standards, and Battelle Memorial Institute, in large part directly by the metallurgical industries." 95

\subsection{Role of International Groups}

When the Smithsonian Institution's first secretary, Joseph Henry, initiated plans for cooperation in international bibliographic efforts in 1848 , he offered to be responsible for the indexing of the American scientific literature if the British Association for the Advancement of Science would undertake the rest. ${ }^{96}$ The immediate successor of this proposal, the Catalogue of Scientific Papers, and several subsequent efforts involved collaboration and cooperation in sponsorship, in financing, or in working contributions. Thus the Catalogue of Scientific Papers was produced from 1851 to 1925 under the auspices of the Royal Society with financial support from the Society, the British Government, individual donations and proceeds from sale of the products; the International $C a t a-$ logue of Scientific Literature was sponsored by an international organization of participating nations in collaboration with the Royal Society; and the Concillium Bibliographicum provided bibliographic services on cards and an index in bulletin

\footnotetext{
94 Rogers and Adams, 1950 [490], p. 278.

95 Gillett, 1941 [216], p. 301 .

96 Murra, 1951 [401], p. 26-27.
}

form financed by an international association of learned societies and individual zoologists, governmental grants, gifts, and proceeds from sales. ${ }^{97}$

It is to be noted that less than a year after the founding of the American Library Association, "sixteen Americans journeyed to London to help form the Library Association of the United Kingdom" and that this "1877 meeting is a landmark in international library cooperation." 98

". . . The first international conference on bibliography . . . convened in Brussels in 1895 ... was not international in the sense desired because planning and issuance of invitations came too late to permit wide participation. Nevertheless an Institut International de Bibliographie sanctioned further adaptation of the Dewey system, recommended it for classifying bibliographies throughout the world, and authorized preparation of a Repertoire Bibliographique Universel . . . ." 99 In 1896, an international bibliographic conference was convened by the Royal Society in London. Two following conferences, in 1898 and 1900, led to the International Catalogue enterprise mentioned above.

This Conference also led to the establishment of the International Federation for Documentation (Federation Internationale de Documentation, or FID) which "had its beginning in the Institution International de Bibliographie, founded in Brussels in 1895 by Henri la Fountaine and Paul Otlet. In 1924, this association of individuals was transformed into a federation of national and international institutions." 100

Similarly there was established, in 1929, with "active American participation," the International Federation of Library Associations. ${ }^{101}$ In 1927, an International Library and Bibliographical Committee was created during the golden jubilee conference of the British Library Association ". . . The Intermational Federation of Library Associations (IFLA) grew out of this Committee's work ..... The chief contribution of the IFLA to the international organization of bibliography has been to provide an international meeting ground. . . . The exchange of information on techniques, processes, devices, training, current work, and common problems is instrumental in attempts being made to standardize forms, methods, processes, nomenclature, etc.; to revise policy; and to revamp professional education." 102

"Further, both FID and IFLA, alone and in various combinations, sponsor meetings, conferences, seminars, and other informational programs and in a number of countries on topics of timely or special interest to all types of librarians and documentalists." 103

\footnotetext{
97 Ibid., p. 28-29.

98 Ludington, 1954 [351], p. 194-195.

99 Murra, 1951 [401], p. 34-35.

100 Murra, 1962 [402], p. 335.

101 Council on Library Resources, 1958 [140], p. 35.

102 Murra, 1951 [401], p. 44.

103 Bonn, 1959 [68], p. 1444 .
} 
An example of the work of IFLA is the International Conference on Cataloguing Principles held in Paris in 1961. 'The aim of the Conference was to "reach agreement on basic principles governing the choice and form of entry in the alphabetical catalogue of authors and titles." 104 Library associations and other interested organizations in all countries with which contact could be established, as well as a number of international organizations, were invited to participate. A "Statement of Principles" was drafted and distributed to participants, Conference sessions were devoted to discussion and amendment of this draft. The final "Statement" arrived at received the support of a large majority of the participants. Some details of the principles adopted will be covered in the section of this report dealing with the cataloging process. ${ }^{105}$

Further examples of cooperation and coordination on an international scale are the joint IFLAFID committees on standardization, on special libraries and information bureaus, on training and on cataloging rules; the United States National Committee for the FID, representing 23 United States private and governmental agencies plus members at large, and the European Productivity Agency sponsorship of meetings of representatives of a number of countries, from 1958 onward, looking toward pooling of translation efforts.

Both organizations joined with representatives of ICSU (The International Council of Scientific Unions) and ISO (The International Standards Organization) in a meeting held at the Hague in September 1960 "to discuss cooperatively developed programs dedicated to improving communication of information in the national sciences." 106

Other examples of groups and organizations concerned primarily with documentation are as follows :

(a) "In February, 1952, a group of librarians and information officers constituted itself under the name of Classification Research Group and submitted to Unesco a report emphasizing in its conclusion, the importance of research into establishing a standard classification scheme." 107

(b) "The documentation organizations in the aviation field in Germany ... collaborate in the Central Organization for Aviation Documentation.... There is cooperation and exchange with documentation organizations in the aviation industries in France and Great Britain." 108

The Institute of Information Scientists was organized in London in 1958 "to promote and maintain high standards in scientific and technical information work and to establish qualifications for those engaged in the profession." 109 Among the

\footnotetext{
104 Murra, 1951 [401] ], p. 44.

105 See p. 61 ff. of this report.

100 Scientific information Notes 2, No. 5, 1 (1960).

107 de Grolier, 1962 [170], p. 10 .

100 Dyson and Farradane, 1962 [182], p. 13.
}

objectives of this organization are the development and promotion of educational and training facilities and provision of publishing mechanisms as appropriate. Also, "a new international society in the information field has been started in Paris under the title, International Association of Documentalists ...." 110

International bodies whose primary concerns are those of international cooperation in areas of scientific investigation as such include both international federations of professional societies or industry-wide common interest and multi-government international organizations-agencies of The United Nations, Unesco, The Food and Agriculture Organization which "maintains the largest library of any international organization in the world," 111 multi-nation collaboration in the International Geophysical Year, and Euratom's Centre European pour le Traitement de l'Information Scientifique, for example.

Further, "the Conseil International du Bâtioment has representatives from numerous European countries that had decided on a joint documentation program. Every national member compiles the titles of works that appeared in his country in the field of structural engineering and exchange them with all other countries. Standard form A7 (74 × $105 \mathrm{~mm})$ has been selected for the international exchange. The titles are supplemented by a table of contents in the language of publication and (on the reverse side of the card) a table of contents in English or French." 112

The International Council of Scientific Unions has already been mentioned. "The Abstracting Board is a nonprofit international organization sponsored by ICSU and incorporated in Belgium. It was established in 1950, its organization stemming from recommendations made at the 1949 International Abstracting Conference held in Paris. The Board's object is to achieve, through international cooperation, improvement in the quality of scientific abstracting and acceleration of distribution of the product among scientists." 113

It is reported with respect to Unesco's programs that "in cooperation with the International Council of Scientific Unions, it will seek to extend the coverage of abstracting journals to new disciplines, a study will be made, in cooperation with The International Federation of Documentation and other international organizations, of means of arranging for coordination between the services responsible for the translation of scientific work." 114

Perhaps under the precedents established by the League of Nations in the establishment of the International Institute of Intellectual Cooperation, ${ }^{115}$ Unesco has been concerned with international co-

\footnotetext{
110 Scientific Information Notes 4, No. 5, 11 (1962).

111 Murra, $1962[402]$, p. 143

112 Frank, 1959 [200] 500 .

11 Science Information News 1, No. 4, 4 (1959).

114 Veronese. $1960[608]$, p. 8 .
115 Murra, 1951 [401], p. $42-43$.
} 
operation in matters of documentation generally and scientific information handling specifically. Unesco activities include giving assistance under its Technical Assistance Program for the establishment of national documentation centers in various countries. ${ }^{116}$

Two other examples of Unesco's continuing interest in documentation are its Committee on Documentation for the Natural Sciences (which "has concentrated a great deal on the production of multilingual dictionaries. It has been useful on problems of Russian literature in the natural sciences. It is ... trying to take a stand in the copyright position ... and it has given a great deal of thought to the subject of the use of authorabstracts," ${ }^{117}$ and the Unesco Clearing House for Publications which, by 1954, was "a very large enterprise for helping libraries to dispose of their duplicates, not in a haphazard way, not merely as a matter of benevolence, but by systematic distribution to the libraries, and only to the libraries in particular, where available publications are wanted." 118

Again, "in furtherance of its role in improving scientific documentation and terminology, Unesco will promote the establishment and improvement of scientific and technical documentation services by member-states and international organizations. Goals in encouraging bibliographic work give emphasis to the improvement and coordination of scientific abstracting and translation services, and the standardization and development of terminology, including investigation of means of preventing dissipation of effort." 119 The periodical Unesco Bulletin for Libraries provides obvious contributions to the fostering of cooperation, including some of the items cited in this report.

Unesco has also sponsored or cosponsored international conferences on the subject of cooperative documentation: The International Conference on Science Abstracting (1949); the First International Conference on Information Processing (1959), and the International Conference on Cataloging Principles (1961), among others.

Among the foreign organizations which include cooperative documentation within their primary fields of interest are the Association of Special Libraries and Information Bureaux (ASLIB), London; The International Association for Agricultural Librarians and Documentalists, Bad Godesburg, Germany; The Royal Society of Great Britain, London; Union Francaise des Organismes de Documentation (UFOD), Paris; International Committee of Patent Office Experts Concerned with the Promotion of Cooperative Research Programs in Information Retrieval (ICIREPAT); Duetsche Gesellschaft für Dokumentation, Frankfort am Main; Netherlands Institute for Documentation and Filing (NIDER), The Hague; and the

\footnotetext{
110 Brownson, 1952 [86], p. 34, Mattson, 1962 [376], p. 330.

${ }_{117}^{11}$ King, 1955 [315], p.7

118 Evans, 1954 [189], p. 97

119 Scientific Information Notes 3, 1, 1 (1961).
}

Abstracting Board of the International Council of Scientific Unions (ICSU).

A comprehensive survey of the library, documentation and information services of a large number of international scientific organizations has been prepared by Murra (1962 [402]). For the more than 400 organizations reporting one or more of these services, the subject interests included such specialized fields as research on bees, cremation, deep drawing of sheet metals, medical electronics, and stratigraphic classification and nomenclature. Another unusual specialty, having to do with unusual types of data and information, is that of International Federation of Sound Hunters which maintains an archive of sound recordings of distinctive natural, regional or local interest. "These recordings include certain sounds unique in the world, typical sounds of daily life, and exceptional noises, such as those of the 'singing' dogs." 120

In 1959, the International Association of Microbiological Societies created the Permanent Committee for Microbiological and Immunological Documentation with assigned responsibilities for recommending procedures for the storage, selection, and dissemination of scientific data concerning microbiological and immunological sciences." 121

The International Federation for Information Processing (IFIP), the first international organization dedicated to all facets of the information processing sciences, came into existence in January 1960, following the first International Conference on Information Processing, sponsored by Unesco and held in Paris in June 1959. Organizations within IFIP are Technical Committee 1 (TCI) on terminology; TC2 on programming languages, with Working Group 2.1 on the ALGOL language; and TC 3 on education. The IFIP Committee on Terminology has affiliated with a similar committee of the International Computation Centre of Rome to form the IFIP/ ICC/TC-1 Terminology group which is developing a multilingual glossary on computer concepts.

As a final example, we note that "incorporation of the International Micrographic Congress has been announced." 122

\subsection{Role of Conferences and Meetings on Documentation}

Cooperative and collaborative efforts in documentation have typically been initiated or fostered through the medium of special conferences and meetings.

At the historic Librarians' Convention of 1853, the topics covered might well form the agenda for similar conferences today: Congressional support for a great national center, prevention of repetition of work of "preparation of titles, composi-

${ }^{120}$ Murra, 1962 [402], p. 360.

121 Murra, 1962 [402], p. 221.

${ }^{122}$ Scientific Information Notes $\overline{5}$, No. 2,3 (1963). 
tion and correction of press, for copies of the same book in different libraries," ${ }^{123}$ securing uniformity in the construction of catalogs, distribution of public documents, indexing, questions of universal classification systems, international exchange, and others. Among the resolutions unanimously adopted were

"Resolved, that this Convention be regarded as preliminary to the formation of a permanent $\mathrm{Li}$ brarians" Association ..." 124 And,

"Resolved, that the members of this Convention cordially recommend the mutual interchange, so far as may be practicable, of the printed catalogues of all our public libraries." 125

We have mentioned several early international conferences; there have been many more since World War II. A chronological listing of some of the more important ones will suffice to show the scope of interest in cooperative activity in the field of information handling.

In June 1949, the Royal Society Scientific Information Conference was held in London; it was the first international conference devoted exclusively to the problems of handling of scientific and technical information. It has been hailed as a "landmark in the exploration of problems of scientific communication both in and out of libraries." 126

The following year, 1949, saw two Unesco-sponsored meetings, the first of which was that of the Coordinating Committee on Abstracting and Indexing in the Medical and Biological Sciences (the outgrowth of informal efforts beginning in 1946 to develop cooperation between World Abstracts and Excerpta Medica). ${ }^{127}$ The second was the International Conference on Science Abstracting, from which soon emerged the Abstracting Board of the International Council of Scientific Unions. ${ }^{128}$ In 1950, Unesco also sponsored a Conference on the Improvement of Bibliographic Services. ${ }^{129}$

One of its key recommendations was: "In every country a recognized planning organization should be established to promote the development of bibliographical and information services, to stimulate research on bibliographic methodology and serve as a clearinghouse of information about research completed and in progress, to coordinate effort and determine priorities, and to act as a link with international planning bodies." 130

In January 1951, a conference on international documentation was held in Paris under the sponsorship of the Carnegie Endowment for International Peace.

In August 1951, a meeting was held at Massachusetts Institute of Technology (MIT) at which

\footnotetext{
123 "Proceedings of the Librarians' Convention . . . 1853," 1915

$[466]$, p. 26 .

124 Ibid, p. 62

${ }^{129}$ Council of Library Resources, 1958 [140], p. $3 \overline{5}$.

127 Brownson, 1952 [86], p. 30.

128 Boutry, 1959 [74], p. 1503 .

129 Brownson, 1952 [86], p. 30 .

130 Ibid, p. 32 (recom. of Unesco 1950).
}

desiderata for evaluating chemical notation systems were discussed, and proposed systems designed to encode chemical compounds were studied in the light of these desiderata. This meeting preceded the Diamond Jubilee meeting of the American Chemical Society; there the Dyson notation system was selected on a tentative basis as the international standard system and an experimental model of a new type IBM punched card machine especially designed for literature searching purposes was demonstrated.

In June 1952, also at MTT, a Symposium on Machine Techniques for Information Selection was held at which new techniques for analysis and systematization of terminology for searching systems were discussed. The IBM Electronic Information Searching System was also demonstrated in fuller detail.

Again at MIT in 1952 there was held the First International Conference on Machine Translation, reflecting the widespread interest in the possibilities for such mechanized or computerized operations.

An international congress on medical librarianship was held in I London in July 1953 ; papers dealt with such subjects as Unesco and medical librarianship and documentation; centralizing medical library resources; a proposal for British combined national depositories and exchange centers for medical periodicals; the relationships of the medical librarian to international cooperation and the World Health Organization; and the medical library resulting from cooperation between university libraries and libraries in medical clinics, laboratories and institutes.

Also in 1953 a workshop on the Production and Use of Technical Reports was conducted in Washington, D.C. It was noted that the ". . . widespread interest in improved handling of report literature is evidenced by the fact that this workshop is sponsored jointly by a university, a scientific society, a documentation institute, a library association and a government agency ...."131 (Catholic University of America, Division of Chemical Literature of the American Chemical Society, American Documentation Institute, Special Libraries Association, and National Science Foundation, respectively).

Cunningham (1956 [152]) reports on the Brussels 1955 International Congress of Libraries and Document Centers.

There have been a series of conferences at the Western Reserve University, first of national and later of international scope, beginning with one held in 1956, the Conference on the Practical Utilization of Recorded Knowledge-Present and Future. The proceedings of this conference have been recorded by Shera, Kent, and Perry (1956 [525]). The conference was cosponsored by 11 organizations reflecting the widespread interest

131. Waterman, $1955[630]$, p. 4 . 
in the subject. Besides the 37 panel talks and full-scale papers presented in open session, six closed discussions were held on specialized subject fields.

As a result of the first two of these conferences, an informal organization called the Council on Documentation Research was created consisting of representatives of Government organizations, libraries, and professional associations in cooperation with the Center for Documentation and Communication Research of Western Reserve. The former was the official sponsor for a 1958 conference at which the latter"s "Plan for the Creation of a National Center for the Coordination of Scientific and Technical Information" was presented and discussed (Shera et al., 1958 [526]).

In October 1956, the Second International Conference on Machine Translation was held at the Massachusetts Institute of Technology; in May 1957, the International Study Conference on Classification for Information Retrieval took place in Dorking, England. The year 1957 also saw meetings of the International Advisory Committee for Documentation and Terminology in Pure and Applied Science and of the International Advisory Committee on Bibliography, both held in Paris with the assistance and support of Unesco.

The Atomic Energy Commission has periodically programmed "specialized technical information workshops to help nations and international organizations with U.S. Atoms-for-Peace collections to derive the maximum value from this resource. The first such workshop was held in Geneva in May 1958." 132

In November 1958, the International Conference on Scientific Information (ICSI) was held in Washington. When the plans for it were being formalized, one of the areas for discussion was entitled: "Responsibilities of Government, Professional Societies, Universities, and Industry for Improved Information Services and Research." The statement on the proposed scope of this area began with the important injunction: "The task of developing and maintaining effective scientific information services is of such magnitude as to require the resources and cooperation of all organizations with an interest in the progress of science." 133 At this time, the responsibilities of national governments with respect to developments in this area were being quite newly recognized.

The ICSI Conference was also noteworthy as marking early examples of machine-produced permuted title and KWIC (Key Word-In Context) indexes to its preprints and for the adoption of typographical compromises intended to facilitate machine experimentation with text from the typesetting" paper tape. "TVhen the proceedings of the 1958 International Conference on Scientific Information were prepared for publication, it was de-

\footnotetext{
${ }^{132}$ U.S. Senate, 1960 [592], p. 49-50.

133 International Conference on Scientific Information, "Proceedings", 1959 [404], p. 1415.
}

cided that the Monotype tapes should be preserved for later availability to workers interested in machine processing experiments. For this reason, the printer was given instructions to provide two spaces rather than one after every period marking the end of a sentence. Notwithstanding the typographer's objections on aesthetic grounds, the 'rivers' he predicted do appear on the pages of the printed proceedings. Otherwise, the distinction between the use of the period as sentence terminator, as decimal point, and as a sign of abbreviation, would be difficult for a machine to make." 134

An international meeting on "Automatic Documentation in Action" was held at Frankford am Main in June, 1959, under the co-sponsorship of FID, German organizations of scientists and of documentalists and the Gmelin Institute.

The First International Conference on Information Processing was held in Paris in June 1959 [576]. At the symposium on the collection, storage, and retrieval of information, papers were read describing the current research efforts and trends in four geographic areas : the United States, Western Europe, the United Kingdom, and the U.S.S.R.

The International Conference for Standards on a Common Language for Machine Searching and Translation was convened at Western Reserve University in September 1959 (Kent, 1960 [310]).

In September 1961, the Third International Conference on Machine Translation and Applied Language Analysis was held at Teddington, England. The conference papers were quite technical and detailed, but reflected a field of research then "in its most creative and least predictable phase." 135

The International Conference on Cataloging Principles, sponsored by the International Federation of Library Associations (IFLA) with the aid of a grant from the Council on Library Resources, Inc., held in Paris in October 1961, recommended that IFLA, in cooperation with other interested international organizations, "should study the possible repercussions on cataloguing rules of the use, especially in large general libraries, of electronic machinery and of mechanical procedures in general." 136

In September 1961, a one-day conference of FID's Study Group on Mechanical Storage and Retrieval (FID/MSR) was held in London in connection with the 27 th general FID Conference. The proceedings, covering reports of current activities in the U.S.A. (Gull, 1962 [228]), U.S.S.R. (Mikhailov, 1962 [385]), Western Europe (Koelewijn, 1962 [322], and Japan (Niwa, 1962 [429]) are reported in the May 1962 issue of Revue Internationale de la Documentation.

The Second International Congress on Information Processing (IFIP Congress 62) was held at

\footnotetext{
134 Stevens, 1962 (543], p. 65.

135 Davies, $1962[156]$, p. 68.

136 Poindron, 1962 [460], p. 22.
} 
Munich in August-September 1962 [462]. Five formal papers on information retrieval were read; in addition, a symposium was organized on advanced methods in information storage and retrieval at which four more papers were presented.

The second International Congress on Medical Librarianship was held in Washington, D.C., in June 1963; and in September 1963, the third annual meeting of the International Committee of Patent Experts ... (ICIREPAT) was held in Vienna. The papers given at the ICIREPAT meeting were on three aspects of teclinical reports : indexing, abstracting, and classification; storage and retrieval systems; and planning, testing, and evaluation of systems (Pfeffer, 1964 [456]).

\section{Current Operations and Proposed Activities}

\subsection{Background}

In the United States, there is an increased concern about the proper exploitation of research and development efforts, especially those sponsored or paid for in whole or in part by taxpayers' contributions. It has been noted that the Federal Government must "play a key role in the process of scientific communication because, among other factors, as the primary [research and development] sponsor, it becomes the primary beneficiary." 1 The extent of Federal support has contributed to the flood of unpublished, but often highly and currently valuable, literature-the progress report, the research-in-progress summary, the summary technical report, and the unpublished, orally delivered papers reporting results at seminars, briefing sessions, conferences, and symposia.

A new characteristic of contemporary research relevant to enhanced dissemination of scientific data is the "vastly increased rate of knowledge conversion [from discovery to application] . . . . This rate . . . in some instances has shrunk to a matter of weeks, stimulating a completely unprecedented sense of urgency and even compulsion for fluent availability of data on current research." 2

The present report is indicative of U.S. Government concern, of inter-agency collaboration, and of the joint interests of Federal agencies and professionally oriented organizations on the mutual problems of coordination of efforts, promotion of collaboration, and search for compatibility in their various efforts towards improved utilization of the records of scientific and technical information.

\subsection{Current Activities in Federal Agencies}

This concern of the Federal Government extends back, as previously noted, to the days of the

\footnotetext{
I U.S. Senate, 1961 [591], p. 44.

2 Ibid, p. 44 .
}

establishment of the Smithsonian Institution and the Library of Congress. But, although the Government's concern is of long standing, the greatest activity looking towards this improved use of information has taken place in recent years, particularly in the period since World War II.

The recent study by the House of Representatives Select Committee on Government Research has examined the documentation and dissemination of research and development results, culminating in a report which spells out the extent of the Federal Government's efforts in scientific and technical information services. ${ }^{3}$ Major information programs are carried out by nine executive departments and 12 agencies; 259 facilities have been established to ease the flow of information. The Select Committee's primary recommendation is for even more coordinated federal effort, including a central clearinghouse for the coordination of all foreign federal activities in documentation and dissemination of information.

In 1963, an NAS/NRC study of communication problems in biomedical research included the following comments in its report: "Pressures for action are developing in both the legislative and the executive arms of government. For some time, the Senate Committee on Government Operations has been probing and exhorting. Meanwhile, the Federal Council on Science and Technology has been working to improve the exchange of scientific information among the many government agencies involved in research, and the Office of Scientific Information Services of the National Science Foundation has been encouraging the systematic study of problems in communication and the search for more efficient methods of processing scientific information, as well as promoting cooperation among all activities, both private and governmental, that handle scientific information." 4

The "probings" and exhortations" not only of Senator Humphrey's Subcommittee but of other Congressional groups and of the Crawford and Weinberg Panels have raised questions of major national policy affecting, directly or indirectly, the problems of cooperation, convertibility and compatibility among information systems. First is the issue of centralization-decentralization and, if centralization, how much, especially the question of a single, centralized national service perhaps after the model of the Russian UINITI.

However, "There is by no means agreement on the modus operandi for achieving increased coordination. Particularly moot is the issue of what the ultimate Federal role should be. Many observers express deep concern lest a monolithic Federal information operation be attempted. But the urgent need for increased Federal and for

${ }^{3}$ U.S. House, 1964 [589], p. 5. See also "Better Information Coordination Úrged," 1964 [61], p. 27.

4"Communication Problems in Biomedical Research," 1963 $[403]$, p. 1 . 
public-private teamwork is now conceded virtually everywhere." 5

At the 1958 meeting of the Council on Documentation Research, Western Reserve's "Plan for the Creation of a National Center for the Coordination of Scientific and Technical Information" was presented. "The discussion was lively and lengthy ... comments ranged from a direct condemnation of existing agencies that have had major responsibilities in this field and that have not taken the initiative, to complacent acceptance of the status quo." 6

While Congressional interests in national information centers has continued, the consensus remains 'much as it was a few years ago: "The staff, following study of the problems involved, has concluded that a Federal center of documentation, originally proposed in the 85th Congress, is not feasible at this time in view of the opposition of scientists to such a centralization of science information activities under Federal jurisdiction and control." ?

In general, then, the effect to date has been the intensification, extension, and improvement of existing services, the establishment of new mechanisms for coordination and cooperation, the initiation of new services in specific areas, and increasing attention to large-scale mechanization especially in DDC, NASA, and NLM and with serious attention to the problems of planning for possible automation in the Clearinghouse for Federal Scientific and Technical Information, the National Agricultural Library, and the Library of Congress, as well as in somewhat more specialized areas.

Examples of these different programs include bulletins which announce the availability of reports and often give abstracts of their contents; the technical information divisions of agencies such as the Atomic Energy Commission and the coordinating organizations such as the Defense Documentation Center; hearings held before different committees of the Congress; the establishment of new agencies such as the National Science Foundation and its Office of Scientific Information Services or new coordinating groups such as the COSATI of the Executive Branch; the activities of these new agencies in support of research and cooperative undertakings, and studies on the possibilities for mechanization of very large-scale information processes in the Patent Office and in the Library of Congress.

"In the general field of scientific information, the Government's role during the past four to five years has become increasingly dynamic ... All branches of the Government have come to recognize that the effective dissemination of scientific information plays a key role in scientific achieve. ment." 8

\footnotetext{
5 Cahn, 1962 [94]], p. 24.

- Shera et al., 1958 [526] p. 83

7 U.S. Senate, 1960 [592], p. 29.

8 Adkinson, 1962 [5], p. 49
}

Finally, it should of course be noted that grants and other means of support to research in the fields of scientific communication, information storage, selection and retrieval, mechanized translation, linguistic data processing, and the like, which involve potential contributions to increased convertibility and compatibility, are provided by the National Science Foundation, the Office of Naval Research, the Air Force Office of Scientific Research, the National Institutes of Health, and others.

\subsection{Traditional Cooperative Activities}

The precedents for cooperation or compatibility in the control and utilization of scientific and technical literature, so vital to expanding science and technology today, may well lie in the efforts by the more conventional libraries to achieve cooperation in acquisition, cataloging, indexing or classifying, preparing bibliographies, searching, storing, and retrieving. In many of these areas, agencies of the Federal Government have participated and, in some cases, provided examples of leadership.

Cooperative efforts among conventional libraries have traditionally been devoted to such areas as the following:

1. Exchange of information about availability of publications. This includes (a) the preparation of catalogs of all, or a selected portion, of the holdings of an individual institution and union catalogs of the holdings of particular institutions within a given area; (b) the preparation of published versions of such catalogs, or restricted parts of the catalog information given for each publication, e.g., union lists of serials received, indexes, etc. All of these services provide, inter alia. a basis for interlibrary loan services.

2. Arrangements of common efforts for the purchase, acquisition, and exchange of publications.

3. Development of techniques for the physical identification (e.g., descriptive cataloging) and subsequent citation of publications.

4. Development of techniques for the subject content identification of publications and for the ordering of groups or categories for such identification. These techniques have resulted in the compilation and subsequent exchange of both subject heading and other authority lists, and other classification mechanisms. Some of these have been accepted in whole or in part as voluntary interlibrary standards.

These traditional cooperative efforts have been either wholly voluntary, sponsored by professional societies, industry, or the government in a particular nation, or sponsored by international cooperation at the individual, professional community, industry or trade, or nation-to-nation level. As a result of these efforts, partial networks of cooperative action today do link to some extent libraries and information centers, public and private, academic, industrial, governmental, national and international. 
The outline of areas in which cooperative efforts have been made can serve as a useful means of discussing current operations and proposed activities in cooperative and coordinated information handling. This outline follows the normal flow of information, at least that portion of the normal flow which falls within the scope of this report: communication or dissemination, including publication of secondary sources; acquisition and exchange of publications; analysis and identification; systematization of analysis techniques; storage and search. We shall also examine attempts and current results of efforts toward standardization of operations, equipment, and the like.

\subsection{Dissemination and Publication of Secondary Sources}

Prerequisite to the acquisition of scientific and technical information items is a wareness of availability of information that has been generated and that can be communicated in some form or another, whether formal or informal, oral or recorded, published or unpublished. Historically, steps taken toward cooperation, compatibility, and convertibility in the handling of scientific and technical literature have been directed to solutions of the following typical questions: "What is available, who has recorded it, and are copies of the recordings available?"; "Who has what, and where, and are copies available?" and "What do I hold, and you do not, and vice versa, that we may exchange?"

Of first importance to a study of cooperation and compatibility, then, is the area of making available information about what information items exist and where they may be obtained. While libraries and information centers are still principally geared to materials in the form of the printed book, periodical, report, catalog card and paper-stock photocopies, this has been and is primarily a matter of cooperation. However, with recognition of the potentialities of mechanization, questions of checking duplications of coverage, identification of whether one listed item is or is not the same as another, of interfiling and updating in machine-processed files, create new problems of compatibility and convertibility, extending to such specific details as citation practice, format, character sets, and even the spelling of authors' names.

This first area is that of listings of monographic publications, of periodicals, and of scientific and technical reports of Federal Government agencies; of the traditional secondary publications, including abstracting and indexing journals, critical reviews and state-of-the-art reports, bibliographies, and, more recently, "current contents" services and citation indexes, and of clearinghouses for current research projects or for specialized subject areas. We shall discuss these various aspects of the dissemination of information in turn.

\subsubsection{Listings of Monographic Publications}

Listings of publications are of value for search not only to people within the organization compiling them but also to people outside the organization who wish to know of the "holdings." In attempting to create these lists, a natural collection unit is the total publication of a given country or community, this concept being known as "national bibliography" and defined by E. Thompson as "A list (or, collectively, lists) of works published in a country; or, in an extended sense, of works about a country, by natives of a country living in that country or elsewhere, or written in the language of a country." 9 A large number of the lists discussed in this section may be regarded as making up part of a national bibliography.

The volumes bearing the title National Union Catalog give documentary information concerning the holdings of the Library of Congress (LC) as represented by the printed cards in its catalog, as well as holdings of libraries throughout the country as reported to LC. They are compiled with the cooperation of the Association of Research Libraries and that of the Committee on Resources of American Libraries of the American Library Association.

"The National Union Catalog, established in the Library in 1926, serves as a means of locating books of research value in the collections of cooperating libraries. These libraries send copies of the catalog cards they prepare for their own use to the Library for filing in the NUC . . . .

"The Union Catalog has grown steadily since its formation ... It now contains approximately 14 million cards. The number of libraries reporting their holdings to the NUC has also grown over the years. The effective use of the NUC requires not only that a list of the symbols used in identifying the cooperating libraries be circulated but that this list be revised and brought up to date in successive editions." 10

Problems of this nature hamper the development and use of such catalogs and their solution is not easy to produce. "Federal libraries participate in a good many union catalog systems. However, taken as a whole, the network of union catalogs is spotty and does not make much sense. How far one should go, as a matter of national policy, in encouraging and assisting the development of such catalogs is a question that merits careful study." 11

Mechanization offers new prospects for the preparation of catalogs and lists of holdings- "the printed catalog produced by means of automatic equipment combines the best features of the conventional card catalog and the traditional catalog, and adds to both features that would have been unbelievable a generation ago." ${ }^{12}$ On the other

\footnotetext{
- Thompson, 1943 [569], p. 90.

10 Statement, U.S. Senate, 1960 [592], p. 86.

11 Evans, 1963 [188], p. 23.

13 Vertanes, 1961 [609], p. 242
} 
hand, such prospects offer new challenges to convertibility and compatibility, making, in particular, the problems of descriptive cataloging a necessary first step in agreement. An example of current cooperative ventures is the joint project of the Medical Libraries of Columbia, Harvard, and Yale for computer preparation of catalogs for books published from 1960 onward (Kilgour et al., $1963[315])$.

Another specific example of a cooperative venture in union catalog preparation and use, with compatibility achieved by means of centralized services, is the Lake County Libraries. All the libraries in this system "share in a growing book collective ... A union catalog in book form, in single or multiple copies as required, is furnished to each participating library; closed circuit teletype communication provides the necessary means of sharing the common collection as reflected in the union catalog." 13

The British have a comprehensive national bibliography, the British National Bibliography (BNB), begun in January 1950 and published by the Council of the British National Bibliography Ltd., "representing the British Museum, the Library Association, the Publisher's Association, and seven other bodies. ... It is published weekly, with quarterly and annual cumulations including a combined author, title and subject index to its entries which are classified according to the Dewey Decimal Classification." 14

The publication in 1937 of the Union List of Newspapers was one of the early cooperative enterprises in this area. By means of this publication and the widespread use of microfilm, beginning in about 1940, a cooperative project was proposed and promulgated for filming important runs of newspapers "in publishers' offices and obscure libraries . . . and placing copies in the large libraries of the nation, a step for which historians have every cause to be grateful." 15

Publication of the National Catalog of Patents was announced in 1963 by Rowman and Littlefield, Inc., of New York City, in cooperation with the U.S. Patent Office. The announcement stated that the "searcher will find all the patents in a given area of interest grouped together by Classes and Subclasses as defined by the Patent Office. Patents granted in their respective fields (as well as allied patents which have primary listing in other fields) are shown in the form of one major claim and one drawing as exemplified in the Official Gazette. This inevitably results in an expansion of search horizons."

The Library of Congress Information Bulletin announced in its November 4, 1963 issue [104] that LC with the Association of Research Libraries plans a centralized register of all master negatives of microfilms, whether in process or already produced. (A "master microfilm" is a negative pro-

13 Burns, 1964 [89], p. 14.

14 Metcalfe, 1959 [382], p. 254.

1s Downs [179], n. 65 . duced under optimum specifications and maintained under archival conditions for the purpose of making prints only.) The new project follows earlier activities at LC (which has a Microfilm Clearing House for reports received in the Union Cataloging Division regarding available microfilms), and activities of the Philadelphia Bibliographical Center, which published the Union List of Microfilms during 1951-1961.

One of the prominent commercial compilers for keys to printed matter is $\mathrm{H}$. W. Wilson Company, the publisher since 1900 of The United States Catatog; Books in Print. Beginning with 1928 , the company expanded this publication and gave it another name: Cumulative Book Index. It is a world list of books in the English language. including "publications in the regular book trade. privately printed books, regular importations of American publishers, Canadian books (in English) not also published in the United States, publications of universities, societies, scientific institutions, and a selected list of publications of the national and state governments." 16

The index, published nine months each year includes frequent cumulations for ease of searching and has been issued in biennial cumulations beginning with 1957 . It is regarded as "indispensable: (1) in order department work; (2) as an adjunct to the library's own catalog; (3) as a reference tool for many subjects: verification of titles, authors' names and dates, authorship when only the title or subject of a book is known, list of books on a given subject, etc." 17

The publications of R. R. Bowker Co. of New York City include the Publishers' Weekly: The Book Industry Journal, which contains lists of new publications of the week, lists of books announced for publication, news notes, editorials and articles, advertisements of books wanted, and the like. The Publishers' Trade List Annual, which consists of a collection of publishers' catalogs, arranged alphabetically by publishers' names, began publication in 1873 and was supplemented in 1948 by Books in Print: an Author-Title Series Index to the Publishers' Trade List Annual. It consists of two indexes bound in one volume; the first arranged alphabetically by author and editor; the second alphabetically by title and series. These give the publisher and price of a book, and further information may be obtained by consulting the pertinent publisher's catalog in Publishers' Trade List Annual.

Beginning in 1957, a companion volume to Books in Print has been published, The Subject Guide to Books in Print: an Index to the PubTishers' Trade List Annuat, generally following the headings assigned by the Library of Congress. Another Bowker publication, American Bool Publishing Record, issued since 1960 and a record of

16 Winchell, 1951 [649], p. 21.

17 Ibid, p. $21-22$. 
American book publication, uses the forms of entry, Dewey Classification number, and subject headings as established by LC for its catalog cards.

\subsubsection{Listings of Periodicals and Periodical Articles}

A major American effort in the listing of serials or periodicals is the Union List of Serials, published by H. W. Wilson Co. The second edition was published in 1943, and has had two supplements since then. This edition records, for more than five hundred libraries in the United States and Canada, the holdings of periodicals and periodical-like publications whose first issue appeared previous to 1950 . The Union List is called "one of the greatest landmarks of American librarianship. After nearly thirty years of constant use it has come to be recognized as a tool of proven and indispensable value." 18 The last supplement covers serials in existence on Dec. 31, 1949.

Beginning in 1950, LC has supplied an adjunct to the Union List in its publication New Serial Titles, a union list of serials commencing publication after December 31, 1949 and received by the Library of Congress and cooperating libraries. The entries are coded by their subject content, by language, and by country of origin. The New Serial Titles was prepared under the sponsorship of the Joint Committee on the Union List of Serials, consisting of thirteen organizations, including the ALA, the American Association of Law Libraries, the Theatre Library Association, and the H. W. Wilson Company. It is of interest to note that New Serial Titles has been regarded as "the first successful nonexperimental punchedcard catalog of periodicals." 19

The British have a publication similar to the Union List entitled World List of Scientific Periodicals, the third edition of which was published in 1952 and records the contents of 247 libraries, with about 50,000 titles. Volume 1 of the fourth edition appeared in 1963 and the remaining two volumes are to become available soon.

Further efforts involve continuing cooperation: "The Joint Committee on the Union List of Serials-a non-profit corporation representing 13 American and Canadian library associations and bibliographical institutions-has signed an agreement with H. W. Wilson Company ... to publish and distribute a third and final edition of the Union List of Serials in Libraries of the United States and Canada. Publication is tentatively scheduled for early 1965." 20

In the United States there have been numerous instances of the establishment of union lists of periodicals in different parts of the country. Librarians of Houston, Texas, in evolving a plan for a Houston Technical Information Center, conducted a survey of the scientific and technological serials available in the area that resulted in the

\footnotetext{
is Osborn, 1954 [444], p. 26.

19 Dewer. 1959 [173], 36.

so Scientific Information Notes 4, 5, 15 (1962).
}

publication of the Houston List, showing the location and availability of more than 8,000 titles. $^{21}$ Similarly, librarians who were active in the Minneapolis Chapter of the Special Libraries Association, produced a union list of periodicals, plus a planned pattern of periodical holdings and negotiations to eliminate overlap and extend coverage. "The master list shows the libraries taking a certain periodical, with an indication of which library would be responsible for the longest file." 22

\subsubsection{Listings of Reports of Government Agencies}

In addition to the traditional methods of publication, newer and less conventional forms include the technical report, the unpublished conference or symposium paper, the mimeographed or otherwise informally prepared preprint and reprint, publication in "auxiliary" or "deposit" form, and computer-produced outputs for both primary-and secondary-type publications. Of these, the technical report is of most importance and interest to this report.

First, because the problems of distribution and subsequently of announcement were major factors in the creation of technical information activities in various Government agencies. Second, because "a significant proportion of the people . . . concerned with the control, storage, and dissemination of reports are, themselves, new to reports, and to bibliographic organization in general." 23 Third, because the nature of the report content aggravates, on the one hand, the need for multiplesubject categorization and indexing in depth, and, on the other hand, in view of its probably high rate of obsolescence, the problem of speed and currency in announcement and dissemination. Thus, "if the large report collection centers are going to disregard reports that are more than four years old, what is the searcher going to do when he comes upon a reference in an abstracting journal to a report that is, say, five years old?" 24 A fourth reason, not entirely independent, relates to the more specific problems of numbering-identification and the attribution (or otherwise) of authorship.

A rationale for the handling of communications resulting from particular agency fundings, for specific in-house and contractor benefit, explains much of the early development of technical information handling activities outside the mainstream of conventional systems for the publication, dissemination, storage, and selective recall of recorded knowledge. There was, on the one hand, a particularly parochial recognition of responsibility. There was, on the other hand, all too often an assumption by traditional and conventional sources of information handling services that the informational material would (a) find its way eventually into the traditional

\footnotetext{
${ }^{21}$ Richardson, 1963 [481], p. 298.

22 Miller, 1963 [387], p. 295 .

23 Herner, 1952 [257]. 1110

24 Herner and Herner, 1959 [254], p. 192.
} 
pattem and could be ignored until it did, (b) would be of ephemeral interest unless and until "tried out" by the conventional methods of refereeing, editing and redacting, and (c) posed too many problems with respect to traditional cataloging, indexing, and abstracting principles to make coverage practically feasible.

Warheit comments in 1952 that only three years previously "one of the largest abstract journals implied rather strongly that report literature was not too important and refused to accept the reports of the U.S. Atomic Energy Commission because they were not generally available to the scientific community." 2 .

Other representative comments with respect to reports are as follows:

"It was not until the second World War that the technical report began to play a leading role in the communication of research results within the government. The Office of Scientific Research and Development (OSRD) . . . . let a large number of research and development contracts with universities, research institutions, and industrial organizations. The research programs of the OSRD were, for the most part, decentralized ... It was essential to develop a means whereby the research groups working on related projects might keep in close touch with each other. Moreover, since a large part of the research was classified from the standpoint of military security, normal channels of publication could not be used and means of communication subject to security control had to be developed. The technical report served both purposes. This prompt interchange of information was a very important element of the success of the research efforts of the OSRD." 26

"Reports are a more primitive form of scientific and technical literature than professional journal articles because they are produced earlier in the research program. Since the scientific community now consumes information virtually as quickly as it is produced, this information must be recorded as quickly as possible." 27

"The progress report is important because it is the only available written source of the material until the summary report or technical journal article is published and delays in writing and publishing summary reports or journal articles may run as high as a year or two. Moreover, progress reports are usually the only written source of negative information, that is, the record of the difficulties and failures experienced with certain experiments or techniques; and of the incidental data such as the preparations necessary for experiments and the rationale for adopting certain approaches." 28

The Federal Government accepted early the responsibility for technical report literature by creating information processing operations in four

25 Warheit, 1952 [627], p. 109.

26 Waterman, 1955 [630], pp. 4-5.

27 U.S. Senate, $1960[592]$, p. 45.

${ }^{2}$ Ibid, p. 45-46. of its agencies, which have evolved as the Defense Documentation Center (DDC), the information organizations of the National Aeronautics and Space Agency (NASA) and the Atomic Energy Commission (AEC), and the Clearinghouse for Federal Scientific and Technical Information. These were established to "acquire, collect, and disseminate scientific and technical report literature which industry had both created and demanded during the war years, when the serious lack of communication and availability of information was intensely felt." ${ }^{29}$ This mission is being accomplished as follows: "The report problem has been approached from two opposing directions at once. First, an interagency cooperative program is assuring that the maximum number of reports prepared with public funds is called to the attention of and made available to the public. The second attack is on the information itself, to guide as much of it as possible into more conventional information channels." 30

Miller indicates that the bibliographical specialist handling report literature has special problems: (1) The unprecedented volume has caused "classical techniques of acquisition, handling, bibliographical processing, circulation and distribution to bog down." (2) Report literature "is more dependent upon a high degree of bibliographical control than almost any other form, and actually has less applied to it." 31

One means taken by government agencies in trying to control report literature is to prepare announcement bulletins, lists of newly generated or newly acquired technical reports and summaries such as AEC's Summary Technical Reports or the Report Bibliography of the Navy Research Section which was a "quickly prepared bibliography which consists of photoreproductions of pertinent catalog cards from the NRS and other Library of Congress files." ${ }_{32}$ These bulletins or lists may contain bibliographic citations to reports, descriptions or abstracts of the reports, and also subject chues or indexes to their contents. We shall consider here only the form of the listings, and shall discuss the abstracts and indexes in the next section.

First, we note that some reports "may be printed and placed on sale by the Government Printing Office, in which case their availability is announced in the Monthly Catalog of U.S. government publications and other advertising media employed by this office." ${ }_{33}$

Announcements of acquisitions, holdings, and processed items available in microform began almost as early as the post-World War establishment of organizations such as CADO, Navy Research Section, and OTS, but, at first, only in informal mimeographed form. For example, be-

\footnotetext{
29 Painter, 1963 [445]. p. 37-38.

so U.S. Senate, 1960 [592], p. 112 .

31 Miller. 1952 [386], p. 92-94

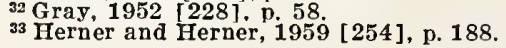


ginning in 1946, the Navy Research Section at the Library of Congress issued TIP (Technical Information Pilot) with abstracts of items processed. On the later merger of NRS with CADO to former ASTIA, the TAB, which originally stood for Technical Announcement Bulletin (now Technical Abstracts Bulletin) began to be issued from 1953 onward.

The now semimonthly $T A B$ of DDC has a subject index with an alphabetic arrangement of the descriptors that have been given an asterisk, i.e., those descriptors which indicate the major technical emphases in each report in that issue of $T A B$. In the Technical Abstract Bulletin Cumulative Index, since the July-December 1962 issue, the entries are composed of three parts: (1) display of all descriptors assigned a report; (2) corporate author or agency preparing the report; and (3) the AD number, the pertinent issue of the $T A B$, and the major subject division of the Distribution Guide.

At OTS, also, the present U.S. Government Research Reports (USGRR) had early predecessors. By 1951, some 300 of the unclassified or declassified reports per month were being selected, listed, and annotated or abstracted in the Bibliography of Technical Reports. Selection was directed toward the interests of industrial laboratories and each monthly issue contained a four-page Newsletter digesting those items of probable interest to small business firms (Gray, 1951 [221]).

OTS and its successor, the Clearinghouse for Federal Scientific and Technical Information, have been concerned with as wide dissemination as possible of the material for which it is responsible: ". . . we do not rely on Government efforts alone to announce the availability of the material. We have enlisted the cooperation of the technical press and the major abstracting and indexing societies. In fact, we consider their interest and cooperation to be one of the most important factors in prompt and effective distribution." 34

In the July 5, 1961, issue of the USGRR of OTS and the July 1, 1961, issue of $T A B$ of DDC (then ASTIA) there was announced a cooperative arrangement for making DOD research information more widely available to the American public. Thereafter the first section of the USGRR would consist of the first "white" section of the TAB, listing only the unclassified reports having unlimited distribution. The second section of the $U S G R R$ would list reports of civilian agencies of the Government and military research reports not found in the $T A B$, most of them older reports acquired by OTS on specific industry request. Each of the reports listed in the first section of $T A B$ listed the OTS purchase price of the report. OTS made three indexes available for the year 1962 . The major portion of two of these indexes is for the unclassified reports having unlimited distribution which DDC and OTS announce almost simul-

s Green, 1959 [226], p. 119. taneously twice a month. A third OTS 1962 index was for the nonmilitary and older research reports distributed by OTS. This index uses descriptors to indicate the subject content of the other reports distributed by OTS, except that there is no indication of the subject content for the reports of the AEC.

NASA in 1963 issued its Scientific and Technical Aerospace Reports (STAR), volume 1, having published the Technical Publications Announcements during 1962. The STAR bulletins are prepared by the Scientific and Technical Information Facility operated for NASA by Documentation, Incorporated, of Bethesda, Maryland. $S T A R$ is arranged in two major sections, the first having complete bibliographic citations with informative abstracts arranged by subject category and the second having indexes for subject, corporate and personal authors, report number, and accession number.

An interesting instance of cooperation between the Federal Government and an institutional organization is the relationship between $S T A R$ and the International Aerospace Abstracts issued by the American Institute of Aeronautics and Astronautics. STAR lists both unclassified report literature prepared by NASA, its contractors, and other responsible organizations in the United States and abroad, and articles prepared by authors from NASA and its contractors that appear in learned and technical journals. The International Aerospace Abstracts lists what is usually considered as the published literature. These two publications are each issued biweekly, appearing on alternate weeks, and use identical subject categories and indexing procedures.

The Bibliography of Agriculture of the National Agricultural Library; Nuclear Science Abstracts, AEC; and Index Medicus of the National Library of Medicine also provide coverage of Government agency reports, particularly those emanating from the parent organizations and their contractors. However, since these provide abstracting and/or indexing coverage of the published literature, we shall discuss them in the next section, mentioning here only the problems of report numbering.

The numbers for reports announced in STAR and $T A B$ are assigned as the documents arrive in the respective places of accession. The reports are not arranged in numerical order in these announcement bulletins. In the Nuclear-Science Abstracts $(N S A)$ of the $\mathrm{AEC}$, however, the reports are announced in strict numerical order. Each entry in the bulletin is supplied with another number for ordering purposes, generally a number indicating the origin of the report in the AEC.

Correlation Index: Document Series and PB Reports, edited by G. E. Runge and published by the SLA in 1953 [501], was responsive to the urgent need for correlation between the numbers used by primary and secondary publications. It includes the unclassified and declassified reports 
listed in Volumes 1 to 17 , January 1946 through June 1952, of the Bibliography of Technical Reports. The correlation, of course, was primarily with the varying schemes for numbering the scientific and technical reports issued by, or with the authority of, agencies of the government. "As a check-list, it will aid in assembling a collection of reports in any one of the series included. It will also help in ordering serial-numbered unclassified and declassified reports." 35

Redman and Godfrey have edited a Dictionary of Reports Series Codes (1962 [469]) which have been used by agencies of the United States and foreign governments for identifying technical reports. These report numbers "offer many advantages for references to security-classified material. When properly used, they provide positive identification of material, and depending on their makeup, may indicate source, date, subject, or availability." But the editors suggest that "codes have become so numerous as to be almost meaningless. Conceived as a shortcut in report reference, they are now often a handicap." 36 "This 648-page Dictionary was compiled by the Report Series Dictionary Committee on the Rio Grande Chapter of SLA.

\subsubsection{Abstracting and Indexing Services and Publications}

The common distinction made between types of publications calls an original article, book, or pamphlet primary publication, while an abstract index, digest, or review is referred to as secondary publication. Of particular interest to this review are the secondary publications, especially the indexing services for periodicals, which manifest many cooperative and collaborative operations and proposals. The usage of the word "index" which interests us is that of an alphabetical list of references to literature in general, usually printed separately. This index "is an independent publication in book form, periodically issued and cumulated, listing journal article references arranged in some order, of which the minimum is by subject." ${ }^{37}$ In addition, periodical indexes and abstracts "cover many periodicals... [they] have been developed to do for many libraries what each separately cannot do for itself, and to avoid duplication of work; they supplement library catalogues, and in much of the reference and bibliographical research work of reference and research libraries they may be used more than the libraries" own catalogues.... Periodical indexes are used as issued and in cumulations and for an indefinite period for specific reference, but being alphabetical they cannot be conveniently used for generic survey of literature, that is, for the survey of both the special and the general literature in a fairly wide field such as chemistry, or organic chemistry, or a subclass of organic chem-

35 Runge, 1953 [501], p. iii

3 Redman and Godfrey, 1962 [474], p. 1 .

s7 Taine, 1962 [551], p. 147. istry. But the fact that they continue to be alphabetical, even in countries with a strong prejudice in favor of classified cataloguing, shows that they meet a major need, that of specific reference. $\mathrm{Ab}$ stracting journals are used as issued, for generic survey, for which they are more or less classified ..." 38

Following the middle of the nineteenth century important developments in the making of indexes to periodicals took place in the United States. W. F. Poole, "was preparing the way for his great indexes to the periodicals of the nineteenth century. These were a new advance, and a considerable one: instead of an index to one periodical for one year, Poole introduced the idea of one index to many periodicals covering a considerable number of years." 39

In 1853 , "a copy of a new index to the Periodical Literature of England and America was exhibited to the Convention, and on motion of Mr. Folsom, it was unanimously Resolved, that we have examined the work entitled 'Index to Periodicals,' by W. F. Poole, Librarian of the Mercantile Library of Boston, and that we approve of its plan and execption, and we recommend that a similar system of indexing to be extended to the transactions and memoirs of learned societies." 40

Next we note that "the first large-scale indexing of current medical-journal literature using institntional team-approach methods had its start in 1879 with he publication, by this Library, of the first volume of the first work to use the title Index Medicus. This was followed in 1880 by the first volume of the first series of the Index-Catalogue of the Library of the Surgeon General's Office." $\$ 1$

The Readers' Guide to Periodical Literature, produced by H. W. Wilson, appeared in 1901 . "Each article in a periodical was indexed under its author and under its specific subject. There were numerous cross-references to link up each subject with related subjects and with aspects of itself, and a very high standard of consistency and accuracy was maintained from the first." ${ }^{42}$ The Readers' Guide index was for the nontechnical periodical of general circulation. Wilson started the Industrial Arts Index, subject index to a selected list of engineering and trade periodicals, in 1913. With the volume for 1958 , the title was changed to Applied Science and Technology Index. In the volumes there is a list of abbreviations for the periodicals indexed, with their more extensive titles, and the location of the publisher of each periodical and its cost.

Engineering Index was first published by Engineering Magazine in the years 1892-1918, with the title for Volume 1, 1884-1891, Descriptive Index of Current Engineering Literature. From 1918 through 1933, the publisher was the Ameri-

\footnotetext{
${ }^{38}$ Metcalfe, 1959 [381], p. 85-86.

39 Collinson, 1959 [131] p. 18.

40 "Proceedings of the Librarians" Convention . . . 1853", 1915

[466], p. 44.

41 National Library of Medicine, 1963 [412], p. 1.

42 Collinson, 1959 [131], p. 19.
} 
can Society of Mechanical Engineers, and since then, Engineering Index, Inc. "For current work the annual index may be kept up to date by a weekly card service which supplies printed cards with brief abstracts for articles in periodicals, translations, reports, etc., in various languages." 43 Since October 1962, the Enginering Index, Inc., has issued monthly compilations in book form of its bibliographic items.

These are but a few examples of earlier periodical indexes, and we shall turn our attention now to current enterprises. We have mentioned various listings of scientific and technical reports from government agencies; their abstracting and indexing practices are of importance to considerations attendant upon potential mechanization.

The monthly publication, Bibliography of Agriculture, of the National Agricultural Library announces articles, monographs, serials, and report literature, most of the reports originating in research agencies within the Department of Agriculture. The December issue each year contains the annual subject and author index, the monthly volumes containing only an author index with the citations to the specific items.

In indexing for the Bibliography of Agriculture, no standard list of headings is followed, "merely the subject index from the previous year, added to when the need arises. The indexing is usually done from both the title and a glance at the report. Each subject heading is typed on a $3 \times 5$ slip of paper along with the citation number of the document which appears in the announcement bulletin. These slips are then filed by subject in a temporary file until early Fall when the December issue begins cumulation. It is purely a manual system. Each document averages 2 to 3 subject headings." 44

In contrast to the Bibliography of Agriculture, the production of indexes to current medical literature has been the target for mechanization considerations for some years, and is still undergoing progressive advancement in the types of equipment used. "The Current List of Medical Literature began publication at the Army Medical Library in 1941. . . . Dr. Seidell convinced the Library ... that the advent of photo-copying services in libraries called for a weekly index to provide for prompt dissemination of information concerning articles available on microfilm." 45 There has been a trend "to change from one type of equipment to another ... From about 1950 to 1959 , the Current List of Medical Literature . . . was typed on individual $3 \times 5$ cards which were laid out in shingle form by hand for photo-offset publication. In January 1960, Index Medicus was launched as the successor ... The entries ... were typed with the paper tape typewriter onto Hollerith card . . . and fed through the Listomatic camera for photo-offset publica-

\footnotetext{
${ }^{43}$ Winchell, 1951 [650], p. 297 .

14Painter, 1963 [445], pp. 91-92.
45 Rogers and Adams, 1950 [490], p. 279
}

tion" 46 and, more recently, the MEDLARS system involving computer and high-speed photocomposition (GRACE, or Graphic Arts Composing Equipment) has been approaching full operation. ${ }^{47}$

The history of this progression in systems is of interest from the point of view of cooperative long-range planning of information systems and services. Thus, "... a research contract was granted to Johns Hopkins University in October, 1948, by the Medical Research and Development Board Office of the Surgeon General". .8 This Army Medical Library Research Project at the Welch Medical Library had among its contract objectives that of exploring "existing and projected methods, emphasizing machine methods, applicable to such pilot projects as may be necessary." ${ }^{49}$ The work at the Welch Medical Library continued for several years, the final report being issued in 1955. Beginning in 1951, the project maintained in punched card form the subject heading authority list used for the Current List of Medical Literature. Garfield has stated that this work "clearly demonstrated the ease of converting alphabetic subject heading lists to categorized or classified lists of terms." ${ }^{50}$ Ingenious use was made of a modified IBMI 101 machine for the preparation of printed subject indexes.

Next, the Council on Library Resources made a grant to the NLM for an "index mechanization project" between July 1958 and June 1960 . As a result of the project, the production of the Index Medicus from January 1960 to the introduction of GRACE used the Listomatic Camera, IBM card punching and handling equipment, and the Friden Justowriter (tape-typewritten with a justified right hand margin). Bibliographic citations, author entries, and subject headings were punched onto paper tape by Justowriters and proofread, the tape permitting automatic duplication of entries on IBM cards in different formats. Collating and sorting equipment produced a mechanically sequenced deck of cards. Proofreading was from a positive paper print produced by the camera. Following correction the film was processed, and columns stripped up for page makeup. The monthly publications were produced by photo-offset. The 12 monthly decks of cards were interfiled by IBM equipment to produce the annual Cumulated Index Medicus of the American Medical Association.

In August 1961, the NLM undertook its MEDLARS project (Medical Literature Analysis and Retrieval System) by contract with the Information Systems Operation of the General Electric Co.'s Defense Systems Department. The monthly

\footnotetext{
${ }^{46}$ Gull, 1962 [228], p. 62.

47 See Scientific Information Notes 6, No. 4, p. 10, 1964 : "The Augnst 1964 issue of Index Medicus was the first to be produced by GRACE. It is a 609-page document, containing more than terial in approximately 16 hours including set-up, running, and terial in approxi

correction time." 48 Rogers and Adams, 1950 [490], p. 283.

48 Rogers and Adams, 1950 [490], p. 283.
49 Larkey, 1953 [332] and 1956 [331].

o Garfield, 1959 [211], p. 471 .
} 
Index Medicus, the annual Cumulated Index Medicus, the annual printings of Medical Subject Headings, the Bibliography of Medical Reviews, and recurring bibliographies all continued. The Graphic Arts Composing Equipment (GRACE) composes finished copy on film suitable for offset printing. Most demand (nonrecurring) bibliographies and all statistical information prepared by the system are printed by a standard computer printer in single font copy on continuous paper or on $3^{\prime \prime} \times 5^{\prime \prime}$ card forms. ${ }^{51}$

Returning now to the more general aspects of the abstracting and indexing services offered by various Government agencies, we note first that the indexes to DDC's TAB were enlarged on 1 January $1965^{52}$ to include personal author, contract, and corporate author/monitoring agency indexes. The combination of subject, corporate author/ monitoring agency, personal author, and contract indexes for each TAB is published as a separate volume but is distributed at or near the same time as the corresponding TAB announcement bulletin. A separate cumulated index will be published at the end of each of the first three quarters of the calendar year. An annual cumulated index will be issued at the end of the year covering the entire year's announcements.

The subject index entries are arranged by the asterisked (weighted) descriptors (most with modifying descriptors for greater specificity) assigned to the documents. Each entry is comprised of (1) a descriptive annotation concerning the document; (2) the DDC document (AD) number assigned to the document; and (3) the number of the subject division in $\mathrm{TAB}$ where the complete announcement appears. It is noted that the DDC is using a "descriptive annotation" which appears to bear comparison with the "notation of content" of the STAR and the combination of main heading with modifying phrases of NSA.

The Corporate Author/Monitoring Agency Index to TAB is arranged in alphabetical order of interfiled corporate authors and monitoring agencies. Within each entry are listed originator report number (if present), title (if unclassified), monitor series number (if present), and $\mathrm{AD}$ number and division number.

The Personal Author Index is arranged alphabetically by the last names of the authors of reports. Unclassified titles and division numbers are also given.

The Contract Index is arranged alphanumerically by contract number. Individual entries contain corporate authors, originator report numbers (if present), monitor series numbers (if present), AD numbers and division numbers. Letter abbreviations indicate Final, Annual, or Summary reports.

The indexes to the USGRR prior to $1962 \mathrm{had}$ the subject content indicated by subject headings,

\footnotetext{
51 Taine, 1964 [552], p. 119-124.

${ }^{52}$ Revision suggested by William A. Barden, private communlcation, March $30,1965$.
}

not descriptors, and a separate section for separately announced reports was unnecessary for either the semiannual index or the individual issue of the USGRR. Each of the issues for the first half of 1961 had individual indexes for corporate authors, a practice which was stopped in July 1961 when OTS began receiving the greatest portion of its copy from DDC. The index for JulyDecember 1961 of the USGRR has the separate cumulative index for nonmilitary and older military research reports.

The introduction to the 1962 annual subject index to AEC's Nuclear Science Abstracts states (page 1) that its main entries are generally specific materials, things, and processes and that these are followed by modifiers describing the properties of, and processes applied to the main entries. The modifiers, modifying phrases, or subheadings, which are "descriptive phrases (modifiers), rather than ordinary subheadings, are used under the main headings to give a better indication of the material covered in an abstract than would be possible with only a word or two, whenever it appears that such information would be useful." Compositon of the index to NSA was mechanized in 1959, involving (1) a composing mechanism, (2) an accounting machine for sorting, (3) a Listomatic camera, and (4) a developing and drying mechanism. Coding and post-machine editing are clerical tasks. Mechanization resulted in a 50 to 75 percent increase in the number of abstracts handled.

More recently, a computer program has been developed to compile Research and Development Abstracts of the USAEC (Sherrod, 1963 [522]). A modification of this program is also used for author, corporate author, item number and subject indexes for the Engineering Materials List, which includes coverage of blueprints and drawings (Davis, 1963 [156]).

NASA follows two levels of indexing, one for direct use by consumers in the STAR index, and a second level, of greater depth, for literature searching and bibliographic preparation by the computer system. For machine retrieval "where greater depth of indexing and retrieval is optimized by the machine capacity," the average number of access points per item is 15 or more. ${ }^{53}$

The introduction to cumulative index issues and to the annual subject index of $S T A R$ states that each item announced in the abstract section of the periodical is indexed with an average of five subject terms and that the item is represented in individual index listings by an abbreviated notation of its content, not the title of the document. Each "notation of content" is composed of the principal subjects of the report and appears under each of the relevant subject terms in the STAR index. The indexes have three kinds of crossreferences: "see," "see also," and "confer." "The 'see' cross-reference is used to relate general con-

\footnotetext{
๒3 Day, 1962 [160], p. 368.
} 
cepts, which are too vague to be meaningful indexing terms, to the more specific terms used in the Index. The 'see also' cross-reference refers from general to specific terms when the postings from the latter are not repeated under the general term. The 'confer' cross-reference relates two conceptually associated terms . . ." The introduction concludes: "As different postings accumulate under the subject headings, the headings become the entry points for the retrieval of relatively broad classes of information. On the other hand, each notation of content under a heading may be regarded as a modifier of that heading which provides the specificity necessary to identify a desired report. Thus, the user can vary the specificity of his search by relating the subject heading with other subjects indicated by the notation of content."

Examples of non-Government abstracting-indexing services include Chemical Abstracts Service and Biological Abstracts $(B A)$. Chemical Abstracts Service, sponsored by the American Chemical Society, publishes Chemical Abstracts $(C A)$ and other specialized searching tools such as Chemical Titles. $C A$ is considered to be the world's leading abstract-index service in the field of chemistry. Its coverage of the world's literature is extensive, its abstracts are informative in style and its indexes are specific and detailed. The number of index terms per abstract averages $3 \frac{1}{2}$; the subject headings are general, but subheadings and modifications make the individual entries specific. No attempt is made to standardize terminology at present, although complete and strict rules are followed for standard nomenclature of chemical compounds. However, the Chemical Abstracts Service is undertaking an extensive and far-reaching program of mechanization in all aspects of its operations.

$B A$ a world leader in its own field of biological sciences, is also undertaking studies of mechanization and, like $C A$, publishes a machine-compiled KWIC index, $B A S I C$. We should note that: "Biological Abstracts, is one of the very few [services] that is completely independent of either a library or a scientific society. It was established as an independent, nonprofit cooperative venture of the world's biologists and incorporated through the joint efforts of the National Academy of Sciences, the American Association for the Advancement of Science, and the Union of American Biological Societies." 54

Chemical Abstracts Service, Biological Abstracts, and several of the Government agencies which publish abstract-index services are members of the National Federation of Science Abstracting and Indexing Services (NFSAIS), mentioned earlier in section 2.3. R. A. Jensen, Executive Secretary of the NFSAIS, stated in December 1961 that "the Federation is a free-will association of autonomous and independently managed corpo-

5 U.S. House 1959 [586], p. 99, statement of G. M. Conrad. rate bodies. In joining together in a Federation these corporations have merely signified their willingness to cooperate with one another to further the interests of science and technology. Consequently, the essential autonomy of its member corporations confines the activities of the Federation to those thing's which least interfere in or compete with the independence of operation of the member organizations ....

"The NFSAIS [is] endeavoring to achieve its aims through cooperative efforts in such problem areas as bibliographic, indexing and abstracting standards; coverage overlaps and gaps; transliteration; copyright laws; definition of terminology; costs and financing; procurement of hard-to-obtain journals; journal inventories; mechanization in all phases of the operation of secondary-source information services; and information retrieval ... During its formative years, NFSAIS moved slowly and cautiously in its activities, confining its tangible work to the preparation of federated or union lists and the establishment of standards." ${ }_{55}$

A steering committee of the NFSAIS gave advice to the Science and Technology Division of the Library of Congress for NFSAIS Report No. 101, $A$ Guide to U.S. Indexing and Abstracting Services in Science and Technology, published in 1960. Report No. 102 of the NFSAIS, titled $A$ Guide to the World's Abstracting and Indexing Services in Science and Technology, was prepared under a grant from the National Science Foundation by the LC Science and Technology Division and published in 1963. This list contains 1855 titles originating in 40 countries; the entries for the United States total 365. The 1963 Guide combines and brings up to date the 1960 NFSAIS Guide and Index Bibliographicus, 4th ed., Vol. I, Science and Technology, published in 1959 at the Hague by the Federation Internationale de Documentation. The services in the Guide are arranged first by the UDC classification, and also alphabetically. Recently the NFSAIS "concluded an agreement with the Institute of Scientific and Technical Information of China in Peking to exchange some of the periodicals of its members for approximately forty Chinese periodicals ... copies ... are made available to members of NFSAIS, the Library of Congress, the Linda Hall Library, the Midwest InterLibrary Center, and the Massachusetts Institute of Technology Library." 56

A National Plan for Science and Abstracting and Indexing Services, dated March 15, 1963, was presented to NFSAIS by Robert Heller and Associates. The Plan distinguishes between profession- and project-oriented secondary publications: the former attempt to cover, on a comprehensive and continuing basis, all significant literature in one or more of the basic fields of science, while

\footnotetext{
55 Jensen, 1961 [298], pp. 556-557.
}

so O'Brien, 1963 [433], p. 203. 
the latter provide comprehensive coverage of significant information for a particular subject, with articles from the literature in any field of science and technology. "The plan outlines steps by which the abstracting and indexing services themselves can organize for cooperative effort to meet the pressing need for improved basic reference tools in all fields of science. They can implement the plan and still maintain their independence, but will need the support of their sponsoring organizations, the National Science Foundation and other government agencies." 57

The Plan has seven major recommendations: (1) Upgrade the profession-type services with the assistance of the National Science Foundation. (2) Establish a central operating unit (Organization $\mathrm{X}$ ) on a joint-venture basis to utilize the raw material of the profession-oriented services and produce new project-type products. (3) Reduce the cost of the profession-oriented services by coordinating journal acquisition and coverage and by exchanging citations, abstracts, and translations. (4) Use the central operating unit to reduce the costs of project-oriented services that are already covering the same general segments of scientific literature. (5) Increase the use of author abstracts. (6) Expand the activities of the NFSAIS. (7) Broaden the membership of the NFSAIS to achieve adequate representation among all types of abstracting and indexing services. Jensen has reported that all the recommendation except numbers 2 and 4 were accepted by the NFSAIS. ${ }^{58}$

In contrast, perhaps, to the activities of the NFSAIS, the "progress in achieving better international coordination of scientific abstracting services has been slow. The program of the Abstracting Board of the International Conncil of Scientific Unions (ICSU), which is supported in part by the National Science Foundation, has had a modest success. Of more significance for the future are the program proposals made by the Foundation to the International Federation for Documentation (FID) for more active participation jointly with ICSU in the coordination of such services. . . ."

Crowther, reporting in 1958 at ICSI on activities of the International Council of Scientific Unions Abstracting Board, noted that while there had been "perennial discussions" on the questions of adopting a uniform practice or style for details of abstracts prepared and of unifying the classification or indexing schemes used, "progress has been slow." 60 Further: ". . . the most fruitful activities of the I.C.S.U. Abstracting Board have been in fields connected with the investigation and acquisition of material for abstracting . . . " 61 Agard Evans (1959[8]) has reported that a

\footnotetext{
57 Heller, 1963 [249], p. 27.

ss Jensen, 1963 [299], p. 341.

U.S. Senate, $1960[592]$, p. 131 , report by B. W. Adkinson. ${ }^{6}$ Crowther, $1959[150]$, p. 486 .

61 Ibid, p. 488 .
}

program for international cooperation in abstracting adopted by the Intermational Council for Building Documentation in 1950 had, after seven years experience, generally failed to succeed. The working plan involved the publication of abstracts prepared in each cooperating country which would be printed on cards of uniform size and which would have standardized bibliographic reference practice and a common classification (modified UDC). Probable reasons for failure include costs, vested interests, lack of central editing and questions of marketing and availability.

As an example of a successful cooperative venture, however, we note: "With the exception of a few publications printed in the United Kingdom ... all periodicals carrying original articles on physics and published in: United States, United Kingdom, Canada, Australia, Netherlands, Belgium, France, and Italy have agreed to publish authors' summaries written according to the rules approved by the Royal Society and by UNESCO." Such cooperative action has definite implications for the abstracting and indexing services themselves. In another field progress is also reported: "Some coordination has been brought about between World Abstracts, Excerpta Medica, and Biological Abstracts in that they have begun to exchange abstracts." 62

Use of machines in the compilation and preparation of printed indexes, as well as catalogs, announcement bulletins, bibliographies, and the like, will, as we have seen, require increased concern for compatibility and convertibility between systems. As the use of machines increases, more material will be in machine formats and codes, thus increasing problems of direct use or easy conversion. Attention must be directed to standard practices in citing and cataloging; use of standard journal abbreviations, such as the Coden system (described in section 3.6 .1 of this report); standard transliteration of foreign names and titles; establishment of common format for citations; standard practice in citing corporate author sources, and standard methods of ordering or alphabetizing lists. Until such problems are met and handled in cooperative action, the outputs from machine processing cannot be used from one system to another, unless difficult conversion steps are undertaken.

These problems are enhanced by the development of machine systems for production of indexes and other lists based on new principles. Methods are being developed by which libraries and information centers can prepare listings of publications in a manner less burdensome than previously known. From shortly after the close of World War II onward, new indexing and operating principles began to be developed and applied, usually to that emergent literature least subject to traditional types of control, the unpublished tech-

62 Brownson, 1952 [86], p. 44. 
nical report. The principal innovations include "express" information services; the "index-byjournal" system of publications reproducing the tables of contents of journals of interest to a specific science or profession; permuted title word indexing; extraction of key words from text, for later post-coordination at time of search; and assignment of "descriptors," also for post-coordination.

Examples of these newer techniques include the "flash reports" started in 1954 by the Association of German Electrical Engineers, which are listings of titles of articles from some 300 periodicals. The companies cooperating in the plan each receive a certain number of these periodicals, select from them the articles considered important enough to go into one large bibliographic listing, and send the titles back to the association which then issues the "flash report." ${ }^{63}$ These report only the titles without any other indication of subject content and without abstracts.

Another example is the "express" or "rapid" weekly information series of VINITI (the All Union Institute of Science and Technical Information of the U.S.S.R.), designed to inform its readers of new advances in science and technology, mainly foreign. ${ }^{64}$ These "rapid information" reports include condensed translations or long abstracts supplemented by photographs, figures, diagrams, and tables of the original articles, and are intended to eliminate the need for seeing the original publication. In 1959 the material was selected from about 2,100 periodicals and was issued in some 48 areas of technology, with the intention to expand in 1960 to some 50 areas. (These publications are not to be confused with the series of express journals published by International Physical Index, Inc., of New York City, which has been issuing comprehensive digests of current Russian literature dealing with topics on automation, electronics, physics, from 1958 onward and on power since 1961.)

Still another form of "express" information is the quick publication of summary information on a project, backed by deposit of auxiliary publications (such as extensive tables of data, graphs, etc.) with a service such as the ADI Auxiliary Publication Program, mentioned earlier in this report.

Current Contents, published by the Institute for Scientific Information, Philadelphia, is one example of the table of contents service; the Institute publishes collections of contents pages, aimed at different areas of scientific and technical specialization.

Looking back toward the earlier predecessors of current activities we note that: "The success of Current Contents is a case proving that what one generation may reject, the next will receive happily. Two publications of the contents-page type,

${ }^{63}$ Frank, 1959 [200], p. 497-498.

64 Mikhailov, 1959 [384], 1962 [385], see also Baker et al., $1963[43]$, p. $155-372$. one in engineering and one in biology, appeared in the United States in the '30s and foundered after several issues. The old Current List of Medical Literature, which made its appearance in 1941, originally was entirely a contents-page listing. ..." ${ }_{65}$ Another table of contents and specialized documentation service is provided to scientific workers by the French Center of Documentation of the Centre National du Recherche Scientifique (CNRS) which reproduces the tables of contents of the principal journals received and publishes a "35-mm microfilm monthly review . . . which covers about 300 periodicals." 66

The Smithsonian Catalogue System, approved by the "First Convention of Librarians," 1853, involved the listing of titles by means of movable stereotype plates for each title, each plate showing "at a glance the heading to which it belongs," and the plates subsequently assembled for printing in alphabetical or classed order. At about the same time, however, Crestadoro in Great Britain was applying the principle of generating subject matter indexes through title listings based on the permutation of words in the author's titles-the first "IWIC" (Keyword-in-context) index (1856 [149]).

A plan by Lloyd P. Smith for the revision and indexing of The Philadelphia Library's catalogue of 1835 and its supplements included the suggestion for perhaps the pioneering KIVOC (keywordout-of-context index) : "take the most important word or words of the title, and index it by them, as well as, in some cases, by some other words more likely to be referred to as the subject ..." $\mathrm{He}$ continues: "In a word, my system amounts to a copious multiplication of cross references." 67

A first and obvious use of machines in indexing processes is in the manipulation of the index entries to produce various orderings of these entries. Machine manipulative operations to sort and to list entries actually constitute an automatic indexing procedure in the special case where these entries are to each and every different word appearing in the text of the item, as in the making of concordances. Variations of the basic concordance technique are found where the entries are limited to so-called "significant" words. Typically, in KWIC indexing, the text of the title in machine-usable form is read into the machine. The first "word", arbitrarily defined as any sequence of characters, either alphabetic or numeric, which is preceded by a blank (or space) to the immediate left and is followed by a blank to the immediate right, is then compared to the words belonging to a prepared list of "stop" words, and, if a match is found, such a title-text word is eliminated from further processing consideration although it is retained for printing on the index entry line. If no match against the "stop" or

\footnotetext{
${ }^{65}$ Rogers, 1962 [489], p. 705.

60 Wvart, 1959 [657], . 607.

e7 "Proceedings of the Librarians' Convention . . 1853", 1915 $[466], \mathrm{p} .52$.
} 
"purge" list is found, the word is accepted as an index entry and is so marked, together with the surrounding left-hand and right-hand context and an item identifier out to the length of the line allowed.

Permuted title word indexing is already a widely used form of publication and service. Two prominent examples of this type of indexing are Chemical Titles, published by the Chemical Abstracts Service, and Biological Abstracts Subjects In Context (BASIC), published by Biological Abstracts. These two services, designed to provide speedy "current awareness" of scientific research by filling the void between primary publication and the appearance of abstracts, are keyword-in-context (KIVIC) indexes produced by modern computers.

There are also several examples of permutedtitle indexes prepared by Federal agencies. The OTS published, for a little over a year, the experimental publication Keywords Index to U.S. Government Technical Reports and distributed the index without charge to subscribers to the $U . S$. Government Research Reports. This index was different from the typical keyword-in-context or KWIC index in two ways: (1) The keyword was out of context, that is, it was separated from the words normally adjoining it in the title resulting in the index being called KWOC, or a keywordout-of-context index. (2) The full title, no matter how long, was available immediately following the keyword.

Thus a typical listing consisted of a title keyword arranged alphabetically in the left-hand column and paired off with the full title, identification number, and price in the right-hand column. The second part of each of the indexes had an alphabetical listing by corporate author including also title, personal author, date of publication, number of pages, contract and report numbers as well as the identification number and price. The Keywords Index to U.S. Government Technical Reports was discontinued in September 1963 because a survey of recipients revealed that a majority of them did not consider it useful enough to pay a subscription fee for its continuance.

NASA'S STAR and the complementary International Aerospace Abstracts of AIAA have machine-compiled indexes based on the KTVOC principle. WADEX (Word and Author Index) is a machine-prepared index to Applied Mechanics Reviews, sponsored by the Air Force Office of Scientific Research and developed at the computational facilities of the University of Texas. It has adopted "some features of the KEYWORDS INDEX published by OTS, using the descriptors 'out-of-context.'" An innovation is the use of the author's names as descriptors so that the subject and author indexes are intermingled in a single alphabetical ordering.

This principle, of course, dates back at least to the 1870's, when Billings decided that the IndexCatalogue was to be "a combined alphabet of sub- jects and authors, arranged in dictionary order under a single alphabet." 68

DDC has published two keywords-in-context title indexes to date, the October 1962 issue for ASTIA documents not previously announced and the February 1963 issue for reprints concerning research of interest to the Department of Defense. The first index was made necessary by the increase in the number of reports received by ASTIA. This index had three main sections: the KWIC index displaying each significant word of the title alphabetically in the center of the column in context limited only by column width; the bibliog. raphy with bibliographic descriptions of the reports arranged by ASTIA subject division and then by ASTIA document numbers within each division ; and the corporate author index, arranged alphabetically by name of corporate originator, giving the subject division and ASTIA document number for each report.

The February 1963 listing had the KWIC index as above; the bibliography containing descriptions of the reprints, including the journals where the articles appear; and an index of personal authors with references to item numbers in the bibliography. ASTIA did not supply copies of these reprints to its readers; they were advised to search the appropriate journals for articles of interest.

The Oak Rirlge National Laboratory of Oak Ridge, Tennessee, has issued a permuted-title index to the laboratory reports received by the Oak Ridge National Laboratory Libraries, entitled Key Word Index to Laboratory Reports Received: Semiannual Index, January-June 1963.

These are a few examples of the many permuted title word index publications now in operation. Since such publications are so well established, a study of use patterns is in order. Study groups need to concentrate on analysis, since many criticisms center around the quality of permuted title indexes. Can titles be improved at the source? Should authors be required to use titles particularly suited for such indexes? Or should the publishers of the indexes improve the titles to suit? However, the expenditure of too much intellectual effort at the editing stage would defeat the purposes of a KWIC index. Some organizations provide standards or guidelines to the authors, and editors then can refine the author's work as necessary. This area is being given special attention by the NFSAIS, and cooperative decisions and actions are expected to be taken.

Another area of NFSAIS activity in this regard is the work of a committee whose purpose is to study the possibility of merging all member services' permuted title operations. Cooperative action might result, for example, in commonly exchanged "stop lists" for KWIC indexing (stop lists signal nonsignificant words to be omitted in permuting and alphabetizing operations). There might also be agreement on providing in its proper

\footnotetext{
${ }^{68}$ Rogers and Adams, 1950 [490], p. 274.
} 
place one entry for each word so excluded, to warn the user of the index list.

Such questions, and the formation of working committees to study them, point to the importance of providing now for compatibility and convertibility requirements of future systems. Machine use in the generation of derivative indexes such as KWIC indexes implies requirements for compatibility and convertibility in the development and adoption of standard practices and procedures. Examples of these are procedures for single or double look-up; identification of informationwhat and where is it, which fields have been reserved for it, etc.; use of symbols to indicate truncation or "wrap around" or inserted extra keywords; line and column formats; conventions for handling special characters and symbols; and, as noted above, stop list listings. Unless cooperative action is taken to provide for standards in these processes, the products of one system cannot be used easily by other systems. The result could be unnecessary duplication of effort both in production and use of such indexes and services.

When cooperative action is taken, results can be noteworthy. As an example, a form of cooperation between documentation centers involves the Fisheries Branch of the Food and Agriculture Organization (FAO) in Rome, Italy, and the Aquatic Sciences Information Retrieval Center (ASIRC) at the University of Rhode Island. Flexowriters are used to prepare punched paper-tape versions of manuscript for the Current Bibliography for Aquatic Sciences and Fisheries, an international bibliography issued serially from the FAO headquarters in Rome. The tapes are prepared according to a specified format to facilitate subsequent computer manipulations of the biliographic entries. Edited paper tapes are forwarded to ASIRC for conversion to punch cards in the KIVIC indexing format. The retrieval center then indexes the material for storage in its literature retrieval file.

We have discussed secondary publications, par. ticularly abstracts and indexes and new forms of indexing services, as tools for the dissemination of scientific and technical information-as means for determining availability of information as a prelude to acquiring and processing that information. These same tools will be discussed in further sections of this report in terms of the analysis of their content, the storage of and search for them, and efforts for standardization of their processing, formats, etc. Here, however, we have concerned ourselves only with the dissemination factor.

\subsubsection{Clearinghouses}

Another aspect of dissemination of information lies with the concept of clearinghouses as sources of information about the availability of information. This might mean information about other information, published or otherwise; about personnel; about current or on-going projects; about transla- tions, completed or in process; or about various information services. Quite recently, increased emphasis has been placed on such service.

For example, the Clearinghouse for Federal Scientific and Technical Information is a central service for government and industry. Its main services are (1) supplying copies of technical reports resulting from federally sponsored research and development, (2) supplying copies of translations of foreign technical reports, (3) publishing a number of semi-monthly announcement bulletins of the above materials, and (4) literature searching. In the near future it is planned that these activities will be expanded, and additional services will be provided when possible.

Similarly, the Department of Agriculture has extended its services. "To avoid duplication of effort and to increase the availability of bibliographies, translations, and studies on mechanized information systems, a clearinghouse was established in the National Agricultural Library (NAL) last year [1963]. . . . Under the system, the NAL maintains records of all agricultural bibliographies or translations being compiled or prepared throughout the United States as well as all documentation studies or systems. Any requester has access to this information, and in return the NAL asks only that copies of completed bibliographies or translations and information concerning mechanized information activities be transmitted to it and made available through its program." 69

The National Referral Center for Science and Technology is a clearinghouse designed to provide comprehensive, coordinated access to the nation's resources of scientific and technical information. Established in the Reference Department of the Library of Congress, the Center has four major areas of responsibility: (1) identification of all significant information resources in the fields of science and technology; (2) acquisition, cataloging, and correlation of data defining the nature, scope, and capabilities of these resources; (3) provision of advice and guidance about these resources to any activity or individual requiring access to them; and (4) determination of the roles and relationships that exist or that should exist among the many facets of the scientific and technical information complex.

In addition to clearinghouses for information from particular sources or on specific subjects or about available services, there are clearinghouses for information from and about a nation or geographic region. Thus, among the functions assigned to INSDOC, the Indian documentation center established in 1952, was "to be a channel through which the scientific work of the nation is made known and available to the rest of the world." 70

\footnotetext{
${ }^{69}$ L.C. Information Bulletin Vol. 23. No. 3S, September 21, 1964, p. 533 .

${ }_{70}$ Parthasarathy, 1962 [448], p. 334.
} 
Clearinghouses for research reports and published literature are well-established, but indexes of research projects have only recently received the serious consideration they deserve. This is perhaps not surprising but does need correcting since much valuable information can be gleaned from review of research proposals and current projects. "With all the documentation facilities at one's disposal for the open literature and the report literature, there are still times when additional information is required, particularly on research underway." 71

From another point of view, "Those who plan, coordinate and manage research programs need to know who is doing or proposes to do what research, to what extent, for how long and where. This knowledge, if promptly available on an upto-date basis, helps to prevent duplication, overemphasis ol serious gaps in subject areas of research. It also promotes optimum utilization of research funds and other resources." 72 The content of proposed and current research can be "as vital to scientific achievement as are published results, and the mechanism of disseminating the relevant information as important to systematize. Project indices thus become a significant element of science information services." 73

In these "project indices" or information clearinghouses important facts about pending and active projects should be registered and made accessible to both administrators and scientists to facilitate their decisionmaking. For example, "... long before projects are completed and the results reach the stage of publication, knowledge of their existence and preliminary results are vital to an effective national program of research." 74 In addition, "information could be provided on the availability of partially used facilities which could be more effectively employed in or by other research facilities so as to avoid unnecessary construction or purchase of duplicate facilities. Considering the sharply growing costs of facilities, and the delays in national programs while awaiting the necessary approval, funding, and procurement of new facilities, more effective utilization of existing apparatus could be a boon. It may well be that utilization of research facilities and maintenance of an inventory of their availability would represent a benefit if not justification of a project index ...." 75

At the present time, no complete inventory exists of the Federal Government's program in research and development. "It has been our view that, if the taxpayer's considerable investment in scientific research and development is to yield optimum results, close attention must be paid to the management and dissemination of information on current, as well as completed, research and development." 76

\footnotetext{
${ }^{71}$ Hilsenrath, 1955 [262] , p. 108.

72 U.S. Senate, $1960[592]$ p. 108

73 U.S. Senate, 1961 [591], p. 34 .

75 Ibid., p. 3.

76 H. H. Humphrey, letter of transmittal, U.S. Senate, 1961 [590], p. III.
}

There have been, however, a number of instances of project-recording systems within agencies and with respect to highly specialized subject areas. A number of examples of the latter, such as that of the Advisory Group on Electron Tubes, are covered in detail in the Senate report on the coordination of such information in the field of electronics (1961 [590]). The report also covers aspects of the project card or DD-613 and CATE (Current ARDC Technical Efforts) programs. The former is referred to as "the foremost single DOD system of information on research and development ... This system is the largest such effort of any Federal agency. The system serves several important uses, including its use . . f for overview of the total Defense research and development effort." 77 Plans were made not only for mechanization of the DD 613 files but also for their amalgamation with the regular DDC documentation services.

The CATE program has been "an information system designed to provide a source for quickly identifying and locating the scientists and engineers working in the technical fields of interest to the Air Force ..." 78 and to "promote interchange of technical information among the scientists and engineers in the Air Research and Development Command (ARDC), its staffs, governmental agencies, industries and universities. . . "79

An exemplar for current research project reporting in specialized subject fields is that for the field of scientific documentation itself-the series "Current Research and Development in Scientific Documentation" issued by the National Science Foundation ([418]).

In project $\mathrm{ECHO}$, Documentation, Inc., operates for the Air Force Office of Scientific Research the Experimental Contract Highlight Operation, recording facts and figures about current projects and preparing reports about them on demand. In the early 1960 's, NIH "began publishing an annual subject index of all its research grants." 80

More recently, a broader scale attack has been anticipated for the Clearinghouse for Federal Scientific and Technical Information, in cooperation with the Science Information Exchange, to provide government-wide coordination of project indexes.

Another approach to the problem of ascertaining research in progress, other than maintenance of central indexes or clearinghouses, is to conduct surveys by fields of research. The National Bureau of Standards "has since 1933 compiled annually . . . [the] publication called Hydraulic Research in the United States [which] contains a summary of each active project including: title, sponsor, correspondent, nature of the project, de-

\footnotetext{
77 U.S. Senate, 1961 ( [590]), p. XXII.

78 U.S. Senate, 1961 ( 591$])$, p. 95.

${ }^{7}$ U.S. Senate, 1960 ( [592]), p. 11 .

80 "Communication Problems in Biomedical Research," 1963 $([403])$, p. 23 .
} 
scription, present status, results, and publications." 81

There is one step farther back than information about initiation of current research projects, namely, the recognition of specific areas where research is needed. In the 1938-1940 survey of "research as a national resource (1938 [415]), the NRC study of research in industry concluded among other findings that "less restriction should be placed on information about existence and nature of problems." 82 Such an objective is the goal of the U.S. Air Force Technical Objective Document (TOD) Release Program (1964 [577]). These documents outline anticipated requirements or capabilities of the Air Force implying the need for research and development efforts. 'TOD's issued in 1964 covered such subjects as flight control, information displays, and photo materials and optronics.

One of the best examples of the index or clear. inghouse concept with respect to on-going research is the Science Information Exchange of the Smithsonian Institution, formerly called Bio-Sciences Information Exchange (BSIE). The history of BSIE may be traced "back to the dissolution of the wartime Office of Scientific Research and Development (OSRD) in 1946, at which time a number of Federal agencies undertook their own support of research in the medical sciences. Information exchanges were established within various agencies, the largest of which was the Office of Exchange of Information of the Public Health Service. TVhen the amount of research supported by Federal agencies in the medical field had grown from $\$ 4.3$ million in 1946 to $\$ 33$ million in 1949 , with corresponding growth in number of research organizations, investigators, and related multiplesubmitted proposals, it became imperative that research project information be coordinated. . . ." 83

The Medical Sciences Information Exchange (MSIE) was then founded as a cooperative venture in July 1950 within the Division of Medical Sciences, National Research Council. Support and administrative policy for the MSIE were provided by the six participating Fedel"al agencies. "This cooperative effort, together with the voluntary cooperation in the Exchange of many private philanthropic organizations, . . made possible this extensive survey of a broad field of research ... 12,923 research grants registered with the Exchange during the period 1946 to 1951 ... illustrates the value of a central clearing house for information of this type." 84 In the Fall of 1953, MSIE was shifted to the Smithsonian, its scope expanded into the fields of biology and psychology, and its name changed to BSIE.

Thus the BSIE and its precursor were organized as interagency management and information

${ }^{81}$ Hilsenrath, 1955 [262], p. 109.

${ }_{22}$ National Resources Planning Board, 1941 [46], p. 1.

${ }^{83}$ U.S. Senate, 1960 [592], p. 56

84 Review, unsigned, of Deignan and Miller (1952 [171]), in Amer. Doc. 3. services, without specific congressional authorization or appropriations, in order "that the various Government agencies providing support of biological and medical research might have knowledge of both applications received by other agencies and grants and contracts awarded. Upon invitation, the major foundations and voluntary agencies joined hands with these Government agencies in exchanging this type of information ...." 85

The Exchange maintained an index of current research projects which represented the only coordinated single source of such information in the biological and medical sciences. It was responsible for gathering, organizing, and relating data on unclassified research supported by both Federal and non-Federal agencies. "Sinco BSIE was originally organized because of concern by Federal granting agencies over unknowing duplication of support in the biological and medical sciences its coverage of federally supported extramural research [was] emphasized. Intra-mural research of some of the participating Federal agencies [was] gradually and voluntarily ... added." 86

Research by private organizations such as medical foundations was also voluntarily reported to the Exchange, and individual researchers listed their non-grant-supported work. "The services of BSIE [were] utilized extensively by granting agencies to determine the amounts and sources of support given individuals, institutions, localities, and types of research as a guide to a balanced program and equitable sponsorship. By this means, gaps in programs or need for multidiscipline approaches were readily detected. . Committees planning symposia and surveys of research [used] BSIE to find out what is being done, by whom, and where." 87

In October 1959, the National Science Foundation, which had been contemplating the pros and cons of a central Federal index in the physical sciences for some years, reported to the Federal Council for Science and Technology its intent to establish a physical sciences information exchange. The question of including physical sciences in BSIE had been discussed by its governing board in March 1959 and, "with NSF encouragement, BSIE and Smithsonian Institution undertook a study during the summer of 1960 of the feasibility of extending their activities. On September 22 , 1960 , the Smithsonian founded a Science Information Exchange (SIE) embracing both the existing Biosciences Information Exchange and the newly conceived Physical Sciences Information Exchange." 88

By 1963, it was reported that: "The [SIE] accepts records from all sources that wish to register and endeavors to establish cooperative ar-

${ }^{85}$ U.S. Senate, 1960 [592], p. 14.

86 U.S. Senate, 1960 [592], p. 5455 .

${ }^{87}$ Ibid. p. $5 \mathrm{~S}$.

88 U.S. Senate, 1961 [591], p. 4. 
rangement with all research support organizations that are interested in contributing information about their programs. . . . [It] does not duplicate or compete with the established library and documentation services. Actually it complements these by covering only the prepublication phase of the total process. ... The Exchange features the development of many different arrays and compilations of information that are tailored with each request to meet a specific need of research management." 89

It is also pointed out that "SIE is several years ahead of the published information in terms of giving leads directly to the man who is doing the research. This is a cooperative Government program in which all of the agencies that are carrying on research and development are cooperating wholeheartedly at the present time." 90

The Crawford Report suggests that national and "international professional organizations should be invited to explore the worldwide phases of the problems and opportunities of information on work in progress." ${ }^{91}$ An example of such a possibility is the program set up in the InterAmerican Institute of Agricultural Sciences with the aid of a grant from the Rockefeller Foundation to provide information "on current research projects by means of a central file of research projects and a central index to the names of Latin American research staffs, and a periodical publication for researchers." 92 For the most part, however, such services to date have been marked by the following: (1) they have been organized and maintained primarily by administrative or management rather than research organizational units; (2) there has been little or no coordination and correlation between the services offered by the various project-record keeping activities; and (3) such services as are available are apparently not generally known nor widely used.

"There is, as yet (Oct. 1963), little evidence of the extent to which working scientists use services such as SIE or the NIH Research Grant Index, or of the potential value of these services for the conduct of research. A study of these questions would be helpful in guiding policy with respect to modifying or expanding these kinds of service." 93

A critical requirement is to amalgamate current resenrch-in-progress reporting with report and publication announcement responsibilities.

In the early BSIE and in most research grant systems, subject categorization has to date been largely limited to administrative and reporting requirements, rather than to current awareness search, and while contributing individuals have requested information about similar on-going research, there has been little or no attempt to pro-

\footnotetext{
${ }^{89}$ Freeman, $1963[203]$, p.
U.S. House, 1963 [582] Adkinson.

Crawford Report 1962 [465], p. 69

Q2 Murra, 1962 [402] p. 173

"Communication Problems in Biomedical Research" 1963 [403], p. 23-24.
}

vide selective reference service, nor to relate current project information to the current availability of either unpublished report or published literature. An exception, again exemplary, is that the Current Research and Development series (National Science Foundation [418]) requests the listing of pertinent bibliographic items from each reporting project and that No. 12 of the series, now in process of preparation for publication, will be a cumulative bibliography of all references cited through the reporting date.

\subsubsection{Copyright and Translation Problems}

Inputs to the total information resources from many nations and in many different languages create new and additional problems of cooperation and compatibility. Problems of awareness of availability, of acquisition, and of avoiding duplication of effort in the area of technical translations assume increasing importance as more and more items of pertinent technical information become available from research and development offorts in many different countries. Specific questions here include the matter of indexes and listings of translations both already available and in process of preparation and the nature and extent of cooperative efforts and exchanges, and aggravated problems of copyright if unauthorized translations are made whether by man or machine.

"Section 7 [of the British copyright act of 1956] provides that there is no infringement if a copy of an article in a periodical publication is made or supplied by or for a librarian of a library in a class prescribed, and in accordance with regulations prescribed, by the Board of Trade. Presumably, for purposes of photocopying, an authorized translation would be treated by those libraries in the same way as the original, but it is not clear that an unauthorized translation would be so treated because, legally, it is an infringing copy. This is an important point that deserves exploration." 94

One opinion about a possible solution has been expressed thus: "It would seem that we may need some international 'Fair Translation Declaration' which would permit those having competent translations to offer for general use to act somewhat along the lines of the Fair Copying Declaration." 95 Reed, however, also points out that ". . . Two copyrights subsist in a translation: the first is that of the owner of the original, and the second that of the owner of the translation ...."

Looking to the general copyright problem we note that "general international collaboration on copyright begain with the meeting together at Berne in 1885 of some eleven powers which included the United Kingdom and seven other European countries; amongst the nonparticipants were Russia, Holland, and the United States. The result of the meeting was the Berne Convention of

थ4 Reed, 1960 [475] p. p. 162.

05 Patrick, 1960 [449], p. 135. 
1887 ... In 1952, a new international group met in Geneva under the aegis of UNESCO to try to bridge between the Berne powers and others who could not, or would not, join them (the latter included the United States and other pan-American powers but still not Russia). The meeting agreed to the Universal Copyright Convention .... ." 96 Although the copyright problem is real and serious, cooperative and collaborative efforts are being carried forward within the framework of copyright conventions. Thus "The Royal Society has issued a Fair Copying Declaration, to which some 131 organizations representing over 190 periodicals have agreed." 97

A new and special problem with respect to copyright is likely to arise as an outcome of the recent decision involving the copyrighting of computer programs. "The Copyright Office of the United States, a department of the Library of Congress, has taken the position that copyright registration for computer programs is possible under the present law." 98

The cooperative and collaborative efforts alluded to above also face problems, among which are lack of familiarity with foreign language materials and difficulties in locating specific translations, in determining whether specific translations have been made, and in reaching agreement on necesary formats, coverage, etc., to aid free and full exchange and use of translations.

These several problems have been discussed at various times and by various workers, thus: "In addition to struggling with the sheer volume of the literature, the American scientific community encounters an increasing complication in dealing with the technical information published in languages other than English. There is a serious lack of awareness in the United States of the growing significance of foreign technical publications." 99

This awareness should be fostered because, for example, according to data compiled by Unesco, the Soviet Union occupies the first place in the world in terms of the number of published works, "providing approximately $20 \%$ of the entire world book output." 100 Also it is claimed that "the language difficulty is reflected in the fact that more than one-third of the world's scientific and technical literature is produced in the U.S.S.R., China, and Japan." 101

"If the location of originals, after years of grinding work by abstracting agencies and collating organizations-and the development of such tools as the World List of Scientific periodicalsis becoming less difficult than it was (though, in all conscience, it is difficult enough), the location of translations is still in a most rudimentary state. ... Though there are cooperative translating and locating services in restricted fields, and

\footnotetext{
96 Reed, 1960 [475], p. 158-160.

97 Brownson 1952 [85], p. 40.

8s Scientific Information Notes 6, 3, 2 (1964).

99 Stanford Research Institute, 1963 [542], p. 5.

100 Tareev, $1962[555]$, p. 338.

101 U.S. Senate, 1960 [582], p. 127.
}

at least one location index which aims at comprehensiveness (namely that at Aslib), there is in fact no swift and sure way of finding out whether a given paper has been translated and how to obtain a copy of the translation. The existing services are too narrow in scope-or, where broad, are too little used. How can we improve this near-chaotic state of affairs?" 102

Adding to the confusion is the fact that "translations of scientific papers of foreign origin are similar in nature to reports. If they are reproduced and distributed at all, they appear as separates and present the same cataloging and filing problems as reports," 103

Further complications arise when, for example, ". . . both national and international scientific organizations and standardization groups have attempted for over 20 years to create some order out of the chaos of conflicting cyrillic-alphabet transliteration systems and to impose some measure of standardization. Relatively little has been written on the problem, but numerous committees have been conceived and dissolved, most of them coming to eventual disagreement over the claims of transcription as opposed to transliteration." 104 (Transcription gives some approximation to pronunciation; transliteration is arbitrary and unambiguous character substitution, according to the SLA Subcommittee on Transliteration.)

Nevertheless, since World War II, translation activities on an international scale have produced cover-to-cover translations of periodicals in science and technology from the U.S.S.R., the People's Republic of China, and a few other nations. These translations began as early as 1949 and are made available by various publishers.

Procurement of publications from the People's Republic of China is receiving the attention of such organizations as the National Federation of Science Abstracting and Indexing Services (NFSAIS) and the Joint Publications Research Service (JPRS). The JPRS publications, according to their foreword, are "prepared under contract . . . as a translation or foreign-language research service to the various federal government departments." The JPRS provides a centralized translation service for interested U.S. Government departments and prevents, where possible, duplication in such work. The JPRS was established in 1957, with branches in Washington, New York, and San Francisco, as a component of O'TS. JPRS products can be classed into two broad categories: (1) ad hoc reports, encompassing either cover-to-cover translations (e.g., of many East European statistical yearbooks) or reports on specific fields of inquiry which utilize a variety of relevant source material, and (2) serialized reports published periodically and offering selected translations from the East and East Central Euro-

\footnotetext{
102 "Technical Translation: Co-operative Action," 1960 [566], p. 130 .

${ }^{103}$ Waterman, 1955 [630]. p. 6.

104 Nelswender, 1962 [421], p. 37.
} 
pean press. (Horecky, 1960 [272] Federal departments having a continuolls need for translations of foreign language publications channel the bulk of material to JPRS. Any component of the Government may utilize JPRS services through the intragovernmental purchase order system, and institutions and individuals may obtain the reports through sales outlets. The JPRS accepts work orders only from government offices and contracts only with individual translators to perform services.

"A pioneering effort in the field of translating Japanese technical material has been started by the Institute of Electrical and Electronic Engineers (IEEE) working in cooperation with the Institute of Electrical Communication Engineers of Japan . . . and the Institute of Electrical Engineers of Japan. As a result of the cooperative effort, approximately 2400 pages a year of Japanese electrical engineering articles will become available to U.S. scientists and engineers." 105

Technical Translations is a semimonthly secondary publication which has been issued by OTS since January 2, 1959, in cooperation with the Special Libraries Association (SLA) Translation Center. The journal lists and abstracts, with source and cost, translated technical literature available from OTS, LC, SLA, cooperating foreign governments, commercial translators and publishers, universities and other sources. The SLA is responsible for collecting translations from non-Government sources, both domestic and foreign; the OTS for collecting translations from both U.S. and foreign government services. The John Crerar Library in Chicago has responsibility for administration of the SLA Translation Center.

The current issues of Technical Translations have four indexes separate from the journal proper. The indexes are for author, subject, journal of the original article, and number index, telling on which page of the Technical Translations the translation may be found. Technical Translations became an international journal upon its affiliation with the European Translations Center (ETC), Delft, the Netherlands, in 1961. The Center has the duty to "cooperate intensively in order to make Technical Translations a truly universal journal, with up-to-date contents which reflect as completely as possible the acquisitions of the large regional centers and of the centers in the countries which are not yet associated in a regional center."" 106

The European Translations Center itself was established in late 1960 by the European Productivity Agency, to collect, make known and make available translations, references, and abstracts (from Russian and other out-of-the-way languages into a Western language) which are not obtainable commercially. The aim was to create a single center in Europe where translations, or

\footnotetext{
105 Scientific Information Notes $5.3,2$ (1968)
}

$106 \mathrm{Wilson}$, et al., 1963 [649], p. 53 . information about translations, could be obtained, thus relieving European countries of the burden of having to build up their own collections. Of the 30,000 translations available, the largest contributor has been the United States with about 20,000 translations, the remaining being European contributions. The Center regards the OTS in Washington and the Translations Center of SLA in Chicago as regional centers for North America and itself as the center for Europe.

Another cooperative translation activity is the Transatom Bulletin, published by TRANSATOM, an information office sponsored by EURATOM (the European Atomic Energy Community), the Atomic Energy Commission of the United States, and the Atomic Energy Authority of the United Kingdom. TRANSATOM is located at the EURATOM headquarters in Brussels where it collects all available data concerning translations of nuclear literature, particularly documents originally produced in languages unfamiliar to the Western reader.

Transatom Bulletin provides up-to-date references of translations, either complete or in preparation. The translations are divided into two sections, translations completed and translations in preparation; within each section, the references are grouped in broad subject categories, substantially those used in Nuclear Science Abstracts. The references to the translations are obviously prepared by a machine technique, probably punched cards, the "Guide to the Reader" giving clues to the items of information contained in each TRANSATOM reference. Issues of the Bulletin are provided with an author index and an original source index.

To supplement translation pools and services, listings of foreign language material available are offered. The Mlonthly Indcx of Russian Accessions, covering receipts both by the Library of Congress and by cooperating libraries, is compiled by the Library "with support from agencies." 107 Also the East European Accessions Index and the Southern Asia Accessions List are compiled by LC. These lists serve to announce available materials as a possible prelude to translating or searching for translations.

The National Science Foundation grants support to the Midwest Inter-Library Center for acquisition of foreign scientific periodicals, another example of cooperative effort in making foreign technical information available to U.S. research workers. Unesco's continuing interest is evidenced by its Committee on Documentation for the Natural Sciences, which "has concentrated a great deal on the production of multilingual dictionaries. It has also been useful on problems of Russian literature in the natural sciences. It is . . . trying to take a stand in the copyright position ... . and

${ }_{107}$ Mumford, 1959 [400], p. 3. 
it has given a great deal of thought to the subject of the use of author-abstracts." 108

In addition, the Cultural Activities Department of Unesco is publishing an annual Index Translationum which lists book translations. "The regular appearance of the Index Translationum and its constantly increasing size has been one of the encouraging signs of the growth of collaboration between nations ... the 1962 volume-the thirteenth in the present series-lists some thirty-two thousand translations published in fifty-eight countries in $1960 \ldots$ and one is impressed by the efficiency of the co-operating national organizations that have contributed the detail entries." 109

The location index at Aslib referred to earlier is another cooperative activity of interest: "Aslib and the British Commonwealth Scientific Office (London) are coordinating information on translations available in the British Commonwealth and an index is being prepared . . " 110

However, not all cooperative translation activities are government or professional society-sponsored. Wright (1960) [653]) describes the cooperative scheme for translations in the British Iron and Steel Industry, where a consortium of 17 companies share in a common service, with the products available for sale to members and nonmembers alike. He includes among the prerequisites for a successful scheme the development of a streamlined administration using standard forms wherever possible, and the issuance of regular and frequent lists of translations available and those in process of preparation.

Further thoughts on cooperative schemes for industry were voiced by Readett, as follows: ". . . The cost per organization participating in the cooperative scheme is much more acceptable than if the translating organization had to bear the entire charge themselves... The next advantage to be gained from a properly organized exchange of translations is that of rapid availability.

"In many fields of research and development in a given industry many translations are produced by other organizations which may contain certain information of utility to the specialist, or which may give him a general picture of a development which has an indirect bearing on his own work. Because of the indirectness of the relationship between these papers and his own special interest, the engineer or scientist would not be able to justify a firm request for the article to be translated ... This would seem to be a consideration which is likely to grow in importance as time goes on, because of the ever-increasing interaction of research and development in various branches of scientific and engineering work." 111

Liebesny (1960 [340]) raises the question of whether an index to translations should serve as a tool to finding out what is available in foreign

108 King, 1955 [316], p. 7.

${ }^{109}$ Collison, 1962 [130], p. 296

110 Brownson. 1952 (85), p. 37.

11 Readett, 1960 [452], p. 156. language materials on a subject matter basis as well as to answer inquiries on the availability of a translation of a known foreign language item. This is a cogent question from the standpoint of expanding and improving the coverage of existing services.

\subsection{Acquisition and Exchange of Publications}

Once the availability of publications, translations, unpublished reports, or data collections has been determined through any one or any combination of the channels of dissemination just discussed, the library or information center takes steps to acquire the material or insure access to it. These steps might involve purchase of the items through well-established ordering procedures, receipt of material as a gift from an individual or from a fund established for the purpose, acquisition from another library or center on a loan or exchange basis, or determination of accessibility in a central location or depository from which the material may be obtained easily as needed.

What to acquire, whether through purchase, gift, or loan, is a problem of some import but outside the scope of this report. Suffice it to say, perhaps, that "the first requirement of a [scientific and technical information] system is to acquire within the limits of practicality all the documents of value to scientists and engineers within its area of responsibility ... unless this comprehensive acquisition can be obtained, no engineer or scientist can be sure that the Documentation Center will have the one document which contains the best information on the subject of his inquiry." 112

The policies that govern acquisition of "all the documents of value..." are varied and diffuse. One comment in this regard is of interest: "... Little more than a third of the reference libraries reporting in the Brookings survey have reduced their acquisitions policy to some written form, and, judging from the examples submitted, most of these statements are of such a general nature as to give the librarian little practical guidance other than to try and get whatever anyone in the agency wants." 113

However, we are more concerned here with how an item is acquired, especially from the point of view of possible cooperative or coordinated activity. Among the cooperative endeavors in this area, we may cite as examples "the successful interlibrary arrangements made in Nashville, Philadelphia, Denver, Ohio, North Carolina, Pacific Northwest . . ."114 and the Bibliographic Center for Research organized in 1934 with a grant from the Carnegie Corporation to provide services among educational institutions and libraries in the Rocky Mountain region and bordering plains states, which pointed the way for similar ventures including the Midwest Inter-Library Center.

112 Vann, 1963 [606], p. 221.

${ }^{113}$ Evans, 1963 [188], p. 5. 
Blegen (1952[64]) discusses the advantages and disadvantages of the cooperation resulting in MILC. If such activity can be applied successfully, problems of acquisition and coverage could be lessened, if not solved. Thus, "a rationalization of the fields of concentration among libraries and the allocation of responsibility in neglected fields would result in more comprehensive and uniform bibliographic services." 115

This thinking is especially applicable in Federa] Government libraries, according to Evans: "There should be far greater cooperation between agency libraries in assigning responsibilities for various subject fields so as to encompass the total significant output of material from given countries." 116 Further, "cooperative acquisition is nothing new, but assignment of national responsibility to other than the three national libraries is just beginning to be explored." 117

On the other hand, ". . The extent to which the cooperative acquisition and sharing of materials may be carried is directly dependent upon the actual accessibility of such materials. Actual accessibility in turn is dependent upon the mobility of the book or reproductions of it, the costs and speed of such mobility, and adequate bibliographic information concerning the existence, relevance, and location of the cooperatively acquired book." 118

To this end, adequate accession lists issued promptly would be of great service. The use of mechanized equipment and systems to sort and reproduce large quantities of information can be applied advantageously to the process of preparing and producing such listings. Automation in libraries, as distinct from specialized collections, has largely been limited to the mechanization of routine operations such as the reproduction of card-catalog sets, the sorting and printing of announcement bulletins and listings of holdings or of catalogs. Extension of these processes, on a cooperative basis, can serve very useful purposes. Of course, cooperative ventures must take into account questions of compatibility or convertibility.

As Evans suggests, ". . . It would be helpful for libraries to issue recent accession lists in their areas of specialization. If federal libraries adopted a fairly uniform format, numbering system, and subject categories for these lists, they would prove most useful to governmental and other libraries."119 Use of such accession lists would ease the burden of acquiring material through interlibrary loans, a popular but sometimes frustrating way of procuring material.

\subsubsection{Interlibrary Loans}

"Loans between libraries are the most familiar form of collaboration in the information field and

\footnotetext{
115 Evans, 1963 [188], p. 23.

116 Ibid, p. 10.

117 Shachtman, 1963 [517], p. 258.

118 Fussler, 1951 [207], p. 17

110 Evans, 1963 [188], p. 24.
}

the most studied," according to Holloway. ${ }^{120} \mathrm{He}$ believes that the usual interlibrary loan has not been as useful as it could be, since the library staff usually proceeds inefficiently: either going from source to source until successful or exhausted, or applying simultaneously to many sources.

"The volume of interlibrary loans, even in such special situations as the federal agency libraries, may be generally underestimated. The Brookings survey found, for example, that 89 of the responding libraries had an average of 45,000 loans in fiscal year 1959, or about 860 items per week." ${ }^{121}$

Such volume is reflected in the growing concern of librarians which led to the development of a general loan code. In this code, it is stated that "Interlibrary loan service is a courtesy and a privitege, not a right, and is dependent upon the cooperation of many libraries." 122

Fussler spoke to both of these points, volume and effectiveness, when he said: "That there is already cooperative access to much of the nation's resources is amply demonstrated by the number of interlibrary loan transactions that are now current. Interlibrary loans are becoming a big business and are an extremely important auxiliary form of access for many research purposes. This should not obscure certain defects in the present system. The method of locating materials is often haphazard and is certainly expensive. Plans for using the National Union Catalog at the Library of Congress for the clearing of all interlibrary loans have yet to come to fruition. The general methods and techniques of borrowing tend to be expensive and slow. Finally, the burden of expense is not equitably upon the principal beneficiaries of the service." 123

Another assessment of the situation claims: "The present informal system of interlibrary loans is periously close to breakdown ...."124

A special example of collaboration and cooperatio in interlibrary loans is the exchange of copies via transmission facilities such as facsimile transmission links and closed circuit TV. On at least an experimental basis, this has been cooperatively explored, for example, by the AEC. "Beginning in 1949, the Commission sponsored the development of prototype equipment by RCA for flatbed facsimile transmission of research materials, tested first between AEC facilities in Oak Ridge and later . . . the Library of Congress, National Institutes of Health, and the Army Medical Library. ... [and, in 1958, it] cooperated with the University of Virginia in its research on the utilization of closed circuit television between libraries." 125

Use of the Union List, or National Union Cata$l o g$, to aid in aequisition via interlibrary loans, has

${ }_{120}$ Holloway, 1961 [267], p. 15.

121 Evans, $1963[188]$, p. $27-28$

122 "General Interlibrary Loan Code 1952," Coll. and Res. Libs. 13,350 (1952)

i23 Fussler, 1951 [217], p. 179.

124 Communfeation Problems in Biomedical Research," 1963 [403], p. 25 .

${ }_{125}$ Statement, U.S. Senate, 1960 [592], p. 37. 
not been as extensive as it might be. For one thing, ". . . the Union List reports only a limited number of locations, whereas it is sometimes important to know the complete holdings in a limited area. A number of the union catalogs reported by librarians in the Brookings survey cover periodical holdings in particular regions. Perhaps recent technological developments, including equipment to sort, find, and reproduce mechanically a vast amount of information, may provide a simpler solution to some of these problems. The matter should be dealt with first on a national basis before remnants of the task are left for regional solutions." 126

\subsubsection{The Farmington and Other Exchange Plans}

An additional means of acquiring material for a collection is through exchange plans or agreements. We have considered these in terms of international cooperative developments; we shall examine them now as means for acquisition of materials. These plans involve not only libraries in the United States but also foreign institutions; they involve not only many federal agency libraries but also other public or private centers. Some plans have been fostered by national governments, others by professional societies, or private enterprise. But all are based on the principle of cooperation to insure as wide and complete coverage of available publications as possible by as many and varied libraries as possible.

The Farmington Plan, originated by the Association of Research Libraries a few years after World War II, was "an experiment in specialization by voluntary agreement among American research libraries. Its objective is to make sure that at least one copy of each new foreign book and pamphlet that might reasonably be expected to interest a research worker in the United States will be acquired by an American library, promptly listed in the Union Catalogue at the Library of Congress, and made available by interlibrary loan or photographic reproduction." ${ }^{127}$ The plan has "repeatedly been cited as one of the most important, most enlightened, and hopeful instances of library co-operation in the history of American libraries." 128 The first acquisitions of books through the Farmington Plan were for works published in 1948. By 1957 the Association of Research Libraries reexamined the plan in the light of the experience of ten years and in its survey (January 1959) concluded that the Association should not only continue the plan but should extend it world-wide.

It is traditional that individual scientists, scientific societies, scientific libraries, and institutions in the United States have served as agents for the international exchange of information. Since 1948 , the major research libraries of the country have been able under the Farmington Plan "to ob-

${ }^{126}$ Evans, 1963 [188], p. 23-24.

127 Gibb, 1960 [215], p. 1, see also p. 13-14 of this report.

128 Talmadge, 1958 [554], p. 375-383. tain maximum coverage on a worldwide basis of books and pamphlets of research interest. Participating libraries have agreed to accept responsibility, based on subject and country allocations, for the procurement of at least one copy of significant research literature. However, the Farmington Plan was originally aimed at liberal arts materials and is weak in science and the production from the Slavic areas." 129

Criticism of the plan points out that "The Farmington Plan ... has certain obvious defects: it has brought in some material of less than first rate quality; it has omitted some material having that attribute; it overlooks many categories of publication, including serials and government publications; it is not world-wide." 130

Another opinion of the operation was expressed thus: ". . Most participants in the Farmington Plan will agree that it is not perfect, but it constitutes a remarkable development in bringing books from abroad to these shores." 131

The plan has been evaluated more objectively by comparing it with the LC Union Catalog Division's Select List of Unlocated Research Books, which is a selection of the books needed by research workers in the United States not found in the 64 leading reference libraries that check the Union Catalog Division's Weelcly List of Unlocated Research Books. The Select List was used to determine the extent to which the plan had reduced the amount of needed research material. Even though there still was some material not available in the United States, it was concluded the plan had been working effectively (Cook, 1954 [135]).

A more somber assessment, perhaps, of the effect of the plan was given by Fussler when he said, "At present, substantial though certain aspects of cooperation are, it has not greatly affected our operations. The Farmington Plan has perhaps made the greatest step in this direction, but important as it is, it has not yet seriously affected the acquisitions or resources of most libraries. There is in fact no reason why it should. IVe shall not see major consequences or derive significant advantages from cooperation until our interrelationships generally make us interdependent." 132

Evans speaking to the same point, pleads the urgent need for a Federal Agency Farmington Plan, or the equivalent, noting that "while there is considerable cooperation between certain federal libraries, much more is called for in allocating the major areas of responsibility for acquisitions, particularly of foreign publications. High priority should be given to extending the Farmington Plan within the network of federal libraries, and to expanding its scope to countries where it does not now operate." 133

\footnotetext{
129 U.S. House, 1959 [588], p. 5.

130 Councll on Library Resources, 1958 [140], p. 27.

13 Fall, 1954 [192]. p. 105

132 Fussler, 1951 [207], p. 176.

133 Evans, 1963 [188], p. 48.
} 
One instance of this type of activity is ". . . a central clearinghouse for information and advice on foreign exchanges established in 1954 in the $\mathrm{Na}$ tional Agricultural Library . . . information concerning exchange has flowed in a two-way direction-to land-grant college libraries, agricultural experiment stations and extension services, and in the opposite direction to foreign institutions." 134

Evans further points out the importance of exchange agreements in building up collections: "A view broader than that of a single library can be achieved only when libraries cooperate, utilizing the publications of other agencies for exchanges to enrich their own collections. Much has been done in this regard [he cites the National Library of Medicine and National Agriculture Library collections built to pre-eminence despite "long periods of parsimonious appropriations"], but more remains to be done to promote wider exchanges of government documents by agency libraries." $13 \mathrm{~s}$

To sum up these facts and opinions, we might say that exchange plans are generally successful and participating cooperating libraries have gained much through their operation. But such plans are not perfect in themselves and often they are not used to full advantage by those in a position to cooperate with them and benefit from them. The Farmington Plan is the best known and most extensive of those in operation; however, others exist in the United States and abroad, contributing to the improvement of cooperation among information systems.

The American Book Center, established for the exchange of publications, was sponsored by several library associations and owed "its initial financing to the Rockefeller Foundation." ${ }^{136}$ The Center's successor is the private nonprofit organization, the United States Book Exchange, Inc. Its purpose is "to serve as a center for the exchange of duplicates of books and periodicals having potential value for research ..."137 Although the Exchange offered promise for the increase of exchanges of scientific publications, it is claimed that, unfortunately, it "has been used but moderately through the decade." 138

One way perhaps to increase the use of exchange plans and thereby increase cooperation among libraries is to centralize the processing of the steps necessary to effect the exchanges. Thus Evans suggests that "arrangements might well be worked out to expand the Smithsonian Institution's exchanges and to utilize the services of State Department publications procurement officers. Computers could be used to prepare multiple copies of orders, and to centralize communications, disbursement, and a wide range of procurement operations. The entire area of acquisitions offers a

\footnotetext{
134 Shachtman, 1963 [517], p. 258.

135 Evans, $1963[188] .6$

136 Ludington, 1954 [351], p. 200

137 Council on Library Resources, 1958 [140], p. 22.

138 U.S. Senate, 1960 [592], p. 131.
}

fruitful field for the expansion of interlibrary cooperation." 139

Establishing connecting links between different documentation centers and/or general documentation centers, e.g., as a prelude to exchange agreements, was "attacked first, I believe, by France in 1939 with the creation of the Documentation Center of the National Center for Scientific Research ... Further, an experiment sponsored by the French Government ... (aims to) gain experience in establishing centers to facilitate the exchange of scientific and technical information and personnel between France and other nations. The first of these was created a few months ago for relations with Italy." ${ }^{140}$ In addition, DOCA (Section Documentaire Automatique, Centre Europeen de Traitement de l'Information Scientifique, EURATOM) is "building up a European Documentation Network for the exchange of information. This network includes the Gmelin Institute, Hoffman-La Roche, Sandoz, Saclay, Shell (BIPM), the Max-Plank-Gesellschaft and the FID." ${ }^{141}$

The British Central Lending Library for Science and Technology and the Microfilm Service of the French Center for Scientific Research are, like the Farmington Plan, seeking a "balance between bibliographical control and supply of actual documents." ${ }^{142}$ In addition, the Unesco Clearinghouse for Publications, mentioned in section 2.4., promotes systematic exchanges between libraries wanting particular publications.

"At a conference held recently in Oslo, Norway. chief librarians representing the national libraries of Denmark, Finland, Norway, and Sweden signed an agreement on the distribution of scientific literature purchases among the main libraries of their countries.

"This pact, similar to the American Farmington Plan, is the first international agreement of its kind ...." 143

A guide to international exchanges is the third edition of the Mandbook of the International Exchange of Publications, published by Unesco in 1963. Account is taken of different types of exchange, transport and customs problems; in addition, exchange offers of international intergovernmental or nongovernmental organizations and national bodies are given, with a select list of current international directories.

Other sources of information about exchanges may be noted: "A list of the official exchange centers for these countries (of Eastern Europe) may be found in the National Science Foundation publication NSF 62-49, 'A guide to the Scientific and Technical Literature of Eastern Europe'... Information on the availability of publications may be found in the 'Guide to Latin American

\footnotetext{
139 Evans, 1963 [188], p. 48

${ }^{140}$ de Grolier, 1958 [169], p. 278, 279

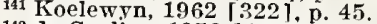

142 de Grolier 1958 169 19.45

${ }^{143}$ Science Information News 1, 5, 9 (1959).
} 
Scientific and Technical Periodicals-an Annotated List', published by the Pan American Union . . . " "144

\subsubsection{Photoduplication Services}

Another means for acquisition, besides interlibrary loans and exchange agreements, is photoduplication of the material in question, either as a central processing operation or carried out at an individual institution. This photoduplication service may be applied to individual articles from technical journals thus serving to decrease the number of journal loans, to bound volumes, or to single technical reports in one or more copies, a more recent development.

"The photoduplication service was established in the Library [of Congress] on a revolving-fund basis, through a grant from the Rockefeller Foundation in 1938, in order to provide means for researchers and others to secure photocopies of materials in the Library's collections which might otherwise not be available, and to provide this service at an economical level. . . .

"During 1959 the photoduplication service produced 1,317,915 electrostatic prints; 4,940,419 negative microfilm exposures; and 790,910 feet of positive microfilm. Of these reproductions, a substantial portion was made for industrial libraries, research laboratories, and government agencies; the material, in the main, was scientific and technical in nature." 145

The photoduplication service draws extensively upon several large collections of technical reports deposited with it, and "acts in a custodial as well as in a photocopying capacity.

"Prominent among such custodial holdings are the deposits of the Publication Board Reports Unit ... Documents and journals deposited with the Photoduplication Service by the American Documentation Institute . . reports . . . of the Technical Oil Mission ... microfilm copies of various Russian scientific and technical journals ...." 146

The National Agricultural Library has, since 1911, made photographic copies of articles in its collection as a means of disseminating scientific information. Two experimental projects in photocopying were carried out: a cooperative program in 1934 with the American Documentation Institute (as mentioned in sec. 2.3) which was later transferred to the Library of Congress; and a project carried on from 1946 to 1956 as a "joint arrangement with the American Chemical Society to provide copies of all articles which were listed in "Chemical Abstracts'." 147

The Photoduplication Service of the National Library of Medicine (NLM) " began rather informally in 1937 when Dr. Seidell provided the Library with a microfilm camera... the weekly

144 O'Brien, 1963 [433], p. 203.

145 U.S. Senate. 1960 [592], p. 89-90.

24 Holmes, 1955 [269], p. 50-51.

$1 \leqslant$ U.S. Senate, 1960 [592], p. 146 .
Current List of Medical Literature was started in 1941 by Dr. Seidell, and through it, readers are kept informed of material available for filming." ${ }^{48}$ In 1943, the Library began free distribution of microfilms specifically as a substitution for loan services." This free (photoduplication) service was to be provided in place of lending the books or periodicals. It represented an extremely interesting development in library economy.

The theory behind the move was expressed in a statement issued on September 1, 1943: "The Library recognized that microfilm copying is a service which publicly supported reference libraries may well perform on an equal basis with that provided for readers and by interlibrary loans. In the pursuance of such a policy, microfilms will be sent without charge in lieu of the loan of books to those who prefer them or where books or journals cannot be loaned." ${ }_{149}$

Yet this commendable service is threatened. "At the current rate of increase in requests to NLM for photocopy loans, the full capacity of its present equipment will be reached by the end of 1964 . NLM studies have indicated that major increases in capacity cannot be achieved without a major design and development program that would cost at least $\$ 3$ million." 150

In its annual report for fiscal year 1963, the National Library of Medicine stated: "The highcost demand systems such as the present NLM interlibrary loan photocopy operation, operating as a single centralized national service, cannot supply the needs of all researchers and clinicians with promptness and efficiency. The real answer lies in expansion of local and regional resources."

Another Federal agency active in microreproduction is "the NASA Scientific and Technical Information Facility which went into full production of microforms in July 1962, producing over 800,000 individual microforms representing approximately 10,000 titles in the remainder of that year." ${ }^{151}$

An example of a foreign organization which maintains photocopy services is VINITI, which reports: "Nnother important facility enjoyed by our scientists, engineers, and technicians is the Institute's photo and microfilm copying service which supplies the former with copies of any original article covered by the Abstracts Journal." ${ }^{152}$ The extent of coverage implied here is admirable, and a goal much sought by other information services.

"In view of the increasing use of microreproduction methods in libraries and other institutions, the UNESCO Division of Libraries, Documentation and Archives has compiled a short provisional list of micropublishers." ${ }^{153}$ "Also, "The ... FID

148 Metcalf et al, 1944 [380], p. 37.

149 Ibid, p. 37-3s.

150 Orr and Pings, 1964 [441], p. 1163.

${ }_{152}$ Bralove, $1963[75]$, p. 78.

153 "List of Micropublishers", UNESCO Bull. Libs. XVI, 198-205 (1962) 
.. has just published the third and revised edition of Photocopies from Abroad, a directory of ... services in 38 countries. Reproduction services listed were collected during a 1962 survey with the help of national members of FID, with entries being selected according to their ability and willingness to serve customers abroad. More than 150 separate services are described. . . ." 154

On the subject of photocopying, Evans points out that it and the provision of microfilm and other forms of microcopying could well be instituted or expanded by many reference libraries. "Only 55 of the 212 reference libraries reported a photocopying service, and in the majority of these, it is designed solely for the use of agency personnel and is not normally extended to other readers; 92 libraries indicated that they had one or more reading machines for microfilm or other microforms. Maximum use of such services cannot take place until the interests of copyright owners have been reconciled with those of readers." ${ }^{155}$

Another opinion was: "Photocopying must come of age, and an organized national plan for copying projects should be established . . . a report prepared for the American Council of Learned Societies ... recommends establishment at the earliest opportunity of a national committee on the photocopying of foreign manuscript and archival material. Other recommendations call for the establishment of a national center abroad to coordinate projects engaged in copying foreign archival records and manuscripts, development of copying priorities in its field by each learned society, careful examination of copying proposals submitted to foundations, and a microfilm clearinghouse which among other responsibilities can insure adequate recording and cataloging of material copied." 156

\subsubsection{Depository Libraries}

We have now reviewed interlibrary loans, exchange agreements, and photoduplication as means for cooperative acquisition of or access to scientific and technical information. Still another form of cooperative venture is the depository library, a system whereby collections of material are placed in a number of libraries, usually scattered geographically but bound by ties to the central office which distributes the material. This placing and distributing can in itself be a cooperative activity, carried out by a group of libraries which maintain a central depository for material to be shared.

This latter arrangement offers a particular library "a net reduction in the number of volumes it must retain for immediate access at the same time that it yields a net addition to the total resources of that library for deferred access. The overall gains may thus be of striking importance.

\footnotetext{
154 Scientific Information Notes 5, 3, 12 (1963)

155 Evans, 1963 [188], p. 2S-29. See also p. 44 ff and 99 of this report.

156 Scientific Information Notes $6,4,3$ (1964).
}

The new Midwest Inter-Library Center has been planned by a group of middle western university libraries to achieve exactly these goals as well as other kinds of cooperative access to materials." 157

Two examples of depository libraries established by Federal agencies are those of the Atomic Energy Commission and of the Clearinghouse for Federal Scientific and Technical Information (formerly OTS).

"In addition to providing information products and services to its own laboratories and those of other government agencies and their contractors, the AEC provides complete collections of AEC unclassified research and development materials to 84 domestic depository libraries and 83 depository library collections in 58 countries outside of the United States. . . . (The collections include) over 28,000 reports, some in microcard form and some in full-size copy ... [and] a microreader." 158

A few years ago, "... On the initiative and with the support of the National Science Foundation," ${ }^{159}$ OTS tried out a national depository library arrangement whereby microfilm reels of Defense, AEC, and NASA reports were deposited in 12 research libraries geographically distributed around the nation. Low usage, however, has apparently discouraged continuance by the Clearinghouse.

NASA, however, has "established an unusual search tape system that provides up-to-date, comprehensive search capabilities at individual research centers of the entire NASA report collection. The collection covers not only the documents announced in Scientific and Technical Aerospace Reports, but also the journal literature announced in International Aerospace Abstracts. Currently the search tapes are in use at six NASA research centers, eight principal contractors, three university centers, and at NASA's Scientific and Technical Information Facility where the tapes are initially prepared ... Microfiche copies of all new reports are distributed to each organization in the search tape program. Each group is thereby entirely self-sufficient in that microfiche or hard copy can be supplied directly upon request." 160

On the international scene, there have been recommendations ". . . To institute regional depots under international coordination to store complete experimental records and other documentation in support of brief published papers . . . ." 161

\subsubsection{Cooperative Exchange of Data}

We might mention briefly a specialized form of cooperative acquisition and exchange, that of new information and data rather than of publications. Two examples will help to define this new form

\footnotetext{
157 Fussler, 1955 [207], p. 178.

158 U.S. Senate, 1960 [592], p. 36,48 .

159 Green 1963 [225] p. 224.

160 Scientific Information Notes, 6, 3, 11 (1964)

161 "International Cooperation in Pure and Applied Science," 1961 [133], p. 989-990.
} 
and to demonstrate why it belongs with other types of acquisition and exchange programs.

The New Drug Information project (NDI) is an experiment among pharmaceutical companies (seven companies in the Fall of 1961) in the exchange of information on biological properties of new chemical compounds, as reported in the current literature. This project was designed "to provide an alerting service for the scientists of each firm that would be more comprehensive than any one company could provide without greatly increased costs." 162

The three military services have agreed on a program "for the interchange of data resulting from tests of ballistic missile components and parts ... Reports of tests conducted by any ballistic missile contractor will be reported to the 'IDEP Data Distribution Center' of the cognizant service. ... The microfilms of the complete report ... plus a summary card ... will automatically be distributed to all participating contractors and agencies which have previously expressed an interest in that particular subject." 163

It may be that these two data exchange programs forecast increasing cooperative activity in the earlier stages of research and development programs. Other examples are the Industrial Liaison Office, the Cancer Chemotherapy National Service Center, and the newly established National Standard Reference Data System.

"The Industrial Liaison Office (ILO) was established by the U.S. Army Chemical Corps to solicit from industry data, know-how, and ideas to enhance the Corps' research and development efforts. Information obtained through this program has provided leads to the solution of some of the most urgent problems and has prevented duplication by the Chemical Corps of costly research already completed in industrial laboratories but which has not been publicly reported.

"More than $90 \%$ of the information sent to the ILO consists of proprietary lists of recently prepared compounds with attached physical, chemical, and biological screening data. At the present time, lists containing approximately 1000 structures are received each month. . . . Naturally, the ILO will not release the data to other groups without the written approval of the company submitting the original sample." 164

"As a part of the cancer chemotherapy program, laboratries across the nation daily compile and send in test reports on drug effects on animal tumors. The data is then processed by computer, providing rapid results on the test compounds for immediate use by NIH, test drug suppliers, and the laboratories ... A master file of more than 200,000 chemical compounds and natural products screened in 26 different cancer systems has been made available to researchers." 165

162 Bohr and Owen, 1963 [67], p. 201.

163 Burnett, 1960 [88], p. 31.

164 Gelberg et al, 1962 [212], p. 7.

165 Scientific Information Notes, $\dot{6}, 2$ (1964).
"A National Standard Reference Data System has been established by the Federal Council for Science and Technology and responsibility for its administration has been assigned to the National Bureau of Standards... The system will provide critically evaluated data in the physical sciences on a national basis, centralizing a large part of the present data-compiling activities of a number of Government agencies ...."166

\subsection{Analysis and Identification}

After the existence and availability of documents have been determined and they have been acquired by some means or other, they must be processed before being put away for later reference. This processing consists of analysis of the form and content of the documents, plus identification and recording of the results of such analysis. We shall discuss these various aspects in turn: physical identification, content identification, and cataloging rules and principles devised to aid these identification operations.

We shall also examine current operations and proposed activities for cooperative or centralized cataloging and for the use of automatic equipment in conventional processing steps and in the newer approaches to cataloging and indexing.

\subsubsection{Physical Identification-Descriptive Cataloging}

The physical description of a document is the most basic of the operations taking place in a library or information center; before the organization can attempt to handle a document, it must know what it has. In this section we will discuss the more important elements of a descriptive cataloging entry, particularly as applied to technical reports. In the section on cataloging rules, (3.6.4) early efforts in the development of common practices among libraries will be reviewed, particularly the origin and growth of standards for a library catalog.

The problems and difficulties of descriptive cataloging assume special significance in terms of future mechanization. For one reason, the rules involve so many complicated alternatives that they have to date defied the programmer's ingenuity. For another, it is precisely the card catalog operation that has received the greatest attention with respect to the possible introduction of machine handling in very large systems.

Descriptive cataloging is defined by Webster's New International Dictionary, Third Edition, as "a library procedure by which a book or other item is identified and described by recording such items as author, title, imprint, and collation-contrasted with subject cataloging." Taube comments that descriptive cataloging is not the "relatively simple and straight-forward affair" that it might seem, that there is difficulty in "devising uniform entries from the haphazard information which appears on

166 Scientific Information Notes 5, 4, 1 (1963). 
the title-pages of the various publications and reports requiring organization." 167

Although, in the opinion of one author, "It is understood that descriptive cataloging is standardized. Consequently, there should be little difficulty in creating a standard for descriptive cataloging," 168 many workers in the field would not agree.

For example, "the prevailing rules of cataloging are based on the Anglo-American rules of 1908 . These have frequently been amended since that time, however, and as a result have become so complicated and difficult of interpretation that the value of the code has in good part been diminished ...." 169

Further, "one of the favorite demonstrations of those who rum the National Union Catalog at the Library of Congress is to hold up 10 catalog cards from the major libraries of this country, all representing the same book, and all beginning with a different main entry; and this despite the fact that all 10 of these libraries were attempting to interpret the same set of rules!" 170

Much discussion and even argument has gone on and continues about rules for descriptive cataloging. It could be a most fruitful area of cooperation and collaboration, but agreement is difficult to attain. We might add here that many workers in automatic system design claim that descriptive cataloging is more difficult for a computer to accomplish than automatic indexing or abstracting. The difficulties will become apparent as we discuss the individual problems.

The traditional means for bibliographic control of a book or a publication has been citation of the author. Items within periodicals are generally referred to by the personal authors of those items. Fven those libraries that do not have a common dictionary catalog containing an alphabetical arrangement of cards indicating authorship and subject matter of publications usually have separate catalogs for authors and for subjects.

With the advent of the technical report in this country, the problems of identifying the organization sponsoring the research or the investigation assumed increased importance, especially where no personal author was identified or where many different authors prepared various reports on the same projects. In the AEC, for example, use of the personal author entry led to some confusion "because the reports were produced by a team of research workers ... When work is performed in this manner, it is not unusual for the first paper to be prepared by one or two members of the team, the second by a different pair and the third by the team as a whole." 171

Uniform identification of corporate source has been a perennial problem, in view of frequent

\footnotetext{
167 Taube, 1950 [556], p. 3

16s Langenbeck, 1962 [329], p. 298

169 Sclentific lnformation Notes $4,5,3$ (1962).

1\% Brandhorst. 1964 [76], p. 43 .

17 Croxton, 1955 [151], p. 126.
}

changes of name, which may require the maintenance of separate history files (Mac Donald, 1953 [364]). But for the technical report the organization must often be regarded as the main entity for entry into the catalog. This involves the use of the corporate author for announcement, cataloging, and filing purposes. The personal author is considered of secondary importance. "Although personal authorship is important, the actual identification of a report must be tied to the corporate agency responsible for the work." 172

Current methods used for designation of corporate authors are complex and difficult to follow. This is partly because ". . . Laboratories place their names on a given series of reports with considerable inconsistency and ... many laboratory names are homonymous and undistinctive." 173

One solution to the complex problem was offered by Taube, who suggested that wherever possible "the most specific corporate body involved was to be employed. Treatment of the most specific body as a subdivision of its parent body was to occur only when it had a name which was capable, and likely, of being a subdivision under many other corporate bodies. Names falling into this category were not defined in a general way, but were specifically promulgated in a list." 174

Another approach to solution was undertaken in 1951 when the Board on Cataloging Policy and Research of the ALA Division of Calaloging and Classification "initiated a study of the second edition of the Code by Seymour Lubetzky, with particular attention to the rules for corporate authors and a discussion of the objectives and principles which should underlie a possible revision. This study was published in 1953 as Cataloging Rules and Principles ...

"Mr. Lubetzky pointed out a number of instances of poor arrangement of rules, cases of inconsistent treatment of similar conditions in different sections of the code, and examples of unnecessary repetition of rules. He gave particular attention to the rules for corporate headings and showed how these had developed into the present confused sections on societies, institutions, and miscellaneous bodies." 175

The complexity of the methods used for designation of corporate author is shown by the rules devised by Lubetzky in an unfinished draft for a new edition of cataloging rules prepared for the ALA Cataloging Code Revision Committee (1960 [349]). He divides the works of corporate authorship into the following types and gives a rule for establishing the entry in each instance: work of corporate body; work of division of corporate body; work of group organized or sponsored by corporate body; work of unnamed group; work of individual that is issued by a corporate body.

\footnotetext{
${ }^{172}$ Warheit, 1952 [627], p. 105

173 Brandhorst, 1964 [76], p. 42 .

174 Ibid. p. 37.

15 Wright, 1956 [655], p. 331.
} 
Government publications may have the following additional rules: work of national or local jurisdiction; work of jurisdiction subject to authority of another jurisdiction; work of government department, office or agency; work of government officials.

The DDC has compiled and revised its Corporate Author List, the most recent list being issued in April 1963. 'The ASTIA Guidelines for Cataloging and Abstracting establish the policy of the Center regarding the List stating that "the corporate author (corporate body directly responsible for preparing a document) is treated as the main entry for each accession cataloged into the DDC collection, and except for the accession number, represents the principal approach to individual holdings."

The AEC also has a list of corporate author entries. The list currently available is Corporate Author Entries Used by the Division of Technical Information in Cataloging Reports, publication number TID-5059 (5th Rev.), issued in March 1962. It has an appendix listing the rules for corporate entry of the AEC, the main principle being: "Scientific and technical reports are to be entered under a corporate form of entry in addition to entry under the personal names of the authors. The corporate entry is to be based on the name of the issuing body current at the time of publication which is experimentally (or technically), editorially and/or contractually responsible for the reports."

In more detail, the AEC, instead of treating all corporate bodies alike, defines several categories of organizations (eight, to be exact) and makes the old distinction between societies and institutions, developing different rules for each category. In addition, AEC demands research beyond the document in hand, so that Ladd Observatory is entered Brown Univ., Providence, Ladd Observatory, but Lick Observatory is entered Lick Observatory, $M t$. Hamilton, Calif., rather than under its parent, the University of California. ${ }^{176}$

NASA has made several listings of its colporate authors, with codes assigned to each one. Such lists are apparently not intended for widespread distribution, probably because of the belief that there is no need for them outside NASA.

A group of government representatives, comprising a modern-day group for the standardization of information services and calling itself the Joint Descriptive Cataloging Group, held meetings in April, June, and September 1963. It proposed to advise the Committee on Scientific Information (now COSATI) of its recommendations as to procedures which could lead to standardization of descriptive cataloging by the producers and distributors of government research reports. A Standard for Descriptive Cataloging of Technical Reports (1963 [195]) was published in December 1963 by COSI. The rules for corporate author

176 See Brandhorst, 1964 [76], p. 39. entries in the Standard were included "in the hope that fruitful discussion of the degree of specificity will be obtained regardless of agreement on the order in which the chosen heading is written. It is planned that a working group representing concerned agencies will undertake the preparation of a combined corporate author heading list."

A special case with respect to main entry cataloging and an extension of the problems of proper determination of corporate authorship has been raised by Gull. He proposes that rules be drafted for entry and descriptive cataloging for automatic authorship, or nonhuman authorship. He points out that "electronic and mechanical devices are already producing mathematical and technical texts (excluding belles-lettres) to which cataloguers can attribute neither personal nor corporate nor anonymous (i.e., personal but unidentified) authorship", and contends that rules must be developed to care for "all works and records of personal, corporate and anonymous authorship susceptible to electronic and automatic equipment." 177

The sum of all these problems and suggested solutions to the author citation question point to ". . . the eventual need for a Directory of U.S. Corporate Authors in the Scientific and Technical Area ... It would serve as a massive influence toward standardizing cataloging practices and reducing cataloging costs throughout the special library and science-techmology information center field. It would be an instrument by which the relationship between existing practices could be displayed to facilitate choice, conversion, etc." 178

Even if the questions of content and order within author and corporate author entries can be resolved, an additional problem remains as to the form of the entry, whether it follows the traditional library practice of main organization with subdivisions following or whether it uses the smallest significant component. There are drawbacks to both forms, but either system can be made to work "by the generous and judicious use of references. It really makes no major difference which form is used as long as yon decide on one and stick to it. In either case an authority book or listing of the names accepted is essential." 179

Many efforts have been made to formulate rules and standards for descriptive cataloging. For 50 years every international library conference has expressed interest in bringing about agreement on such rules. One of the major roadblocks to extensive agreement has always been the conflict between two major cataloging traditions in the matter of corporate authorship. The European tradition, taking its lead from the so-called Prussian Instructions, does not recognize the principle of corporate authorship, and prefers to enter works under their title or personal author. The

\footnotetext{
177 Gull, 1963 [230], p. 284.

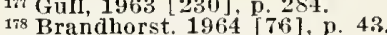

${ }_{179}$ Croxton, 1955 [151], p. 127.
} 
Anglo-American tradition, "branching from $\mathrm{Pa}$ nizzi, via Jewett and Cutter," champions the principle of corporate authorship but finds it difficult to apply in specific situations. It is necessary that the rules now used for this aspect of cataloging be substantially simplified. "They must be shorter, easier to understand, quicker to use, and capable of greater consistency of application; and their results must be better directed towards the legitimate functions of the catalog and the needs of the users, and less costly in their operations." 180

Another entry in descriptive cataloging of an item is the title. The informal nature of report literature sometimes makes the selection of a title difficult, since some reports have multiple title pages, some have cover titles, and some show no titles. It is essential that the information given as the title be informative as well as accurate, and that the substance of it be quickly understandable. To this end, titles beginning with such words as Progress Report are often inverted so that the subject information appears first. ${ }^{181}$

The determination of the date of a report is another problem because many reports are issued either without dates or with multiple dates being given. "The date of a report is of considerable importance to the user in judging its worth and in determining the priority of research effort." 182 The date is also important in cataloging for identification of delayed proceedings, collections of hitherto unpublished papers and talks, and manufacturers' brochures and manuals.

Still another area of descriptive cataloging which receives continuing attention and effort toward standardization is that of citing journal references, especially in abbreviated form. One tool aimed at helping this effort is the Coden for $P e$ riodical Titles, prepared and maintained for Committee E-13 on Absorption Spectroscopy of the American Society for Testing Materials (Kuentzel, 1963 [324]). The book contains nearly 20,000 coden for titles. The term "coden" is defined as "the combination of letters, numbers, and symbols assigned to a document or other item as the result of applying a set of coding rules." 183 The coden are sets of presumably unique four-alphanumeric character codes for the titles of periodicals. However, many possibilities of homographic ambiguities are evident and obviously involve a continuing problem area.

The ASTM list of coden was derived from one desecribed by Bishop in 1953 [62]. The most commonly used format gives a title code first, followed by volume and page numbers and year of issue. Thus JACS-77-2282-55 indicates a reference to page 2282 of volume 77 of the Journal of the American Chemical Society published in 1955. The coden use four-letter codes only for periodicals; nonperiodicals, patents, and one-time publications

\footnotetext{
${ }^{180}$ Brandhorst, 1964 [76], p. 36.

181 See Croxton, 1955 [151], p. 128.

189 Ibid., p. 129

183 Bishop, 1953 [62], p. 58.
}

receive a different code. While the coden for periodicals are mnemonic, those for proceedings of a symposium, minutes of a meeting, or a collection of papers consist of two digits and two letters, bearing no mnemonic or other relation to the publication but serving to identify it via an index.

Other types of abbreviations for titles of periodicals have been used for years in the compilation of bibliographies and "lists of references", and there have been many different rules developed to abbreviate the titles. Impetus should be given to the attainment of standardization of the abbreviations by approval of the American Standards Association American Standard for Periodical Title Abbreviations. The standard was prepared by a subcommittee of the ASA Section Committee Z39 on Standardization in the Field of Library Work and Documentation. The Subcommittee on Periodical Title Abbreviations was organized in December 1961 and began compilation, with the use of punched card equipment, of a primary list of periodical title words that are frequently abbreviated. This primary list was compiled from lists of abbreviations supplied by Index Medicus, Biological Abstracts, Bibliography of Agriculture, and Chemical Abstracts. The standard gives definitions of terms and rules for omission of letters, word order, single word titles, articles, conjunctions and prepositions, capitalization, punctuation, plurals, compound words, clarification in abbreviation, and multilingual abbreviations.

After the composition of the citation has been stabilized, its form must be considered. The GSIS card with the citation to the left and main entry by corporate author and tracings to the right "has the advantage of being applicable in the direct photographic preparation of bibliographies using cards from any or all . . cooperating agencies."184

The question of photoreproduction raises the further example of complications in descriptive cataloging: "The catalogue entry of a publication in microform should be identical with that of the original. The first supplementary note should indicate the microform and whether it is a positive or negative copy .... For positive copies the location of the negative should be indicated, if it is known." 185

\subsubsection{Content Identification-Subject Cataloging}

The Utopian ideal in literature indexing, universal bibliography or indexing, means indexing everything in a piece of literature, "intentional, incidental and accidental, that could possibly be of interest to anyone, anywhere, anytime." 186 This is not practical even with full text search "by some mechanical brain indexing everything on everything." 187 Instead the operations of subject cataloging attempt to provide at least some meas-

\footnotetext{
184 Croxton, 1955 [151], p. 131, see also p. 14-15 of this report 185 Gunther, 1962 [232], p. 10.

${ }^{180}$ Metcalfe, 1959 [381], p. 12-13.

187 Ibid.
} 
ure of control, to indicate what a book or document "is about", and to provide a central means of access to all items in the collection which are "about" some subject or subjects.

For example, in a printed index or card catalog, the objective is the entry of all that is indicated on a given subject at one point in the catalog. Single volumes and sets of volumes, constituting bibliographically complete works, are cataloged by their general subject or subjects; in addition some parts are recognized as linked bibliographical units, such as chapters and essays in books and articles in periodicals, and theses may be indexed for their general subject contents. This indexing or analysis is fairly completely and systematically done for some subjects or some periodicals in periodical indexes and abstracting journals such as the British Library Association's Subject Index to Periodicals, the Wilson Indexes, Plant Breeding Abstracts, Chemical Abstracts, and many others. Subject cataloging is not however as easily and consistently accomplished as might seem possible at first glance. Efforts are made to develop rules and principles for subject cataloging as for descriptive cataloging, but the task is long and difficult. Thus, serious efforts will continue to be made in order to make subject cataloging easier, more consistent, and more useful for the searcher of a collection. Toward these ends, many techniques have been proposed or are in practice for the analysis and recording of the subject content of documents.

Systems of documentation may be used in the selection, dissemination, and retrieval of information (or more properly of "documents containing information"). Such systems for retrieval of information "have been created because it was impractical, inconvenient, or excessively expensive to locate records personally." 188 Retrieval has been accomplished traditionally by schemes for indexing and schemes for classifying. These schemes assist a searcher, inspecting a file or library of records, to find particular records usually in terms of their subject interest. Such a searcher must (1) predict the vocabulary of authors, probably unknown to him, in dealing with matters which interest him; (2) predict the terminology with which librarians or documentalists, probably unknown to him, have analyzed the records; and (3) predict the symbols or other clues used by these librarians or documentalists to record the results of their analyses.

Indexing is the usual prerequisite for both the selection and retrieval of documents and the information in them and for selective dissemination of documents. It creates or uses one or more previously created surrogates for the content of a document and indicates or records those surrogates associated with the document. An index is ". . 'anything used to indicate, point out, or guide.'

${ }^{1 s s}$ Kent, $1963[311]$, p. 267.
The process of indexing involves selection of words or ideas from a graphic record on the basis of welldefined rules; the purpose of indexing is to facilitate the identification or selection of desired graphic records (documents, books, etc.) after they have been sorted and shelved or stored." 189

In traditional American librarianship, the provision of a single point of access to items having similar subject content has been by means of the selection of an appropriate term or terms from a set of alphabetically arranged subject headings.

A subject heading is defined by Frarey as a "word or verbal expression deliberately chosen from among the various alternatives to express the particular content of the material which it describes and which will be (1) in harmony with the usage of the audience to whom it is addressed, (2) accurate and precise in its specification of the exact subject of the material, (3) uniform, in the sense that the same word or verbal expression will be used consistently to describe the same subject, and (4) amenable to integration with other subject headings to provide a usable arrangement. In American library practice ... the use of subject headings implies an al phabetical arrangement." 190

The sixth edition of the Subject Headings Used in the Dictionary Catalogs of the Library of Congress states: "The present edition, like its predecessors, is a record of the headings traced on the Library's printed catalog card and used in its card catalogs and cumulative Catalog series. The list is the product of evolutionary forces, among them the growth of the Library's collections, semantic changes, and varying theories of subject heading practice over the years. As a consequence the list is, at any point in time, an accurate reflection of practice but not a complete embodiment of theory." 191

In the summary to his review and evaluation of literature concerning the alphabetic subject catalog, Frarey makes 11 points, among which the following are pertinent: (1) Present theory and practice of subject cataloging "is based primarily upon tradition and assumption and does not reflect any clear understanding of function or purpose." (3) Evidence indicates that the subject catalog "will be found to serve best the needs of any user for general purposes, i.e., it will orient him to the subject area of his inquiry; it will help him to select the best material available for securing this orientation; and it will guide him to the other instruments for subject access in his field of inquiry if his needs extend beyond those of simple orientation." (8) Those imperfections and inconsistencies in present practice which have been shown by studies of terminology, form and structure and which cannot be eliminated or minimized "will have to be resolved by the adoption of standards

189 Ibid, p. $267-268$.

190 Frarey, 1960 [202], p. 5-6.

191 Ltbrary of Congress, 1957 [338], p. ili. 
based upon sound knowledge of linguistics, semantics, and grammar, study of which in relation to subject catalog terminology and structure is only in its infancy at the present time." Further, (9) the syndetic reference structure (provision of see and see also references) is infrequently used and has even occasionally been abandoned altogether, thus implying that the provision of a comprehensive inventory by a subject catalog does not derive from an actual or a significant need, and that, in any case, the ability of the reference structure to do this is limited by the practical limitations which have been imposed upon its development. The ability of the subject catalog to give some measure of satisfaction emphasizes "the need served by it and that a subject catalog is likely to continue to be an essential feature in effective library service. The evidence suggests further that there is an excellent chance that a highly effective subject catalog can be effected." 192

Becker and Iayes (1963 [48]) regard the cata$\log$ of the library as its most important tool for management of its collection. They believe that the artificial or arbitrary decisions required of an indexer at the input stage when he makes his initial assignments to documents are a drawback to the subject heading system, although the question can logically be asked whether this is not the case in any human indexing scheme. The semantics of a heading change with time, as do the concepts underlying an indexer's choice. The subject heading system also has the disadvantage of increasing rapidly in terms of size and complexity.

Morris, in writing about the duality concept in subject analysis, was concerned that the tenet "voiced most persistently today is that the more 'direct' and 'specific' the heading the better the subject analysis." ${ }^{193}$ Such headings are illustrated by the alphabetically arranged sequence: Carbon. steels, Extra high carbon steel, High carbon steels, Steels. Indirect entry (by qualifying inversion) is made to the principal noun common to all four headings which then becomes the guiding word for their alphabetic sequence in the Catalog: Steels, Steels (Carbon), Steels (Carbon, extra high), and Steels (Carbon, high).

Morris was convinced "that in modern subject cataloging, the phrase 'direct and specific' is synonymous with 'not subdivided extensively and not inverted.' The most that can be said for this as a basic principle is that in practice it succeeds in separating (albeit scattering throughout the alphabet) nonidentical data but it does practically nothing to the end that similar or related data will be brought together. Carried to its full implication it renounces completely one of the fundamental purposes of subject cataloging, the twin of the duality concept concerned with giving the user some compresensive view of sizable segments of a collection and bringing pertinent relationships

\footnotetext{
192 Frarey, 1960 [202], p. 63-65.
}

193 Morris, 1954 [395], p. 121. into juxtaposition through a card catalog. This becomes doubly significant if, for large areas of the library collection, subject cataloging must carry also the burden of substituting for library classification of data." ${ }_{194}$ The other twin of the duality concept of Morris is "to enable a user of a library catalog to determine readily whether the library has available the particular bit of information which he desires . . . ." 195

Concept coordination, or coordinate indexing. another approach to information storage and retrieval, "was discussed in theory in the latter part of the 19 th century but was applied only in severa] isolated situations until the beginning of World War II. In the years since the war, concept coordination has gained progressively more acceptance as inherent problems have been solved which originally limited utility and effectiveness. .

In concept coordination, information is analyzed and characterized for storage and subsequent retrieval primarily by single word units to describe single ideas or unit concepts." 196

The striking characteristic of coordinate indexing systems is that the single terms used for indexing are not combined in advance for storage, as is true with the main headings plus modifiers of subject heading systems. Coordinate indexing. systems are said to be post-coordinated; that is, combinations of the terms which describe a question are made at the time of asking the question. Further, "the basic principle of "coordinate indexing' is that of free combination of concepts . . . to define a multidimensional search . . . "197

Concept coordination systems are found in several forms, depending on the amount of complexity or structure present. Some systems even conduct some amount of precoordination.

Coordinate indexing is defined more broadly "to include all systems in which the logical operation of intersection, union, and negation are brought into play in the manipulation of index terms. whether Uniterms, keywords, descriptors, unit concepts or structerms. ..."198 Examples will illustrate the different types of systems.

The Uniterm system of coordinate indexing, developed by Taube in the early 1950 's, described the informational content of documents, "after appropriate analysis by qualified personnel, by the simplest practical word units of information referred to as Uniterms. Uniterms are subject headings for unit concepts, with all Uniterms possessing equal hierarchical stature, none subordinated or superordinated to any other (as in classification) and none existing in precoordinated arrangement with any other (as in traditional subject heading arrangement). Taube visualized Uniterms as predominantly single words." 199

\footnotetext{
194 Ibid, p. 122-123.

195 Ibid, n. 117.

193 Costello, 1961 [138], p. 21

197 Taube et al. 1954 [562], p. 62

193 Jaster. 1962 [2961.p. 23.

19 Costelio, 1961 [138], p. 21.
} 
"In the summer of 1952 , the Armed Services [echnical Information Agency awarded a conract to Documentation Incorporated for an inestigation and experimental installation of a then ompletely novel system for filing and retrieval of nformation, the Uniterm System of Coordinate ndexing ...

"Coordinate indexing as a generic term covers ill forms of indexing in which the retrieval of pecific items of information involves the determiation of the logical product of a number of lasses ...

"The Uniterm System as a species of coordinate ndexing is a manual method of determining the ogical product of two or more classes through the levice of 'arithmetical' coordination. The dissovery of a common number on two or more Unierm cards establishes that there is a class which s the logical product of the classes denoted by the Jniterms and that the class has members. The nembers are, or course, the documents or other tems designated by the common numbers." 200

Changes in Taube's original system between 1951 and 1961 affirmed the importance of the prinsiple of bibliographical coordination even though hey diverged sharply from the simplified initial soncept. Among the changes which have been nade in systems originally based on Uniterm are ejection of equal values for terms, introduction of hierarchial relationships; retention of subject uthority and cross reference systems, and the inroduction of "role indicators" to serve as standard subdivisions or modifiers and "links" to prevent undesirable coordinations among terms. Artandi ind Hines argue that the changes introduced by isers of coordinate indexing "show, although this s obscured by the terminology, a steady growth of icceptance of the use and utility of major elements of conventional subject-heading practice as it has leveloped from Cutter's basic work in 1876." 201 Premodification or precoordination of terms (the compounding of a plurality of terms substizuted for single terms when necessary to specify the subject accurately for the purpose and search method at hand, e.g., Boundary layer or Aircraft fire control systems) resulted in more or less iighly controlled terms. Another method of conrolling the terms for a concept coordination sysiem is by using "descriptors," general terms whose neanings encompass meanings of several other erms; descriptors were devised to reduce the numjer of terms in coordinate indexing vocabularies. By definition, a descriptor system has a limited rocabulary; a descriptor dictionary is usually naintained, with "scope notes" to define the scope ind meaning of each descriptor for the system. The Zatocoding System of Mooers uses descriptors n this way (1951 [394]).

Mooers has described his descriptors as follows: 'The neologism 'descriptor' was purposely intro-

200 Taube et al, 1954, [562 ], p. 44-46.

201 Artandi and Hines, 1963 [35], p. 77. duced in 1950 in order clearly to distinguish the new method of indexing language from the other and older systems such as: word indexing, stichwort classification, schlagwort, subject heading, etc. ...

"Ve may think of the whole descriptor, including the definition, or scope note, to which the label is attached, as a packaged idea, as a concept which is to be used primarily for retrieval in some particular retrieval system. . .

"Another characteristic, which is rather subtle, is that the set of descriptors as a whole, and the descriptors individually, are tailored to do a particular retrieval job." 203

More complex and structured schemes for concept coordination systems use role indicators and links to modify the basic terms and to prevent "false drops" or inaccurate coordinations.

The highly complex abstracts of documents or "telegraphic abstracts" devised by Perry, Kent, and Berry are another effort at reducing the problems of false drops and the difficulties with subject interrelationships occurring in the coordinated index or superimposed coding types of schemes.

According to Vickery, the central semantic problem of subject indexing is the relation between terms, and the three following modes of analysis, distinguished in traditional logic, are used in different systems of information retrieval: ". . . the physical analysis of a thing into its parts or constitutents, or of a group into its members; the logical analysis of a generic concept into its species; and the metaphysical analysis of a concept into its attributes. A special instance of the last is the analysis of the definition of a concept into its elements." ${ }^{204}$ Vickery sees also three techniques of semantic analysis in selection of indexing terms: the "analysis by definition" of Perry, Kent, and Berry (1956 [455]) the "analysis by operational definition" of Andrews and Newman (1956 [31]), and the "facet analysis" of Ranganathan (1957 [469]).

Perry et al., have analyzed words in science and technology and find that "semantic factors," i.e., terms not further analyzed, and combinations of these factors are sufficient for representation of the words. Andrews and Newman represent a word by the combination of a limited number of attributes, providing a series of "modulants," of categories or inflecting codes, which serve to form descriptors by inflecting the "ruly roots" for things named in the literature (the "ruly" roots being opposed to common "unruly" parlance). In the facet analysis of Ranganathan, each of the terms in a subject field is defined with respect to its parent class. The terms are then sorted into the categories formed, such as substance, state, property, reaction, operation, or device, so that these categories can be combined to form compound terms.

203 Mooers, 1963 [392], p. 27

204 Vickery, 1959 [613], p. $855-858$. 
In these three types of analysis the choice of semantic level of indexing terms is aided or controlled by the formulation of categories which are concepts mentally fabricated with reference to the world of experience. "There is general agreement that the most helpful form of classification scheme for information retrieval is one which groups terms into well-defined categories, which can be arranged in hierarchies where this conforms to the recognized structure of relations between them." 205

A quite different approach to control of vocabulary and semantic and syntactic relations of terms has been described by Walton of the David Taylor Model Basin, Navy Department, who has developed an artificial procedure-oriented language FROLTC (Formal Retrieval-Oriented Language for Indexing $C$ ontent), by which a machine may manipulate those multifaceted descriptions of subject content of documents generated by analyticsynthetic techniques. The language "is built around a categorized and hierarchically arranged vocabulary combined with a simple grammar for indicating certain essential roles or relationships between index terms. . . . The key to the proposed system is a thesaurus-dictionary in which word associations and meanings are recorded. ... The basic or elemental concepts of the language are displayed in a Classified Schedule, where they have been gathered into a few general categories. The primary division is into the names of things and the various characteristics that can be ascribed to them, viz, properties, conditions, actions and relations." 206

The division, things, is classified into physical substances and objects, the former being divided into energy and matter and the latter into natural objects, bodies (masses), and constructs (artificial objects), each of which is further divided. Walton suggests that "the classification of basic concepts (rather than subject headings), along with semantic analysis of complex concepts, should help to unmask much current technical jargon, while the development of an interdisciplinary vocabulary of wide application in scientific documentation should ultimately lead to greater compatibility between systems." 207

Differences between subject headings and the terms, simple or structured, for post-coordination systems are useful for categorizing indexing techniques. A few other distinctions of categorization merit attention.

The steps to be taken by an analyst in the selection of indexing terms to represent a document may be outlined as follows: "The text is scanned to select a set of words, phrases or sentences which collectively represent its subject. . . . a decision is taken as to which of these subject descriptions are worth recording as being relevant to the purpose

\footnotetext{
205 International Federation for Documentation, 1957 [2851], p. iii.

206 Walton, $1963[626]$, p. 22

207 Walton, 1963 [626], p. 22 .
}

of the retrieval system. . . the relevant subject descriptions are transformed into the standard de. scriptor language used in the system." 208 In scan. ning the text two methods are commonly em. ployed: "First, the indexer reads the text and car 'understand' it-i.e., he can formulate the subject in his own words, which need not be the words usec by the author. Second, the indexer cannot 'under. stand' the text in this sense, but he picks out from it words, phrases or sentences which the author has emphasized as important-the title, introduction section headings, conclusions, summary, and s on." 209

This distinction between methods is reflected ir contrasting "derivative" with "assignment" index. ing (Luhn, 1962 [353]; Herner, 1962 [255]). BJ this method of differentiation, "derived" terms are taken from the texts of the documents themselves while "assigned" terms are taken from a list o terms or subject categories that exists independ ently of the documents. Indexing by assignmen is obviously more likely to be concept indexing than word indexing, and indexing by derivation is word indexing rather than concept indexing Herner believes that the Uniterms of Taube, a least initially, were derived and that "Keyworc indexing and/or permutation indexing, whethes based on titles, amended titles, or texts, constitutes an extreme example of indexing by derivation."

As examples of indexing by assignment in non. conventional systems, Herner cites both Zatocoding and the work of Schultz in the man-computes indexing of the 1960 Federation of Americar Societies of Experimental Biology (FASEB) papers. Herner states that elemental to Zatocod. ing "is the analysis of documents in terms of care fully developed sets or classes of criteria that guide the use of and application of substituent indexing terms or 'descriptors.' . . . Zatocoding tells you when and how to select words or descriptors in a vocabulary. In so doing, it helps to diminish re. dundancy and lack of consistency and con text. ..." ${ }^{211}$ In the work of Schultz with the FASE $\dot{B}$, "authors of papers selected appropriate index entries from a list of possible entries fur. nished them by the Federation and also from the terms used in the abstracts of their papers." 21

Kent makes a similar distinction between worc indexing and controlled indexing. Controlled in. dexing "implies a careful selection of terminology for storage in the index, in order to avoid as far as possible, the scattering of related subjects under different headings. The control may be imposec by limiting the indexing (a) in the number of sub jects that may be chosen, (b) in the number of aspects of subjects that may be chosen, and (c) ir the language used to express the results of the analysis." 213

\footnotetext{
${ }^{208}$ Vickery, 1961 [616], p. 15-16

200 Ibid, p. 16.

210 Herner, 1962 [255], p. 5.

211 Herner, 1962 [255], p. 5

212 Sehultz, 1963 [509], p. 9

21 Kent, 1963 [311], p. 268 .
} 
Four "schools" of documentation with respect to the selection of indexing terms are discussed by Becker and Hayes (1963 [48]). These schools are of (1) Taube of Documentation, Inc., Bethesda, Md., with coordination of concepts by use of Uniterms, usually in the form of single words or concepts; (2) Mooers of Rockland Research Institute, Inc., Cambridge, Mass., who uses "descriptors" and "superimposed coding" for efficient storage by compacting codes randomly in a limited storage area; (3) Perry and Kent, formerly of the Center for Documentation and Communications Research of Westem Reserve University, Cleveland, who introduced "role indicators," "semantic factors," and "analytic interfixes," and also the "telegraphic abstract" based on elements for describing a document's information content; and (4) the facet analysis and colon classification schemes of the school of S. R. Ranganathan, which postulates that the relationships among things in a universe can be described in terms of their positions with respect to each of a set of fundamental facets.

Maloney and Batchelor relate indexing terms to words in languages and to the types of languages evolved during the last century. One of their tentative principles of information retrieval is that "retrieval index entries take three forms of isolating, agglutinative, and aggregative codes that words in languages do. Isolating codes show a minimum of 'structure' and the greatest independence of context and order in the specification of meaning. Descriptors, uniterms, and key words are examples of such codes. Most classifications are examples of agglutinative codes, but colon, UDC, and other faceted classifications, as well as semantic factor codes, are examples of aggregative codes." 214

There have been perennial arguments pro and con "word" or "derived" indexing and "assigned," "controlled," or "subject" indexing. Crane and Bernier say that word indexes for articles in periodicals that are merely indexes of titles of papers or of abstracts are to be regarded as generally incomplete: the titles frequently do not reveal, even in a broad sense, the contents of papers. "Many so-called subject indexes are really indexes of words instead of subjects. There is a vast difference. Word indexing leads to omissions, scattering, and unnecessary entries." 215

An index entry as used in Chemical Abstracts includes a heading (word or phase selected to act as guide to the subject, concept, author name, etc.), a modification if necessary (additional statements explanatory of the individual heading), and a reference (for finding the item from which the index entry was derived). "The subject index is designed to be a key to the information, not to be the information itself. Index-heading terms usually represent more or less general areas of in-

214 Maloney and Batchelor, 1963 [369], p. 108.

215 Crane and Bernier, 1958 [147], p. 515. formation in the document, but do not give specifically the information itself." 216

Welt (1959 [640]) also believes that word indexing (as opposed to subject indexing) is of dubious value for indexing periodicals. Subject indexing, however, involves rigid standardization of terms. The lack of standardized subject headings and their flexibility or inconstancy both lead to a significant number of failures to retrieve the information that is desired.

Holmstrom suggests: "In the lexicogxaphy of science it is of first importance to appreciate and maintain the distinction between concepts-the ideas or notions, phenomena or applications which science uncovers, examines and exploits-and the terms which scientists, in their reasoning and communications, use as symbols to denote these concepts." 217 He continues that "the concepts, once established, are fixed and immutable, but the terms which scientific writers use as symbols for them are fluid and susceptible to change. To a considerable extent they depend on nothing more solid than fashion." 218 Furthermore, except for Chinese and some Japanese "the terms are symbols not for the concepts directly but for the sounds which those who happen to have been born in a particular country are accustomed to utter or to imagine when they have particular concepts in mind." 219 Holmstrom stresses that the concept of an action or a thing is not always known by the same word or words in a given language.

It is for such reasons that the different types of indexing, derived and assigned, precoordinated and postcoordinated, tend to converge. The problems of construction and use of thesauri, to be discussed in section 3.7.1, are not very different from the traditional work of establishing, standardizing, and revising subject heading authority lists. In this area, we note a particular example of proposed cooperation on a broad scale: in 1954, Angell proposed that a national committee be formed on the initiative of the Division of Cataloging and Classification of ALA, and that it should be a "joint committee on standardization of subject headings. There should be representatives of such national associations as the ADI, the Association of College and Reference Libraries (particularly the Reference Libraries Section), the Association of Research Libraries, and SLA; of such maintainers of information systems as the H. WV. Wilson Company and the LC; and of the informal group of Government agencies working on these problems under the title Group for the Standardization of Information Services... [The committee] should formulate the objectives and principles, identify the research studies and form them into an integrated program, lay out the steps of proce-

\footnotetext{
${ }^{216}$ Bernier and Crane 1962 [55], p. 117.

277 Holmstrom, $1955[270]$, p. 73 .

218 Ibid, p. 74
}

219 Ibid. 
dure precisely, set up a budget, get the moneyand supervise the execution of the work." ${ }^{220}$ This probably will have to be done to standardize the universality of language to be used for storing information among various groups in this country.

In summary, we might quote Herner to the effect that "the phenomenon that best characterizes modern documentation is the recurring denunciation and discovery of the need for context and resolution in index entries." 221 and Artandi and Hines who suggest that coordinate indexing "is moving toward the use of conventionally formed subject headings on the simplest possible level which can serve for the identification of a distinct subject and then applying bibliographic coordination of these headings." 222

\subsubsection{Cooperative and Centralized Cataloging}

The history of cooperative cataloging in this country had its beginning when "as early as 1851 Charles Coffin Jewett proposed an organization of libraries in the country with the Smithsonian Institution as a center which would include cooperative cataloging among a group of cooperative enterprises. ... The Smithsonian officials declined to develop the program ... The organization of the American Library Association in 1876, later developments in the compilation of Cutter's Rules, and the arrival of the $3 \times 5$ inch card had much to do with the picking up of the proposals." ${ }^{223}$

Centralized cataloging, a form of cooperation, is defined by $\mathrm{E}$. 'Thompson in her glossary, (1943 [569]) as " 1 . The preparation in one library or a central agency of catalogs for all the libraries of a system. 2. The preparation of catalog cards by one library or other agency which distributes them to libraries." She also defines cooperative cataloging as "The production of catalog entries through the joint action of several libraries, in order to avoid duplication of effort. Particularly, the plan by which cooperating libraries prepare copy for catalog cards to be printed by the Library of Congress." 224

In its position as the largest library in the United States, the LC has been influential in affecting the manner with which many libraries here and abroad perform their tasks, this influence tending to promote cooperative activities among libraries. One of the first evidences of such influence was the issuance of printed catalog cards by LC for sale to the general public about 1901 . The format of these cards including the suggested classifications according to both the Dewey Decimal Classification and the LC schemes helps librarians to keep records of what they have and where they have them. As Tauber says, "In the United States, the Library of Congress has been a centralized agency for cataloging, in addition to serving as a base for cooperative cataloging . . . .

\footnotetext{
${ }^{220}$ Angell, 1954 [33], p. 195-196.

${ }_{221}^{220}$ Angell, 1954233$]$ p. 195

222 Artandi and Hines, 1963 [ 35$]$ ], p. 76

223 Tauber, M., 1960 [563], p. 191 .

224 Thompson, E., 1943 [569], p. 26.
}

The H. W. Wilson Company, which distributes cards to libraries on a more restricted basis than the Library of Congress, is also a centralized cataloging agency." He continues, "Centralized cataloging was started by the Library of Congress in 1902. A cooperative arrangement for acquiring card copy from other government departmental libraries was also put into effect. In 1902 there were 212 subscribers to the printed cards, returning a total of $\$ 3,785.19$ to the United States Treasury." ${ }^{225}$ The importance to librarians of acquiring these printed catalog cards is shown by the insertion of the LC card number in many books now published. In April 1930, LC began to add Dewey numbers to its printed catalog cards.

Recently an interesting but unsuccessful experiment, called "cataloging-in-source," was tried by the Library. It involved reproduction of the actual LC card on the verso of the title page of new publications. Publishers furnished LC with page proofs and data sheets for their publications, LC was to catalog the titles, and the publishers were to print facsimiles of the LC cards in the published book. Libraries were then to transfer the catalog entries from the books to cards for filing, by means of special camera equipment. Although the experiment was subsequently abandoned, Evans suggests that the difficulties which were encountered could be overcome and that an effort should be marle to extend the practice to a wider range of publications both here and abroad. Such a system could sharply reduce the cost of cataloging in the world's libraries. ${ }^{226}$

Types of publication which raise problems for catalogers in many other libraries as well as LC include technical reports and serial technical publications. "The problem of cataloging and classifying the mounting volume of [technical] reports (some carrying a security classification) originating in countless sources and varied forms outside the conventional channels of publication calls for extensive cooperation by federal and non-federal libraries .... A centralized mechanism to deal with these reports should certainly be established. ... The total task is too huge to be accomplished by any single library, but a great deal could be achieved by a coordinated system of indexes to which many libraries would contribute." 227

Evans continues, "The Library of Congress has long been active in the preparation of 'analytics' card entries for items in periodicals and other publications. This service might well be expanded on a government-wide basis as part of a major program which is needed to index and abstract the rising flood of serial technical publications." ${ }^{228}$

If cooperative cataloging could not be extensive, an abbreviated record short of a full catalog entry would help to relieve the pressure of accumula-

\footnotetext{
225 Tauber, 1960 [563], p. 174-175, 191

226 Evans, 1963 [188], p. 21.

227 Tauber, 1960 [563], p. 49.

228 Ibid, p. 50.
} 
tions of unsorted and unidentified material which plague librarians. Even maintenance of an author card file and shelving by author would help. But centralized cataloging such as is carried on by the Veterans Administration would seem to offer much promise. The VA, which has been compared to a city library with 450 branches in 50 states, operates a coordinated acquisition and cataloging service centrally and supplies new books and their catalog cards ready for filing. The operation has brought cataloging costs down to 35 cents per title, as compared to an estimate of gross personnel costs of $\$ 3$ to $\$ 4$ per volume. ${ }^{229}$ A nother figure for cataloging a nonfiction book shows variations from 35 cents to $\$ 6$ per title..$^{230}$

Veterans Administration officials indicate their willingness to consider requests from other Government libraries to use this service on a cost basis. In regard to this centralized operation combining purchase and analysis, Evans suggests" ... the fuller use of acquisition and order records as the first step in cataloging; the present failure to exploit this information is most wasteful." 231

Another Government agency taking advantage of coordination in cataloging is the Clearinghouse for Federal Scientific and Technical Information which, since the inception of its cooperative program with the Defense Documentation Center, has made some changes in cataloging practices to avoid duplication and achieve economy. 'The Clearinghouse uses DDC descriptors in its subject indexing and produces paper tapes for input to the DDC computer as a by-product of its own announcement function and catalog card preparation, modifying an earlier arrangement between the predecessor agencies, Office of Technical Services and the Armed Services Technical Information Agency.

Two cooperative ventures in cataloging have been undertaken by the National Federation of Science Abstracting and Indexing Services: (1) installation of a bank and share arrangement for in-shop files, glossaries, instructions, etc. for use of other member services (e.g., CA microfilm of 60,000 cross references for its subject index, DDC frequency analysis of descriptors) and (2) set up of a warning system for changes in format and coverage detail in existing systems of members, to encourage overlap and continuity between members in indexing.

\subsubsection{Cataloging Rules and Guidelines}

We shall review, roughly in chronological order, the concerted activities in the United States looking toward rules and directions for the physical and content identification of books and other publications. This is perhaps the area where the greatest amount of cooperative activity is needed and has been accomplished.

\footnotetext{
229 Evans, $1963[188]$, p. 4.

230 Oellrich 1962 [435], 67

231 Evans, 1963 [188], p. 25.
}

Charles A. Cutter strongly influenced the subsequent cataloging activities of librarians by his 1876 Rules for a Printed Dictionary Catalog ([153]) as claimed by Landau, this is probably the first complete code of rules for a dictionary catalog and is still the basic standard code. ${ }^{232}$ Among the first of the achievements of the ALA that are contributions to cooperation and compatibility was the issuance of a guide in three successive editions: Condensed Rules for an Author and Title Catalog, 1883; Cataloguing Rules: Author and Title Entries, 1908, issued by the ALA and the Library Association (Great Britain), the first international catalog code; and ALA Cataloguing Rules for Author and Title Entries, 2d ed., 1949, [19].

During the early 1950 's there was considerable thought given, around the world, to the adequacy of cataloging codes, and at the 21st annual conference of the Graduate Library School of the University of Chicago in June 1956 a series of papers devoted to this subject was delivered..$^{233}$ Angell took the view that the catalog should be a means of access not only to printed materials but to all the preservable manifestations of human communication, from manuscripts to sound recording to sculpture. He questioned whether the next coding system could be no longer traditionally book-oriented but equally suitable for all forms of records. Osborn, representing the group appointed by the International Federation of Library Associations to promote coordination in cataloging, spoke principally on those developments which affect the two great cataloging traditions, stating that the real trouble spot was the corporate entry. Chaplin spoke on a universal cataloging code and related the events leading to the decision by IFLA, at its Zagreb conference in 1954, to set up a working group on the international coordination of cataloging principles.

Effort is being expended by representatives of the ALA and LC to prepare a new code of cataloging rules as is shown by the tentative publication in 1960 by the ALA of Code of Cataloginy Rules: Author and Title Entry [349]. Subtitled "An Unfinished Draft for a New Edition of Cataloging Rules," the publication was prepared by Seymour Lubetzky of LC for the Catalog Code Revision Committee of the Cataloging and Classification Section of the ALA Resources and Technical Services Division. The draft is accompanied by an explanatory comment by Paul Dunkin who claims that Lubetzky "rescues" the library profession with his code and that Lubetzky begins by restating objectives which C. A. Cutter had stated in 1876.

The objectives Lubetzky sets forth are (1) to facilitate the location of a particular publication, i.e., of a particular edition of a work, which may

232 Landau, 1958 [327], p. 65.

233 See The Library Journal, October 1956. 
be in a library, and (2) to relate and display together the editions which a library has of a given work and the works which it has for a given author. The draft of the Code contains four parts: works of personal authorship; works of corporate authorship; government publications; and works of unknown, complex, or changing authorship.

There have been important changes suggested in the rules for the Code. As of 1961 most librarians were ready to recommend use of the new rules primarily for new authors with only limited effort to be made in changing established headings, but in general there is still no agreement on rules for descriptive cataloging in a dictionary cata$\log :$ ". . . the library profession, since the appearance of the ALA revision, has not agreed on its cataloging rules." ${ }^{234}$

A booklet containing instructions for the cataloging of technical reports and related materials has been made available by an agency of the U.S. Government. This is the DDC's ASTIA Guidelines for Cataloging and Abstracting, which also contains instructions on matters other than descriptive cataloging.

Joint meetings on descriptive cataloging were held in 1963 by representatives from DDC, NASA, OTS, and the National Bureau of Standards. One result of these meetings was the Standard for $D e$ scriptive Cataloging of Technical Reports, needed for the effective retrieval of reports as reference material. Such use was hampered by the wide variety of labels and codes attached to them in great but seemingly meaningless array.

Taube in 1950 discussed the cataloging of publications of corporate authors, stating that the rules for corporate entries in the Science and Technology Project of LC began with the specification that $"$... corporations or other collective bodies of men under whatever name are to be considered and treated as authors of their official reports, proceedings, and other publications for which they are collectively responsible. . . E Enter the publications of a corporate entity under its name.

The form of the name is to be determined by information available in the work being cataloged and in authority lists from cataloging previous works and from these two sources only. The form of the entry given on the title-page or elsewhere in the work being cataloged may be modified in the entry only if a different form has already been established and is used in the cata$\log . " 235$ Such a rule relieved the cataloger from performing "research work" or searching to discover other possible and perhaps more accurate forms for entry. A third rule concerned the subdivisions of corporate bodies whose names are not suitable for entries: "If the title-page or other parts of the work being cataloged disclose that a division or part of a corporate body was respon-

234 Commerce by Taube, Conference Session II, In Markuson, $1964[372], p .58$.

235 Taube, 1950 [556], p. 15. sible for the report, entry should be made under the division or part." 236

These rules are still advocated, as suggested recently: "Any new code developed by agencies working in the report literature should at least take these trends [cataloging from the information contained in the document itself, use of name most frequently used in publications rather than official names, rejection of distinctions between types of corporate bodies and of entry under geographic location, emphasis on entry under most specific entity, etc.] into account. They are the result of a great deal of work by experienced and progressive librarians engaged in a needed reform activity, and they are undoubtedly the pattern for future international growth in this area. Any given report-processing agency might be either too small, with a custom-built system operating reasonably well, to consider any drastic changes; or it might be too big, with too much invested in existing card catalogs, tapes, indexes, etc., to consider changing. But those not in these categories, agencies just starting their activities, or those who must arrange for consistency or compatibility among various agencies, could with profit study these developments." 237

Descriptive cataloging rules concentrate on physical identification of publications; content identification also raises problems and needs principles for guidance. "Subject cataloging ... has many ramifications. It is not suggested that a tight standard be attempted but rather a general guideline standard with the requirement that subject cataloging be done in depth on each technical report. It is suggested that the professional librian of the activity originating the report set forth the subject cataloging entries in a descending order of importance as they pertain to the report. This will allow a receiving library to scan the entries and select those used in their own library subject catalog." 238

The International Conference on Cataloging Principles, sponsored by IFLA, was held in Paris in 1961. The preliminary official report of the Conference was published by the UNESCO Bulletin for Libraries (1962 [286]). The official report was published in 1963 by the International Federation of Library Associations in London and was made available in the United States in 1964 by the ALA, Chicago. Atherton, an observer attending the Conference, reports that the delegates "discussed the fundamental principles underlying the choice and form of headings and entry-words in alphabetical author-and-title catalogs. . . . The discussions about corporate authors (what works should be entered under corporate authors; form of heading for corporate authors, and subordinate bodies) showed quite clearly that it was going to be possible to have greater agreement in library

\footnotetext{
278 Ibld, p. 18.

${ }^{237}$ Brandhorst, 1964 [76], p. 42

238 Langenbeck, 1962 [329], p. 298.
} 
catalogues of the future than it could have been hoped possible." 239

Resolution IV called for the compilation by each country of lists of the names of the principal corporate bodies existing in each country, for the purpose of standardizing corporate author cataloging. ${ }^{240}$

\subsubsection{Use of Machines for Description and Identification}

There is a dearth of mechanical devices, multipurpose forms, and other means of reducing the clerical work connected with cataloging. For instance, catalogers could record most of their decisions on a dictaphone or Stenowriter. The tape typewriter, of which Mooers spoke so eloquently in England, France and Germany in the Spring of 1960 ([389]), is one tool that can be used for catalog production. The tape typewriter plan offers means for (1) improving cataloging and eliminating duplication of effort in cataloging among libraries and (2) increasing clerical efficiency in the cataloging operations now being done at each library.

The tape typewriter is described as having a keyboard whose operation causes both the characters to be imprinted on a sheet of paper placed in the machine and a perforated paper-tape record to be made of everything typed. 'The typewriter must also have a "reader" to read the perforated tape and operate the typewriter in accordance with the perforations on the tape.

Mooers states that "in a fully capable tape typewriter the letters of the alphabet, numerals, punctuation, 'capitals,' 'carriage return and line advance,' 'tabulate,' and 'backspace' are all recorded by patterns of punches in the tape." Once the paper tapes have been read into the memory of an electronic computer, "the machine can rearrange the sequence of entries making up each card, putting (for example) the author's name first. 'Then inside its electronic and magnetic memory, it can also perform an alphabetization by author's name for a large collection of cards. When these alphabetization operations are completed, the machine can then perforate a new tape which will control a typewriter to type up cards in alphabetical sequence according to the authors' names!" 241

"The basic principle which is being stressed by Mr. Mooers in his tape-typewriter plan is that any mechanical storage which is accomplished should be done in standardized machine-readable form so that the machine-readable text can be used by many persons and installations throughout the world." 242

"This plan offer's several advantages to the retrieval center and cooperating institutions in addition to the speed of manuscript transmission via paper tape. First, this machine-readable record. of the bibliography or portions thereof, will be

\footnotetext{
239 Atherton, 1961 [40], p. 583.

240 See Brandhorst. 1964 [76], p. 38

241 Mooers, 1960 [393], p. $277-281$.

243 Gull, 1962 [228], p. 58.
}

made available to cooperating documentation units and the possibility of reciprocal exchange exists. Also the preparation of edited machine-readable bibliographic entries is done once, never having to be repeated.

"The first large scale implementation on an international basis of the 'tape-typewriter plan' for cooperation between documentation centers, has been initiated between Italy and the United States. This particular application of the plan entails the transmittal of entries in an international serial current bibliography from the ... FAO ... headquarters, Rome, to the Aquatic Sciences Information Retrieval Center (ASIRC) at the University of Rhode Island." 243

Within one to two years of Mooers' announcement, Bernstein (1962 [57]) of Euratom/CETIS, Brussels, Belgium, was writing in the German Nachrichten für Dokumentation and in the UNESCO Bulletin for Libraries that generally a Flexowriter is economical under the following circumstances: (1) where a number of different documents must be processed; (2) where the documents must be processed by a routine that is invariable or only slightly variable; $(3)$ where the routine can be divided into stages for successive processing; and (4) where information from previous stages is repeated at these stages, other information added, and part of the resultant total body of information transmitted to the next processing stage.

Lipetz describes techniques and equipment for simultaneous production of manual and machineusable book cataloging records as a first step in introducing a machine record system for the book catalog at the Research Library of the Air Force Cambridge Research Laboratories, L. G. Hanscom Field, Bedford, Mass. Punched paper tape was created in the course of continued production of $3 \times 5$ inch index cards as similar as possible to those in the existing catalog. The input typing format, designed for a special-purpose computing machine, the Crossfiler, produced sets of catalog cards at less cost than the utilization of a general-purpose computer. Sets of catalog cards were obtained with identical text in the body of a card but different tracings (entries at the top of a card for title, abridged title, subject, etc.), derived automatically from the text contained in the primary punched tape. ${ }^{244}$

An example of an early investigation into mechanized documentation is the activity preceding the arrival of MEDLARS at the National Library of Medicine, the "TVelch Medical Library Indexing Project," a research program conducted by the Welch Medical Library of Johns Hopkins University and supported by the Armed Forces Medical Library through a contract between it and the University. Larkey reported (1953 [332]) that the Project began with the interest of

243 Scientific Information Notes 5, 3, 1 (1963).

${ }^{244}$ Lipetz, 1963 [343], p. 119, 121 
the Army Medical Library in the program of the Welch Library (following World War II) for training medical librarians in the necessary research aspects. The scope of the project included (1) studying the problems of indexing medical literature; (2) exploring the theory and practice of subject heading (nomenclature) and classification (coding) as they concern medical literature; and (3) exploring methods, particularly machine methods, applicable to medical bibliography, operating any pilot projects needed, and reporting on suitability of machine methods in the operation of the Army Medical Library.

Larkey reported at the 1956 [331] "Conference on the Practical Utilization of Recorded Knowledge-Present and Future" on the prospects for cooperative information processing in medicine. He suggested that until that time there had been little effective cooperative effort. In the 1920's the American Medical Association, publisher of Quarterly Cumulative Index, and the Surgeon General's Library (later Armed Forces Medical Library, and still later the National Library of Medicine), which sponsors the Index-Medicus, cooperated to compile a merger, the Quarterly Cumulative Index Medicus. In 1956 the AMA became solely responsible for the Quarterly Cumulative Index Medicus, and the Armed Forces Medical Library revived the Current List of Medical Literature, begun in 1941, destined to become the new Index Medicus.

Larkey also saw a need for "full and frank discussion as to how and why the various information aids are produced; why they select material from certain documentary sources (periodicals and other sources of information); then, in turn, why these documentary sources exist, for what purpose, and their relation to the local research effort." $245 \mathrm{He}$ identified an additional area for cooperation in the preparation of the subject indexes for the Current List or Chemical Abstracts by machine methods, with the modification of the "coding as used for the index to coding for machine searching." Larkey related that the Welch Library Indexing Project had found real possibilities on the basis of experimental runs. "Here we made use of the subject entries and subdivisions from the actual subject indexing slips for an issue of Current List. It might be advisable to code for information, as from the 'modifications,' as in Chemical Abstracts and Current List." 246

The MEDLARS project, current work on mechanized indexing at the National Library of Medicine, has already been described briefly. The subject headings published in Medical Subject Headings "are the only tags that may be used as headings in Index Medicus. . . . In effect, there is one level of indexing for Index Medicus and two levels of indexing for both demand and recurring bibliographies. ... It is anticipated that each citation will have an average of 10 tags assigned, but

245 Larkey, 1956 [331], p. 304-305.

246 Ibid, p. 306. only an average of three of these tags will be checked by the indexer as those tags under which the citation will appear in Index Medicus." 247 Other tags prepared by the indexers and never appearing in Index Medicus will include provisional headings for new descriptors, age group tags, Public Health Service support group tags, and geographical tags.

In the case of Nuclear Science Abstracts, Day and Lebow describe a procedure which began in 1959 to provide four indexes for subject, personal and corporate authors, and report number (with availability information) for each semimonthly issue of the AEC's $N S A$. "The new AEC techniques have eliminated the time consuming and costly manual operations by using speedy and economical machine operations. The new system uses equipment that is readily available and is successful through the effective adaptation and combination of the products of several manufacturers. In its simplest terms the index production system provides for : (1) typing of index entry in a prescribed area of an IBM accounting machine punch card; (2) machine coding the punch card so that the thousands of index entries can be machine sorted and arranged; (3) machine controlled photographing of the cards at a rate of 230 cards (lines) per minute; and (4) arrangement and makeup of the resultant negatives into plate negatives for photo offset printing." 248

Day and Lebow suggested that there would be no need for AEC catalog cards thereafter: "Each user of Nuclear Science Abstracts, whether at the laboratory bench or in the library, will have in effect a complete catalog to nuclear science information." 249 Sherrod, however, sees that ". . . the elimination of one requirement introduces a new requirement. Specialized bibliographies with abstracts no longer can be prepared easily by manual shingling of catalog-abstracts cards. Thus, there is a new requirement for storing abstracts in such a way that when special bibliographies are provided on request it will be a simple matter to include an abstract with each entry without going through the laborious process of retyping." 250

The AEC Division of Technical Information Extension has experimented with tape typewriters for producing technical abstracts and also with "semiautomatic indexing" from the information contained in an abstract and from a single effort in the production of that abstract for hard-copy purposes. The experiments on indexing are reported and demonstrated in RDA-3 and -4 , the Research and Development Abstracts of the US$A E C$ for July-September and October-December 1962. The reasoning of the AEC, as explained in these issues, was "that, if the title plus the abstract could be used as a source of subject headings, the depth and range of subject indexing would be con-

${ }^{247}$ National Library of Medicine, 1963 [412] b p. 9-10.

248 Day and Lebow, 1960 [161], p. 122.

249 bid, p. 127 .

250 Sherrod, 1963 [529], p. 215. 
siderably increased over that possible with $\mathrm{KWIC}$ indexing from titles only. . . . Words or phrases were underlined by the abstract editor to provide suitable subject points. These terms were then coded in tape by the Justowriter operator at the time the abstract was prepared for the journal."

The method was "devised to code or 'lock' into the tapes the various components, terms, phrases, etc., of the abstract that would produce the following indexes: (1) personal author, (2) corporate author (source), (3) subject, (4) report number, and (5) journal citation." In a paper describing the project, Sherrod concludes that the economic feasibility and other technical advantages of this method over former conventional procedures was proved: "What remains to be determined are the retrieval efficiency and/or the degree of user acceptance of this new subject index." 251

A most significant development in the area of achieving cooperation, compatibility, and convertibility by virtue of author-editor-machine collaboration in the indexing of journal articles and conference proceedings is the FASEB experimentation with machine-aided compilation and normalization of indexes. In a sense, this is the first example of a computerized authority list; in another, it is a practical application, at least in a prescriptive manner, of a mechanized thesaurus.

Schultz and Shepherd have described (1960 [512]) the use of the UNIVAC computer in scheduling the meeting of the Federation of American Societies of Experimental Biology (FASEB) in April 1960 and preparing an index for the meeting. During the summer of 1959 the $2,383 \mathrm{ab}$ stracts of the 1959 meeting were indexed; a computer was used to determine those index terms with enough specificity to classify the abstracts into groups of 10 or 12 each. 'The computer findings were then modified and rearranged to produce a list of subject categories designed to make explicit the areas of current research in experimental biology of interest to FASEB. The UNIVAC computer and other equipment were then used (1) to publish the 2,526 abstracts submitted or sponsored by members in $1960 ;(2)$ to arrange the abstracts into subject groups of 10 or 12 each for purposes of programming the meeting; (3) to schedule the sessions to avoid conflicts whenever possible; and (4) to prepare a subject index to the abstracts.

In 1963 Schultz ([509]) used a magnetic-tape thesaurus and a computer program to edit authorproduced indexing terms and phrases for the FASEB Proceedings of that year. 'The FASEB thesaurus was constructed after considerable perusal of other authority lists in the biomedical field. For input to the computer routine, there were the key-punched title to each paper to bo indexed and the indicia supplied by the author, the words thereof being marked "with the number of the document from which they originate as well as the

${ }^{251}$ Sherrod, 1963 [529], p. 215. number of the sentence or phrase and the position within the sentence or phrase." After the meaningless words were extracted from these sources, the "remaining words are resorted into their original order within each document description and all sentences and phrases are sorted into alphabetical sequence. Processing against the thesaurus is begun on a word-by-word basis for each of the sentences and phrases."

This computer program uses the thesaurus to perform four basic functions: (1) it accepts certain words without modification; (2) it recognizes certain words as being acceptable if modified, and then it modifies them; (3) it recognizes certain words as acceptable and adds other indexing terms on the basis of their presence, (thereby performing a "syndetic" function, i.e., automatically posting "see also" terms); and (4) it deletes certain nonindexable words not on the original delete list because of the possibility of their being contained in an acceptable indexing phrase.

Three other citations are of interest in the matter of application of computer techniques. Welt in speaking about indexes and index mechanization in biomedicine says, "It is now possible to provide general, shallow indexes to the entire field as well as specialized, deep indexes tailored to the needs of specialized research workers or practitioners." 252 Taube is convinced that "the design and display of terms in an authority list or 'thesaurus' to be used for both machine searching and as a guide to a published index remain to be determined. Experience may indicate that the two purposes cannot be combined and different code books of 'thesauri' may be necessary for the mechanized retrieval portion and the published portion of an information center's apparatus. It may also turn out to be the case that different types of guides and instructions are required for the indexer and searcher." 253

Weber, writing in 1957, decided in considering the quagmire of scientific literature that "the conclusion to be drawn is that the use of machines for storage and retrieval of information is likely to be practicable only through a man-machine partnership, and is not going to be commonly feasible for many years to come." ${ }^{254}$ He says specifically concerning indexes that "it is logical to expect that a great increase in extremely brief subject entries, arranged in chronological order, will characterize the future subject indexes to scientific materialwith the older material being indexed merely by an author file, and with subject cards thrown out after a period of time." 255

Machine use in the generation of assignment indexes implies requirements for compatibility and convertibility for mutual agreement as to contents and scope of commonly used technical thesauri or mechanized authority lists; mutually agreed upon

\footnotetext{
252 Welt, 1963 [641], p. 173.

253 Taube, 1963 [558], p. 179.

254 Weber, 1957 [631], p. 106.

255 Ibid, p. 118.
} 
listings of equivalent index term vocabularies for interconversion, one system to another; and specific identification of format, field designators, and coding practice if all machine-usable records are to be interchanged.

"For automatic indexing, statistical methods based on frequency of words in documents are being investigated. Similar procedures are also being tested in the production of 'automatic abstracts.' The effectiveness of such procedures in selecting the significant portions of scientific papers has yet to be demonstrated. . . . Further research is needed to determine whether automatic indexing and abstracting procedures and normalized languages will be of practical use in storage and retrieval systems." 256

\subsection{Systematization and Terminology Control}

Enforcement of both lexical and syntactic regularities in indexing vocabularies and documentary languages requires either compatibility or convertibility if processed materials are to be exchanged between two or more systems. In addition, compatibility or convertibility within a single system is required if the searcher or user is to be freed from rigid adherence to the prior indexing rules and language.

Two rather comprehensive examples of such documentary languages are the Western Reserve semantic code and telegraphic abstract system and SYNTOL (Syntagmatic Organization of Language). In both these cases, some consideration has already been given to mechanized procedures for automatic conversion from ordinary language to the system language. Convertibility between the language of search requests and the selection indicia within these systems is achieved by consistent application of the translation rules both to the language of the requests and to that of the items stored. That is, a translation is made from ordinary words in natural language text to regularized words or terms in a documentary language.

Standardized, or mutually agreed upon, vocabularies at a variety of levels are required: (1) at the level of code representation of characters in machine language: number of characters accommodated by code, which characters are accommodated by code; (2) at the level of characters acceptable as input: size of allowable vocabulary, what characters; provision for other characters as required for multiple-coding, shift keys, etc.; (3) at the level of characters acceptable as output; (4) at the level of indexing vocabulary or documentary language; (5) at the level of aids, e.g. wordlists, thesauri, dictionaries, stop lists, and the like, and (6) at the level of internal processing of character strings: fixed versus variable word length, fixed versus variable field length, fixed versus variable record length, and fixed or variable file length.

${ }^{250}$ U.S. Senate, 1960 [592], p. 105.
Next, and more crucial, is the level of the docu. mentary language itself "There is no doubt that, if rational methods of automatic information retrieval are to be established, a study of the linguistic structure of documents from which the information is to be drawn cannot be neglectedregardless of the particular method used. Furthermore, one of the problems which documentation must certainly solve in the future (and perhaps its most important problem) would seem to be that of devising a rational 'documentary language' standardized on an international scale." ${ }^{257}$

Even though such study of linguistic structure seems necessary, "there have been relatively few studies of principles of organizing or classifying knowledge systematically and few attempts to devise better systematic organization irrespective of the techniques (manual or mechanized) subsequently used in processing information." 258 There have been developed, however, ". . . a certain number of rather general practical procedures, resulting from common requirements and conditions which are imposed upon them by characteristics peculiar to the new 'machines' (this term is here used in its broadest sense) for the retrieval of documents and the information contained therein. Such were, for example: the breakdown of complex subjects into simple factors (or, at least, less complex) ; the transition from highly hierarchical classification systems to less hierarchical systems; the realization of the necessity of expressing not only the elementary terms used in the analysis of documents, but also the relations between them." 259

Early experiments with such developments are found in the work of Perry, Berry, and Kent. The capability for using hand-sorted marginpunched cards for small collections of information had been reported in 1945 by Cox, Bailey, and Casey ([145]). In 1946 the Board of Directors of the American Chemical Society set up a Committee on Punched Cards with James W. Perry, then a library fellow at the Massachusetts Institute of Technology, as head. In 1947, a modest sum was obtained from industry to continue the investigation. Following the expiration of the ACS grants, the support of the activity was taken over by the MIT Center for Scientific Aids to Learning, with the aid of a grant from the Carnegie Corporation, Perry continued as chairman of the renamed ACS Committee on Scientific Aids to Literature Searching and at this time he and G. Malcolm Dyson approached Thomas J. Watson, Sr., president of IBM, suggesting the development of machines suitable for searching literature.

H. P. Luhn, of IBM's engineering laboratory, then proposed sending the standard IBM punched card through a machine end wise, devising a punch code by which any information could be punched in any of the 80 vertical columns, and using photoelectric scanning and the principle of comple-

\footnotetext{
257 de Groller, 1962 [170], p. 144.

258 U.S. Senate, 1960 [592], p. 103-104.

${ }^{250}$ de Grolier, 1962 [170], p. 10.
} 
mentary pattern matching: To look for a given piece of information, "the complement of its codea 7-hole pattern-is punched in a question card. The question card is mounted in the scanning machine so that the cards to be examined pass between it and the photoelectric cell. When a match is made, no light passes, and the punched card is kicked out." 260

Perry and his associates then began work to develop a machine language for literature searching (1956 [455]). They centered their attention on the semantic aspects of machine searching, concluding that the analysis of index terminology could be incorporated into a code dictionary since the semantic significance of most words for scientific and technical indexing remains reasonably invariant in different contexts. Perry and his associates arrived at the concept of semantic factoring where words are examined for their semantic components. (A colorimeter is a machine for analysis with color, so its code designation must refer to all these factors.) Perry also developed "role indicators" whereby there is affixed to the codes for various terms special symbols for designating the function or role. In this way distinction between initial reactants, final products, and conditioning agents is possible by preceding their code designations by $\mathrm{S}, \mathrm{F}$, and $\mathrm{K}$, respectively.

These investigators proposed four steps for processing information for search by automatic equipment: (1) underlining keywords and phrases or supplying marginal notations to designate important aspects of a subject; (2) editing the underlined or annotated words or phrases to produce an "abstract" of unusual literary style which, however, is intelligible before encoding; (3) encoding the edited abstract with the aid of the code dictionary; and (4) recording the encoded abstract by means of a card punch. The fourth step may be eliminated when encoding will be accomplished with an automatic, key-punching dictionary.

The general approaches to standardized languages or vocabularies for information systems are concerned with thesaurus development, with classification schemes, and with interchange of indexing languages. We shall examine these in turn.

\subsubsection{Thesauri}

The potentialities of thesaurus-aided systems for indexing, abstracting, storing, selecting, and retrieving pose both new requirements for cooperation, compatibility, and convertibility, and new opportunities in each of these areas. For the most part, the early proposals for a thesaurus-type approach to mechanized documentation envisioned manual compilation and preparation and manual scanning for either indexing or searching purposes. It was quite generally assumed that major cooperative efforts between representative users and subject matter specialists would be required to

260 "New Tools for the Resurrection of Knowledge," 1954 $[423]$, p. 867 . organize such tools. More recently, it has been suggested that machines can be used to assist in construction, and updating or reorganization, and to provide an "early-warning" system with respect to changing terminology or to changes of subject interest in a collection.

Examples are "words not found in the dictionary would be noted by the machine during the encoding process and spelled out for subsequent manual editing. This would involve the assignment of a notional family or families to the new word and its addition to the index. As a matter of course, each new document would also be submitted to a search operation to discover duplications, variations, and contradictions with respect to previously stored documents. This search would also serve to obtain a measure of the discriminatory characteristics of the system as the collection grows." 261

"If it is assumed that the documents in a typical technical library reflect the purpose of the library reasonably well, then it is logical to allow these documents to generate both the indexing dictionary and the thesaurus. One way of doing this is to prepare a word-association matrix of the type developed by the Integrated Engineering Control Study of DuPont. This is essentially a list of associated terms statistically generated from the documents in the DuPont store. It is primarily a thesaurus used as a word-reminder list, but tends also to generate connotative definition of words in the sense that two words almost always found in the same document reflect on the meaning of each other." 262

"Use of a thesaurus in editing the input data for the index is an optional feature of the generalized indexing technique ... Once the thesaurus has been constituted, it is convenient to use it as a means of proofreading the input descriptors. Thus, every descriptor not appearing in the thesaurus (and therefore not recognized by the indexing system) is put out for human inspection. Discrepancies ... may be either mispellings . . . or new descriptors not yet recognized." 263

Even in the early proposals for thesaurus use in documentation a number of aspects likely to involve machine considerations of compatibility and convertibility were raised. Some illustrative examples are as follows: ". . . It is reasonable to think that the further we can go in routinizing and mechanizing the techniques of translating ordinary language into a regularized language and of coding for machine manipulation, the more will we be likely to achieve economically feasible machine searching on a large scale ... [Some investigators] have come up with the thought that the best answer ... may be the application of a mechanized thesaurus based on networks of related meanings." 264

${ }_{261}$ Luhn, 1957 [360], p. 316

202 Lockheed Aircraft Corp., 1959 [348], p. 34-35.

203 Schultz and Schwartz, 1963 [511], p. 422.

204 Brownson, 1957 [83], p. 99-100. 
"Indexers and searchers have in the past got along" without such a tool-or, rather, each has used the network of word associations in his own mind, aided perhaps by a dictionary, as a personal thesaurus. It is in contemplating the possible mechanization of indexing that the need for this tool has been recognized. Passage from text-words to key-words can be achieved by machine only if such word associations have been previously stored in its memory." 265

The question of where and when the use of a thesaurus-type device to provide greater vocabulary compatibility or convertibility was first proposed, and by whom, is an elusive one. Vickery writing in 1960 [614] on "thesaurus" as a new word in documentation, discusses prior usage by Brownson (1957 [84], Luhn 1957 [360], 1959 [352]), Bernier and Heumann (1957 [56]), and Taube (1955 [561]), the latter for the idea of both indexers and searchers referring to word-association lists. Vickery further discusses usage of the word by Americans, ignoring the emphasis in the Cambridge Language Research Unit on thesauruslike approaches to both mechanized translation and information retrieval from at least as early as 1956 onward. ${ }^{265 a}$

T. M. Williams in a private communication to H. L. Biownson dated August 2, 1961, cited her own use of the word in the Avion report of November 1956 (Williams, 1956 [648]) and of less formal usage both in oral presentations and in correspondence with Bernier during 1953-54. Williams also notes that Bernier may well have implied the functional concept, although without the use of the specific term, in unpublished papers given in 1953 and 1948 .

Luhn is credited by de Grolier with having advocated, at least as early as 1951, a thesaurus method: ". . The process of 'broadening the concept' which he described was linked, in an interesting manner, to research strategy, and he proposed the compilation of a dictionary of notions where each of the specific terms not retained for indexing would appear under as many headings as necessary to represent it by the different 'key terms' where it would thus be indexed. Such a dictionary is very similar, in fact, to the Thesaurus of English Words and Phrases by Peter Mark Roget ... and since that time it has been the custom to refer to the thesaurus method." 266

In November 1951, Mooers issued his Zator Technical Bulletin Number 65 (1951 [394]), noting in the preface that it was substantially the same as a paper informally circulated to members of the Punched Card Committee of the American Chemical Society in February 1947. In it, he states: "To surmount this problem of alternative expression, there must be a word book or encyclo-

\footnotetext{
205 Vickery, 1960 [619], p. 183.

255a Masterman, 1956 , $\left.\mathrm{p}_{4} \mathbf{1}_{4}\right]$ and Parker-Rhodes, 1956 [446]. 260 de Grolier, 1962 [170], p. 109, 187-188 cites Luhn (1953 [358]) as having first appeared as Appendix I (dated 10 Sep

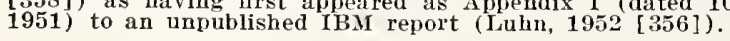

pedic source of volcabulary having features common to a thesaurus, a dictionary, and an encyclopedia." 267

Finally, in addition to these "anteriorities" of discussions of proposed thesaurus-type functions without the use of the term and of linkages of the term to proposed functions, a reference appeared in 1954, in Appendix III of the Bush Committee Report: "Then there might be a large index and cross-reference file, adaptable to frequent addition, revision and reorganization. This file should be capable of rapid data processing and access. It might include a thesaurus so that the processing machine itself can translate search inquiries from a variety of sources into a standardized machine language, and so that changing terminology may be readily incorporated into the search and retrieval procedure." 268

The term "thesaurus" has also been applied to the somewhat narrower concept of an authority list incorporating syndetic devices including "generic to" or "specific to" cross-references. Such tools are provided by $\mathrm{AIChE}$, by DDC, and by EJC, in their respective thesauri.

"Probably the most outstanding [of the solutions developed for control of synonyms] is the thesaurus approach, which has been very successfully used by Dr. Fred Whaley at Linde Air Products Laboratories ... and by the Engineering Information Center in . . . the DuPont company. Thesauri may be created in several ways, one of which is the Committee approach to consideration of vocabulary, a typical product of which is identification and definition of synonyms and nearsynonyms ... The thesaurus approach can solve the problem of generics as well as the problems of viewpoint and semantics. The indexer can refer to his thesaurus for the terms he has selected and from the appropriate lists under each term, select those associated terms which refer to generically higher concepts appropriate for indexing the information more broadly." 269

Wall wrote about "information retrieval thesauri" under the sponsorship of the Engineers Joint Council in 1962, saying that such referents as a thesaurus for information retrieval and Roget's international thesaurus serve their users "for similar immediate purposes and in approximately similar fashions. Both users wish to identify terms 'related' in some manner to a term or terms they have already thought of. Both users look up alphabetically the terms already in mind.

Each user observes that some of the related terms found are of interest to him at the moment and some are not. Each user may use some related terms which are of interest to him as 're-entry'

\footnotetext{
207 Mooers, 1951 [394], p. 14

268 U.S. Department of Commerce, 1954 [596], p. 63. It should be reported, however, that Stevens when compiling material for this Appendix had access to both the Mooers 1951 Bulletin [394] and to the Luhn 1952 report [356] the latter having been included in the list of selected references, p. 76 .

269 Costello, 1961 [138], p. 22-23.
} 
points in his thesaurus to find other terms of interest." ${ }^{270} \mathrm{He}$ wrote again about an information retrieval thesaurus, that "it must certainly list the terms of the system vocabulary. It must exhibit relationships among these terms ... relationships such as synonymy, hierarchy, and relationships which may indicate synonymy or hierarchy from some points-of-view but not generally. It should define the vocabulary terms to the extent required." 271

Herner, writing about the possibilities for convergence of word and concept indexing through the intermediary of the thesaurus, expresses the hope "that designers and users of indexing vocabularies will recognize this-if they haven't already - as a very basic purpose for thesauri, subject authorities, indexing dictionaries, or whatever name we give them." He gives examples where "thesauri and similar indexing authorities have been used as means of converting words or symbols and groups of words or symbols into concepts." 272 This, then, is the general setting for the current usage of the term in this country and by some of the agencies of the U.S. Government.

Taube suggests that ASTIA and "several other organizations and individuals have continued to insist that in 'thesauri' there are provided structures of connections between words which are necessary to ensure satisfactory operation of mechanized systems of coordinate indexing." He then asks, "Is a thesaurus or any authority list an independent semantic standard for an indexing system set up by a process of lexicography, or is it a description of a particular indexing system as developed from a concatenation of subject competence, the literature being indexed, and the requirements for efficient machine search?" 273

Taube claims "that a cross reference structure of any complexity can be derived from, and need not be prescribed for, any given indexing system. Further, if . . a descriptive structure contains cross references which reflect the extensive relation of classes of items rather than prescriptive semantic relations of terms, there is no real problem of compatibility between descriptive systems." 274

He suggests further that for revising its first thesaurus ASTIA should have printed out the terms and postings recorded during the indexing operation following the appearance of the edition. From this document there could "be derived all necessary 'see' references and references to indicate the inclusion of one class in another. For studying the relations which are basic to 'see also' references, it is necessary to have a printout of the tracings. If any two terms have identical postings, a 'see also' reference from one to the other is redundant and wasteful. In such a case, one set of

\footnotetext{
${ }^{270} \mathrm{~W}$ all, 1962 [623], p. 7.

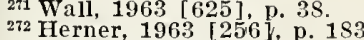

272 Herner, 1963 [256], p. 183.
273 Taube, 1963 [558], p. 177.

273 Taube, 1963
274 Ibid, p. 178 .
}

postings should be eliminated and a 'see' reference substituted for the 'see also' reference." 275

A final interesting comment is that of Cleverdon and Mills: "Work on thesauri and classifications, where it has been practical in nature, appears to consist of compiling lists of terms which go out of favor as quickly as any list of subject headings in the past ...." 276

Turning now to established thesauri, we note first the ASTIA thesauri. Heald states that the purpose of Project MARS ( $M A$ chine Retrieval System) was to prepare a thesaurus of scientific descriptors from the 70,000 ASTIA subject headings and to assign descriptors to all $\mathrm{AD}$-numbered reports in the ASTIA collection. ${ }^{277}$ The subject headings in the 1959 volume were divorced from their subdivisions, about 150 subdivisions were eliminated, and some subdivisions were included "in other headings as synonymous or definitive terms." 278 The almost 7,000 descriptors were "divided into a number of generic groups for display purposes. Hence, the full scope of the subject coverage is divided into about 290 = major categories." 279

Slamecka comments on the grouping of indexing terms: "Classification may be exhibited in a thesaurus in two ways; through relationships . . . among terms and through grouping terms into categories. The latter device is very helpful if the indexing environment is very broad, as it is in the subject field interests of AS'TIA." ${ }^{280}$ "The number of "descriptor groups" in the first ASTIA Thesaurus is actually 292, and we shall see that they have been used in experimentation for converting one indexing language into another. The first edition of the ASTIA Thesaurus was revised in late 1961 and 1962 under a contract between the Engineer's Joint Council and ASTIA, the second edition appearing in December 1962. Of interest here are the experiences of a worker with the first edition.

Hicks reported her experiences with government-sponsored research reports in areas of physical chemistry to the Division of Chemical Literature of the American Chemical Society in May 1962. One of her searches was on the Dissociation and recombination kinetics of hydrogen, the halogens, and the hydrogen hatides. Machine searches at ASTIA headquarters yielded 82 pertinent ASTLA reports. Manual search was made of the subject files in the AS'TIA Los Angeles

\footnotetext{
${ }_{275}$ Taube, 1963 [558], p. 179. Note that in the chemical engineering thesaurus (to be discussed below in the section on AlChE and EJC thesauri), the terminology " $R T$ " for related terms is used instead of "see also." Taube (Ibid. p. 180) re marks that "Even authority lists for manual catalogs have difficulty with 'see also' references unless they are restricted to references from general to more specific classes; and what emerges from this analysis is the thesis that the notion of 'related term' as an explanation of 'sec also' references is too vague to be significant either to the indexer or the scarcher in a mechanized system.

276 Cleverdon, 1962 [124], p. 1.

${ }^{277}$ Heald, 1960 [243], p. 117.

$2 \pi s$ Ibid.

${ }^{279}$ Ibid, p. 119

280 Slamecka, 1963 [534], p. 227.
} 
Regional Office for reports from 1953 to the end of 1959, and selected sections were examined page by page. By manual searching, 242 reports were found. Three reasons were ascribed for the disparity in the number of items found: "(1) inaccuracies and insufficient depth of indexing at ASTIA; (2) manual location of relevant reports which we had not anticipated finding and which we had not asked the machine to find; (3) less than optimum prescription of retrieval terms on our part." 281

Hicks' second example was Vacuum ultraviolet photolysis of organic compounds. She manually searched $T A B$ for $1960-1961$, finding 23 reports on vacuum ultraviolet photolysis of various compounds. She comments that it was apparent "that the easiest way to assuring nearly complete retrieval of these reports would be to prescribe one descriptor only, Photolysis, requiring manual screening of at least 112 cards or examination of at least four times as many cards as those found pertinent. Because of underassignment of terms, complete retrieval of these 23 reports would require programming for all reports assigned Photolysis, plus all of the reports assigned Ultraviolet radiation but not Photolysis, plus all of the reports assigned Photochemical reactions but not Photolysis or Ultraviolet radiation. The percentage of irrelevant information would be quite high." 282

The First Revision of the Thesaurus of ASTIA Descriptors, written by Eugene Wall and issued by ASTIA August 6, 1962 [622], is the final report on the contract between ASTIA and the Engineers Joint Council (EJC). This report states that the purpose of the revision was "to create for ASTIA an improved indexing and retrieval authority, based upon Edition I of the Thesaurus, and to insure that this authority would be as useful as possible to organizations other than ASTIA." 283 The descriptors in the first edition were reviewed for deletion or addition, "for elimination of synonymous terms, for provision of extensive crossreferencing, for addition of scope notes to those descriptors needing such treatment, and for assignment of descriptors to subject-matter fields-ofinterest. To achieve compatibility with other operating systems, it was necessary to call on the advice of dozens of other systems operators and subject-matter specialists . . . ." ${ }^{284}$

The greater portion of the second ASTIA Thesaums is the scope note index, which lists the descriptors and use references in alphabetical order. The indexing terms or descriptors are again arranged into descriptor groups, now reduced to 170 in number, which are themselves arranged into descriptor fields (increased in number from 19 to 26 ) covering the $\mathrm{AD}$ collection in terms of subject matter disciplines. A new feature is the display of generic relationships for

\footnotetext{
281 Hicks, 1963 [260], p. 145.

282 Hicks, 1963 [260], p. 146

${ }^{283}$ Wall, $1962[622]$, p. 1.

284 Ibid.
}

some descriptors in terms of "specific to" and "generic to" entries.

The ASTIA Chemical Thesaurus, a supplement to the Thesaurus of ASTIA Descriptors, second edition, has fragment descriptors and specific guidelines for indexing organic compounds. The fragment descriptors designate the functional groups and the substituted groups, radicals, or ions of the molecular structure of the compound. The reasoning of the editors was that compounds such as drugs, biologicals, enzymes, and vitamins should be indexed by these appropriate terms when their chemical structure was not under study. The introduction to the chemical thesaurus states that the system is intended to entail "coding the chemical structures in a given document into one code format without the use of links, interfixes, or other devices for keeping the information separated. Thus, when chemical structures are composited, a new structure that contains all of the characteristics of the individual compounds appearing in the document is generated within the code sheet." 285

By November 15, 1963, eleven "microthesauri" had been compiled by ASTIA-DDC in the following subject areas: biological warfare, bionics, chemical rocket propulsion systems, masers, microbiology, physical oceanography, psychophysiology, radiobiology, refractory metals, semiconductor devices, and ultraviolet and infrared detection. These were compiled in order to allow more detailed categorization of information than permitted by the regular Thesaurus. In order to make these microthesauri have "general acceptability and compatibility" contributions and criticisms from experts outside ASTIA were requested. DDC is currently making possible (as of October 1963) rapid telephone search service in these disciplines to organizations having an approved Field-of-Interest Register (FOIR) at DDC.

An early effort by a professional organization to compile thesauri has made considerable impact. The first part of the Chemical Engineering Thesaurus, published by the American Institute of Chemical Engineers (AIChE) in 1961 as "a wordbook for use with the concept coordination system of information storage and retrieval" ([18]), lists terms of a chemical engineering nature, and the second part lists purely chemical terms.

The Chemical Engineering Thesaurus was developed from one originally prepared by the Engineering Dept. of E. I. du Pont de Nemours \& Co. Each term of the thesaurus was reviewed for generic relationships and semantics, as well as its suitability for inclusion, by a subcommittee of the AIChE Standards Committee.

The types of references used under the terms are different. For example, since ethyl alcohol is not a term in the thesaurus, it is merely listed alphabetically in the second part as Ethyl alcohol see Ethanol. Under Ethanol there are two notations:

${ }^{285}$ Defense Documentation Center, 1962 [162], p. 1. 
SF Ethyl alcohol (meaning that the person perusing Ethyl alcohol has been told to see (seen from) Ethanol) and PO Alcohols (meaning that Ethanol has been "posted onto" the term Alcohols, thereby causing the latter to bear the notation $G T$ Ethanol). This indicates that Alcohols are "generic to" Ethanol and a great many other alcohols, that to be truly all inclusive any document having information on ethanol may be regarded as having information on alcohols as well. Another notation is RT, applied to "terms which have a similar meaning or a frequent association with the main term, but which are not strict generics or synonyms ..."286 meaning that they are "Related Terms." For example, Flameproofing has two RT listings under it, Protection and Safety. Under Protection, similarly, there is the reference $R T$ Flameproofing but not RT Safety, while Safety has RT's to both Flameproofing and Protection. These "related terms" are similar to "see also" terms.

As partial explanatory text to the Chemical Engineering Thesaurus there are included two articles reprinted from the May and June 1961 issues of the periodical Chemical Engineering Progress; Morse states that these issues "will form the AIChE Information Retrieval Standards . . . ." 287 Morse also illustrates the use of keywords and catalog cards in concept coordination and the application of links and roles. He states that "numerals (links) define groups of key words that were linked with one another in the original article.... The letters (roles) after each key word designate a code implying the way the key words were used - that is, the role of the key word in the original article," ${ }^{288}$ for example, whether a specific chemical was used as a raw material, catalyst, intermediate, or product.

Holm in the June 1961 Chemical Engineering Progress gives a "how-to-do-it" explanation of the program initiated that month by the AIChE. The program was for retrieving technical literature in a publication where each technical article published was accompanied by both an abstract and key words supplied by the author. He considers that use of this system will be helpful to three types of users: the individual chemical engineer who needs a small personal file of minimum complexity; the medium-size organization with broader interests; and the large organization serving many people with wide interests. ${ }^{289}$

Theso activities of the $\mathrm{AIChE}$ led to the EJC sponsorship of a symposium in New York City in January 1962. The purpose of the symposium was to consider how the engineer might improve his ability to retrieve recorded information. The proceedings of that symposium contain addresses on (1) the size of the problem of storing and retrieving technical information, (2) the technology

\footnotetext{
${ }^{286}$ American Institute of Chemical Engineers, 1961 [18], p. II. 283 Morse, 1961 [399], p. 58 .

288 Ibid, p. $57-58$.

280 Holm, 1961 [268], p. 76-77.
}

used to attack the problem, (3) working systems for retrieval, and (4) a two-part "action plan" for tho abstracting and indexing of technical articles and books of lasting value concomitantly with their publication, and the creation of a single "Thesaurus of Engineering Terminology" for all branches of engineering. The "EJC Action Plan" stated that the cost for creating this thesaurus "will be relatively small because of the work already done on the Chemical Engineering Thesaurus and the steps already taken to insure compatibility with the new ASTIA Thesaurus." 290

The EJC was given a grant by the National Science Foundation under which Eugene Wall, as Director of Information Services, conducted a "study of engineering terminology and relationships among engineering terms." The final report on the EJC study (August 1963, [186]) noted 18 contributors who responded to the request made to the national professional engineering societies and other organizations, "to submit any subject heading lists, thesauri, glossaries, or any other item lists which they employ as indexing anthorities or which they consider useful for that purpose. ... These eighteen contributors submitted about 119,000 terms, of which 87,550 were "unique." 291

The EJC Engineering Terminology Study Committee of 131 members, dividing itself into ten subcommittees, gave volunteer and detailed assistance in the research effort. "Twenty-seven subcommittee meetings were held, full-time for one week per meeting; 130 man-weeks of volunteer assistance were provided by the subcommittees ... A total of about 10,500 terms were treated during this period. A 1000 term sample of this proposed vocabulary was analyzed and from the results of the analysis, the following conclusions are drawn: (1) The investigational procedures used during the study were appropriate. (2) Overlap of term usage within the engineering profession is significant $(74 \%)$. (3). Ambiguities in term meanings within the engineering profession are fairly frequent ( $8 \%$ ), but are easily resolved. (4) Most terms of any major degree of interest to even one portion of the engineering profession have been detected and considered. (5) It is feasible to provide a unified vocabulary for use by the entire engineering profession." 292

The Medical and Mealth Related Sciences Thesaurus, issued in March 1963 by the Division of Research Grants of the National Institutes of Health, was developed during 1960-62 simultaneously with the preparation of the initial annual Research Grants Index, a subject-matter index of research projects supported by the Public Health Service. This thesaurus has 12,200 terms and groups of related categories of information as convenient broad access points for related concepts.

\footnotetext{
290 Ibid. p. 76 .

291 Engineers Joint Council, 1963 [186], p. 2-3.

292 Engineers Joint Council, 1963 [186], p. 1.
} 
The groupings include (1) subheadings of three general kinds, subordinates of body systems or functional units of body systems, terms for commonly accepted functional attributes, and taxonomic terms for collecting related information although the taxonomic arrangement is nonhierarchial; (2) alphabetical groupings for "tied terms" of related data, for example, Radiolabeled arsenic and Radiolabeled carbon instead of the more exact Radio-arsenic labeled and Radiocarbon labeled, respectively; and (3) indication by cross reference, rather than subheading, for the relationship of terms which would constitute an arbitrary grouping. For example, Epinephrins is made a main term with cross references to it from both Sympathomimetic agents and Catecholamines, rather than having these terms grouped arbitrarily under drugs.

The National Library of Medicine issued the second edition of Medical Subject Headings, as part of its January 1963 Index Medicus; the subject headings include the main headings and cross references used in Index Medicus and the National Library of Medicine catalog. Although the volume is not termed a thesaurus, it contains a total of some 5,700 "descriptors", Another listing of these descriptors by 13 categories is appended, the categorization of terms being intended "as an ordering of terms to suggest relationships, not as an official classification...." ${ }^{293}$ Each subcategory list is preceded by a group of major generic headings under which most of the terms within the category will fall; they serve as guides to the materials in the list.

Two thesauri were prepared in late 1963 by other U.S. Government agencies. The Bureau of Reclamation in Denver prepared the tentative edition of its Thesaurus of Descriptors: $A$ List of Keywords and Cross-references for Indexing and Retrieving the Literature of Water Resources Development in October 1963. Camp ([599]) of the Technical Library of the Bureau of Ships completed the compilation of a Thesaurus of Descriptive Terms and Code Book for the Bureau in December 1963. The Bureau of Reclamation Thesaurus of Descriptors is presented in three parts. Part $I$ is an alphabetical list of descriptors and "use references", which constitute the main indexing and retrieval tool. Part II gives first a listing of 47 descriptor groups, arranged alphabetically, with indication of that descriptor "field" to which each group belongs, and then gives a listing of the descriptor's pertaining to each group. Part III lists the six descriptor fields and then the descriptor groups pertaining to each field. These fields are civil engineering; earth sciences and agriculture; electrical, mechanical, and industrial engineering; materials engineering; physical, chemical, and biological sciences; and social sciences and miscellaneous.

${ }^{293}$ National Library of Medicine, 1963 [411], p. vi.
The Thesaurus of the Bureau of Ships was developed for use in conjunction with Project SHARP (SHip Analysis and Retrieval Project), a cooperative project between the Technical Library and the Applied Mathematics Laboratory of the David Taylor Model Basin for the design and testing of an automated information storage and retrieval system for the Library's collection of 170,000 reports, using the IBM 7090 and 1401 computer facilities at the Laboratory. This thesaurus is "a word-association list generically structured to enable indexer's and subject analysts to describe the subject information of a document to the desired level of generality or specificity at input, and to permit searchers to describe in mutually precise terms the information required at output. It is a flexible authority list for vocabulary control with provision for the use of terms in combination, for concept coordination, in contrast to standard library subject heading lists which do not permit this degree of flexibility." ${ }^{294}$ "The method of indexing of the EJC was used for "facilitating the formal manipulation of document descriptions and queries by computer." 295

Finally, we reemphasize the reported close kinship between the modern thesauri and the more traditional subject authority lists. Thus, "One of the keystones of the entire [MEDLARS] system is the subject heading authority list, Medical $S u b$ ject IIeadings .... the 1st edition ... was carefully compiled in $1959 \ldots$. . to prepare for the computerized retrieval system, the full scale revision of this list was initiated. The huge task of converting 4400 main headings and sixty-seven standard topical subheadings contained in the 1959 list into a 5700 main heading system with no topical subheadings was completed in October 1962 and published in January 1963. The cross-reference structure was augmented by a completely categorized arrangement of the main headings in addition to the purely alphabetically ordered listing." 296

\subsubsection{Classification Schemes}

The search for a systematic classification of all knowledge has had a venerable but erratic history, reaching back at least to the Aristotelian categories. Vickery indicates that the "subsequent history of classification has been the attempt to find a new rational system of the sciences to replace that of Aristotle. . . ." ${ }^{297}$ He points out, however, that "history presents a series of cultural epochs. Each is a span of years within which knowledge presents a more or less unified structure which can be expressed in a classification, but each new epoch requires a new classification ... Indeed, the better fitted a classification

\footnotetext{
204 Bureau of Ships, 1963 [600], p. vi-vii.

295 Ibid, p. iil.

296 Taine, 1964 [552], p. 123

297 Vickery, 1959 [610], p. 159.
} 
is to a given epoch, the less suitable will it be for any other epoch." 298

Similarly, Shera suggests that: "Even a cursory examination of the history of the classification of the sciences emphasizes the extent to which any attempt to organize knowledge is conditioned by the social epistemology of the age in which it was produced. This dependence of classification theory upon the state of the sociology of knowledge will doubtless be even more strongly confirmed in the future. . . ." 299

Pings is among those who are convinced that universal classification is untenable because each science or discipline develops its own ways of understanding the elements of that discipline, and that to generalize a method for covering all sciences or disciplines would lead to confusion of terminology and ideas. He states: "A standardized vocabulary can only be a universal classification scheme if both the subject content and the language are dead. It is quite possible that all the knowledge and events of the Roman Empire could be classified in Latin. The significant and erroneous knowledge of these centuries found its way into the language. The efforts of bibliographers to standardize language only compounds the natural property of language to keep pace with the experiences of man." 300

Nevertheless, since at least the seventeenth century and earlier, general purpose or universal purpose classification schemes have been developed and applied to problems of bibliographic control and to the ordering of books and documents on shelves. Early examples are cited by Shera as follows: "Bacon's scheme influenced the early classification system of the Bodleian Library. Thomas Jefferson founded upon it the classification for his own books and from this it was absorbed into the plan of book arrangement at the Library of Congress, where it was employed, with modifications, for almost a century. In inverted form it was used by William T. Harris, from whom Melvil Dewey took it for his own Decimal system. ... The classification devised by Konrad Gesner for the organization of his Pandectarium sive partitionum universalium, [was] considered by Edwards to be the first bibliographic system, and certainly the greatest early attempt to relate the subject arrangement of books to the educational and scientific consensus of the day." 301

In this section we shall consider some of the major schemes that have been devised since the middle of the nineteenth century and that use a numeric or alphabetic notation for the classified organization of information.

The decimal classification of Melvil Dewey, first published in 1876, has had a marked influence on schemes for classifying books and is used by most of the public libraries in this country. The 1951

\footnotetext{
298 Ibid, p. 158.

299 Shera, 1951 [523], p. 82.

800 Pings, 1960 [458], p. 12

30 Shera, 1951 [523], p. 74, 75. 76.
}

edition of the Dewey Decimal Classification, the 15th, was compiled within the Library of Congress, to be succeeded by the 16th edition published by the Lake Placid Club in 1958 (Dewey 1958 [174]). Besides its extensive use in public libraries, the Dewey Decimal Classification has served as the basis for the Universal Decimal Classification (UDC) which has become the widely used European classification for libraries and for denoting the subject categories of articles in scientific periodicals. Because of its acceptance in many areas as a common classification language and because it is has been established and is maintained as an international cooperative effort, the UDC will be discussed in more detail below. First, however, we will consider briefly other approaches to universal or general purpose classification systems.

C. A. Cutter compiled a series of seven successive classification schemes, each an expansion of the other. Cutter did not approve of the notation or order of Dewey's classification and worked out a new order which he claimed to be evolutionary within its divisions and which used for notation the letters of the alphabet and numbers one to nine. An outline was published in 1879. When the $E_{x}$ pansive Classification, Part I: The First Six Classifications, 1891-1893, appeared, it was designed for collections of every size "from the village library in its earliest stages to the national library with a million books." The LC classification was influenced considerably by Cutter's work.

Cutter also published his Table, alphabetical order schemes consisting of decimal numbers so constructed that they may be combined with initial letter or letters of surname or words, thereby supplying an alphabetical method for arranging items in a file and books on the shelves by the names of the author or originator. The Cutter numbers, or some variant thereof, are used extensively today. The best known of these variants is the Library of Congress Classification. "Starting in 1901, the classification system of the Library of Congress (LC) began to appear .... This is a system of traditional type; it is entirely enumerative, and it would be useless to seek therein an expression of general categories: Specific subjects only will be found. Fundamentally, it is, after an interval of two centuries and a half, an undertaking very similar to that of the great librarians of the Bibliotheque Mazarine, and later those of the Royal Library in Paris, i.e., a careful and detailed arrangement of the greatest collection of books in the world, on the basis of groupings of the latter, let us say by affinities." ${ }^{302}$

Landau records that "Dr. Herbert Putnam was appointed Librarian [of Congress] in 1899 and brought to fruition the gigantic task of arranging a great national library according to a modern classification. It is doubtful if such a project

${ }^{302}$ de Grolier, 1962 [170], p. 43 . 
can ever be completed .... Thus, the [LC Classification] scheme itself, while most scholarly in detail, does not pretend to have any but the loosest connection between its main classes. . . . The schedules consist of a series of separate main classes each of which has its own relative index. There is no index to the whole, but the list of Subject Headings Used in the Dictionary Catalogues of the Library of Congress can be a substitute." 303 These limiting characteristics must be taken into account when considering schemes for classifying or indexing information for mechanized storage and retrieval of information.

Similarly, in view of some of the problems and difficulties of melding central services with more specialized needs, it might be noted here that it was found ". . impossible ... for the Library of Congress to modify its medical classification sufficiently to persuade the Army Medical Library... to refrain from developing its own system. Probably both libraries were correct in their respective decisions . . . ."304

Still another example of a traditional enumerative type of classification scheme is that of Bliss ([65]). "In 1910, Henry Evelyn Bliss published in the Library Journal ' $\Lambda$ modern classification of libraries, with simple notation, mnemonics, and alternatives.' The 'Bibliographic Classification' did not, however, begin to appear in abridged form until 1935 ... Bliss developed the use of auxiliary tables (systematic auxiliary schedules)

$\mathrm{He}$ recognized also, in a certain measure, the inadequate character of a classification system in which the main classes are based on disciplines and not on subjects studied, and established numerous 'alternative locations,' so that the same complex science could be placed in several different classes ... It was only in 1948, perhaps under the influence of Ranganathan's ideas, that he advocated the use of relationship signs." 305

Faceted classification schemes, and especially the prototype Colon Classification of Ranganathan, are directed both to multi-aspects identification of subject content, reflecting different possible approaches, and to improvements in notation. Speaking to the latter point, Ranganathan himself has discussed limitations of prior notation schemes and the solution of rigidities as follows: ". . . the field of knowledge soon outwits even the cleverest guess about the gap that should be left between any two integers brought into use at the time of designing the classification. It often happens that certain gaps do not get filled up at all, while certain others soon get glutted and it is in these glutted regions that newer and newer specific subjects come up.

". . . Rigidity was first broken by the simple device of numbering the known specific subjects, not by consecutive integers, but by nonconsecutive

\footnotetext{
${ }^{303}$ Landau, 1958 [327], p. 189. Note however, that an index to each volume is provided.

305 de Grolier, 1962 [170], p. 43.
}

ones leaving a reasonable number of unused integers between them-by gap notation, so to speak.

"The greatest forward step in classification was taken less than a century ago by one whom I always call the 'Father of Modern Librarianship'-Melvil Dewey. He broke the second rigidity in notation ... by abandoning the use of integers altogether and introducing pure decimal-fraction-notation . . [ [which] provides for infinite hospitality." 306

Ranganathan points out further, however, that "hospitality of notation has to be two-fold-in chain and in array" and that "... in a faceted notation-in the Colon Classification-a class number can grow not only at its end but also at the end of each of its facets." 307

The multi-aspect subject approach of Colon and faceted classification has been summarized by Vickery as follows: "The first explicit use of categories in classification was made by Ranganathan. His Colon Classification exhibited from the start a division of classes into facets or categories. For example, in his main class Medicine, before starting a family treo subdivision, Ranganathan first formed two groups of terms: organ (e.g. femur, diaphragm, blood, eye, tooth) and 'problem' (e.g., morphology, physiology, disease, hygiene):...

"Ranganathan also found the need to introduce other groups of terms, to express the symptoms of disease (e.g., fever, inflammation), its agents (e.g., virus, bacteria, poison) and its handling (e.g., surgery, diet, nursing, therapy). He was thus able to form compound headings of the type FEMUR-MARROW INFLAMMATION (OSTEOMYELITIS)-PHARMACOTHERAPY .... The Colon Classification, by dividing its terms into categories or facets, and making notational provision for linking facets together, was thus able ... to bring together terms [in coordinate relationships]. By prescribing a fixed combination order for the facets, the classification settled the problems which worried Cutter and Miss Prevost." 308

Other remarks may be noted here which are related to the notion of universal classification schemes. The possibility of a systematic classification of all of knowledge, of course, has been an enticing activity as long as there has been recorded knowledge at all. Ball suggested in 1947 a "National Iibrary of Science, patterned after the present Library of the Department of Agriculture, with facilities organized on a scale to embrace all of the fields of scientific and technical effort. ... A system of classification such as is used in the Patent Office, integrated perhaps with the Universal Decimal System, could serve as a basic framework on which to build a really effective system of technical and scientific classification. Such a system would justify a corps of

\footnotetext{
300 Ranganathan, 1951 [468], p. 98.

307 Ranganathan, 1951 [468], p. 100

308 Vickery, 1959 [610], p. 12-13.
} 
specialists continually supervising its development in accordance with the needs of scientific and technical workers using it. A council of recognized leaders in the major fields of science and technology should meet at periodic intervals to study proposed revisions and guide the efforts of the staff to maintain the system effective and acceptable to all concerned." 309

Newman followed with the suggestion that the classified files of the U.S. Patent Office could be used as a basis for the classification of technology. He suggests that the existing system might be enlarged to include theoretical science (1961 [420]). $\mathrm{He}$ noted later that "Classification experts believe that the best classifications for documentation are those which classify differences. . . Since each patent contains one or more claims which precisely define the advance made by the inventor in relation to that which was heretofore known, the ability to create an hierarchical classification by the differences between claims is possible. Furthermore, the subclasses of this classification often utilize relationships between concepts to set out these differences. It is clearly demonstrable that, when looking for related information, the specific relationship of the elements of a 'thing' is many times more important and fruitful than the specific details of the elements so related." 310 "These characteristics of the Patent Office classification scheme permit dynamic revisions in meeting changing needs and emphases.

Wahlin of Sweden (1963 [614]) proposed a universal system of classification based on fundamental concepts arranged with consideration to their generic relations. His Ideal Universal System (IUS) has such groupings as abstract basic concepts (number, space, time, motion, force, mass); energy and matter; the universe and the earth; physical life; the individual; society; material civilization; intellectual culture; and countries and people. These concepts are those commonly given as the "subjects" of the various fields of knowledge. He has also developed a variant system, the Technical Universal System (TUS) that is adapted to engineering and technology. "Here those branches of engineering and technology which constitute applications of some elementary fundamental concepts (e.g., electrotechnics) are combined with these fundamental concepts, theory and practice keeping each other company to an increasingly low level the more specialized the concept and its application are." 311

Foskett reports that the Classification Research Group of England has met nearly every month since 1952 "with no resources beyond the native wit of its members, no allegiance to any existing system of classification, no fixed target ...." The group published a memorandum in July 1955, concluding "that any subject index, alphabetical,

309 Ball, 1947 [44], p. 35.

310 Newman, 1961 [424], 208.

\$11 Wahlin, 1963 [619], p. 185-186. classified or mechanical, relies for its efficiency on the coordination of concepts or ideas expressed in documents, so that a set of concepts stated as the requirement of a research worker can be matched with the same or similar sets already existing in the library or information system." ${ }_{112}$

Foskett further states that although the Group rejected all existing schemes it "decided to adopt at least some of the Colon terminology and method" of S. R. Ranganathan. The Group adopted the term " 'facet' . . . to describe the homogeneous groups of terms that result from dividing a subject into its appropriate categories. It did not seem, however, that Ranganathan's principle of deriving the facets of a subject by their relation to five 'fundamental' categories (Personality, Matter, Energy, Space, and Time) offered a wholly reliable extension of the idea of categories, and the CRG has never accepted this as a general theory ...." 313

Turning now to the Universal Decimal Classification, we note first that it was developed by the International Institute of Bibliography (established in 1895, later to become the FID). Under the direction of Paul Otlet and Henri LaFontaine, the objective was to develop for purposes of bibliographical control a comprehensive word repertory for the organization of knowledge. "After examining existing systems, Otlet and LaFontaine concluded that the Dewey Decimal Classification offered the most promising basis. . . . Permission to modify and expand his scheme was obtained from Dewey on condition that the order of main classes and divisions be maintained and that maximum compatibility in development be sought. ...

"The new scheme, the Classification Décimale (CD), was first published in a complete international edition (in French) in 1905 as the 'Manuel du répertoire bibliographique universel.' From 1927 onwards, further full international editions, embodying the fruits of international cooperation in additions and revisions, appeared in French, German, and English together with numerous abridged editions in these and other languages." 314

While UDC has been widely accepted abroad, with a few notable exceptions it has not been as generally received or used in the United States. The collection of the Engineering Societies Library is classified according to UDC, somewhat modified. G. K. Hall \& Co. of Boston announced in late 1963 the publication in 13 volumes of the classed subject catalog of the library. The director of the library, Ralph H. Phelps states in the announcement that the library with its 180,000 volumes "acts both as an archive for the older material and as a working library of current information, primarily for the graduate and practicing engineer, but also for the engineering student, as well as other persons needing technical

\footnotetext{
312 Foskett, 1962 [199], p. 127.

313 Ibid, p. 128

314 MIIlls, 1964 [388], p. 9.
} 
information." The published catalog has 212,400 cards and its index 27,300 cards.

Additionally, the John Crerar Library, the Libraly of the U.S. Naval Ordnance Test Station at China Lake, the Technology Department of the Carnegie Library of Pittsburgh, the U.S. Weather Bureau Library, the Library of the Housing and Home Finance Agency, the Columbus Memorial Library in Washington, and (understandably) the United Nations Library in New York are among the organizations that use the UDC classification scheme.

The general introduction to the abridged English edition of the Universal Decimal Classification (UDC), published by the British Standards Institution (1961 [82]), states that the UDC "is a scheme for classifying the whole field of knowledge." Further, there are three basic principles involved in its construction and use: (1) It is a classification, "depending on the analysis of idea content, so that related concepts and groups of concepts are brought together. ..." (2) It is a universal classification where the "universality at the conceptual level is supported by notational devices, which permit the linking of simple main numbers (for simple ideas) either with other main numbers or with auxiliaries denoting Place, Time, and similar commonly recurring categories-in each case forming combined or compound numbers." (3) It is a universal decimal classification "proceeding from the general to the more particular by the (arbitrary) division of the whole of human knowledge into ten main branches, each further subdivided decimally to the required degree."

The first volume of a new series on the Intellectual Organization of Information being prepared under the aegis of the Rutgers Library School (Mills, 1964 [388]) provides a comprehensive study of the UDC, clarifies many of the common misconceptions about it, and highlights both advantages and disadvantages of such a universal classification scheme. Mills emphasizes that while the UDC is usually employed in systems involving conventional card catalogs or book-form indexes it can be used in term-entry as well as itementry systems ${ }^{315}$ and that it can be adapted to mechanization in several ways: "(1) It provides a carefully organized and very comprehensive vocabulary of terms, providing a search programming aid (by indicating a very large range of connections) more thorough than any existing thesaurus. (2) The terms are the product of intensive analysis, they exist in a form sufficiently elementary to allow a wide range of post-coordination ... (3) Its notation is often hierarchical and is readily usable as a code (for punched-cards, say) expressing hierarchical relations ... (4) The production of full, detailed schedules, continually

${ }^{315}$ Mills, $1964[388]$, p. 54. updated, and perhaps in a number of different languages, is susceptible to mechanization...." 316

Among the advantages of use of the UDC cited by Mills are that it has the widespread acceptance of more than 5,000 organizations, that it can be applied both to books and to materials other than books, and that it has a highly organized machinery for revision, maintenance, and development, with extensions and corrections issued at regular 6 -month intervals and cumulated every 3 years. ${ }^{317}$ On the other hand: "The physical difficulties of altering documents and indexes is a serious problem ... and a major problem in maintaining UDC is that of keeping a balance between conservation in the retention of existing locations (favored by older users with substantial files already established) and the pressure of new members for relatively radical changes. There is a formal 'ten-year-rule' whereby a number which is cancelled is not used with a different meaning until 10 years have elapsed. Some users regard this as unnecessarily restrictive and it is sometimes ignored in private files." 318

Tackling some of the common misconceptions about a scheme such as the UDC, Mills first points out that it need not be lacking in specificity of subject content indication down to the 'microthought' level as required. ". . . A single UDC number may represent several different terms; e.g., 543.361 .3 is equivalent to using the following terms: Chemistry, Chemical Analysis, Analytical, Water, Salt Content, Halides, Fluorides." 319

Secondly, the UDC type of system need not be limited to use of the classified structure alone but is effectively supplemented by an alphabetized ("A/Z") index to the classification schedules. Such an index performs several major functions: "It is a key to the location of classes, providing a lead-in from the terms of the natural language to the highly artificial notational language. . . . It remedies to a significant degree the great drawback ... [of a classified index] the scattering of what are 'distributed relatives' .... All the different classes under which the subject is scattered are automatically assembled together as qualifiers of the common factor. ... The ambiguities of language and common usage will always be a central problem in information retrieval; a classification like UDC remedies them partly by referring things to systematic contexts. If the reader asks for 'Rockets' but really means 'Missiles' he will soon find this out when he finds the context is one of engines only and not vehicles, and the $\mathrm{A} / \mathrm{Z}$ index often provides this sort of 'classification' by its qualifying terms." 320

Examples of adverse reactions to the UDC to be found in the literature typically include the complaint that the UDC is not continuously revised, that although "many committees and single con-

\footnotetext{
316 Ibid, p. 14.

317 Milis, 1964 [388], p. 11, 14.

318 Ibid, p. 68 .

319 Ibid, p. 85 .

${ }_{220}$ Mills. 1964 [388], p. 25-26, 105.
} 
tributors are trying to keep the UDC up-to-date ... tens of thousands of UDC users either do not know of these changes and innovations or do not care to insert them into the tables and to classify accordingly ...." Wellisch proposes that the user of the UDC subscribe only to those parts of the tables that he needs and that there be an adequate index.

Vickery, in an article on the UDC and technical information indexing (1961 [469]), makes such suggestions as having schedules for new subjects such as plasma physies and solid state physics, reconsideration of notation in order to achieve shorter class numbers, and reorganization of the physics and physical chemistry sections. Vickery considers "that UDC notation is not useful for mechanized search systems, although the schedules themselves provide a valuable source of terms and hierarchies for such systems." 322

In contrast to Vickery's opinion with respect to search systems, the situation with respect to announcement bulletins and index preparation is one indicating the feasibility of mechanization. Mills reports consideration by the U.S. National Committee for the F.I.D. of machine production of UDC schedules in different languages and, further, that "recently a few examples of UDC indexes on tape have been reported, although these are primarily for the production by computer printout of book-form indexes for scanning in the normal way." 323

The Meteorological and Geoastrophysical Titles, second experimental issue, is an example in being. Rigby, in the introduction to this issue, reports on the success of experiments to mechanize the UDC, undertaken under a grant from the National Science Foundation. Some pertinent comments are "Owing to the varying length of the decimal groups, and to a number of special features such as brackets, colons, diagonal lines, etc., many documentalists have concluded that the UDC was not 'machineable' and that it should even be discarded as an internationally recommended system for classification. Our experiments during the past year to use this system for arrangement and cross-indexing of titles, have, as can be seen from this issue, led to just the opposite conclusion, namely that the system is ideal for systematic indexing in almost any field of knowledge requiring fairly simple machines, and that with more sophisticated machines such as the IBM 1401 or 704 used in the KWIC Indexes, or their equivalents of other makes, a superb job of organizing material of any complexity at any 'depth' could bo achieved with a little experimenting." 324

It has been further reported that these experiments have "demonstrated that the UDC scheme is suitable for treatment with tabulators or electric computers, and that in spite of some small

\footnotetext{
321 Wellisch, 1960 [639], p. 145.

322 Vickery, 1961 [616], p. 136.

323 Mills, 1964 [388], p. 43.

$\$ 24$ American Meteorological Society, 1962 [20], p. 1.
}

difficulties the advantages, and possibilities for enhancement, of the use of UDC are greater than had been expected." 325

\subsubsection{Interchange of Indexing Languages}

Five studies have reviewed the possibility of the interchange of indexing terminology. The first one, the Datatrol study of Hammond and Rosenberg in 1962, considers the questions of possible convertibility between the vocabularies of several agencies ([236]) of the U.S. Government. A related report of Datatrol, by Jaster, appeared in February 1963 ([296]). The third study, that of Painter in 1963 ([445]), is concerned with the duplication and consistency of subject indexing involved in report handling at the Office of Technical Services. A fourth study of a large-scale transformation of one of the basic documents mentioned in the other studies, although not about in.terchange as such, is the work of the Information and Documentation Center of EURATOM, Brussels, Belgium. This study is described in the report by Rolling, A Keyword List for Machine Documentation in the Nuclear Field (1962 [491]). The fifth report is Datarol's Technical Report IR10 of December 1963 ([155]) on the question of common vocabulary approaches for government scientific and technical information services.

In the second half of 1961, the Ad Hoc Interagency Study Group on Language Compatibility in Mechanized Storage and Retrieval Systems was first organized in Washington. The formation of this group was an indication of Government recognition for need of greater cooperation and compatibility to avoid unnecessary duplication of effort. Although there was no attempt at first to define "compatibility" accurately, it was suggested that a precedent had already been set by the Group for the Standardization of Information Services. Gray had pointed out that the earlier Group had found enough common subject headings "so that the subject heading problem will not prevent the interfiling of cards from the various agencies and the termination of duplicate processing." 326 and Taube had the opinion that "some progress has been made towards the development of a single standard list although it must be reemphasized that the final achievement of a single list remains a future contingency." 327

What is now desired is a degree of compatibility permitting the interchange of items for bibliographic control contained on such recording media as magnetic tapes, not only within such an organization as NASA (having research establishments in various parts of the country) but also among NASA and like members of the government "reporting community" (AEC, DDC, and the Clearinghouse of Federal Scientific and Tech-

\footnotetext{
325 As reported in Scientific Information Notes 5, (AugustSeptember 1963), p. 9.

326 Grav, 1951 [221], p. 8-9.

327 Taube, $1952[560]$, p. 23 .
} 
nical Information) and with the National Library of Medicine and the National Agricultural Library. Hammond suggested in August 1962 that "a hypothesis has been advanced that convertibility is a more attainable objective, particularly in view of the assistance now available from modern computers." 327

In September 1962 Hammond was differentiating between compatibility and convertibility, noting that the latter is "the ability to go from one indexing vocabulary to another, defining the path in such a way that any incompatibility is circumvented. For example, in that the ASTIA descriptors and $\mathrm{AEC}$ subject headings cannot be interfiled with a resulting one-to-one match, and in that a composite of the two vocabularies would be excessive for either agency, the two vocabularies would be called 'incompatible.' Since, however, equivalents - that is terms that one or the other would use as substitutes for the others-can be determined, the vocabularies are "convertible." ", 328

Painter's study distinguishes between convertibility and compatibility as follows: "Convertibility means the ability to take separate operations, or, in this case, information, draw parallels or equivalencies, and then through some type of manipulation be able to extract similar information from all units; convertibility implies similar intellectual expression. Compatibility, on the other hand, means that while the separate units are completely dissimilar as far as both system and intellectual expression are concerned, the output of the system can be used by another system and the information supplied can be retrieved. There does not have to be equivalency at all. Compatibility is usually applied to systems and programs or physical objects, while convertibility applies to terminology, information or intellectual expression." 329

Can the compatibility of indexing terminologies be achieved by having them convertible? The seeds to a first approximation for resolving the problems of interchange of such terminologies among the scientific agencies of the U.S. Government might be found in the answer to this question.

In the Datatrol studies, the essential task was to take each of the 7,145 descriptors in the 1960 first edition of the Thesaurus of ASTIA descriptors and find its identical, synonymous, or usefully equivalent counterpart in the third (January 1960) edition of Subject Headings Used by the USAEC Technical Information Service. The object was to develop if possible a table of indexing equivalents, which would be unidirectional in that it shows AEC equivalents for ASTIA's vocabulary, but not vice versa. Datarol "decided to approach the task in ASTIA's Group and Field environment. While one-for-one comparison in straight alphabetic order would reveal identical

\footnotetext{
327 Hammond and Rosenborg, 1962 [236], p. 1

328 Hammond, 1962 [235], p. 224 .

s29 Painter, 1963 [445], p. 99.
}

terms, it would be inefficient, more difficult, and less meaningful for finding other relationships." 330

The 292 descriptor groups of ASTIA's first Thesaurus had been compartmentalized in order to gain coherency within relatively small groupings of descriptors. The 292 groups were then further placed into 19 fields. The 7,145 descriptors are subsumed under the 292 groups, and the latter are subsumed under 19 broad fields. Datatrol took each one of the 13,385 subject headings of the AEC and subsumed it under (assigned it to) one of the ASTIA groups, a not inconsiderable task. "Each ASTIA Descriptor was analyzed individually in its Group and Field environment and in context with related AEC terminology. Eight separate degrees of convertibility were established so that the ASTIA terms could be categorized as to their degree of convertibility for closer study. A numeric code was assigned to each category." "331

These eight degrees of convertibility between descriptor and subject heading were as follows: (1) identical terminology in spelling and context; (2) synonymous but not identical terminology; (3) standardized AEC subheading ${ }^{332}$ is identical to, or synonymous with, the descriptor; (4) a subject heading in combination with a subheading is synonymous with or generic to a descriptor; with the dropping of the subheading the relationship would be represented by No. 6; (5) two or more subject headings are required for equivalent indexing terminology; (6) a subject heading of a broader generic level subsumes the descriptor; (7) the descriptor of a broader generic level subsumes the related AEC terminology; and (8) no equivalent AEC terminology could be identified at any useful generic level. So far, then, Datatrol placed the subject headings of the AEC into the descriptor groups of ASTIA, associated specific subject headings with specific descriptors, determined that there were eight categories of convertibility, and indicated the particular category for each descriptor and the pertinent subject headings allied therewith.

The bulk of the Datatrol report consists of its table of indexing equivalents thus developed. In this list, each descriptor from the 1960 ASTIA Thesaurus is arranged by ASTIA field and within each field by group: to each descriptor there are added (1) the AEC equivalent term or terms (if any), (2) the category of equivalence as determined by Datatrol, (3) the ASTIA frequency of use (so far as Datatrol could determine it), and

\footnotetext{
330 Hammond and Rosenborg, 1962 [236], p. 3.

331 Ibid, p. 4

332 The AEC subheading, standardized in January 1960 but no longer used as such, creates a problem in determining a final table of indexing equivalents. The current (1963) practice of ADC is to replace such terms by modifiers or key sentences under the entry for the main subject heading in the Nuclear Science Abstracts (NSA). The corresponding ASTIA terms are used analogously, namely "as modifiers through the technique of coordination, but they would not be used as main entry points in ASTIA's cumulative indexes. The terms in this category are represented by analysis, design, effectivencss, measurcment, the ASTI in the 8 rears of ASTI borg, $1962[236]$, p. 7 ).
} 
(4) the code number assigned by ASTIA to that particular descriptor.

For 38.1 percent of the ASTIA descriptors, the closest equivalent was an $\mathrm{AEC}$ subject heading of broader generic level; for 7.4 percent of the descriptors, the ASTIA terminology was of broader generic level than its closest AEC equivalent. The usage of ASTIA terms in both these groups for eight years of documentation represented only 29.7 percent of ASTIA's total usage of all terms. Synonymous terminology with AEC subject headings was found in 4.2 percent of the ASTIA assignment to its collection for the eight year period. For 10.9 percent of the ASTIA descriptors there was no AEC equivalent, this percentage representing only 6.1 percent of ASTIA's eight-year assignments. Datatrol's explanation for this last phenomenon is that in most instances "AEC did not have a requirement for the ASTIA indexing terminology simply because it did not have documentation of the same nature to index." 333

Painter reports that 85 percent of the AEC terms studied by Datatrol fell into three ASTIA fields, those for chemistry, materials-metals, and physics-mathematics, and that in these same three fields only 31 percent of the ASTIA descriptors appeared. Painter makes a distinction as to what may be inferred from the Datatrol study and the duplicate indexing analyses of her study on OTS: the Datatrol study "was done on a theoretical basis in the sense that it employs the total number of descriptors in the Thesaurus and the total number of subject headings in the AEC list. . . . The Datatrol report attempts to show what is possible; the duplicate indexing analyses check what actually occurs in practice." ${ }^{334}$

Datatrol insists that although its study should be considered experimental only, the "results indicate that patterns of conversion exist such that the ultimate goal of a Dictionary of indexing equivalents can be attained." 335 "Further, the levels of convertibility are generally in the categories of identity, synonymity, and generics. "Difficulties in the two latter areas exist, but are not insurmountable. The assigning, for example, of a higher generic term as a useful equivalent tends to be subject to nonrigorous criteria. Knowledge of the system users' requirements, however, can provide fairly realistic solutions. Other criteria can be devised as well." "s86

Hammond speaking in September 1962 ([235]), cited a specific instance of possible convertibility where there could be the substitution of an "equivalent"-an instance which may be regarded as unfortunate in the light of subsequent events. Descriptor group 98 on Food, of the first edition of the ASTIA Thesaurus, had a descriptor preservation (which was unquestionably placed there because the thinking in ASTIA was that most of such

\footnotetext{
${ }^{333}$ Hammond and Rosenborg, 1962 [236], p. 7.

${ }^{334}$ Painter, 1963 [445], p. 67 and 94.

335 Hammond and Rosenborg, 1962 [236], Abstract.

336 Ibid, p. 19.
}

reports in its collection had been on preservation of food) for which there was no equivalent $\mathrm{AEC}$ subject heading. Therefore, Datatrol determined to make the subject heading Food equivalent to ASTIA's descriptor Preservation (indicating, by the way, that this is a term of higher generic level). "In AEC's five-year cumulative index to $N S A$ we were able to see that, in fact, $\mathrm{AEC}$ had placed documents on food preservation under the subject heading Food." 337

The dangers inherent in such subsumption of one entity under another are illustrated by the location of Preservation in the 1962 ASTIA Thesaurus. In the revision, descriptor group 64, Food, contains only "things" (actual physical entities), for example, foods or collection of foods, as in dehydrated foods and military rations, while Preservation is placed with descriptor group 169 on Abstract Concepts. The entry for Preservation in the revised Thesaurus itself has the term placed in descriptor group 179 on Industriat and Laboratory Processes (in which group, incidentally, it is not found) and the term is defined with a scope note as "Prevention of deterioration of stored commodities, structural members, materials, etc." The descriptor Preservation has an "also see" in the thesaurus to Storage, which descriptor is placed in descriptor group 38 for $C$ ontainers and Packaging, this descriptor being the only one in group 38 that is not a "thing."

Hammond also describes (1962 [235]) two studies which he contends support the earlier Datatrol study: convertibility of most frequently used AEC terms, and comparative analysis of the AEC and ASTIA indexing of a common body of reports. The first of these supporting studies had been reported in the first Datatrol study. It indicated that "the 905 most frequently used AEC headings (used at least once a month), while representing only 7 percent of the total AEC fiveyear vocabulary, accounted for some 80 percent of AEC term assignments. Over half of these headings were identical or directly convertible, and the others easily convertible to ASTIA descriptors. These figures clearly show that, to give a true picture, any measures of convertibility of terms must take into account their frequency of use, since each assignment represents an event having convertibility potential." 338

In the second supplementary Datatrol study, Jaster compared the AEC and ASTIA indexing of 277 reports cataloged by both agencies. The sample was selected from the AD reports listed in the Semiannual Report Number Index to NSA for the period January-June 1961. To index these 277 reports ASTIA used 2,571 descriptors and AEC 840 subject headings, about half of the latter figure being identical, or practically so, with the ASTIA assignments. In 59 of the documents, representing 21 percent of the sample, all AEC

337 Hammond, 1962 [235], p. 224. 
terms were matched by ASTIA terms. Hammond concludes ". . . it was apparent that conversion of the ASTIA descriptors by means of the table of indexing equivalents would, in fact, substantially have generated the terms AEC used." ${ }^{339}$

The Datatrol report by Jaster (1963 [296]) describes a tool devised for compiling a dictionary showing multilateral equivalence among the indexing terms of the AEC, DDC, and NASA. In the preparation of the "subsumption" scheme, the field and group structure of the ASTIA 1960 Thesaurus was modified by three techniques: deletion, addition, and distribution of terms. There resulted 20 fields instead of the 19 of the ASTIA Thesaums. One variance in procedure adopted in the modification of the ASTIA/DDC scheme was provision for assigning indexing terms to any number of indexing groups whereas in the preparation of the first ASTIA Thesaurus each descriptor was assigned to only one descriptor group. In the preparation of this subsumption scheme consideration was given to the use of broad categories, possibly to be attained by (1) merging the fields of ASTIA/DDC, the categories of the NASA Scientific and Technical Aerospace Reports, and the categories of the AEC Nuclear Science Abstracts or (2) extrapolation from other schemes for categorization or classification such as the AEC evaluation lists, ASTIA Distribution Guide, or NASA distribution categories.

Datatrol continued this line of attack in its December 1963 report on common vocabulary approaches for government scientific and technical information services. This study was given impetus by the interest of the Committee on Scientific Information of the Federal Council for Science and Technology, and its object was "to develop and document guidelines and criteria to be used in reaching a decision on a single Government-wide approach to an information retrieval vocabulary." 340 Datatrol was assisted in its inquiry by an Interagency Task Group on Vocabulary Study, formed to act as expert consultants to COSI, particularly in matters regarding common vocabulary. The members of the Task Group, with a representative of the National Science Foundation as Chairman, included representatives from the AEC, DDC, NASA, National Agricultural Library, National Bureau of Standards, National Library of Medicine, and OTS.

At the invitation of the Chairman of the Operating Committee of COSI, members of the Science Information Exchange participated in the study, and members of the COSI Operating Committee and other responsible and knowledgeable individuals were consulted. The three specific requirements of the study were (1) to identify the alternative courses of action available for government-wide adoption respecting common vocabulary approaches for information storage, search,

339 Hammond, 1962 [235], p. 227.

${ }^{340}$ Datatrol Corp., 1963 [155], Foreword. and retrieval; (2) to evaluate each course regarding its economic impact on each agency within the COSI Operating Committee; and (3) to report on evaluations and on the guidelines and criteria useful for reaching a decision on a single, governmentwide approach to a vocabulary.

The following five approaches to the alternative courses of action of the first requirements were given consideration: (1) single thesaurus: preparation of one vocabulary reference for indexing all government scientific and technical documents; (2) single subject heading list: preparation of one list of subject headings for indexing all government scientific and technical reports; (3) correlated thesauri: preparation of a thesaurus by each agency for its use and preparation of a machine-independent computer program for correlating all government thesauri; (4) combined thesaurus and subject heading list: preparation of a thesaurus or list of subject headings by each agency "according to its option (status quo)," i.e., its current method of conducting its documentation, especially its current tackling of vocabulary, plus preparation of one or more machine-independent programs for locating all words used by government agencies to describe identical objects and concepts; and (5) common subsumption scheme: "preparation of a single list of broad generic subject categories that will subsume the composite subject content of government research reports. Such a scheme to be used by each agency to categorize reports independently of the indexing vocabulary. Preparation of a computerized application for correlation of indexing data among the agencies." 341

Datatrol elected to evaluate these five approaches on the basis of effectiveness and cost of indexing for announcement and retrieval of the government scientific and technical information systems. Regarding the indexing of the reports for purposes of their announcement, Datatrol concluded that the indexing by either AEC, NASA, or DDC did not satisfy the requirements of each other. Regarding the indexing of the reports for purposes of their retrieval, Datatrol saw "no evidence that, under the current modus operandi, a single thesaurus, subject heading list, or correlated thesauri would offer any significant advantage over the status quo for searching multiple collections. Superimposing a common subsumption scheme ... appears to offer the most promising approach under either a computer-correlated approach or for mutual organization of indexing data of several agencies." 342

Furthermore, adoption of the common subsumption scheme by all operating agencies was regarded as possibly providing the points of departure for computer generation of indexing equivalents for searching different systems. Datatrol defines its common subsumption scheme as "a

341 Datatrol Corp., 1963 [155], p. 8.

342 Ibid, p. 72. 
tool of convenience for grouping and displaying associated terms of a given indexing vocabulary to serve as an authority for indexing, storing, and retrieving reports or data from a given information system. The associations may be vocabulary oriented and/or agency program oriented ... i.e., based on subject category, scientific discipline, project or other special interest, or a combination of any of these associations." 343

Datatrol thus regards the statistical association of indexing terms as the most promising approach for correlating the indexing data of the different operating agencies for retrieval. ${ }^{344}$ The multidimensional correlations of statistical association techniques include the term profile or statistically associated terms from the indexing data of a given system and the identification of equivalent search terminology employing association profiles of terms used by different systems to index reports of related subject categories. ${ }^{345}$

The study by Painter, submitted as a doctoral thesis to the Graduate School of Rutgers, The State University of New Jersey, was conducted as part of a cooperative Office of Technical Services-National Bureau of Standards project examining the feasibility of automation of information handling operations in OTS. The three primary objects of the Painter study were to determine (1) the types, amount and frequency of duplication among reports submitted to OTS from other government agencies; (2) the amount and frequency, as well as the significance, of duplicate indexing efforts by the contributing agencies; and (3) the consistency of subject indexing within major agencies contributing to O'TS (DDC, AEC, and NASA) and also at the National Agricultural Library, which does not contribute to OTS.

Painter summarized her findings regarding duplication of reports sent to OTS as follows: "Duplication, examined by the regular search procedure in practice at OTS, was found to occur at three levels: one necessitated almost complete processing before search, one required only partial analysis, and one needed only one search item for identification. The duplication rate occurred at a maximum of 50 percent with the second and third of these levels. Most of the duplication was identified through the report or series number or the AD number. It was concluded, therefore, that machine search [for duplicates] was feasible at the simplest level of processing (report number or series number). This would put preparation time at a minimum and eliminate the duplicated materials." 345a

Painter also undertook a determination of the "equivalency of terms and their possible convertibility as revealed in an analysis of the indexing of a report or reports by two or more agencies."

\footnotetext{
343 Datatrol Corp., 1963 [155], p. 53.

344 Ibid, p. 71 .

\$45 Ibid, p. 98-99.

345a Painter, 1963 [445], p. vii-viii.
}

She took as basic the Datatrol study on the convertibility between the ASTIA descriptor and the AEC subject heading, and she made a comparison with the results obtained by Jaster of Datatrol, reported above. Painter examined 200 items which had been indexed by both ASTIA and AEC in order to learn what equivalency of assignment had been made by the respective agencies. She found that of the 2,217 ASTIA descriptors and 640 AEC subject headings there was a total of 426 terms that were either equivalent, word-byword, or synonymous. "Thus the percentage of equivalency within the AS'TIA descriptors was 20 percent as opposed to 67 percent within the AEC subject headings. On the basis of the total number of terms assigned $(2,857)$, the degree of similarity in indexing between the two systems would be 30 percent." 346 This last figure was obtained as a ratio of the sum of the ASTIA equivalent terms plus the $\mathrm{AEC}$ equivalent terms to the sum of all ASTIA terms plus all AEC terms.

Painter's summation of the two Datatrol studies and her own related one is that: "Taken as a whole, the three studies seem to point out a degree of convertibility between ASTIA and AEC. A large percent of the AEC documents could be retrieved by converting to ASTIA descriptors, at least in the three fields where comparison is most valid. A third of this is exact equivalency, or synonymity; a majority of the comparisons of terms are complicated by generic (term in one scheme subsumes two or more of another) relationships, but according to the basic Datatrol report this need not be a serious block to retrievability. Only 10 percent possibly would not be retrieved." 347 Painter suggests, however, that more evidence is needed that satisfactory retrieval results from the use of a term of higher generality.

$\Lambda$ comparison and analysis was also made for triplicate indexing between ASTIA, AEC, and NASA for a small sample of 16 items. To these 16 items, ASTIA had assigned 219 terms, NASA 74 , and $\mathrm{AEC} 32$. In these assignments there were 25 equivalents appearing among all three, making 12 percent equivalency with the terms from ASTIA, 64 percent from NASA, and 78 percent with those from AEC.

Painter made two comparisons between assignments by ASTIA and NASA for 90 NASA documents indexed by ASTIA between April and July 1962. There were 306 ASTIA descriptors and 87 NASA Uniterms (subject headings and subheadings broken "into single units usually consisting of one word which can be coordinated either manually or by machino in a variety of different combinations ...")..$^{348}$ Of the terms assigned, 52 were equivalent within each system, giving equivalencies of 17 and 60 percent respectively for the ASTIA and NASA terms.

\footnotetext{
346 Ibid, p. 76.

s1 Painter, 1963 [445], p. 79

348 Ibid., p. 74.
} 
The ASTIA rate of equivalency ranged from 11 to 19 percent when compared with AEC headings in the duplication check by Painter and the supplementary Datatrol study of Jaster, but in the basic Datatrol study the ASTIA rate jumped to 28 percent when the entire list of ASTIA descriptors was used, including obsolete terminology. The AEC rate of equivalency, however, ranged from 34 to 72 percent as compared with the 15 percent indicated by the basic Datatrol study, which "is figured on a theoretical basis of the total term list only part of which is in current use." 348a

Painter's conclusions are that although the figures are too sparse for firm convictions, (1) most of the systems can be converted into the ASTIA descriptor structure but not into any of the others; (2) since equivalency of indexing terms between ASTIA and AEC was not more than 28 percent of the larger system (ASTIA) but was as high as 72 percent of the smaller (AEC), the smaller could be adapted to the larger but not vice versa; and (3) "with only 60 to 70 percent consistency of indexing within each system and equivalency of only 30 percent within the broadest system, a table of equivalents is at present of little value in either a manual or a machine system." 349 She contends that in order to apply a table of equivalents, both a high degree of indexer consistency and a high degree of equivalency of terms used are essential.

The Information and Documentation Center (CID) of EURATOM, an international organization located in Brussels, Belgium, has published its work of transforming the Subject Headings of the U.S. Atomic Energy Commission (TID-50001, third edition) into a thesaums of key words. The thesaurus is used for the storage and retrieval of information regarding physics, reactor technology, protection from radiation, application of isotopes, materials, electronics, radiochemistry, and radiobiology. CID reduced the 1960 AEC subject heading list of 12,809 terms to about $4,500 \mathrm{key}$ words, "known also as descriptors, selectors or subject headings ...." ${ }^{350}$ This reduction was accomplished in large part because of the methods used in the AEC list for indicating alloys and phase studies of mixtures and also because only 7,208 terms were used in the 1960 cumulative index for Nuclear Science Abstracts.

CID split up the 4,500 key words into about 50 groups, according to subject field, in order to collect the synonyms and the generic and subordinate terms and examine their contents comparatively. Graphic displays were made for the groups of key words which permitted grouping terms of like association together. "The related terms were linked by lines or arrows, and this provided an impressive and lucid representation of the 'see-

348a Painter, 1963 [445], p. 82.

349 Ibid, p. ix.

350 Rolling, 1962 [491], p. 2 also references' included in the American subject headings list." 351 Eventually the organic compounds (1,854 key words) and isotopes (1,386 key words) were excluded from the list, leaving a residue of only 1,127 key words.

Reference has been made to the desire of the Committee on Scientific Information for an overall index to the report literature of the agencies of the U.S. Government. Science, Government and Information, the January 1963 report of the President's Science Advisory Committee (the Weinberg report), finds with respect to a system for handling scientific or technical information in a network of separate subsystems, that "rapid and efficient switching between the different elements of the system is essential, " ${ }^{352}$ that the first among the means for rapid switching is compatibility and that, at least so far as title formats and key words are concerned, to be compatible means to be "easily intertranslated." 353

The National Library of Medicine is an example of a governmental agency planning for both centralization and decentralization. The NLM hopes that its MEDLARS medical bibliographic system will meet a rise expected in demands for service, especially demand-search requests. The Library sees two ways to meet the increased load: First, "increase the capacity of MEDLARS to process the requests, coupled with an increase in communication lines, and possibly coupled with remote input/output facilities located at centers of large demand. Second, decentralize the servicing of requests by using remotely located search facilities: the acquisition, indexing, conversion, and storage for retrieval would be done at NLM while magnetic tapes comprising the files would be reproduced by the Library and distributed to remotely located search centers." ${ }^{354}$ There is no mention here of centralization of NLM's information with that of any other governmental agency.

Rothgeb (1963 [496]) reports that the Scientific and Technical Information Facility operated by Documentation, Inc., for NASA, "is designed to maintain a centralized processing system for maximum decentralized use." Rothgeb claims that the centralized processing (1) enables NASA field centers to contribute documents to the system for ready availability to other users of the system, (2) provides the field centers with their own search tapes, and (3) permits searching capabilities which cover information from journals before they are printed and before the search tapes reach the field centers' search system. There is no mention of centralization of NASA's information with that of any other governmental agency.

A report to the National Science Foundation by Arthur D. Little, Inc., on centralization and documentation recommends that before elaborate

\footnotetext{
351 Rolling, 1962 [491], p. 3

${ }^{352}$ President's Sclence Advisory Committee, 1963 [464], p. 4.

${ }_{354}^{353}$ National Library of Medicine, 1963, [412], p. 61-62.
} 
word thesauri are developed for existing partially centralized information retrieval systems, there should be more investigation of the statistical techniques for generating thesaurus lists automatically and for automating functions performed by human intermediaries. ${ }^{355}$ Existing large-scale coordinate retrieval systems are regarded as scaledup and computerized versions of punched card searching systems based on index term matching; their overall performance in terms of precision and recall measures appears low and inadequate to provide a thorough searching facility. ${ }^{356}$ The Arthur D. Little report was made at the behest of the Foundation for the Panel on Science Information of the President's Science Advisory Committee, as reported by Weinberg. ${ }^{357}$

We should note here that Warheit in his review of the Arthur D. Little study (1962 [629]) believes that "the essential conclusion that a large general collection cannot be searched with any real precision or completeness just doesn't stand up. It can be shown theoretically, it is said, that the models developed (in the study) show the inability of making a precise and complete bibliographic search in a file of over 100,000 items. Yet librarians almost every day make effective searches in much larger files."

There appear to be logical questions, too, as to the ability to handle all scientific disciplines in the same way. For example, the Summary of Discussion on Area 7 at the 1958 International Conference on Scientific Information reported by Clapp and Rogers (1959 [121]) reemphasizes the points made by Boutry of the Abstracting Board of the International Council of Scientific Unions theorizing that the many problems in the documentation of the biological disciplines may be accounted for by their magnitude, amounting to about 50 percent of all abstracted literature, by contrast with one fifth to one sixth for physics, and less than one third for chemistry. This is cited in connection with the thought of merging the vocabularies for the physical and life sciences.

Hyslop contends, on the other hand, that there are similarities in the system of the American Society for Metals at Western Reserve University, designed for computer processing and a centralized information service, and the system of the AIChE, designed primarily for manual or simple card files and for use by individuals, but adapted for machine use as well. She believes that "the similarities between the two systems lie in philosophy or methodology used to analyze the information contained in the original document-whether this analysis is done manually or by machine. Both systems utilize three devices for subject analysis. In the ASM-IVRU system these three devices are designed as 'code dictionary,' 'role

355 A. D. Little, 1963 [344], p. 4

350 Ibid, p. 2.

357 Weinberg, 1962 [636], p. 4. indicators,' and 'punctuation.' In the AIChE system the corresponding terms are 'thesaurus,' 'role indicators,' and 'links." "' 358

Brenner and his associates of the American Petroleum Institute report that the centralized information retrieval system for the petroleum industry makes use of a thesaurus, its Subject Authority List, which is "similar to those of the AIChE, E.JC, and DDC." Further, "no other one vocabulary contains all the technical terms used in the publications covered by $A P I$ Abstracts." 359

Several representatives of the Federal Government have proposed a centralized system of code cataloging for machine retrieval. Langenbeck of the Naval Ordnance Laboratory suggests that "a DOD-wide standard code and dictionary can be realized by comparing individual library codes of activities using machine retrieval and arriving at a compromise. A very carefully drawn standard and a control system will be necessary for periodic revisions of the standard code and dictionary." He proposes also for "each activity to do the descriptive cataloging, subject cataloging, and machine coding for all reports it creates and distributes. This information is to be incorporated as an integral part of the report on a specific page reserved for library use." 360

Hooker hopes that experimentation on the bibliographic control of scientific literature "will lead to some standardized or centralized systems which will put all this information on magnetic tape and that we, the users, can buy the tapes and each do his own retrieving. . . the logical solution seems to me to be preparation of the product centrally with the reference use or retrieval of the information locally." 361

Three other citations, already made, may be referred to again regarding difficulty in centralizing indexing vocabularies. Ball (1947 [44]) favors a system for classification, such as that of the Patent Office, integrated with the UDC and he would have a corps of specialists supervising this system continually. Pings (1960 [458]), on the other hand, would have nothing to do with attemps at a universal classification, contending that there will never be agreement upon a universal classification unless there is agreement in dealing satisfactorily with limitations of scientific inquiry. The UDC, too, has had its detractors such as Wellisch (1960 [634]) who finds that many users of the UDC do not know of the changes made in the classification and do not have interest to abide by changes made by the many committees and contributors. Such varying opinions certainly have bearing on the success of attempts to interchange or centralize indexing vocabula ries.

\footnotetext{
358 Hyslop, 1963 [278], p. 293.

350 Brenner, et al., 1963 [ 78 ], p. 290-291.

360 Langenbeck, 1962 [328], p. 13, 17.

se1 Hooker, 1962 [271], p. 17.
} 


\subsection{Storage, Search, and Selective Dissemination}

The scope of this report includes storage in some aspects - standardization of formats, compatibility and convertibility between forms of storage media, maintenance of cooperative deposits, and search, in the sense of what is obtained as product of a search. The need for considerations of convertibility or compatibility is especially pressing for mechanized information systems. Conventional manual systems require consideration of cooperative and coordinated action but in the realm of analysis, identification, and systematization of indexing processes, as we have already seen. Mechanized systems must also consider coordinated action in the matter of type and form of storage medium and of search product. Current operations in this area are not extensive. Some proposed activities have been formulated, but we can review the considerations and needs for cooperative steps along these lines.

Hayes points out that not only does the mechanization of information handling processes require "a detailed specification of every minute step and operation" but also that the costs of mechanization are great enough so that the procedures which must be specified in detail must also be highly efficient." ${ }^{361 a}$ "This means, among other things, that the inefficiencies of reediting, retransscription, reformatting, and the like should be avoided when materials processed in one organization are also to be processed by another. Wherever cooperation, exchange, and interchange are involved between two or more organizations, at least one of which uses a machine system, effective cooperation will thus require the development of appropriate measures of compatibility, as well as the making available of minutely detailed specifications. If, for example, either DDC or the Clearinghouse for Federal Scientific and Technical Information wishes to make copies of magnetic tape files or of paper tapes used to print announcement bulletins available to other organizations, the copies cannot be used elsewhere unless they are accompanied by specifications in such fine detail as whether descriptors in a list of descriptors are separated by two or by three blank spaces and the different sort-sequences resulting from interpretation in different machines of the bit patterns used to encode characters.

TVe must then consider questions of convertibility from one machine-usable format and/or character set to another, from one machine language to another, from a single problem-oriented language to more than one machine language or interpretative program, and from one notation system to another. In addition, there must be considered the question of automatic conversion from one indexing language to another, the question of automatic conversion from natural language to a

\footnotetext{
361a Hayes, 1960 [241], p. 6
}

documentary language, and the question of automatic conversion from natural language to amplified searching languages.

Let us turn our attention to two forms of storage which involve cooperative action by information systems and centers. The first form is the cooperative depository library, wherein participating libraries and centers store their cooperatively acquired collections, their little-used material, or even items they no longer need but wish to make available to other organizations. We have already mentioned depository libraries established and maintained by a central facility, such as the AEC network. These also constitute cooperative storage.

Such cooperative storage facilities could alleviate many of the weeding-out problems by providing temporary disposals subject to recall as needed. "Weeding requires a great deal of staf" time in selecting the items to be discarded, changing the catalog records, actually removing the books from the shelves, deciding how to dispose of the books, and observing federal regulations on the disposal of government property." 362 Removing obsolete works from a collection may have little significance so far as space saving is concermed, but it does expedite research by facilitating access to the more valuable material.

The second form of storage we might consider is microphotographic storage-microfilm, microfiche, cards and the like. Such media relate mainly to the improvement of physical accessibility; in themselves they do not contribute to the solution of content accessibility. Microphotographic material can be acquired and stored by an individual library or cooperatively by several libraries; the latter possibility is of greater interest to us here.

One point to note in regard to cooperative acquisition of microforms is that microfilms made from master negatives do not go out of print, and may therefore be acquired when and if needed. Fussler emphasizes that "mircofilm can economically be acquired either as an edition copy or as a single acquisition to meet an existing need-in contrast to acquisition in anticipation of a future need. The gains in the latter are very great, for it means that large masses of highly specialized and peripheral literature-systematically and cooperatively collected-would be available on a deferred basis, when needed, at costs less than multiple acquisition, cataloging, and storage." 363

A cooperative program that combines depository storage and microforms is that for "auxiliary" or "demand" publication in which documents are deposited in a central repository and from which copies can be had on demand. This requires an announcement through published summary or condensed article of the availability of the deposited document. The technique of auxiliary publication already has been used for distribution of U.S. gov-

362 Evans, 1963 [188], p. 5.

363 Fussler, 1951 [207 ], p. 82 . 
ermment research reports by OTS and theses by University Microfilms, Inc., and in the ADI's "auxiliary publication program", wherein tabular data and extensive texts not ordinarily published by scientific journals, but useful for a limited number of specialists in the field, are placed on microfilm. They, along with microfilms of certain rare and out-of-print journals, are transferred to the LC Photoduplication Service where photocopies are made available upon request.

University Microfilms, Ann Arbor, Michigan, maintains files of many publications in microfilm form, and will duplicate its files in either microfilm or hard copy. There are five categories which reflect the major interests of this organization: periodicals, newspapers, books, special fields, and equipment. The periodicals include microfilms of modern periodicals, English literary periodicals of the 17th, 18th, and 19th centuries, Russianlanguage periodicals, American periodicals of the 18th and 19th centuries, and Chinese-language periodicals not previously available in the United States. Newspapers on microfilm include Irish newspapers prior to 1750 in Dublin libraries, selected English newspapers, modern newspapers (including the New York Times, Osservatore Romano, and Commercial and Financial Chronicle), and Arab newspapers. Books on microfilm include English books of the 15th, 16th, and 17th centuries, scarce manuscripts and books on Americana, and out-of-print books including Russian material.

Among the efforts to control microfilm material bibliographically have been "the Union List of Miorofilms, published by the Philadelphia Bibliographical Center, the Microfilm Clearing House maintained at the Library of Congress . . . ." \$64

Also, "The Navy Research Section's experience with the Microcards has been in connection with an experimental program proposed late in 1950 by the Office of Naval Research ... distributing .. a particular type of Microcard for the Unclassified and Restricted reports abstracted in NRS' abstract bulletin-the 'Technical Information Pilot (TIP). This card consists of a conventional Microcard laminated to the back of a standard NRS catalog card." 365

All the problems associated with the use of microforms have not been solved. As Fussler points out, ". . . In many respects photographic access is of critical importance in relation to the success of any broad plan for the cooperative acquisition of original materials ... [but technical advancements will be required to] increase accessibility by promoting ease of use, by reducing costs, and by faster a vailability." 366

Three government agencies-the AEC, NASA, and DOD--have reecntly standardized a microfiche system for reproducing all research and de-

364 Council on Library Resources, 1958 [140], p. 19.

$363 \mathrm{Gray}, 1952$ [223], p. $5 \mathrm{~s}$.

36 Fussler, 1951 [207], p. 183. velopment reports from these agencies and their contractors. The microfiche is a negative card containing document pages in micro form. The agencies have not only agreed to the outside dimensions of approximately $4 \times 6$ inches, but to other stanaard dimensions as well-spacing between pages, reduction ratio, and others. These standards make it possible for documents from the three agencies to be viewed and reproduced by the same equipment, viewing screens and projection lenses. Dissemination of reports will be faster and simpler, and the agencies will be able to cut costs.

The Federal Council for Science and Technology adopted the standard in the Spring of 1963 for government-wide use. ${ }^{367}$ There is also the possibility that central Federal support should be provided for the procurement (or development as necessary) of inexpensive readers capable of handling the new standard microform and their placement in all Federal libraries and in all cooperating public or private libraries.

Assuming that storage, subject to selective recall and retrieval, has been effectively achieved, what is the situation with respect to the compatibility or convertibility of the search product?

The product that is obtained depends largely on the type of system from which it comes. For example, some systems store data, technical or administrative in nature, and process this material to produce factual results in the course of normal operations or in answer to specific queries. Chemical compounds are tested for biological activity and the results recorded in a data-storing system; then studies are made of correlations between chemical structure and biological effects. The products of such a system are actual facts and figures on correlations, structures, and activities.

On the other hand, some systems store references to data, or to the documents containing data, and produce notations of pertinent references in answer to particular queries. The number of such systems is large and their operations are highly diversified with reference to the degree of mechanization employed in their operations. Still other systems store data or references but produce general search aids as part of an integrated operation. Search aids include indexes, biblographies, and publication aids providing, for a specific area of science and technology, a means for individuals to make particular searches or to maintain current awareness. Alternatively, the product of an information system might be a machine-searchable file, such as the reproduction of decks of punched cards, with which the individual can set up his own system for making specific searches.

In all cases, products of information systems, whatever their form, need to be considered in terms of their compatibility or convertibility one to another. The question is whether these prod-

307 "Microfiche Standards Adopted," 1964 [383]. 
ucts can be used by others than those who produced them, and whether they can be exchanged and incorporated into other files. The question, in general, has been explored elsewhere in this report. Here, we shall mention only those few further illustrations of possibilities of compatibility in the area of the production of selective bibliographies.

Betty Gray of the Textile Fibers Dept. of E. I. du Pont de Nemours uses ${ }^{368}$ the tape typewriter in the preparation of annotated bibliographies to reports. A punched paper tape, produced when reference cards are typed on an automatic typewriter, is used for type-out of a final master copy of the bibliography. The sections of the punched tape corresponding to individual references can be arranged conveniently to satisfy the final arrangement desired, and the searcher is not confined to a predetermined order in making the search. The use of this system results in a saving of 60 percent over the time required for manual typing of a bibliographic report.

A further comment may also be of interest: "Not only is the ability of federal librarians to prepare useful bibliographies most inadequately utilized, but those which have been prepared have generally been issued in quantities too small to reach all who would benefit from them. A coordinated bibliographic service, established through the cooperative efforts of departmental libraries, would do much to improve this situation. Such a service should, of course, complement and assist rather than duplicate the bibliographic work of nongovernmental bodies so as to promote broad, high quality, national bibliographical coverage." ${ }^{369}$

Selective bibliographies are related on the one hand to specialized mailing lists and on the other to the selective dissemination systems first suggested by the Luhn (1958 [355], 1962 [353]). An early Government example of selective mailing lists was that of "the Solid Propellant Information Agency (SPIA), which was established in 1946 at the Johns Hopkins University Applied Physics Laboratory ... A unique feature of SPIA's operation is its Joint Army-Navy-Air Force Mailing List for the distribution of solid propellant technical information." 370 Another cooperative defense agency example was the ArmyNavy-Air Force Guided Missile Mailing List which had "the effect of grouping of individuals working on similar research and providing them with information of mutual subject interest." 371

Selective dissemination, or SDI, systems are tailored instead to individual subject interests, particularly the research worker's current awareness needs, where he has filed a "profile" of his current subject interests which can be updated by machine as a result of feedback from him. Incoming items that "match" his stored profile result in

\footnotetext{
${ }^{368}$ Gray, 1961 [220], p. 71.

369 Gvans, 1963 [18s], p. 30

วั0 Herner and Herner, 1959 [254], p. 190.

${ }^{371}$ Heald, 1952 [244], p. 140.
}

notifications being sent to him of the availability of these items on a turn-around card so that he may order any of the items. Kraft, reporting in 1963 on the then state-of-the-art of SDI systems makes the following comments :

"Those people who have a current awareness need should furnish lists of words which characterize their various interests. These are the same 'hot-button' words which the reader looks for when he browses ...

"At the time of this writing, there are in excess of a dozen SDI systems in the country ...

"Efficient dissemination, when a document first appears, reduces the retrieval problem later. SDI is a kind of 'retrieval-in-advance'-a current awareness program that helps users keep abreast of new information ...

"An analysis of users' replies indicated that twothirds of the notices were 'of interest' and onethird of 'no interest.' Considering that a 'typical' user received an average of five SDI notices per day, the noise level of 34 percent was tolerable, since it required less than one minute to read an SDI abstract and punch out the reply card." $\mathbf{3 7 2}^{372}$

At NASA, an SDI system is under development and experimental trial. "Reports having a probability of specific interest to a particular individual are selected by specially prepared computer programs. Each man's 'interest profile,' consisting of subject terms and phrases related to his activities and interests is compared with the subject indexes of all reports to be annotated in current issues of $S T A R$. When an optimum match between terms occurs, an abstract of the selected report is mailed directly to the participant, delivery being made even before the abstracts are available in STAR." ${ }^{373}$

\subsection{Standardization}

In spite of our earlier statements to the effect that too little progress has been accomplished and too little effort is being expended on problems of cooperation, compatibility, and convertibility, we can report considerable efforts toward agreement and standardization in progress.

Such efforts are being carried forward by organizations primarily devoted to standardization, by societies devoted to professional activities but vitally concerned with standards, and by other groups whose work is affected by and would benefit from the development of standards. These standards are concerned with hardware, equipment, physical formats, and the like; they are also concerned with intellectual aspects, languages, codes, subject contents, and similar points. Many of these have been touched upon in earlier sections of this repolt. Here we shall discuss the standards and standardization efforts in terms of the groups working on them.

\footnotetext{
${ }^{372}$ Kraft, 1964 [323]|, p. 143-151.

373 Scientific Information Notes 6, 1, 1-2 (1964).
} 


\subsubsection{Programs of Federal Government Agencies}

Activities of the Group for the Standardization of Information Services were mentioned earlier in this review: four government agencies (AEC, NACA, Central Air Documents Office, and LC Navy Research Section) came to an agreement regarding a few of the problems encountered in their bibliographic services. The problems were attacked in meetings of working-level individuals by first setting up standardization goals, the attainment of which would permit each agency to use the products of the others. Following discussion, the tentative decisions reached were taken back to the appropriate authorities in each agency for approval, which was generally quickly forthcoming. The major items on which agreement was reached included the common format for library cards and the development of a subject heading list that would be as nearly common to all agencies as was possible.

In 1956 Connor, of the Technical Library of the U.S. Naval Air Missile Test Center at Point Mugu, Calif., in citing the need for standardization in the documentation of government research reports, asked specifically for a "statement setting forth physical and bibliographic requisites in the preparation and publication of reports." 374 This was to be one of the specifications within a government contract. The items which Connor wished to see standardized were (1) with reference to physical format, the size and kind of paper on which the document is inscribed, and the types of cover and of binding (e.g., whether stapled or sewed); and (2) with regard to bibliographic data, title pages were to show only company or agency along with personal authors, dates including inclusive dates for periodic reports, title, report number, and address of organization responsible for the report.

The attention of military agencies to standardization and compatibility is demonstrated by the activities of the DDC which include work on abstract standardization. "A uniform abstract covering all bibliographic elements for technical reports is being devised for use by originators and authors, thus paving the way for automation on common grounds and large savings in time, expense, and repetitive bibliographic efforts." 375 Col. Vann, then director at DDC (ASTIA), spoke to this point: "[It is] important . . . to start at the point of generation with a format and standards which will speed up the cataloging, indexing, and retrieval of a document when it reaches the Documentation Center." 3i6

Another area of DDC effort is concerned with interchange of magnetic tapes. The prerequisites here are an essentially complete automatic data processing system and uniform processing of information. Exchange of compatible tapes will then be feasible and permit rapid interchange of information with minimal duplication of effort.

\footnotetext{
374 Connor, 1956 [134], p. 155.

37s ASTIA statement in NSF-63-5 1962 [418], p. 66-69.

$370 \mathrm{Vann}, 1963[606]$, p. 221.
}

Heald emphasizes these points (1963 [175]) when he states that ASTIA has made efforts toward standardization and compatibility in the revision of its Thesaurus of ASTIA Descriptors and in the desire for adoption of abstract standardization. He lists the entire bibliographic citation for describing a report as being one of the elements of a standard abstract, along with the summary or body of the abstract. This standard abstract includes title, author, originating agency, identifying number, and subject indexing, as well as the summary.

Heald contends that by means of coordination within the abstract standard there will be attained (1) compatibility of indexing and abstracting; (2) computer-to-computer communication through interchange of magnetic tapes and rapid network transmission; (3) reduction in the time for processing information, between its origin and its being made available; and (4) reduction of the cost of index and abstract processing: ". . . tremendous gains are possible by building a vocabulary as compatible as possible with other information activities, such as those of NASA, AEC, OTS, and DOD activities and contractors. The eventual pay-off here is computer-to-computer interchange of information and interchange of magnetic tape." 357

Similar opinion was expressed by Hall, who said, "Standardization in such matters as report designation, layout of covers and preliminary pages, the furnishing of abstracts and catalog cards within the reports themselves, bibliographic usage, arrangement of contents and indexing accomplishes two important and money-saving ends. It provides for a more rapid and accurate production of the reports themselves . . . and at the other end of the cycle provides for faster and more effective indexing, cataloging, coding." 378

The survey of scientific and technical information retrieval schemes within the Department of the Army, by Weik and Confer (1962 [633]), has remarks pertinent to compatibility and standardization. They find that there is very little uniformity or standardization among such schemes, and that the great tendency to devise codes for easing the classification, storage, and retrieval problem is evidence of the great ambiguity in the English language.

The Institute for Defense Analysis made a digital computer applications study for the Adranced Research Projects Agency of the DOD. This study also found that there is lack of coordination in efforts at automation, resulting in functional and technical system incompatibilities and lack of standards for machine languages and programming languages, an important factor in convertibility problems. ${ }^{379}$

3 it Heald, 1963 [242], p. 42

378 Hall 1960 [233]

sig See "Where the Computer Fits in Command and Control," 1962 [643]. 
The hearing before the House Subcommittee on Census and Government Statistics of the Committee on Post Office and Civil Service which was held on June 11, 1963, on the use of electronic data processing equipment has several statements relevant to standardization and compatibility. The Comptroller General of the United States, Mr. Joseph Campbell, found that (1) lack of compatibility between magnetic tape systems used in equipment of different manufacturers results, unless "special additional equipment is designed to overcome this shortcoming or unless the data on the magnetic tapes are converted to punched card or paper tape media and then reconverted to magnetic tape for use in follow-on operations;" (2) "costs are incurred because of the need to convert and reconvert files and records from one type of data processing equipment to other models of equipment;" and (3) "a central management office is needed to properly exploit the possibilities of Government-wide integration of systems and to plan for their development and growth." 380

On August 1, 1963, the same subcommittee submitted to the parent Committee its Interim Report on the Use of Electronic Data Processing Equipment in the $\dot{F}$ ederal Agencies (1963 [584]). The subcommittee states, "In fact, in almost every problem area identified during the subcommittee hearings, contradictory testimony was given. Some agencies, for instance, wanted more centralized control, others wanted less. Some agencies testified that common machine languages (COBOL, FORTRAN, etc.) were timesavers; others indicated that they had not, as yet, found these languages particularly helpful. . . On the subject of standardization and compatibility, some witnesses testified that the Federal Government was making substantial progress in achieving greater compatibility, whereas other witnesses believed that considerably greater Federal initiative and effort were needed in this area."

These remarks are applicable not only to business or management data processing systems, but also to the scientific and technical information processing systems with which we are concerned here.

The basic form of the bibiographic entry has received the attention of the Committee on Scientific Information, as was related in an earlier section of this report. As a result, a Standard for Descriptive Cataloging of Technical Reports was published in December 1963 by COSI ([195]). There is still the necessity, however, for coding the items of the entry in order to make possible the "ordering out" or retrieval on those items.

We have also mentioned earlier the efforts of Federal agencies to standardize the form and use of the microfiche. Thus an agreement was reached in 1963 by NASA and the AEC whereby a uniform ratio of reduction in microphotocopying would

${ }^{380}$ U.S. Congress, 1963 [585], p. 7-9. allow the use of the same reading and printing equipment on all microfiche versions of technical reports regardless of the agency origin of the reports. This agreement was extended to OTS (Clearinghouse) for use in its large program for distributing DDC reports as well as other government-generated or -acquired material.

Another event of interest in the field of standardizing microforms is the publication of standards and specifications for microphotography of DOD engineering data. The DOD has issued throughout the years such standards and specifications, the most pertinent of which were assembled and published in 1963 by the National Microfilm Association. These documents, according to the Association, "supply basic data as it relates to the microphotographic reproduction of engineering drawings and related materials in accordance with the requirements of the Department of Defense." 381

In 1962 the DOD was given the annual award of the National Microfilm Association as its major recognition for outstanding service in the field of microreproduction. In the citation for the award the DOD is credited with developing and introducing "new and improved concepts of recording and reproduction of engineering documentation; the collection, interpretation, coordination, development and publication of standard specifications; industrywide acceptance of standardization of procedures and nomenclature. . . ."

\subsubsection{Programs of the American Standards Association (ASA)}

The American Standards Association is a privately supported organization "acting as the national clearinghouse and coordinating agency for voluntary standards in the United States." 382 Its main functions are to provide systematic means for development of standards, to promote their use, to coordinate standardization activities in the United States, and to act as a clearinghouse for information on standards. "An American Standard is a voluntary national standard, arrived at by common consent, and available for voluntary use." 383

ASA Sectional Committee X3 on Computers and Information Processing has seven working subcommittees. Subcommittee X3.1 is on optical character recognition (OCR), having task groups on font development, printing, and applications. Subcommittee X3.2 is concerned with coded character sets and data formats and has one completed standard, American Standard Code for Information Interchange (1963 [23]). This American Standard, 3.4-1963, was approved by the ASA on June 17, 1963, with the Business Equipment Manufacturers' Association as sponsor. The standard presents the standard coded character set to be

\footnotetext{
331 National Microfilm Association, 1963 [414], p. iil.

3s Henriques, $1964[251]$, p. 23.
3s3 Utman, $1963[605]$, p. 9 .
} 
2. STANDARD CODE

\begin{tabular}{|c|c|c|c|c|c|c|c|c|c|c|c|c|}
\hline \multicolumn{5}{|c|}{$\mathrm{D}_{7} \mathrm{O}_{6} \longrightarrow$} & ${ }^{\circ}{ }^{0} 0$ & ${ }^{0}{ }_{0}$ & ${ }^{0}{ }_{1}$ & & & ${ }_{1}{ }_{1}$ & 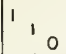 & 11 \\
\hline$i_{i_{1}} b_{4}$ & $b_{3}$ & $b_{2}$ & $\because$ & Column & 0 & 1 & 2 & 3 & 4 & 5 & 6 & 7 \\
\hline 0 & 0 & $\overline{0}$ & 0 & 0 & NUL & OLE & SP & 0 & ' & $P$ & $@$ & $D$ \\
\hline 0 & 0 & 0 & 1 & 1 & $\mathrm{SOH}$ & $0 \mathrm{OCI}$ & $!$ & 1 & $A$ & 0 & a & a \\
\hline 0 & 0 & 1 & 0 & 2 & STX & $0<2$ & " & 2 & $B$ & $\mathrm{R}$ & b & $r$ \\
\hline 0 & 0 & 1 & 1 & 3 & ETX & $0 \mathrm{OC3}$ & $\#$ & 3 & C & $s$ & c & 5 \\
\hline 0 & 1 & 0 & 0 & 4 & EOT & $O C 4$ & $\$$ & 4 & 0 & $T$ & $d$ & 1 \\
\hline 0 & 1 & 0 & 1 & 5 & ENO & NAK & $\%$ & 5 & $E$ & $u$ & $e$ & $u$ \\
\hline 0 & 1 & 1 & 0 & 6 & ACK & SYN & 8 & 6 & $F$ & $\mathrm{v}$ & $f$ & v \\
\hline 0 & 1 & 1 & 1 & 7 & $B E L$ & ETB & $\because$ & 7 & $G$ & $w$ & 9 & $w$ \\
\hline I & 0 & 0 & 0 & 8 & BS & CAN & 1 & 8 & $H$ & $x$ & $h$ & $x$ \\
\hline 1 & 0 & 0 & 1 & 9 & $H T$ & $E M$ & 1 & 9 & I & $Y$ & $i$ & $y$ \\
\hline$T$ & 0 & 1 & 0 & 10 & $L F$ & SS & * & : & $j$ & $z$ & $i$ & 2 \\
\hline 1 & 0 & 1 & 1 & 11 & VT & ESC & + & ; & $\mathrm{k}$ & [ & $k$ & $t$ \\
\hline 1 & 1 & 0 & 0 & 12 & $F F$ & FS & , & $<$ & $L$ & $\sim$ & 1 & 7 \\
\hline $\mathrm{I}$ & 1 & 0 & 1 & 13 & $C R$ & GS & - & $=$ & $M$ & J & $m$ & 3 \\
\hline 1 & 1 & 1 & 0 & 14 & so & $\mathrm{RS}$ & . & $>$ & $N$ & $\hat{\imath}$ & $n$ & 1 \\
\hline 1 & 1 & 1 & I & 15 & SI & US & 1 & $?$ & 0 & - & 0 & OEL \\
\hline
\end{tabular}

used for information interchange among information processing systems, communication systems, and associated equipment.

The standard specifies the correspondence of seven-bit patterns with 128 graphics and control codes; the graphics are for printable characters, and the controls are to initiate appropriate equipment functions. The 128-character code set covers 36 controls, 28 special characters, 10 numerics, and the 26 alphabetic characters, leaving 28 bit patterns unassigned. For example, the 7-bit positional order for the letter " $R$ " from the high- to the low-order position is 1010010 .

The standard does not define the means by which the coded set is to be recorded in any physical medium nor does it include any redundancies. It does not define techniques for error control. It does not specify a standard collating sequence. The code is referred to in the trade as "ASCII," pronounced "asky." (See figure 2.)

Bemer, in his first article on ASCII for Datamation, states that it may be expanded to 8 bits and that representations in various media are not defined. "The set can be collapsed in a regularized and prescribed manner, if required, into a 6-bit set for existing 6-bit machines and other equipments, to a 5-bit set for modification of existing Teletype and Telex sets (particularly in Europe), and even to a 4-bit set." 384 In his second ASCII article Bemer states that the code demands that "whenever the computer talks with strange equipment, not of its own lind, that it do so through the medium of this code." 385 Hence, each machine will have to talk only with ASCII instead of the other internal codes, numbering now about sixty.

Bemer lists the following advantages for computer programming purposes: (1) manipulation of graphics by classes; (2) fewer instructions in scans because of regularity and unique codes; (3) faster and cheaper sorting when the collating sequence is identical to the binary sequence of the codes for the graphics; $(4)$ reduction in the num-

384 Bemer, 1963 [49]; p. 35.

383 Ibid, p. $40-41$. ber of routines required to be programmed, particularly for satellite equipment; (5) fewer tables for mixed codes in communications, particularly those controlled by store-and-forward message switching systems; $(6)$ clarity of printed output, particularly the reproduction of the source program in the printed record of processing; and (7) a tendency for keyboards to be identical with typing communications equipment.

Bemer comments also "that some other internal code plus the translation mechanisms required might be more economical for some equipment then would ASCII internally.... The new code has so many inherent economies that it might pay for the redesign itself. IBM has perhaps the least problem of any manufacturer; with 9 different codes already in their various computers, ASCII presents only 11 percent additional probleins." 386

The International Business Machines Corps. in the August 7, 1963, special issue on ASCII of its IBM Data Processor states that "IBM plans to provide whatever means are practical to meet customer needs for using the standard code as soon as possible after media standardization is approved by the American Standards Association."

To inject a less serious tone, perhaps, we note that "the Federal Government, the military services, the manufacturers' society, and the computer community are now engaged in an extended debate on just what the characters in a 6-bit set should be and how these characters should be encoded within the set. There are already almost more variations on this basic set than there are rabbits in the Western United States." 387

Subcommittee X3.2 of the ASA Sectional Committee X3 is also actively engaged in concern with the problems of input-output media, including a code for perforated tape and specifications for the physical dimensions of both 1 -inch and $11 / 16$ th-inch perforated tape; codes for magnetic tape and punched cards; codes for both perforated and magnetic tape for numerical machine tool control; and with specifications for the physical dimensions of $1 / 2$-inch magnetic tape and for the 80 - and 90 column punched card and the edge-punched card.

Subcommittee X3.3 is concerned with digital data transmission. It proposed the first American standard in information processing, that on signaling speeds for data transmission. Standard X3.1-1962 was approved August 1962 by the ASA (1962 [26]) with the Business Equipment Manufacturers' Association as sponsor. The establishment of the speeds was considered necessary to ensure compatibility between communication channels and data terminal equipments of communications systems. The standard signaling speeds are $600,1200,1800,2000,2400$, and 3000 bauds. The statement concerning signal element duration is that "a synchronous signal train at the

356 Ibid, p. 40.

387 Patrick and Black, 1964 [450], p. 31. 
interface between the data communications equipment and the data processing terminal equipment, after synchronization is established, shall consist of a sequence of marking and spacing signals, all of which are integral multiples of the signal element. The signal element duration is equal to the reciprocal of the signaling rate in bauds."

Subcommittee X3.3 has six task groups on liaison, glossary, data transmission formats, end-toend control characteristics, system performance and digital data transmission speeds. Subcommittee X3.4 is concerned with common programming languages, to be discussed in section 3.9.4. Subcommittee X3.5 is on terminology and a glossary for information processing and hopes to produce a proposed American standard glossary soon.

Subcommittee X3.6 is on automatic data processing problem description and analysis and has a proposed standard which prescribes and defines the symbols used on flowcharts to represent both the sequence of operations and the flow of data and paperwork of information processing systems. The basic symbols include those for input/output, processing, flow direction, and annotation. Specialized input/output symobls are those for the punched card, magnetic and punched tapes, document, manual input, display, communication link, and on-line and off-line storages. Specialized processing symbols include decision, predefined process, manual operation, and auxiliary operation. There are additional symbols for a connector and a terminal. (These symbols are somewhat reminiscent of the graphical drawing symbols allowed by the U.S. Patent Office, in its Guide for Patent Draftsmen, for use on patent applications. The symbols recommended in the Guide are for common materials, such as metal or cork, electrical elements, and mechanical elements). Subcommittee X3.7 is on magnetic ink character regonition (MICR) which is closely related to the optical character recognition interests of X3.1, taking over earlier work by the Office Equipment Manufacturers Committee in conjunction with the American Bankers Association.

It is interesting to note that Sectional Committee X3 (SC X3) of the ASA was organized in 1960 to work on standards for software (program instructions and operating procedures for information processing equipment) more than 18 months before Sectional Committee X6 (SC X6) was organized to handle standards for hardware (equipment, especially information processing equipment).

Sectional Committee Z39 of the ASA covers Library Work and Documentation. Its purpose is to develop standards for concepts, definitions, terminology, letters and signs, practices, methods, supplies, and equipment used in the field of library work and the preparation and utilization of documents. The committee is sponsored by the Council of National Library Associations. Sectional Committee Z39 in the first quarter of 1963 was giving particular attention to four areas: abbreviations for periodical titles, abstracts, transliteration, and trade catalogs. The standard proposed for the transliteration of modern Russian letters had been developed by the Subcommittee on Transliteration in close cooperation with the Royal Society of London.

The Subcommittee on Abstracts of the ASA SC Z39 regards an abstract as an abbreviated rendition of the significant content of a scientific paper or report, book or other documentary item. The intention of the proposed standard on $a b$ stracts is to comment briefly on the function of an abstract, its character, content, style, and language, and on the publication of abstracts by abstracting services.

There is also a Subcommittee on Classification, which held its first meeting in November 1963.

The Subcommittee on Transliteration of Z39 is concerned with transliteration from one language alphabet to another: Greek to Roman, Russian (Cyrillic) to Roman, Chinese to Roman, etc. Activities of this committee are aimed at developing a system acceptable to librarians and information specialists in the United States, with hopes for coordination with similar activities in organizations abroad. The subcommittee aimed, for example, to present a single new system of Cyrillic transliteration for modern Russian only; having worked on this program for some time, it turned to consultation with British representatives on the needs and aims of transliteration programs overseas.

The need for standardization in this area is obvious, especially in light of the ever-increasing and ever more important foreign language material to be processed. (The question of language problems as such is discussed in section 4.1.2 of this report.) The transliteration problem touches not only conventional information handling systems but mechanical translation research programs also. Interests of the latter were expressed by Kellogg when he said, "If we [U.S., Russian MT programs] could agree on two simple things, we would both be happy. One is a uniform transliteration system, just for changing people's names from one alphabet into the other. We have a system by agreement within the Western World, the Russians use a different one.

"Secondly, if we could agree to have them print a little box instead of a period at the end of a sentence, and a comma that is a little more definite than the kind we have now, and if we traded them journai for journal, this would save us troublebut we can't get agreement." 388 However, attempts to reach such agreement do continue.

Some standards have been promulgated successfully. Thus, American Standard Z39.1 was sponsored by the ALA, approved on June 7, 1943, and reaffirmed in 1959. It concerns the manner by which periodicals are issued, numbered, and

${ }^{3 s s}$ U.S. House, 1960 [588], p. 61. 
named, and the manner by which their pages are numbered; it requests that each periodical include a title page, table of contents, and index.

American Standard Z39.4 was sponsored by the Council of National Library Associations and approved on May 5, 1959. The criteria are for indexing books, periodicals, and other documentary materials. An index within the fields of library practice and documentation is defined as "a guide to the contents of any reading matter or other documentary materials which provides a systematic, sustained subject analysis of the contents of such materials arranged according to alphabetical, chronological, numerical, or other chosen order. Each entry is followed by page number, paragraph number, or other indicator showing the exact location of the reference." 389

The word "subject" as used in the above definition is defined as "a unit concept found in, or derived from, the material indexed. The unit concept may be found or expressed as a thematic topic, a name, a date, the first line of a poem, the title of a work, an expression coined to give the gist of the material indexed, etc." 390 The matters covered concerning the content, organization and style of indexes include the entries (headings, subheadings, and modifications), the alphabetizing or filing, inversion of headings or names of companies or organizations, references (mainly to pages), typography, and cross references.

Z 39.5-1963, "American Standard for Periodical Title Abbreviations," has also been issued. "General rules are provided in the standard for the omission of letters, punctuation, conflicting title words, and multilingual abbreviations... The product of two years' research by a committee of experts, the new standard contains more than 2400 abbreviations for words commonly found in periodical titles." 391

In 1960 the American Standards Association and the International Standards Organization decided to form joint committees on computers and information processing. The groups involved were the ASA SC X3 and the ISO Technical Committee 97 (TC 97). Scopes for these committees "were adopted in organization meetings held in 1960 and 1961. ISO assigned the Secretariat of TC97 to the United States and the ASA, which in turn recognized the Business Equipment Manufacturers Association (BEMA) as sponsors of $\mathrm{X} 3$ and TC 97 , with $\mathrm{X} 3$ to develop proposed standards for both the U.S. and the world." 392

Formal standardization work in photography, at least in the United States, was first initiated in 1938 under the procedures of the ASA. The committee established at that time was designated the ASA Sectional Committee on Standardization in the Field of Photography, Z38; the committee

\footnotetext{
389 American Standards Association, Inc., 1959 [22], p. 5.

390 Ibid.

381 Scientific Information Notes 6, 3, 17 (1964).

392 Utman, 1963 [605], p. 9.
}

operated for more than 10 years under the sponsorship of the Optical Society of America and was responsible for the development of over a hundred standards. On November 30, 1950, ASA Committee Z38 was disbanded with four new committees replacing it, and a fifth was organized on June 25, 1953. ASA Sectional Committee PH 5 on Photographic Reproduction of Documents was given responsibility for standards "for photographic materials, apparatus, and processes pertaining to production, use, storage, and preservation of document reproduction." Sectional Committee PH 5 has been of considerable interest in the field of documentation owing to its standards on the various kinds of film. The American Standard PH 5.3 is the one of most direct interest to endeavors in microphotography although it was intended basically to be of interest for motion picture film.

\subsubsection{Programs of the International Standards Organization (ISO)}

Donker Duyvis wrote in 1954, as the Secretary General of the International Federation for Documentation, on Standardization as a Tool of Scientific Management. He gives as a positive definition of standardization: "to bring production to a higher level, to guide and plan judiciously the necessary diversity in order to promote harmony in variety, and to assure that human labor will be used in a wortlyy way." ${ }^{393}$ He lists as subjects belonging to standards in librarianship: the material and layout of documents; the elements and editing of their contents; their arrangement, filing and storage, and various mechanical devices. Donker Duyvis stresses that ". . . particularly for librarians and documentalists, standardization loses half of its value if it is not done on a worldwide basis." 394

It may also be of interest to note an example for documentation for standards. "The late F. Donker Duyvis, former Secretary General of the International Federation for Documentation, united his interest in providing documentation service for standards with that of the ISO, and became chairman of ISO's Committee for Index Cards for standards that are issued by Member Associations." 395

The International Standards Organization (ISO) had in 1954 a technical committee on documentation called ISO/TC 46. In that year, ISO in collaboration with UNESCO published draft recommendations for the layout of periodicals, for bibliographical citations (the citing of titles of documents), and for bibliographical references (the identification of publications, considered either as bibliographical units in themselves or as parts of larger works) ; it published also ISO/R4, accepted by the ISO Council as its recommended International Code for the Abbreviation of Titles

\footnotetext{
303 Donker Duyvis, 1954 [176], p. 410.

${ }^{394}$ Ibid, p. 426

395 Murra, 1962 [402], p. 407.
} 
of Periodicals. These examples are cited as evidence of continuing international activity in the standardization of documentation. "Progress in intermational standardization work in the field of documentation has been steady, if not spectacular; since the war, there have been five meetings of Technical Committee 46 (Documentation) of the International Organization for Standardization ... but much of the real work has been done by correspondence and in special meetings of working parties." 396

In 1954 Lloyd ([346]) prepared a selective list of standard-practice recommendations available from a baker's dozen of standards-issuing organizations. He noted that of the many problems which plague the technical editor, those which involve layout, references, transliterations, abbreviations, proof corrections, and the like can be simplified by the adoption of standard practices. The Lloyd list includes seven recommendations for abbreviation of periodical titles, two for abstracts and synopses, six for bibliographic citation practice, five for symbols and abbreviations, and four for Cyrillic alphabet transliteration. The then pending ISO recommendations thought to be most urgently required were: ISO R4 (1954) : International code for the abbreviation of titles of periodicals; ISO Draft Recommendation 23 (1953) : Bibliographical citations; ISO Draft Recommendation 24 (1953) : Bibliographical references; ISO Draft Recommendation 3 (1953) : Layout of periodicals.

Lloyd remarked that "some of the most useful recommendations are not as well known as they should be, partly because they are not always readily available and partly through lack of publicity." 397

New items considered for standards work by ISO/TC 46 at its meeting in Brussels in 1954 included not only the layout of index cards, proof correction signs, and transliteration of Oriental alphabets, already mentioned, but also two other proposals, which, however, were deferred not only on grounds of overlap with other organizations but also because of serious question as to the feasibility of reaching agreement. These were for 'canons' or 'guiding principles' for cataloging and classification rules. With respect to the latter, in particular, the FID General Secretary stated that his organization "had long been studying the problem, and had found it impossible to reach much international agreement yet on such philosophical subjects." 398

In addition, ". . . At the recent Brussels meeting of ISO/TC 46 , it transpired that criticism of Draft ISO Rec. 24, Bibliographical references (full references) had been so severe as to necessitate a complete redrafting . . ." 399 More successful, though, were "The Code for Abbreviation and

\footnotetext{
${ }^{396}$ Lloyd, 1955 [347], p. 49.

397 LIoyd, 1954 [3+6], p. 282.

393 Lloyd, 1955 [347], p. 53.

390 Lloyd, 1955 [347], p. 50.
}

Layout of periodicals, with Bibliographical citations and Bibliographical references, [which] were regarded by Unesco as sufficiently important to warrant a special grant, and the ISO/TC 46 Secretariat has recently discharged its obligation to Unesco by issuing these, together with an introduction, in the form of a report to Unesco entitled Standardization in the domain of documentation..." 400

In the field of microreproduction, ISO has also been active: "In April 1950 the International Standards Organisation (ISO), meeting jointly with the International Federation for Documentation (FID) at Ascona, established a subcommittee of Technical Committee 46 to draft recommendations for (a) the terminology of microcopies and (b) the size of the microcopies. The meeting of the ISO committee at Paris in June 1955 advanced, but did not conclude, these studies. In 1953 the American Standards Association established a new Committee (PH 5) to develop standards for materials, apparatus and processes connected with the production, use, storage and preservation of photographic documentary reproductions." 401

The ISO has established standards in this area: "ISO Mire (Test object) is made up of a $25 \mathrm{x}$ $50 \mathrm{~mm}$ area with lines of artificial 'words' in varying sizes of type, each 'word' consisting of four symbols in the form of a conventional (ISO) octagon with two diagonal lines, replacing ordinary letter characters, which can often be guessed at even when not strictly legible ... ISO Micromire (Micro Test Object) is a carefully prepared microcopy (1:10 reduction) of the ISO Test object. Strips of the Micro Test object are then mounted in the form of a pattern on a chequered black-and-white ground, and this chart is used for testing image sharpness, etc., in microfilm cameras and reading apparatus." 402

Donker Duyvis wrote (1954 [176]) of his hope for the ASA to cooperate closely with the ISO in formulating standards for reading apparatus. Lloyd reports, "Two new draft proposals referring to the testing of microcopy reading apparatus are now under consideration by the nineteen member countries of the main Technical Committee ISO/TC $46 \ldots .{ }^{403}$

Furthermore, "The subcommittee [ISO/TC 46/SCI Documentary Reproduction Subcommittee] unanimously adopted a recommendation from a three-man ... commission to abandon the terms 'Microcard,' 'Microcarte,' and 'Microprint as confusing, indefinite and possibly also proprietary. In place of these, it accepted a definition of the word 'Microfiche' (same word in both French and English ...." 404

A few citations to standardization on translit. eration seem appropriate inasmuch as the trans

\footnotetext{
400 Ibid, p. 49-50.

401 Born, 1956 [69], p. 168

402 Lloyd $1955[3+7]$, p. 51-52.

${ }^{403}$ Lloyd, 1955 [347], p. 51.

104 Ibid, p. 51-52.
} 
literation of the languages of the world has always caused so much heated controversy. Frontard, of the French Standards Association, reviewed international efforts toward standardization of transliterations, beginning with Recommendation ISO/R 9 of the Technical Committee 46 on Documentation of the International Standards Organization (1961 [205]). ISO/R 9 was published in 1955 and recommended an international system for the transliteration of Cyrillic characters. Progress was reported on the transliteration of Greek and the nonvocalic languages, such as Hebrew and Arabic. At a meeting of ISO/TC 46 in London in June 1960, Chinese, as an ideographic nonsyllabic language, was regarded as incapable of transliteration and amendable only to transcripcion, etymologically shifting from writing in one alphabet to writing in another.

Neiswender wrote in 1962 that the ISO/R 9 "was a landmark in the history of transliteration, for it represented the first system based on international agreement, and it secured the approval of 20 linguistically dissimilar countries . . ." 405 However, the ISO system, although adopted by UNESCO for its bibliographical publications and library catalogs, "did not secure general acceptance among English-speaking countries, largely because of the long-standing United States commitment to the Library of Congress system and because of previous attempts by the Royal Society to formulate a British standard."

Neiswender gives as organizations interested in transliteration (in addition to $\mathrm{LC}$ ), the British Standards Institution, the Board of Geographic Names (U.S.A.), the New York Public Library, the Slavic Review, and Mathematical Reviews. She also distinguishes transcription "as the process by which some idea is conveyed of pronounciation as well as of spelling from transliteration as the process by which characters in one alphabet are arbitrarily and unambiguously represented by characters in those of another, disregarding phonetic accuracy." 406

Finally we note recent ISO activities paralleling those of ASA for character recognition and codes for information interchange:

"The ISO Technical Committee 97 ... just concluded a series of meetings in New York City ... World wide standards on optical and magnetic ink character recognition and business machines were drafted by the group . . .

"The ISO draft proposal for magnetic ink character recognition. Two different type fontsE13B and CMC-7-are being proposed. . . .

"The new code (ISO) for information interchange includes recommendations for both six-bit and seven-bits sets ... Some of the code positions have been left unassigned to meet the needs of individual countries ... the code is generally compatible with the American Standard Code for In-

4 Naicwender, 1962 [421], p. 38.

406 Ibid, p. 37. formation Interchange (ASCII) approved by the ASA last year." ${ }^{40 z}$

\subsubsection{Programs of Other Organizations}

An organization complementary in its specialized field to the ISO is the International Electrotechnical Commission (IEC), whose Technical Committee 53 is concerned with computers and information processing. The IEC recommends electrical standards only, whereas the ISO recommends international standards in all fields of endeavor except electrical. The chairman of IEC/ TC 53 is A. B. Credle of the United States, who provided this information to the June $1963 \mathrm{Com}$ munications of the $A C M I$ : TC/53 held its first meeting in London in 1961. It has four subcommittees: SC 53A on digital input/output equipments, SC $53 \mathrm{~B}$ on digital data transmission, SC $53 \mathrm{C}$ on analog equipments for information processing systems, and SC 53D on input/output media. A joint steering committee has been set up, composed of the chairmen, secretaries, and technical advisors of IEC/TC 53 , ISO/TC 97, and ISO/TC 95 (office machines), to avoid conflicts of interest and duplication of effort.

We note further that: "To facilitate the translation of papers from one language into others, ... the most important aspect is a precise, unified terminology. In particular, the use of international dictionaries is of the greatest importance. An example is the International Electrical Engineering Dictionary, which is now in its second edition and is presently being published in a third edition by the International Electrical Engineering Commission." 408

By 1958 the International Federation for Documentation had published a bibliography of standards on documentation, with M. Schuchmann responsible for the publication (1961 [505]). In 1961, with the financial assistance of UNESCO, FID published a supplement to the bibliography, bringing it up to date. Part I of the bibliography has a listing of the standards classified by countries and ISO recommendations, supplemented by a list of all editions of the UDC recognized by FID; within the national groups, the standards are listed by serial number. In part II the standards are listed in a systematic arrangement by UDC. Each standard is listed only once, under its main aspect.

ECMLA (the European Computer Manufacturers Association) came into being officially in May 1961 and has as its main purpose the development of methods and procedures for facilitating and standardizing the use of data processing systems. Information on the organization of ECMIA was transmitted to the June 1963 Communications of the $A C M$ by C. G. Holland-Martin, of Leo Computers, Ltd., of the Coordinating Committee, and D. Hekimi, the Secretary General. The technical

407 Creating Order out of Confusion, 1964 [148], p. 26

408 Tareev, 1962 [555], p. 339. 
committees are : TC1, input and output codes committee; TC2, general programming languages committee; TC3, flow charting committee; TC4, character recognition committee; TC5, ALGOL Committee; TC6, COBOL Committee; and TC7, MICR (magnetic ink character recognition).

Programming electronic data processing systems is no simple task. As a consequence, programming languages have been devised both to provide means for noncomputer-oriented programmers to use such systems as well as to make instructions to computers less complex and tedious for trained programmers. The first of these languages, quite logically, was developed for scientific and mathematical application; Fortran (Formula Translation) first, followed by ALGOL Algorithmic Language). Subsequently COBOL (Common $B$ usiness $O$ riented Language) has been developed as a general-purpose language, and a number of more specific problem-oriented languages have also been considered.

Actually, there had been earlier efforts for the interchange of programs, beginning with those written in machine-oriented assembly language. This was demonstrated by the establishment of the SHARE organization, an informal cooperative among users of the IBM 704. Early in 1954, a group of aircraft companies in the U.S.A. found, while replacing IBM 701's by 704's, that considerable duplication and redundancy had existed in the usage of the earlier machine.409 The cooperating groups (groups of functioning users and groups oriented to particular applications or disciplines) found that each member acquired means of using his machine much more efficiently in return for their exchanges.

COBOL (a procedure-oriented and machineindependent programming language), had its origin in a meeting convened on May 28 and 29, 1959 , by the Department of Defense to consider the standardization of commercial data processing languages. "The COBOL System is composed of two elements . . . a source program written in COBOL by the customer, and a manufacturer's compiler which translates the source program into a machine language program capable of running on a particular computer.410 The "compiler" is sometimes called a "translator." Wofsey made an analysis of COBOL compilers for four computers: UNIVAC II (Sept. 1960), UNIVAC Solid State 80 (Sept. 1960), RCA 501 (Dec. 1960), and RCA 301 (June 1961) to discover differences which would necessitate changes if a source program from one machine were processed for another with its compiler. Differences ran from 1 to 44 in number, averaging 21.5, with a mean of 23.

Subcommittee X3.4 of the ASA X3 Sectional Committee on Computers and Information Processing is devoting itself to the standardization of

409 Bemer, 1960 [50], p. 338-340.
410 Wofsey, 1962 [651], p. 1. programming languages. It has task groups for establishing the United States positions in regard to ALGOL, FORTRAN, COBOL, and the APT (Automatically Programmed Tool) System with numerically controlled machine tools. Utman reports ${ }^{411}$ that "Internationally, TC 97/SC5 has prepared a Programming Language Survey which is now being published in professional journals, and has invited IFIP/WG 2.1 (a Working Group of the International Federation of Information Processing Societies) and X3.4 to provide draft proposals for ALGOL, FORTRAN, and COBOL for consideration as international draft recommendations." ("TC 97/SC5 refers to Technical Committee 97 of the International Standards Organization and its Subcommittee 5.)

Indicative of the importance of programming languages is the experience of Minder and Lazorick in the automation of the acquisitions department of the library of the Pennsylvania State University. They used the FORTRAN language with the IBM 7070, 7074, 1401, and 1620 generalpurpose computers available on the campus. They conclude that "ADI, ALA, and SLA could do a service by forming a joint committee to study this whole problem of computer language for library operations. I suspect that FORTRAN is the inferior language. I also suspect that others will senselessly duplicate our efforts due to the lack of coordination and standardization." 412

An indication of the activity regarding standardization with the electronic data processing industry in the United States as seen from England is given by Pearce Wright (1963 [654]). He states that "Trade associations, professional bodies, etc., are striving with the American Standards Association to provide acceptable standards by which users can assess equipment in the field.

Perhaps the most arduous and complex project in this amorphous mass is on programming languages. Tremendous effort is being poured into resolving the tangle surrounding the English language programming system COBOL." Wright regards calling the COBOL language a standard as a mockery since there are "so many revised. versions of COBOL reports and sub-sets of the language . . . " Still, he says, "People engaged in this work hotly refuted suggestions that one monster might succeed another, and expressed the belief that sub-sets of COBOL should also work adequately on the large number of smaller installations." 413

One organization interested in progress in standardization and destined to take an active part in such work is the National Federation of Science Abstracting and Indexing Services. In 1963 it published its NFSAIS Standard No. 63-1, Transliteration of the Modern Russian Alphabet, claiming that "Its principal virtues are its wide acceptability and its minimum use of diacritical

411 Utman, 1963 [605], p. 12.

412 Minder and Lazorick, 1963 [389], p. 456.

${ }^{413}$ Wright, 1963 [654], p. 10. 
marks. It represents a slight modification of the Russian portion of British Standard Institution's (British Standard 2979: 1958) system for (modern) Cyrillic-English transliteration." ([410]) This represents only one area of NFSAIS interest in standardization for information handling systems.

\section{Problem Areas}

The current problem areas which can readily be discerned include both those that are general with respect to any information handling system whether manual or mechanized and those that are more specific to mechanized systems and the present and future prospects for machine language compatibility. In both the general and specific aspects, the problems of problem definition, of languages, and of human factors and user acceptance are paramount.

We will recapitulate here some of the findings, current and proposed activities and efforts and prior experiences which have a bearing on the problems, difficulties and complexities of working toward mechanized-systems compatibility. All of these difficulties are of course aggravated by ". . . (1) a rapid increase in the record to be controlled, involving new terminology, taking new forms, and appearing under widely dispersed auspices; (2) an increasing need to employ finer detail, to incorporate the new terminology more promptly, and to retrieve documents from unanticipated points of view; and (3) technical developments in the area of information theory, of information processing equipment, and in library science and its tools." I

\subsection{General Problem Areas}

The problem of problems is that of problem definition itself. First is the need for recognition that cooperation, compatibility and convertibility should extend through the whole complex cycle of information handling from its initial generation to its ultimate use. Adkinson, reporting on studies made by the American Institute of Physics and by the American Institute of Biological Sciences states that common to them both has been: "... the recognition by leading scientists in the fields involved (a) that the information problem is very complex; (b) that simple statements like 'what we need is more abstracts' or 'what we must do is mechanize' or 'scientists should write less,' if taken in isolation, ignore a whole host of variables and vastly oversimplify the problem; and (c) that any long-range or lasting solution must consider all phases of information recording, dissemination, and control." 2

As Adkinson states further, the first area of problem definition requiring attention is that of acquiring "much deeper understanding of the strengths and weaknesses of the whole complex of scientific information services and practices and

\footnotetext{
1 Maloney, 1959 [368], p. 1365.
}

2 U.S. Senate, 1960 [592], p. 102 . of the true requirements of scientists." 3 Such understanding is prerequisite to the determination of the needs of the generators of scientific information (from bench scientist to program director), the needs of those who communicate or prepare secondary publications and critical reviews, the requirements of those who disseminate, acquire, store, search and retrieve the literature, the needs of those who use and evaluate the products of the information handling services.

This implies that network requirements, system requirements, user requirements, and implementation or equipment requirements should be investigated at all possible levels and for all types of users. We can expect to find important differences between international, national, regional, and local level requirements; between interdisciplinary areas and within specific disciplines or groups of related disciplines; between interdisciplinary areas and within specific disciplines or groups of related disciplines; between research, development, application, evaluation, and teaching; and, particularly, between mission-orientation and the more traditional disciplinary approaches. The differing needs of expert, practitioner, apprentice or intern, student and teacher; of the grant administrator, project coordinator, research manager, product development or marketing specialist; of the patent attorney, librarian, documentalist, scientific information officer, all require systematic consideration.

"Effecting coordination within the Federal establishment is complicated by the varying basic missions of different scientific information services. Some are permitted to serve only their parent agencies or some well-defined group of users; others work primarily for the benefit of their own agencies, but have some official responsibility toward the scientific community as a whole, still others are set up specifically to serve science and scientists everywhere. Any overall coordinating effort must try to combine maximum value to the national scientific effort with the minimum jeopardy to the various programs' individual responsibilities." 4

Recognition of these many different objectives, even of missions, requires a corresponding recognition of differing requirements, needs, and potentialities. Thus, for example, "large organized programs of research are the exception and the technical report, which plays so important a role in engineering and in areas of the physical sciences that are oriented toward technical development, is a relatively unimportant channel for biomedical communication ... New forms of communication and new types of services that serve other scientific communities effectively will not necessarily be appropriate to, or of comparable usefulness in, the biomedical sciences."

3 Ibid, p. 109.

4 Seientific Information Notes 4, 4, 1 (1962)

5 "Communtcation Problems in Biomedical Research", 1963 $[403]$, p. 9 . 
"Our first problem and the major one in the field of information retrieval is to define the system requirements." 6

\subsubsection{Difficulties of Problem Definition}

A single example may suffice to indicate that the questions of improved cooperation, compatibility, or convertibility are inextricably related to consideration of the whole complex of information handling activity. Let us consider that these objectives are to be sought in a network of services.

After studying the possibilities for automation in the Library of Congress, the survey team reported: "This concept of linking many libraries and other users together for mutual support and cost reduction raises a different set of data-transfer design considerations. Probably high data rates, in bursts, are desirable in order to avoid the cost burden of having long distance communication channels open for long periods of time. Compatibility with the local data links will certainly not be insurmountable but must be planned far ahead even though the actual realization of the network feature of the system may come at a later date." r

What are the problems, delays, costs and availabilities of transmission facilities, given that the requestor or user is at a remote location? A centralized facility may have available closed-circuit TV, facsimile transmission systems, data transmittal services, telephone or teletype leased lines, various types of postal service. Do all, or even a majority, of its customers have suitable receiver equipment to obtain the transmitted information within a reasonable scale of both time and cost? If not, can the products of such centralized facilities be transmitted in various different ways suitable to the needs of a variety of customers?

Over and above these physical characteristic and economic feasibility considerations there is a special two-fold substantive system problem here, that of knowing what the local needs of the various customers are and of setting these local needs in the context of the network. With respect to the definition and evaluation of special-purpose requirements, any systems-planning effort involving improvements in cooperation, compatibility, or convertibility must ask whether these are merely matters of parochial practice and prejudice, or whether they do indeed reflect valid local needs.

In many cases, what might appear to be the protection of vested interests or merely resistance to change can instead be the result of a valid concern for the special interests of a specialized clientele. For example, a report-numbering system resulting in identifying codes too cumbersome or too long for handling in a machine-compiled or machinegenerated index format may be an important source of identification of organizational cognizance, of considerable usefulness to contractors of an important agency such as the AEC.

6 Genereaux, 1962 [214], p. 44

T King, 1964 [319], p. 238 .
In other cases, again, tools such as authority lists and thesauri painstakingly developed to serve the broad overall interests of a large collection or a particular community or profession may nevertheless be far too general to meet the needs of a special library or specialized information center which nevertheless must receive material from and contribute to the larger collection or community.

The experience of Lunin and Stovall of the departments of pathology and physics of the M. D. Anderson Hospital and Tumor Institute of the University of Texas at Houston (1963 [362]) seems to indicate that complete interchange of indexing vocabularies is not possible. They constructed a thesaurus for the fields of radiobiology, radiation physics, and trace metals as these relate to the cancer problem. They tried to make their thesaurus compatible in terminology with the descriptors of the NLM, the thesaurus of the National Institutes of Health, and the Radiology Vocabulary of ASTIA. They regard compatibility as implying the "use of the same word although number (singular or plural) or form (noun or adjective) may vary."

They found that compatibility for general terminology (all subject areas covered with the exception of tumors) was 37,43 and 32 percent, respectively, for NLM, NIH, and ASTIA. For neoplasia terminology the figures were 21,16 , and less than 1 percent, respectively. Lunin and Stovall therefore conclude that "national thesauri cannot be used for indexing individual reprint collections of researchers. Examination of the three national vocabularies demonstrated that (a) information in several areas did not appear in sufficient detail, (b) many terms desired for use in the institutional program were not included in the national thesauri, and (c) researchers in this institution did not always agree with the organization of terminology in the three thesauri." 8

Accommodation to local special-purpose needs can range all the way from recognition that "ASTIA does a general cataloging operation on technical reports that it receives. However, this general cataloging is not in sufficient depth or detail to satisfy the requirements of large research and development organizations. Further ... to wait for ASTIA cataloging would be too long for most activities," 9 through the practice of the Library of Congress which, if it "rejects a heading supplied by a special library ...., prints the rejected heading along with its own heading because the Library of Congress officially recognizes that the purposes of a special library may require a degree of specificity in indexing not necessary or desirable for its own general purposes," 10 to questions of the equipment facilities readily available.

Altmann says, for example, that, "not only within the framework of the technical information

${ }^{8}$ Lunin and Stovall, 1963 [362], p. 190.

- Langenbeck, 1962 [329], p. 296-297.

10 Taube, 1951 [559], p. 67. 
office itself, but also within the entire installation, the operations must be made compatible with the existing machine system. These adjustments dictated by economy and budget limitations in addition to the peculiar subject interests in each installation make it difficult to follow those whn advocate the centralization of services."

He continues, "While national centers proceed to develop retrieval systems and methods which they deem appropriate for their own operations, they fail to consider that in most medium-sized research and development installations, the services of the technical information office do not and will not justify the acquisition of a separate computer. Because the information office must utilize the system which its agency has installed for a variety of activities, economic considerations and good managerial practice place restrictions on the form of processes and procedures as well as on the type of auxiliary equipment used to produce punched cards or punched ribbons . . .

"If national centers continue to establish their systems without accepting mutual compatibility as an overruling principle and without a definite program for the easy utilization of their catalogs and bibliographies in other and especially the smaller document collections and services, the technical information offices of research, development, and engineering establishments cannot help but develop their own operations in conformity with the particular missions and tasks of the laboratories, using such tools of automation as they can afford." 11

Freeman points even more specifically to a major implication of general versus local need in the Federal sponsorship of improved cooperation, compatibility, and convertibility. He says, "... It does not seem unreasonable that many agencies with major research programs have, and will continue to develop information systems specifically designed and oriented to their own internal control purposes. Attempts to standardize these different systems or to enforce compatibility among such systems must recognize the basic fact that management practices and procedures are necessarity different." 12

The approach to the problems of problem definition based on viewing the "whole complex" involves also the recognition that the handling of the new forms cannot safely be divorced from at least the appreciation of the problems of the handling of the traditional literature; that the processes of handling, from the original generation through publication, dissemination, storage, selection, and ultimate use are typically interdependent, and that, as of today, we lack not only objective data but even a consistent methodology by which such data might be obtained. Some representative corroborative opinions on these points are as follows:

"At the present time our knowledge of the uses

\footnotetext{
11 Altmann, 1963 [12], p. 24
}

to which literature is put, and the demands made upon bibliographic resources by those who consult them, are lamentably fragmentary. One cannot talk intelligently about the problems of classification or devise effective schemes for the several branches of knowledge until he can answer with some degree of certainty the question: how does any consultant search for and use the literature that theoretically is at his command? To this the users themselves can give no valid answer. Conjecture and generalization based upon subjective opinions are not enough." 13

". . . We must know more about the traditional dissemination pattern if we expect to improve it in a systematic way. Measurements and means for continually monitoring the composition, volume, and rates of growth of the literature must be established before any comprehensive plans or policy decisions can be made. . . ." 14

"The communication problems of Government are inextricably intertwined with those outside the Government. Both the Government and the nonGovernment communities are concerned with the same total body of information; the progress made in each contributes vitally to the other." 1.5

"It is anticipated that systematic study of user needs and characteristics as well as research on the logic of information systems will have to be undertaken. Methods of classifying, abstracting, indexing, storing, retrieving and disseminating increasingly formidable amounts of information will have to be studied in detail. No scheme for accomplishing these operations adequate to the needs of the scientific community is yet at hand." 16

"The most pressing need therefore is for the development of reliable methods for studying and assessing requirements, for determining the role of information and information services in science, and for measuring the value of information and the utility and effectiveness of present and proposed services." 17

"It is a curious and unfortunate fact that libraries of today have virtually no way of knowing how well they are performing from the point of view of what the user ought to be getting from the system. In general, there is no way of knowing how much information responsive to a subjectoriented request is not found. Possibly one of the most important consequences of automation will be to provide a capability for maintaining use history and for implementing measurements on a sampling basis in order to install a good system of quality control in the library's operations." 18

Specific attempts to achieve greater compatibility or convertibility between present systems are likely to be doomed to fail (or, worse, to set back future improvements) in the absence of far more objective and more detailed information than we

\footnotetext{
13 Shera, 1951 [523], p. 88-89.
14 Bourne, 1962 [73] p. 162.

15 Crawford Report, 1963 [465] (App.), p. 33.

16 Stanford Research Institute, 1963 [542], p. 9-10.

17 U.S. Senate, $1960[592]$, p. 110.

$18 \mathrm{King}, 1963$ [318], p. 23.
} 
have today on present requirements, present costs, and present effectiveness. Even where the application or proposed operations are new, relatively self-contained and capable of implementation without too serious an involvement in the redoing of prior work, the lack of definitive data for problem definition is critical.

In one of the relatively few examples of proposed cooperative action in the establishment of a mechanized system to be shared by various specific contributors and users, the initial study team was surprised by the nature, extent, and implications of this problem: "What are library services worth to industry? How much are they willing to pay? What is the average dollar value of various kinds of library services? How much money is saved by using library services compared with not using them? No one seems to have answers to these questions. We have found no evidence of controlled evaluations, and industrial librarians found estimates difficult to make, whether for themselves or for the proposed cooperative system." 19

In a fundamental sense, current difficulties of problem definition stem from lack of knowledge and objective data about requirements, about the parameters of the problem, about the value of existing services and systems, about the effectiveness of these systems, about suitable techniques for measurement and evaluation, and about suitable criteria of effectiveness and value.

\subsubsection{Problems of Language}

The problems of language in the mechanization of scientific and technical information handling are manifold. There are problems of source language and identification ; input languages and media; indexing and classificatory languages; coding languages; internal machine languages; programming languages; and the devices and languages of retrieval, display and output. To an important extent, however, problems of language, of various levels of language, and of various languages affect all systems for the handling of scientific and technical information.

Incoming documentary items received at the library or information center, or at an abstracting or indexing service, will have been written in some particular natural language or in more than one language. Whether or not the center or service has a mechanized system, the problem of source language and identification are particularly severe when there are many foreign language inputs.

For compatibility to be achieved between such systems there must be agreement reached as to conventions and practices. Is the title to be retained in the original language, given as translated, or both, and if so how is the one form to be distinguished from the other? Can a standardized system be established for transliterations

19 "A Joint College/Industry Library With Automata," 1964 $[302]$, p. 5 . even if only for author names? Crowther suggested in 1958, for example, that "the standardization of a system of translation of Russian author's names, or at least the reduction of the number of alternative systems in use to no more than two, is rather an urgent matter for scientific documentation . . . The I.C.S.U. Abstracting Board and its member journals are agreed on the value of adopting a uniform system. ..." 20

Other typical questions and difficulties that require resolution, especially for mechanized systems, range from standardized spellings of place names to the increased size of the input alphabet that will be required to accommodate non-Roman alphabets and the use of diacritics, and questions of how to sort on compound foreign names and how to handle foreign abbreviations, including the case of the use of diphthongs as initials. Parenthetically, we may note that in terms of international cooperation, other nationalities have complementary difficulties to face. Thus, for treatment of foreign language references at VINITI, "Neither the author's first name nor his initials are given in the Russian transcription because (unless the full name is known) it is often impossible to find adequate equivalents for the initials." 21

From the standpoint of international collaboration, cooperation, and compatibility, or of systems at any level accepting as direct inputs items originally prepared in various foreign languages, it is clear that serious consideration should be given to either direct use of, or convertibility into, an artificial documentary language or notation scheme for identification, filing, and subsequent selection. This scheme would preferably be one involving numeric rather than alphabetic file ordering. Thus, for example, Mills points out that "UDC is an international language in that a file organized by UDC makes sense in any language. One organized on the basis of alphabetical order of terms for example suffers a national limitation." 22

In the discussions following the Mills presentation at a Rutgers Graduate Library School seminar, "Mr. Rigby thought that the neglect of UDC in the United States was due partly to the fact that Americans, enjoying one language, did not realize sufficiently the problems raised by the use of many different languages and the usefulness of a neutral, intermediate language as an aid to retrieval in such a situation." ${ }^{23}$ "Further, Wooster suggested consideration of the use of the UDC as an intermediate language for purposes of translation. "We could go from an English term to its UDC number and from that to its subject description in other languages ... In France they are seriously proposing the use of UDC as an interlingua for mechanical translations." 24

\footnotetext{
${ }^{20}$ Crowther, 1959 [150], p. 487.

21 Mikhailov, 1959 [384], p. 519

22 Mills, 1964 [388], p. 12.

23 Ibid, p. 106.

24 Ibid, p. 105 .
} 
In the area of cooperative actions involving preparation, announcement, and exchange of technical translations, one additional special problem may be mentioned. This is the question of providing copies to other cooperating organizations involving questions of makeup, since in many smaller agencies only the translated text may be available for distribution in multiple copies and reinterpolation of drawings, data tables, equations and the like may be difficult if not impossible.

Reed speaks to this point, and raises the further difficulties of copyright and unauthorized translation, as follows: "Many different ways are used in making up translations. It would be very useful if information about them could be assembled and perhaps some recommended procedures reached. I am personally interested at the moment in the possibilities of microfilm in both making up and lending translations. Unfortunately, if you need to go outside your own organization to have a microfilm made, and the translation is unauthorized, you will find no commercial supplier who is willing to break the law for your sake!" 25

Other obvious general language problems are those of specialization, which de Grolier calls a "second Tower of Babel, a confusion of tongues within one and the same tongue," ${ }^{26}$ of different meanings attached to the same word ("plasma" in the biological and physical sciences), of the coinage of new terminology and the use of "technese." These are problems that have been and are being attacked by professional societies and institutes for many specialized fields. The requirements of interdisciplinary areas and mission-oriented information services, however, point up the needs for centralized or coordinated sources of information about on-going projects in glossary construction and standardization of terminology as well as for the exchange of products.

In terms of looking forward to machine processing of full text (whether for mechanized translation, automatic content analysis, or storage, search, and retrieval purposes), additional types of "language" suggest themselves for standardization or agreement as to preferred practice. These are the languages of equations, formulas, special symbols, diagrams, and other graphic material. Tareev, for example, has emphasized requirements for terse, simple language, standardized terminology, the use of generally accepted practices with respect to units of measurements and methods for writing equations as being "especially important in the application of machine language techniques." 27

In this connection we note that at the UNESCO 1949 Conference on Abstracting and Indexing it was recommended that: "the metric system should

${ }^{25}$ Reed, 1960 [475], p. 165.

20 de Grolier, 1958 [169], p. 276.

27 Tareev, 1962, [555], p. 339 . be used for weights and measures and the centigrade system for recording temperatures in medical and biological communications" 28 and that with respect to chemical ciphers and notations "a proposed international standard notation system, based upon the Dyson notation, has been . . . published by the International Union of Pure and Applied Chemistry." 29

At another level of language, the difficulties are those of standardizing or of coordinating the indexing or classification languages. As we have seen, the SLA collection of subject heading lists is an example of a cooperative effort aimed at maintaining information about the availability of language resources useful in the construction and evaluation of new and revised schedules, indexing vocabularies, and thesauri. The typical differences of approach between documentalists and librarians, and between those advocating classification rather than coordinate indexing, however, may have prevented more helpful efforts in this direction. For example, at the Rutgers seminar on the UDC system, "Mrs. Brownson asked whether the special language of the UDC and its structure represent a language resource which has not been exploited in the development of the thesaurus as a method of displaying relations." 30

The 1962 comments of Markus are still appropriate. He said that there was ample opportunity for coordinated research aimed at producing more and better published indexes at lower cost. One approach would be to "explore the possibility of standardizing the index format for various scientific fields, to facilitate inter-disciplinary use and permit development of standard computer programs for processing indexes. This project would include the improvement of subject heading lists and thesauri in each field." 31

"In 1950, Mortimer Taube at the conference on bibliographic organization held at the University of Chicago, presented a report on the 'Functional Approach to bibliographic organization,' in which he formulated, in his conclusion, the idea that UNESCO could encourage the development and standardization of various 'categories' used in specialized codes, particularly those likely to apply to fields other than those for which they were originally intended." 32

Unesco has been and continues to be interested in terminology. Early steps included the commissioning of Dr. J. E. Holmstrom to study the availability of technical dictionaries. " $A$ Bibliography of Interlingual Scientific and Technical Dictionaries, second Edition, Paris, UNESCO, 1951 . . covers 1044 dictionaries, grouped under 224 subject heads and indexed under 45 languages." 33

\footnotetext{
28 Brownson, 1952 [85], p. 38.

20 Marden and Koller, 1961 [370], p. 5

so Mills, 1964 [388]: p. 101 (discussion).

81 Markus, 1962 [371], p. 21.

32 de Grolier, 1962 [170], p. 10.

33 Brownson, 1952 [85].
} 
"The standardization of terminology, involving maximum precision in defining the concepts used in different languages and a search for equivalent terms in other languages is viewed by UNESCO as an essential condition for progress in documentation and especially for the classification, retrieval, and translation of scientific publications." 34

Cooperative efforts at agreeing upon indexing terminology are of course noteworthy in major recent programs discussed elsewhere in this report, such as the revision of the ASTIA Thesaums and the development of the EJC Thesarus for the use of the engineering societies.

The considerations of the Weinber $\mathrm{g}$ panel included the suggestion that the various Government agencies assume responsibility for one or more horizontal or mission-oriented systems and that then the Government could support the technical society which would be in charge of each of the vertical or discipline-oriented systems such as a chemical system, biological system, or physics system. "Such a scheme could result in a reasonable standardization of indexing, and abstracting; it would require that the discipline-oriented system be compatible with the mission-oriented systems." "35

Nevertheless, there remain substantial difficulties. First is the question of whether the thesaurus or classification system designed for broad subject coverage can be used for specialized collections and services. In establishing the terminology for the Medical and Health Related Sciences Thesaurus it is reported that "effort was directed toward compatibility with existing compilations ..." but that "due to the diverse and detailed nature of the basic biological and medical investigations currently supported by the Public Health Service, no existing thesauri provided adequate coverage." 36 Similarly, with respect to classification systems, "In practice the needs of the organization concerned usually take precedence over standardization, and it is said, to indicate the most pessimistic view, that there are as many UDC's as there are users of UDC." 37

The second difficulty to be noted is that of present widespread incompatibilities in previously indexed or classified materials. An example reported by Shera in 1955 can undoubtedly be replicated today. "... Semantics lies at the base of all classification, and the standardization of terminology is a prerequisite to its success. The need for such standardization is emphasized by the results of two tabulations recently made by the Graduate Library School [Chicago]. In the first the subject headings used in the card catalogs of nine industrial relations libraries were analyzed to determine the uniformity of subject entry among the several cooperating institutions in-

\footnotetext{
34 Scientific Information Notes 3,1,1 (1961).

35 Weinbers, 1962 [636], p. 6.

MeGee et al., 1963 [377], p. 347

37 Mills, 1964 [388]. p. 47.
}

volved. Of a total of 938 headings, of which 218 (or 23 percent) showed significant alternative forms, 57 percent were unique to one library, 17 percent were used by only two libraries, 9 percent by but three institutions, and 7 percent by four; only 10 percent were common to five or more libraries. A similar dispersion was evident from an analysis of the concepts appearing in the indices of three general textbooks in bacteriology in which, from a total of 2,256 concepts, 66 percent were unique to one text, 23 percent were found in only two, and only 11 percent were common to all three." 38

Thus another major effort that shows promise is the systematic investigation of possibilities for converting one indexing language into another, as in the Datatrol Studies (1962 [235], [236]; 1963 [155], [396]). The problems of language raise a number of specific questions of index language compatibility and convertibility. The questions of interchange of indexing languages, and specifically the Datatrol studies have previously been considered in connection with systematization. Here, however, we will reconsider them in the light of problems and difficulties raised, especially the implications for compatibility and convertibility.

The Committee on Scientific Information of the Federal Council for Science and Technology in its status report on scientific and technical information in the Federal Government dated June 18, 1963 ([196]) states that the National Science Foundation, in cooperation with AEC, DOD, NASA, OTS, and others, is taking steps necessary to assure that one overall index to report literature can come into being. The intention is not to replace indexes already serving "the individual needs of specific agencies and disciplines, but to supplement them with a broader and more generalized indexing system for interdisciplinary and interagency use, and for use by the U.S. scientific community at large." 39

For the stored materials of information centers to be compatible, Center $\mathrm{B}$ must be able to take the physical storage media from Center $\mathrm{A}$ and retrieve information therefrom without difficulty despite the manner of indexing which Center $A$ used in determining the locations of storage of the information on the media and in labeling it with suitable selection criteria for retrieval. Obviously, if the same practices are used as to the designation of author name, corporate source, report number and subject identifiers and if these identifiers and selection criteria are recorded within the same encoding, recording, order, and format conventions in two or more centers, there should be compatibility of usage between them. However, such situations are rare indeed. Thus the questions arise as to whether, from formats to indexing languages, some degree of convertibility can be achieved.

\footnotetext{
${ }^{38}$ Shera, 1951 [523] . pp. 84-85.

${ }^{39}$ Federal Council for Science and Technology, 1963 [196], p. 5 .
} 
The Datatrol Corporation has explored some of these questions with respect to the indexing languages used by the major U.S. Government information-disseminating agencies. As a part of these studies, Datatrol prepared a table of indexing equivalents for the different indexing systems, $\mathrm{AEC}$ and DDC, contending that with the use of such a scheme, Center B could determine which of its indexing terms could be substituted for those of Center A, and vice versa. This action, of course, would make the terms of the respective dictionaries of each center "convertible," thereby circumventing many of the problems of incompatibility. However, Datatrol's actual table shows only the AEC equivalents for the DDC vocabulary, and does not show the DDC equivalents for AEC's vocabulary, which would be necessary both for a workable system and for other tables of equivalents. Furthermore, Datatrol's study was made on the entire first edition of the ASTIA Thesaurus, including its "obsolete" terms as Painter (1963 [445]) calls them, not on the terms in actual use, as her study does.

The Datatrol reports affirm "that patterns of conversion exist such that the ultimate goal of a Dictionary of indexing equivalents can be attained." 40 Datatrol's statement with regard to the assignment of higher generic terms as a useful equivalent is interesting. Consider an instance where Center B had media from Center A, and that a specific term used by Center B was not available in the vocabulary of Center $A$ although the latter did have a higher generic term which would "logically" include Center B's term. Datatrol claims that the assignment of such "a higher generic term as a useful equivalent tends to be subject to nonrigorous criteria," but that realistic solutions can be attained by "knowledge of the 'system users' requirements ...." 41

The procedures detailed in Jaster's February 1963 report [296] give evidence of a desire to compile a dictionary showing multilateral equivalence among the indexing terms of the three agencies. The subsumption scheme is a tool to be used in the compilation of such a dictionary. "Its purpose is primarily to be a display or grouping device for convenient scanning of the vocabularies for equivalent terminology. Of course, it will also be useful in that the scheme itself points up many simple generic relationships, since the grouping provides some degree of context." 42

The Jaster 1963 report does not illustrate the categorization of terms themselves into groups and fields. It does show twenty fields and 221 groups as compared with the 19 fields and 292 groups of the first ASTIA Tesarus and the 26 fields and 170 groups of the second edition. Such categorization of terminology is surely "classification," but the categorization has not proceeded far enough in her

\footnotetext{
40 Hammond and Rosenborg, 1962 [236], Abstract.

41 Ibid, p. 19.

42 Jaster, 1963 [296], p. li.
}

report to be of immediate value to $\mathrm{AEC}, \mathrm{DDC}$, or NASA.

The December 1963 Datatrol report [153] continues the Jaster assumptions in that it strongly advocates a common subsumption scheme. The scheme would be a list of generic subject categories subsuming the composite subject content of government research reports. At least two uses of the list are envisioned. First, each agency would use the list to categorize its reports independently of the use of its own specific vocabulary for indexing. Secondly, there would be a computerized application of the list for the correlation of indexing data among the agencies, the most promising technique for the correlation probably being the statistical association of indexing terms announced by Stiles in $1961([545])$.

The common subsumption scheme is envisioned as providing about 20 major divisions that would encompass "the scope of the subject content of the document collections of the operating agencies. These major divisions would subsume, but not necessarily be limited to, the subject categories of the announcement publications and distribution guides of the operating agencies." 43 These 20 major subdivisions would subsume from 150 to 200 partitions or groupings of information, and these groupings would subsume 1,500 to 2,000 "clusters" of information. Datatrol in its diagrammatic illustration of the subsumption scheme projects beyond the "bound" of the scheme to indicate that the indexing vocabularies of the operating agencies may number in the tens of thousands and the scientific concepts and/or indications of the subject content of the research reports may run as high as the millions.

The Datatrol studies indicate further that the maintenance of such a scheme might be the responsibility of a clearinghouse facility in coordination with the operating agencies. Datatrol views the object of its considerations not as a scheme "in being" but rather "a convenient tool for correlation of indexing data of the several operating agencies. Both the indexing data and the subsumption scheme are associated with research reports - and are in machinable form convenient for computer correlation. This approach can therefore be as dynamic as the situation demandswhether it be for retrieval or for mechanically organizing report announcement entries for publication." 44 One of the obvious questions that arises is who or what agency is to determine that "approach"?

Painter's summation of the Datatrol and of her own studies is that they "point out a degree of convertibility between ASTIA and AEC. A large percent of the AEC documents could be retrieved by converting the ASTIA descriptors, at least in the three fields where comparison is most valid." 45 Of course, she suggests that the origi-

${ }^{43}$ Datatrol Corp.. 1963 [155], p. 53

44 Ibid., pp. $54-55$

4 Painter, 1963 [445], p. 79. 
nal Datatrol report produced only a "theoretical" rate of equivalency, ${ }^{46}$ attempting "to show what is possible; whereas the duplicate indexing analyses [of Painter] check what actually occurs in practice." 47 Hammond seems to have been coming to somewhat the same conclusion, even though by a different route, in his statement that " $\because$ to give a true picture, any measure of convertibility of terms must take into account their frequency of use..." 48

Painter's conclusions do not support the Datatrol proposal for interagency equivalency dictionaries. She foresees that equivalency can be categorized from both AEC and NASA to DDC but not otherwise; she sees also that the indexing system with the smaller list of terms can be adapted to the one having a larger list. But the major objection to dictionaries of equivalencies is found in the results of her study on the consistency of indexing. Without an improvement in consistency higher than 60 to 70 percent and with "an equivalency of only 30 percent with the broadest system, a table of equivalents is at present of little value in either a manual or a machine system." 49 She suggests as alternatives to the use of a table of equivalents (1) the merging of all the terms from the vocabularies of interest into one master dictionary with definitions and cross-references and (2) the establishment of a new hierarchical subject scheme whose superstructure will embody all of the vocabularies. ${ }^{50}$

Painter's alternatives to the 1962 proposal of Datatrol for a table of equivalents, however, still leave unresolved the difficulties of establishing and maintaining consistency, reliability and quality of indexing-a major problem area. There are those who contend that the classifier or indexer performs his functions too subjectively, that it is practically impossible for him to attain unbiased indexing, that automated techniques would indeed operate consistently, if not objectively. For the present, however, continued reliance is going to have to be placed upon the human indexer, and thought should be given to increasing the consistency of his work.

"Subject analysis of documents will remain, at least for the near future, an intellectual operation." 51

\subsubsection{Consistency, Reliability, and Relevancy in Indexing}

A general problem area affecting the determination of system requirements, the evaluation of retrieval effectiveness, the comparative evaluaton of different systems, the use of prior human indexing as a basis for automatic indexing or for search renegotiation, and, especially, the possibilities for convertibility from one indexing vocabulary to another is that of the consistency and reliability with

\footnotetext{
46 Ibid., p. 82 .

47 Ibid, p. 94.

48 Hammond and Rosenborg, 1962 [236], p. 4.

10 Painter, 1963 [445], p. ix

50 Ibid. p 100

51 Orr et al., 1964 [440], p. 1144.
}

which two different indexers would index the same item or the same indexer would index the same item at different times.

There is, in general, very little objective data with respect to this critical factor. Jacoby and Slamecka report (1962 [293]) experimentation on indexing consistency with minimal conditions for six indexers (three experienced and three beginners) in the indexing of 75 chemical patents by the Uniterm system. The minimal conditions involved indexing without the use of existing tools, communication, or post-indexing editing. The experienced indexers attained more interindexer consistency with less internal variation than the beginners, but it was surprisingly low for both, averaging 12.6 percent for the beginners and 16.3 percent for the experienced. Each indexer tended generally to be about 50 percent consistent with himself when reindexing "equated" documents and using a vocabulary of "general" (shared) terms.

Slamecka and Jacoby report further (1963 [535]) on the effect over base-zero (minimal) conditions of three types of tools as indexing aids on the consistency attained by individual indexers on randomly selected chemical patents. The tools having significant improvement over base-zero interindexer consistency were a classificatory device (Manual of Classification of the U.S. Patent Office) and an alphabetical subject-authority list of terms (the Chemical Patents Coding Manual of Documentation, Inc). The Chemical Engineering Thesaurus of the AIChE failed to effect the consistency of the indexers. Improvement in indexer reliability and quality of indexing are believed attainable by use of prescriptive indexing aids containinng a minimal display of variable semantic relationships among terms. Such aids formalize the relationships among terms so as to enjoin consistency of their assignment by indexers. The most striking difference occurring within the use of each aid, and in comparison with each other, is that between bounded or specified sections of the patents and the unbounded sections. If a section for indexing is clearly defined, fewer terms are used by the indexers, regardless of indexing aid, and less variability is encountered in the number of terms used per patent.

Slamecka further suggests, with regard to the use of aids in coordinate indexing, that "aids which contain large numbers of variable, optionally employed references increase the range of terms descriptive of a document, and hence, they are unlikely to improve indexer reliability to any considerable extent." 52

Painter, in her analysis of duplication and consistency of subject indexing involved in report handling at OTS, (1963 [445]) made a study of indexer consistency within DDC (at that time ASTIA), AEC, OTS, and the NAL. Each agency was asked to index a number of items twice, with an interval of one to two months be-

52 Slamecka, 1963 [534], p. 227. 
tween times of indexing. Indexing the second time was without reference to that of the first. There was no attempt to have the same indexer. process each report: the experiment was designed to test the system and not the individual. The terms identical to each other in the two indexings afforded a means for determining consistency. There was about a 65 to 72 percent consistency on the a verage for the four systems.

Painter concludes that to raise the level of indexing consistency there are four possible methods: (1) ensure adequate subject training of the indexers before they index at all (without the training, the act of indexing "becomes more guess than knowledge, or else indexing from the title"); (2) have indexers experienced in the art of indexing; (3) standardize the indexing code or rules being followed; and (4) supervise the assignment of indexing terms by the indexers, including the new terms being proposed. ${ }^{53}$

Although the purpose of Painter's analysis was primarily to investigate the conversion of one indexing vocabulary to another, her observations concerning consistency itself are well taken. She states of the type of equivalence tables suggested by the Datatrol Studies (Hammond and Rosenborg, 1962 [235], [236]) that: "The value of equivalency studies and most particularly the table of equivalents presuppose the consistency of indexing. Convertibility between systems is thus dependent on the consistency of indexing. Without consistency, the vocabularies as units are not sound; equivalencies cannot be drawn or effectively used for convertibility." 54 She also points out, as quoted earlier, that "with onlv 60 to 70 percent consistency of indexing within each system . . . a table of equivalents is at present of little value in either a manual or a machine system." 55

Related to the problems of consistency and reliability of indexing is the question of the relevancy of the indexing terms that are assigned to the actual subject of the document. More generally, the question of relevancy, difficult though it may be to measure or assess, is generally considered to be crucial to the evaluation of an information system. In particular, such measures as the recall ratio, i.e., the number of relevant documents retrieved as against the total number of relevant documents known to be in the collection, and the relevance ratio, i.e., the percentage of relevant documents among the documents actually retrieved, have been used as evaluation criteria in the comparative testing of two or more systems.

In the matter of comparative evaluation, as in the case of studies of consistency, there is as yet relatively little experimental data with the exception of the ASLIB Cranfield Project (Cleverdon et al., 1959 [123]; 1960 [122]; 1962 [124]; 1963

63 Painter, 1963 [445], p. 107-108.

${ }^{54}$ Ibid, p. 109

55 Ibid, p. ix.
[127]; 1964 [125] [126]). Of the following four representative experiments on the intercomparison of indexing systems or methods, three were completed within the past 10 years and one is contemplated.

The first of these experiments was as between ASTIA Reference Center personnel conducting searches against a conventional subject catalog and personnel of Documentation, Inc., making the same searches against a coordinate Uniterm Index (Gull, 1956 [231]; Warheit, 1956 [628]). Gull reports that a fairly thorough search of the literature indicates that this comparison of two reference systems is "the first undertaken so far . .." 56 The desire was to learn how the Documentation, Inc. and ASTIA groups would respond to a set of questions which each had processed, the first group by the use of Uniterms and the second group by the use of regular subject headings. The results, however, were subject to question and criticism: "Unfortunately, the conditions of the test were very poorly designed so that, in the final analysis, each group was the sole judge both of the scope of the original request and of the adequacy of the bibliography produced. The resulting claims are of course contradictory." 57

"It would appear that when the searches were completed, each organization then looked at the documents which had been retrieved and decided on those which were relevant to each particular question. The two groups then met to compare results. Immediately they came up against the problem of deciding what was relevant and found that they were quite unable to agree on this point. Each group had its own interpretation of the question and therefore its own views as to the relevance of the documents. It appears that after some lengthy discussion, the decision was taken that each group should compare the retrieved documents and make its own analysis. The report prepared by Documentation, Inc., as discussed in the paper by Gull, would appear to indicate that the uniterm system was more successful than the alphabetical indexing of ASTIA. It also seems that the ASTIA group, as a result of their analysis, were of the opinion that the position was the reverse." 58

The second series of testing was reported by Schuller of the Armed Services Technical Documentation and Information Centre (TDCK) of the Netherlands Ministry of Defence at the 35th annual conference of ASLIB in September 1960 ([506]). TDCK was then using two different systems for retrieval: the UDC and Uniterms. "The application of two systems which differ fundamentally in their nature and philosophy will always put us in command of the sum of the possibilities inherent in the two systems." 59

B6 Gull, 1956 [231] p. 329.

ธ7 Warheit, 1956 [628], p. 274.

5s Cleverdon, 1962 [124], pp. 7-8.

59 Schuller, 1960 [506], p. 379. 
In the first TDCK test 100 queries were put to the two systems. Although the Uniterm system gave slightly better results, the UDC "procured many valuable documents not found by the other system, which fact will support TDCK in its conviction that the two systems should be used together." In the second test 200 queries were put to the systems for retrieval of specific reports, known by title, from the center's collection of ASTIA-processed documents. The recommendation resulting from these two tests is that a Uniterm system should be used for a collection of technical reports with known titles, for the following reasons: (1) there was only about a 1 percent chance that the report would not be discovered against $181 / 2$ percent by UDC; (2) the average search lasted only $11 / 2$ minutes against 10 minutes required by UDCं; and (3) the librarian did "not need the help of a technical information officer to recover a specific report." 60

The third experiment was one of a series of comparative tests that have been conducted by Cleverdon and his associates under a grant to ASLIB by the National Science Foundation beginning in 1957. The tests were undertaken at the College of Aeronautics in Cranfield, England, and consisted of the indexing of 18,000 documents by the UDC, an alphabetical subject index, a special facet classification, and the Unitem system of coordinate indexing. The first stage of the investigation was concerned mainly with indexing the documents and preparing the four indexes; this stage was reported upon by Cleverdon in Sepember 1960 [122]. In the test program anestions were at first directed to a collection of 6.000 documents. These "Cranfield I" tests established the experimental recall ratio "by conducting searches for questions which had been based on documents known to be in the collection, and the result of this showed that, on an average, about 80 (percent) of the source documents were being retrieved." 61 Further tests against the full corpus of 18,000 items again showed a recall ratio ranging between 75 percent and 85 percent for all four indexing systems. ${ }^{62}$

The investigators themselves have characterized the Cranfield I experiments as follows: "Its main endeavor was that it tried to measure the operating efficiency of complete indexing languages in a simulated real life situation, and also that it used, as its major measure of performance, a relatively crude gauge of relevance based on the retrieval or nonretrieval of a single source document." 63 The 1962 Cranfield Report (Cleverdon [124]) also emphasizes various reasons or failures to retrieve source documents. The findings have been subjected to some criticisms on these and other grounds, including apparent indecisiveness with respect to bases for choice among different systems.

\footnotetext{
60 Ibid, p. 386

61 Cleverdon and Mills, 1963 [127], p. 6.

${ }^{62}$ Cleverdon et al, 1964 [125], p. 87 .

63 Cleverdon and Mills, 1963 [127], p. 12
}

The answer given by Cleverdon as to which of the systems should be recommended is that: "This is impossible to answer without qualification, for no system which has been investigated has shown itself to be so markedly superior as to justify its use in all conditions. The size of the collection, the number of users, obviously the subject matter; these are the type of considerations which would influence a decision." 64

Richmond, however, in a review of the Cranfield work, remarks that the answer as given by Cleverdon "hardly satisfies the purpose of the experiment or does justice to its results." ${ }_{65}$ Moreover, in the present state of the art of evaluation of information selection, storage, and retrieval systems, it may fairly be observed that: "The outstanding large-scale and realistic experimental work is that of Cleverdon," "66 and "many observors believe that the Cranfield study constitutes the most important work done in the field of cataloging in recent times." 67

Cleverdon and Mills have proposed a second series of tests called Cranfield II, which "will try to measure the impact on recall and relevance of particular indexing devices-the elements which go to make up a complete index language; and secondly, it will try to use decidedly more precise measure of relevance." In the Cranfield II series, 1,500 documents in the subject area of high-speed aerodynamics: "are being indexed with great thoroughness but without reference to any particular scheme. For each report, all significant terms appearing in title, summary and text are given. . . " 68 Cleverdon and Mills are using four levels of description : an abstract, themes, concepts and terms for this study.

\subsubsection{Problems of User Acceptance and Human Factors}

It should be recognized that the problems of user requirements and user recognition and accep. tance are, at least today, strongly interdependent. Several far-sighted and progressive systems have failed or have been discontinued because of lack of demonstrable, continuing usage value or because of user indifference. "No index ... [and no current-awareness announcement service or search retrieval system] . . . is useful unless it is used." 69 Further, "there is no virtue in any information service unless people use it actively." 70

The exemplary case is that the ChemicalBiological Coordination Center. While the primary reason for failure was undoubtedly financial, it is likely that financing might have been readily attained had the CBCC's services been more widely known and used. It is to be noted that although at least 60 scientists had served on subcommittees of the CBCC, only about 30 letters

\footnotetext{
64 Cleverdon, 1962 [124], p. 92.

65 Richmond, 1963 [482], pp. 310-311.

6o Kochen, 1963 [321], p. 12.

e7 Randali, 1962 [467], p. 381

es Cleverdon and Mills, 1963 [127], pp. 12-13.

69 U.S. Senate, $1961[541]$, p. 53.

70 Knox, 1962 [320], p. 27.
} 
expressing regret were received at the time of the announcement of termination. ${ }^{71}$

At the 1958 Western Reserve Conference on the possibilities of creating a "National Center for the Coordination of Scientific and Technical Information," Bernier remarked: "There have been at least three mechanized services available to scientists in general. All these three services had a deficiency of questions coming in to them. The Chemical Biological Coordination Center in Washington failed. The CBCC, the CNRS in Paris, and the Gmelin Institute in Frankfort report very few questions coming in to them. The reasons behind the failure of the CBCC and the shortage of questions coming to these three centers should certainly be investigated carefully, I feel, and explained before another general searching service is attempted." $z_{2}$

An earlier and revealing example is that reported by Warheit as follows: "In 1951 Irma Wachtel adopted the Batten system to index the nuclear properties of the isotopes ... At the Argonne National Laboratory sets of these cards were placed in the chemistry and physics libraries. Nothing happened. We then started pushing them and displaying them as if they were new books and succeeding in getting one person to use them. After two years of effort that is the measure of our success in promoting this really useful indexing file. However, when the Nuclear Data Cards were issued by the National Research Council and these were placed in the libraries, we were immediately asked ... if they could have a set of the cards . . . The end product was an oldfashioned fixed file of over 2000 cards." 73

Studying the problems of centralization for documentation operations, the $\mathrm{A}$. D. Little studyteam reports: "Existing systems have not been used extensively, and our study shows that these systems have had difficulty in justifying their existence in terms of their utilization." ${ }_{\eta_{4}}$

More recently, Adkinson has reported as follows: "For the systems listed in Nonconventional Technical Information Systems in Current Use, 50 percent of those using punched card equipment answer fewer than one query per day; of those using computers, 50 percent handle fewer than three queries per day." "75 In the specific case of DuPont's Engineering Center, a 1962 statement reports: "Now in its fourth year of operation, EIC has an inventory of 10,000 accessions . . It is handling 1,200 inquiries a year, which is less than the rate should be." 76

There are many plausible reasons for neglect by users of new and improved services. One is a matter of inertia: "The most important step in the dissemination of scientific information is that of assuring easy access of this information to

71 Dougherty, 1963 [177] p. 14

72 Shera et al.. 1958 [526], pp. 204-205.

${ }^{73}$ Warheit. 1956 [628], p. 270.

74 Arthur D. Little, Inc., 1963 [344], p. 45

${ }^{75}$ Adkinson, $1964[6]_{\mathrm{h}}$ p. 2.

7o Genereaux, 1962 [214], p. 43.
American scientists. Perhaps this should be the simplest task of all; in reality it becomes the most difficult, not only because of logistics but because it involves overcoming the inertia of the American scientist and entering into competition for a portion of his time." ${ }^{78}$ Further, "an outgoing, aggressive, use-oriented, service, in effect, asks the individual to change, sometimes in a radical manner, the information acquisition and handling pattern which he has developed for himself over his lifetime." 78

This problem is further aggravated by deficiencies of training of scientists and engineers to make use of the traditional, much less the newer and non-conventional, types of services. "The training of scientists to take advantage of the scientific literature of their own disciplines has been grossly inadequate, leading to ineffectiveness and inefficiences that the nation can ill afford." ${ }^{9}$ Thus, "a continuing educational program is required to convince all of today's engineers that modern documentation services can provide useful information that they are not likely to find themselves or even attempt to look for." so Again, "there is a tremendous education problem still ahead of us in terms of getting an engineer or scientist to recognize the existence of these resources and find ways to fit them into his daily work habits." 81

It should also be recognized that the problems of cooperation, compatibility, and convertibility must extend to the whole complex of documentation operations in the handling and use of scientific and technical information. A five-minute, or a five-second, or even a five-millisecond response time to a scientist's search query will not avail much if, given the address-locators of possibly pertinent documents he must wait a frustrating 30 minutes or more for others to move about in the stacks in search and physical selection of the desired hard copies (many of which are likely to be "not-on-the-shelves"), or even if he must transport his microcopy "direct" retrievals to one or a few readers located elsewhere in his building, complex of buildings, or geographical area, and then there wait his turn in the queue of other clients.

Sincere but often impractical gestures of collaboration and cooperation have been typically bogged down by real differences of special-purpose interest, inertia, undue reliance on presumed customer acceptance of present products, and the all too prevalant human reluctance to change. "... In many instances there is opposition to cooperation, e.g., opposition based on fear that privately worked out documentation practices and forms will have to be abandoned in favor of a new, coordinated documentation. This is a psychological problem." 82

\footnotetext{
77 U.S. House, 1959 [587], p. 8.

78 Knox, 1962 [320], p. 27.

79 Adkinson, 1962 [5], p. 50 .

80 Genereaux, 1962 [214], p. 43.

81 U.S. House, 1963 [582], p. 144, statement of W. H. Carlson.

8. Frank, 1959 [200], p. 502.
} 
Probably far more serious from the standpoint of ultimately improving the utilization of recorded scientific and technical information is the fact that many present and potential users lack awareness of the availability of materials, services, information service products and guides to such products, services, or materials. This lack of awareness was strongly emphasized in the analysis of questionnaires addressed to research administrators in the electronics industry with respect to their needs for current, on-going project information.

In the first place, "only a minority of the respondents emphasized the need for information prior to publication in their specific replies to the items of the questionnaire." Secondly, "a number of responses expressed quite general satisfaction with existing facilities and services in marked contrast to responses which were critical or which recommended radical new solutions." Thirdly, "a wide difference of opinion was noted with respect to the estimated numbers of people in the responding organizations who need to be kept informed on the status of current research . . . ranging from one or a few to several thousand." Finally, and most importantly, "similar disparities in recognition of the nature and urgency of the problem are perhaps implicit in a lack of awareness on the part of at least some respondents of what services are in fact now available. For example, one respondent complained that OTS facilities are not available to him since he is not now a Government contractor whereas, of course, OTS services are available to the general public." 83

Corroborative evidence from the literature on the point of lack of awareness or lack of mechanisms for utilizing what is a vailable may be further exemplified by the following: "There are defects in the existing information system, but there do not appear to be any major faults in the system as significant as the fact that so many who might use the system more, hardly use it at all." 84

Similarly, in a case of international cooperative enterprise, "O.E.E.C. entered this field a few years ago by launching a document exchange scheme ... Reports of work issued by Government agencies should be exchanged between various national documentation centres .... and through them made available to firms. This scheme has been only partially successful. Very little was exchanged which was not received by the countries in any case, but when the situation was looked into a little closer, it often appeared that the material had not previously been easily available to industry because internal organization had not developed to meet the practical needs of the industrial user." 85

This problem is obviously related to that of realistic determination of user needs. "The essential difficulty is that, though the user may

\footnotetext{
83 U.S. Senate, 1961 [590], pp. 108-109.

84 Urqubart, 1952 [604], p. 234.

85 King, 1955 [316], p. 9 .
}

well know what he wants from an information service, he is in no position to know what he needs from it, namely what variations in the system would help most to further his work. Consequently, any action based on analysis of present user habits is unlikely to produce impressive results." 86 One of the further difficulties is that, "unfortunately, the problem is too often vaguely described as 'satisfying the user's need for information' without defining the need or appearing to recognize the extreme ranges of variation that can exist both in the nature of the user and the nature of the information." 87 The obvious further complication is that "the real needs of scientists and their conscious or expressed needs may be quito different. 88

Human factors, especially those involving local or special-purpose needs, also affect the content, order and format of bibliographic information that might be exchanged between cooperating organizations. An example is given in a report of the American Petroleum Insitute's Central Abstracting Service. "Studies in one company of an abstract-writing style that drops bibliographical data to the end of the abstracts, to speed information transfer, had met with highly favorable reader reaction. This led to adoption of an intermediate abstract-writing style that begins with document titles but places the rest of the bibliographical data after the text." 89 Such practices would obviously have a direct effect upon machineusability of abstracts prepared in this form if they are to be interpolated into files containing abstract information in more conventional formats.

Similarly, while the informality of corporate source entries at a Navy laboratory library - "We use nicknames (NOTS), abbreviations (lab., co., and est.), and colloquialisms (BuShips)," ${ }^{90}-$-may be 'good public relations' for the local community, they would create obvious difficulties for interfiling or duplicate checking anywhere else.

In those areas of human factors involving questions of user acceptance of machine products, much basic fact-finding remains to be done. For example, KWIC indexes and other indexes compiled or generated by computer are undoubtedly serving genuine current-awareness needs and they can be prepared promptly and cheaply. However, they are marred by disadvantages of line length, arbitrary truncations of words and excessively long blocks of entries centered on some indexing words. The limited-to-upper-case types of computer printout typically offered afford disadvantages of acceptability and probably of physical legibility in terms of the quick scanning that is desirable.

Within the general problem areas, then, it may be concluded that "IIuman factors and machine factors constitute the two major operational con- 
siderations that must be systematically examined, and which will lead to a host of research problems." ${ }^{11}$ Before considering some of the specific problems introduced by prospects of mechanization, however, we shall first examine some of the special problems which have arisen in connection with changes in the nature of materials to be handled.

\subsection{Special Problems Raised by Changes in the Nature of the Materials to be Handled}

Major changes in the nature of the materials to be handled in scientific and technical information systems raise special problems. These major changes include the phenomenal growth in the amount of the literature to be covered, the increased quantity and importance of foreign language materials, the emergence of less conventional forms of publication and communication as bearers of forefront information, and the use of nondocumentary forms, especially in the area of photographic and sound recordings.

"To the documentalist, information resources consist not only of the formally organized contents of libraries and archives-their books, journals, serials of all descriptions, reports, all the traditional library materials, whether in original or reproduced form, but also of stored data in hundreds of forms: reprint and abstract cardfiles; graphic charts, such as infrared spectra; tabular records of experimental data; data stored on IBM and edge-notched cards, on microfilm, on recording tape, on electronic memory drums, et cetera." 92

As an example of new and specialized types of material for which bibliographic controls, announcement mechanisms and means for exchange or loan are needed, the case of the technical film may be considered. "The technical film is becoming of increasing importance in technical information dissemination." 93 These films may, for example, provide data on phenomena not detectable by the human eye and involving slow motion, time lapse, or photography in invisible parts of the spectrum.

"The Encyclopedia Cinematographica ... is a growing collection of research films initiated ... by Dr. Gotthard Wolf, of Gottingen, West Germany. Operated on a supranational basis, the program involves the collection, classification, and publication of carefully selected research films that present motion phenomena of scientific values .... The encyclopedia now consists of 340 separate film units . .. " ${ }_{94}$

Another example is "most interesting among new Library acquisitions will be the Psychiatric Recording Library . . . recordings . . . of spon-

91 Stanford Research Instltute, 1963 [542], p. 9.

92 Adams, $1956[3]$, p. 73.

03 U.S. Senate, 1960 [592], p. 48

a Scientific Information Notes 2 , No. 5, p. 8 (1960). taneous group discussions among psychiatric patients ..." ${ }_{95}$

Further, "for biomedical information recorded in audiovisual form, the National Audiovisual Facility of the Communicable Disease Center of the PHS should be developed to the point where it is analogous to the National Library of Medicine as a central resource for such records and a compiler of 'tools' for their retrieval." 96

Unusual materials in the sense of traditional documentation may extend also, as in earlier days at the U.S. Patent Office and the Army Ordnance Corps Museum, to models, devices, and physical samples. Thus, as a result of the post-World War II foreign acquisitions program, "through OTS and Army, American industry has been able to borrow for testing and examination, many fascinating and novel devices: a horizontal mercury type chlorine cell, a miniature Diesel locomotive, a portable mortising tool . . . . " 97

At an ASLIB Conference held in London on the prospects for cooperative action in the field of technical translation, the Chairman opened the sessions with comments on the major problems of the information specialist, first, that he must scan an enormous quantity and variety of materials, and second, that much of what he must scan is written in various languages.

". . Much of the output of information is to be found in technical periodicals and in the flood of ad hoc reports which tumble forth in increasing volume from Government departments and other official agencies, here and abroad. The organization of the publication and issuance of all this material is as nearly chaotic as any human activity could be: we all know that for every significant article in any field, published in the dozen or so periodicals in which it could be expected, there are likely to be at least one or two equally significant articles in the remaining tens of thousands of regular periodicals, to say nothing of the occasional and non-serial publications. This points to the information worker's first problem-the scanning of a vast and growing body of literature for material relevant to the needs of those he serves ... In doing so, he meets his second main problem: only 40 percent are in English. The remaining 60 percent are in a foreign language-or, rather, in many foreign languages." 98

Problems of coverage and scope in terms of cooperative attempts to attack these problems in the light of the phenomenal growth in the sheer quantity of items to be considered are stressed throughout the pertinent literature. Two further observations may highlight these difficulties here. Thus, "the UNESCO Scientific Abstracting Conference Report in 1949 accepted one-third as the

\footnotetext{
93 Army Medical Library News, 1, 3 (Nov. 1945)

a "Communication Problems in Blomedical Research," 1963 [403], p. 16.

97 "Distribution," 1947 [175], p. 10.

as L. V. Chilton, statement in "Technlcal Translation: Cooperative Action," 1960 [566], p. 129.
} 
fraction of scientific papers published which are abstracted in some way," 99 and the situation has improved only a little: "Some indication of how far we are from the indexing coverage of the world's literature may be obtained by noting that in 1961, all of the major U.S. scientific abstracting and indexing services combined ... will cover only about 16,000 of the world's estimated 30,000 scientific and technical journals ..." 100

One of the most dramatic changes in the nature of the materials to be handled in systems for processing scientific and technical information has been the emergence of the umpublished technical report as the major vehicle for communicating current research and development progress. The flood of such reports has resulted in a number of special problems and difficulties, ranging from the inadequacies of conventional coverage to specific questions of specific identification. The nature of the first major problem, that of inadequate coverage by libraries and the traditional abstracting and indexing services, has been stressed in a study by Herner and Herner. For example, "with the exception of Nuclear Science Abstracts, the major abstracting and indexing services in the United States have tended to ignore the reports that lie outside well defined and easily identifiable series ..." 101 The reasons include small volume publication, the relatively ephemeral nature of the subject matter covered, and quality considerations.

A second major problem in the handling of the report literature is the question of what in traditional systems is considered the "main entry" for cataloging purposes. The decision that in many cases the corporate source should logically constitute the main entry has complicated the already controversial area of rules for descriptive cataloging. As we have seen, the earliest attempts to achieve interagency compatibility in the U.S. Government had as a principal concern the question of proper recording of corporate authorship.

Writing in 1952 on the problems of identification and control of the report literature, Warheit indicates that coverage desired at $\mathrm{AEC}$ ranged from omission of all authors with recognition only of the divisional director in a laboratory to listing all authors, all who worked on the research program, "plus the total hierarchy who approved the report and were generally responsible for the work done." 102

The argument advanced by Taube (1950 [551]) with respect to corporate author entries, that the cataloger should not be required to go beyond the information available to him from the item itself, becomes all the more cogent when the human cataloger is replaced by machine. The argument will also extend to other entries-the dates of births and deaths of authors, for example. True,

\footnotetext{
99 Visscher, 1954 [617], p. 85.

102 Herner and Herner, 1959 [254], p. 192. Sere also p. $29 \mathrm{ff}$. of this report.

102 Warheit, 1952 [627], p. 105.
}

the machine can apply rules consistently, but the costs of compiling, maintaining, and updating the necessary lookup lists, directories, biographic data files and the like would add prohibitive extra expense.

Special problems are also raised with respect to the control of the report literature, especially in terms of the prospects for mechanizations. Existing announcement bulletins such as $T A B$ or $U S G R R$ often carry items which have no title, but where the input to the bulletin-preparation is in form suitable for machine-compilation of title indexes, suitable provision must be made for the supply of a pseudotitle which the machine program can use.

Another specific problem is that of identification of reports by one or more numbering systems. Warheit points out that "although potentially it is one of the best and most convenient devices for identifying reports, the report number in actuality does have many drawbacks. To begin with, many originators do not assign numbers to their documents and, with each recipient providing his own distinctive number to these 'orphans,' there has developed a veritable babel of identifying symbols and notations." 103

Connor suggests that along with other specifications in government contracts there be "a brief statement setting forth physical and bibliographic requisites in the preparation and publication of reports," including a reasonable scheme for numbering. ${ }^{104}$ Rubinoff of the Technical Operations Committee, Information Retrieval Subcommittee, of the Institute of Electrical and Electronics Engineers (IEEE) declares that the IEEE, among other tasks, needs to agree on a "document numbering system for all documents including Standards." 105

Mahany, Creager, and Herner have reported to the National Science Foundation the results of their study on functional symbols currently in use in government reports (1962 [367]). The study suggests "how widely agencies differ in their reporting policies generally, as well as in the names and symbols they apply to constituent parts of their report systems." The semantic problemthat of names and symbols-is considered to be "but one of a series of problems, some wider and more fundamental, in report production and control." Until resolved, the differences in reportage among the agencies "must continue to bar the standardization of report designators, unless simplified designators are designed with greatly circumscribed functions." 106 The design of a standard Government or Department of Defense-wide system of report designation would presuppose, and its implementation require, extensive revision of most agencies' reporting practices both in scope and structure. Any system developed would de-

\footnotetext{
${ }^{103}$ Warheit, $19552[627]$, p. 106.

104 Connor. $1956[1341$, p. 155

105 Rubinoff, 1963 [500], p. 3.
100 Mahany et al., 1962 [367], pp. 29-30.
} 
fine a standard code of symbols serving to give each report title a unique identity and yet relating it to a report series and a report system and possibly providing other information. It would probably require essentially complete change by all agencies using such report designators.

Unpublished conference or symposium papers, as well as published proceedings of such meetings, are among the newer, important forms of information sources. "Conference papers, conference proceedings, and information about the conferences themselves represent a serious problem in the technical information field. Papers presented at a conference may contain the most up-to-date information available on a subject, and as a consequence considerable effort is devoted to getting copies of them. At the same time such papers are frequently difficult to locate." ${ }^{107}$ Experience in support of this opinion has been reported: "Over two-thirds of the papers published in the reports of ten conferences were not individually abstracted in the journals searched, and nearly half were neither abstracted nor listed and indexed." 108

Suggestions have been made for lessening such problems: "If all conferences adopted a brief direct title incorporating the subject of the conference and left all the attributions of organizations, sponsorship, etc., to a subordinate portion of the title, the cataloguer's and the reader's difficulties would be greatly reduced." 109

At the 1958 International Conference on Scientific Information Liebesny reported [342] on "Lost Information; Unpublished Conference Papers." Several years later Ruth Hooker (1962 [271]) reported that proceedings of conferences and symposia were becoming an increasingly important source of information at the Library of the Naval Research Laboratory, and she raised the question as to whether material so published is adequately covered in abstracting and indexing services.

Some of the government report announcement bulletins attempt to cover this material. Thus, in each issue Nuclear Science Abstracts announces its methods for (1) arrangement of abstracts and (2) supplying indexes to the publication. Part of the announcement regarding abstract arrangement states, "In the case of comprehensive progress reports, or conference proceedings and symposia, an abstract is provided both for the whole publication and for each individual topic, sentence, or paper." An example is the announcement of three volumes of the Proceedings of the Seminar on the Physics of Past and Intermediate Reactors, held in Vienna Austria, August $3-11,1961$. Volume I is announced as item 26503 , followed by separate abstracts for items 26504 through 26534 on neutron physics and integral experiments in that volume.

In $1963, N S A$ began a concerted effort to account for individual papers associated with a

\footnotetext{
107 Davis, 1963 [158], p. 237.

108 Hanson and Jones, 1961 [236], p. 145.

109 Jolley, 1963 [303], p. 60.
}

particular conference not yet published in formal proceedings. The conference is assigned a CONF -designation, and thereafter, all papers associated with this conference are so identified. The identifying numbers appear in the abstract, and also in the report number indexes, grouped together. Availability of the individual papers is shown at this point. If proceedings are published later, the availability of the proceedings as a whole is shown and the individual papers are dropped. $S T A R$ has a method generally comparable to that of $N S A$ for announcing the papers given at a meeting.

"Availability of Nuclear Science Conference Literature (TID-19000) is a new service initiated by D'TIE [The Division of Technical Information Extension of the Atomic Energy Commission] in July of this year (1963) which should be a partial solution to the problem. It will give information about the availability of proceedings or individual papers of conferences in which DTIE is interested and in which other AEC installations have by their queries indicated an interest ... The availability information will include such items as future publication plans, negative publication plans (much time can be wasted looking for proceedings that will never be published), journal citations, (proceedings are particularly hard to locate if published as part of a journal), and known intentions of anyone to translate." "110

On an international scale also, the question of conference papers and proceedings is being studied: "The International Federation for Documentation (FID) on 14 September 1959 signed a contract with UNESCO . . . for the preparation of a 'study on the content, influence, availability and value of scientific conference papers and proceedings'." 111 'The Union of International Assocations, Brussels, Belgium, has received a National Science Foundation grant "to compile and publish a monthly bibliography of all proceedings and reports resulting from international meetings, congresses, conferences, and symposia." 112 From another point of view, "ISO $\mathrm{TC} / 46$ is now studying a preliminary draft international recommendation on title pages, which includes a special paragraph on symposia." 113

Finally we should note, in terms of the problems implied by potential exchange, interfiling and compatibility among information systems, the question of the handling of "separates," both preprints and reprints. Brownson reports a recommendation of the Royal Society Conference (1948[498]) with respect to desired common practice: "It is recommended that all separates (reprints) be headed with a full reference (name, number, volume, and date of the original journal), and keep the original pagination ...."114

\footnotetext{
110 Davis, 1963 [153], p. 237.

11 Report by Poindron, published in two parts UNESCO Bull

Libs. XVY, 113-126 and 165-176 (1962) [459], [460]).

112 Scientific Information Notes 3, 6, 11 (1961-2).

113 UNESCO Bull. Libs, XVY, 172 (1962).

114 Brown son, 1952 [85], p. 38 .
} 
Again, with respect to questions of descriptive cataloging alone, for future compatibility in the case of preprints, what date shall be used, that of the preprint itself, if ascertainable, or that of subsequent publication?

\subsection{Special Problems Raised by the Prospects for Mechanization}

One of the principal reasons for increasing concern about cooperation, convertibility, and compatibility is precisely the potential impact of machine processing capabilities. Mechanized capabilities for (a) processing bibliographic data for multipurpose use, (b) preparing tools for currentawareness searching and dissemination, and (c) providing techniques for storage, retrospective search, and retrieval create new needs and provide new opportunities.

First, machine use-and in particular, preparation of material for such machine use-are expensive operations. The advantages that machine techniques offer (of speed, consistency, multiple copy possibilities, storage economies, direct tie-in to various communication links, and rapid updating of files, catalogs, and indexes, and the like) can be best achieved, despite the costs, if there are many users. Similarly, many contributors may be required. Cooperaton among users, among contributors, and between them and the processing centers involves mutual agreement as to coverage, format, division of effort, priorities, and proper balancing of service in terms of the various customer requirements.

Second, machine use requires material in machine-usable form. Once material (whether it is a catalog card or other form of descriptive cataloging information, a record of index entries, an abstract, or even full text) is in machine-usable form, it can be reused for many different purposes and it can be replicated for use in other locations and by other organizations. Thus exciting new possibilities are opened up not only for the exchange of records and other materials but for significant reduction in duplications of effort such as are involved in the cataloging and indexing in one agency of an item already cataloged and indexed by others. However, realization of these potentialities depends upon compatibility, or at least convertibility, between systems with regard to such varied factors as the physical characteristics of recording media, the format of recordings, machine language and character sets used, the identification of contents of recorded information, the special symbols or codes used, the citation or cataloging practice, and many others.

Third, machine use and communication system links imply new organizational and service possibilities. For example, many different users may tap in to a remotely located source of information about literature, information, and data availabil- ity. Cooperating centers can maintain their individual responsibilities at their separate locations with effective coordination at the national level.

In practice, however, mechanization of systems of documentation and information handling operations has to date been limited to relatively small, specialized collections, such as systems for handling less than 25,000 internally generated technical reports for which no conventional means for control had previously been attempted. There are a few exceptions, such as the very large Minicard and IntelloFax installations in military and intelligence agencies.

Studies made in recent years by Stanford Research Institute, Arthur D. Little, Inc., the Library of Congress automation team, and a group studying the possibilities of a cooperative library system to be supported by local industries and Harvey Mudd College provide a consensus as to the limited applications of machines to date and as to the lack of compatibility both functionally and with respect to equipment used, for example:

(1) "No present machine is equal to the task of storing the immense quantities of information available. Even further from solution is the probblem of achieving rapid access to a specific small fraction of a very large body of stored information." 115

(2) "Present automation techniques do not deal adequately with raw text. At the outset only catalogs, inventory files, and indexes should be considered for automation. ... The economic and technical feasibility of automatically retrieving information directly from the text of documents has not yet been established and is an extremely complex subject. For this reason, there is likely to be greater emphasis for some years on the retrieval of bibliographic information." 116

(3) "The investigation revealed that there is no standard method of handling information storage or retrieval. Each organization tries to meet its. own needs by its own methods. Just as there is no standard procedure for information retrieval, so there is no standard equipment. All systems studied share the problems created by the tremendous amount being published and the time required to prepare it for processing through automatic equipment. All lack adequate storage (unless a large computer is used) and all lack a rapid printing process to handle the output . . . " 111

For these reasons, there is as yet no discernible "state of the art" with respect to cooperation, compatibility, and convertibility, even as between a few mechanized systems, much less between large and small, mechanized and nonmechanized, conventional and nonconventional. Instead, what can be discerned is a state of affairs, from which two contradictory conclusions emerge. One is that while maximum cooperation and convertibil-

\footnotetext{
115 Stanford Research Institute, 1963 [542], p. 1.0.

116 King, 1963 [318], p. 11.

${ }_{117}$ "A Joint College-Industry Library With Automata," 1964 [302], pp. 13-14.
} 
ity must be urgently encouraged, most efforts to achieve compatibility or standardization are premature. The other is that, whether improved cooperation and convertibility are or are not achieved, greater compatibility is imperative now.

Still other, but related, reasons for concern, expressed in the literature to date, include the following: "The trend toward mechanization continues throughout major Federal agencies. This trend makes possible, indeed it renders essential, efforts to assure reasonable compatibility between the machine systems." 118

"The danger in the current situation is that attention will be so strongly focused on automation that the primary problem of achieving compatibility in the scope and use of agency collections will be neglected." 119

Writing about the problems of planning for compatibility within a single large company, but with cogent comments much more generally applicable, Anderson (1962 [29]) provides a detailed and thought-provoking exhibit of discussion questions which should be investigated in the development of compatible systems, ranging from what identification criteria are needed and whether different ones required can be merged into a single system to the possible pitfalls of coding and fixed fields for print-outs, conversions, sorting, and the like. She stresses that: "It is important to remember that attractive but irreversible decisions may beckon at every turn. . . . Such decisions should be made with cautious deliberation where costly operations, such as the analysis of documents by subject specialists, are involved." 120 She concludes that "compatibitity with the future should not be sacrificed for compatibility with all parts of the company." 121

A major reason for current concern is that mechanization of some sort is now in progress or is contemplated for the near future in many different organizations, with respect to quite different areas of machine application, and with respect to collections ranging from quite small to the very large. Decisions at a variety of levels in a variety of places, and intending to accommodate, locally, a wide diversity of interests, needs and facilities can not only contribute to but escalate present incompatibilities to a level of continuing chaos. This is because of the sheer costs and time required to convert any existing records and items to machineusable form.

\subsubsection{Machine Language and Bibliographic Information}

Machine language compatibility tomorrow implies the requirement for considering such compatibility today in present systems as they are currently used. Achieving compatibility in the routine steps to which mechanization has been principally applied to date should be easier from many

118 Cahn, 1962 [94], p. 23.

119 Crawford Report, 1962 [465], p. 35.

120 Anderson, 1962 [29], p. 114.

121 Ibid. standpoints than that which would be required for those operations and processes so far still requiring luman analysis and judgment. Why cannot standards for the content and format of catalog cards be applied? Why cannot standard conventions for descriptive cataloging be developed and adopted? Why cannot standard methods for recording, preparing and reproducing catalog cards be established as is being explored for the Library of Congress by Buckland and associates of Inforonics, Inc. (1964 [144])?

Prior efforts to achieve agreement on rules and standards for descriptive cataloging are reviewed elsewhere in this report, but it is probably important to emphasize again that while the pessimism expressed by Wright in 1956 . . "When the subject for this paper was suggested ... my first reaction was to protest that a report on progress in the revision of our catalog code would resemble only a dissertation on the religion of Frederick the Great or a monograph on snakes in Ireland-a collection of blank pages" ${ }^{122}$-is probably not as justified today, there is evidence that many very real difficulties remain.

Permissive alternatives in cataloging practice, which appear to be a major result of cooperative attempts toward standardization agreements to date, merely complicate the mechanization problem. For example, deliberately cooperative attempts to achieve greater compatibility often lead to greater difficulties of compatibility and convertibility on the practical side. Thus, while "the possible disadvantage of bilingualism (in a proposed single international Journal of Physics Abstracting) seemed a cheap and acceptable mutual concession," 123 it is also clear that the "constant recommendation of alternatives may be a rational procedure for securing agreement in an international meeting but in itself it weakens the precision, the economy, and the efficiency of the catalogue." 124

From the standpoint of prospective mechanization, moreover, the problems are aggravated not only with regard to substantive questions but with respect to details of storage requirements, typography and character sets as well. (Parenthetically, the physical medium for storage of catalog entries was a factor in early Anglo-American cooperative efforts when "by adopting centimetersized cards, American librarians gave evidence of their hopes for international exchange of catalog cards." $)^{125}$

Decisions on elements to be included in records and files, the coding or notation systems adopted, and the number of types of characters to be recorded will have a direct and obvious effect on present and future storage requirements. The implications of potential mechanization on the format and content elements of bibliographic references

\footnotetext{
122 Wright, 1956 [655], p. 331.

193 Boutry, 1959 [74], p. 504.

124 Jolley, 1963 [303]. p. 61.

125 Ludington, 1954 [351], p. 194.
} 
and citations are particularly evident in the areas of interfiling catalog card information for machine search, of producing machine-compiled citation indexes, and of machine processing of full text.

Margaret Thompson (1963 [570]), describes a computer program that will take bibliographic references or citations, once they have been compiled, and process them automatically, arranging the citations into a standard format so that the parts are unambiguously identified. Nine items, the basic elements of a descriptive catalog entry, are accommodated in her program: (1) author or authors, including the designation " Jr." or "III ;" (2) title of book or paper; (3) title of journal; (4) volume, (5) issue, and (6) page numbers; (7) name of publisher, and (8) city; and (9) year of publication. The program also can sort and match the parts of the citations, thereby making possible the identification of similar citations and the effecting of various rearrangements of items.

We note, however, that the citations must first be compiled and suitable designators for the elements given. The difficulties here are at least two-fold: first, that the standardization of rules has not yet been achieved, and second, that practices are not consistent even for humans and are therefore not yet amenable to direct processing. Clapp remarks on the somewhat ironical situation that ". . . While in the traditional systems the identification of a document (known in library parlance as descriptive cataloging) is considered perhaps less difficult than content analysis (known as subject cataloging), with the computer the reverse is true." 126

With respect to machine compilation of citation indexes, for example, Pauline Atherton points out that: "Unless the references are assembled in a standard form, the data collected in separate citation indexing operations can not be matched and resorted by machine. A rigidly standard form for machine manipulation is necessary to insure this type of coordinated searching and sorting. To date almost everyone developing citation indexes has their own code and form." 127

What might be called "chaos in card catalogs" is of course as serious in many manual systems as for those involving potential mechanization. For example, in the 1944 survey of the Army Medical Library, it was found that: "Two different systems of filing have been used, one, a word-by-word system, and the other, a letter-by-letter system. As a consequence identical entries may be filed in two different places...

"Even when an entry has been found in the card catalog... the next problem is to find a call number or class mark on the card . . . The most prominent notation on many cards is the accession number, but that is of no use for this purpose. Another number, the one in the upper left-hand

${ }^{128}$ Clapp, 1963 [116], p. 7.

127 Atherton, 1962 [39], p. 4. corner, has to be disregarded also, since it is an indication of how many cards were typed for that particular item. Other figures in the same corner may, however, be location symbols. In blue or black pencil, or typed on the card, they may indicate the pamphlet box where the item is filed. Sometimes that number is prefixed by a symbol such as "P" or "Bx". . . the box number may have been printed at the end of the entry . . . Dissertations are indicated by a star, prefixed to the first word of the title ..."128 and so on. Hopefully, the example is of academic interest only by now, but it serves to point up the very real difficulties of transcribing catalog cards.

On the other hand,". . . computer people are learning somewhat to their amazement (and the librarians' amusement) that, as one 'machine' man put it recently, 'every mark, every space, every position, every word on a Library of Congress catalog card means something." " 129 .

Under a grant from the Council on Library Resources, Inforonics and the Library of Congress are studying possibilities for multi-purpose recording of bibliographic information in machineusable form. A press release sets forth the study objectives, in part, as follows: "The firm ... has undertaken to demonstrate that bibliographic information, when suitably punched into a perforated paper tape record by a tape-producing typewriter, can be reproduced in any form, whether complete or abridged, typewritten or printed in any one of a variety of type faces, as may be required for the various records used in library operations. The purpose of the demonstration is to lay the basis for seeking general agreement among libraries and other users and processors of bibliographic information as to the standards of conversion of such information to machine-readable form in order to assure compatibility and interchangeability of the product resulting from work performed at different locations." 130

Supposing that such compatibility can be achieved for the future, however, there remain the enormous burden and cost of integrating the new products with the old. Here a number of special problems and factors meet to emphasize the present seriousness of the impact of proposed mechanization. First, there is the prospect that automation of the more routine aspects of cataloging and bibliographic work will proceed well in advance of the design of systems capable of mechanized search and retrieval for the very large collections. Second, there is the tremendous problem of converting present catalog files and related bibliographic information into machineusable form. Third, there is the question of character sets required both for in put and output.

\footnotetext{
128 Metcalf et al.. 1944 [380], p. 23-24.

129 Adkinson, $1964[6]$, p. 5 .

130 Council on Library Resources, 1964 [144], p. 1
} 
With respect to the first of these problems, the team studying possibilities of automation in the Library of Congress has concluded that "the retrieval of the intellectual content of books by automatic methods is not now feasible for large collections, but progress in that direction will be advanced by effective automation of cataloging and indexing functions." ${ }^{131}$ Their report stresses, however, that "there must be compatibility between the Library of Congress and other research libraries, particularly with respect to the kinds of equipment developed. There is some urgency with respect to this compatibility since some efforts at automating individual libraries are already underway. The effort of establishing compatibility, or at least appropriate interfaces, is probably small compared to expected benefits." 132

The second major point is more general in that it applies to all information that is required to be in machine-readable form and this problem is therefore separately discussed. The question of the number of characters in catalog information, however, has been investigated in enough detail to provide data of both present and future concern. First, with respect to the number of characters per record, Sprenkle and Kilgour have made preliminary investigations of the average number of units (characters, punctuation marks, and spaces) in main entries, titles, imprints, notes, collations, subject headings, and added entries of sample catalog cards used in several biomedical libraries. They found, for example, that the number of such units used for personal author names varied from 10 to 37 . In general, their results showed considerable uniformity of the average number of characters used. They conclude: "The internal consistency of the results of this study strongly justifies this type of analysis for producing findings useful in estimating machine capacities required for catalogue cards." 133

The conclusions of the Library of Congress automation study team ${ }^{134}$ are that: "The conversion of catalog cards is an enormous task; the National Union Catalog, for example, contains about 15 million cards with an average of approximately 50 words per card. Running text can be keypunched and verified at roughly one cent per word. At this rate the complete conversion of the $\mathrm{Na}$ tional Union Catalog would cost about $\$ 7.5$ million. However, the heavy mixture of numerals and the necessity for a certain amount of formatting, error correction, and quality control suggest that the one-cent-per-word figure may be somewhat low." 135

\subsubsection{Storage Requirements}

Another special problem raised by present and future prospects for the mechanization of docu-

131 King. 1963 [31S], p. 2.

132 Ibid., p. 18

133 Sprenkle and Kilgour, 1963 [541], p. 205.

${ }^{134}$ king, 1963 [318], p. 9.

1зs lbid. mentation operations is that of storage capacity required. In September 1963, John Senders reported on three different calculations of information storage requirements for the contents of the libraries of the world. He summarizes:

"The total range of the various estimates is only slightly more than one order of magnitude: $7.5 \times 10^{7}$ to $7.7 \times 10^{8}$. At $10^{5}$ words per book and five letters per word, the number of letters to be stored is between $3.8 \times 10^{13}$ and $3.8 \times 10^{14}$. At 50 characters per alphabet and with 50 alphabets, there are 2,500 characters to be identified, or about 12 bits per character. The information storage measure of the "world's literature" then is between $4.6 \times 10^{14}$ and $4.6 \times{ }^{15}$ bits; $2 \times 10^{15}$ is conveniently close to the mean ...

"The growth rate is estimated to be about 3.1 percent per year, doubling in 22 years. 'Thus, the current addition rate is about $6.2 \times 10^{13}$ bits per year, or $2 \times 10^{6}$ bits per second." ${ }^{136}$

Even if mechanized records of library and information center holdings are to be limited for some time to come merely to the contents of secondary records, such as present-day card catalog information, the storage and machine processing problems remain enormous. The King Report estimates, for example, that "the procurement of hardware, software, and necessary file conversion for automation of the central bibliographic operation of the Library of Congress would amount to about $\$ 30$ million." 137

The situation of the combined departmental libraries of the Federal Libraries is not dissimilar. "As of June 1959, the holdings of the 212 reference libraries reporting in the Brookings survey totaled almost 14 million books, serial volumes, and uncataloged pamphlets (to which should be added some 5.6 million technical reports held by 107 of the libraries)." 138 Presumptively this total would include a large proportion of overlap in holdings, but how can the specific duplications within a group of diversified collections of this size possibly be determined without machine processing?

Related to the general problems of machine storage requirements are the more specific questions of fixed, specified, and variable record lengths allowed for records, fields, words, and other entries, and questions of possible truncations or artificial transformations used to reduce the redundancy of natural language words and texts.

Patrick and Black give an example of special machine considerations involving the need for further agreements on descriptive cataloging conventions and practices. ". . . If we held 2 full decimal dates in 6-bit BCD (binary coded decimal), 48 bits would be required to store the information about the year of an author's birth and the year of his death. By adopting a suitable convention (the base year 1000) and an appropriate pair of defini-

\footnotetext{
${ }^{136}$ Senders, $1963[515]$, p. 1068

137 King, 1963 [318], p. 2.

138 Evans, 1963 [188], p. 3
} 
tions-the first field contains an increment such that the year of birth is obtained by adding the first field to the base year, and the second field contains age at death-we can reduce the number of binaly positions required from 48 to 17 . . Whenever information is required on a printout ... it will be displayed as it now appears on a catalog card." 139

These authors suggest further that ". . . the library community should be stimulated to debate, in publication and open forum, the requirements for the master catalog file. In particular, the community should be encouraged to discuss, and eventually to agree on, the following: 'Resolved, the present catalog card contains information deemed unnecessary in an automated system for reasons of economy. These items are...' Some of the topics to be discussed are the myriad type sizes, fonts, and faces that have been used on catalog cards." 140

Similarly, Wright suggested earlier: "We should start with the question, "Why do we need the author's name?' And when we have answered that we should consider whether the answer implies the need for the full name and dates of birth and death. If it does not we next should ask what other reasons there are for including them. Are these reasons sufficiently cogent to justify the cost of securing and recording the information?" 141

The problems and costs of securing and recording such information raise the further questions of the language and media of the documentary languages themselves; the language and media of encoding, inscription and storage of document surrogates and condensed representations used for search, selection and retrieval, and the language and media of reproduction, display or transmission. We shall next consider some illustrative problems of input, internal machine language, and character sets.

\subsubsection{Problems of Input}

First is the question of obtaining machineusable input to any mechanized system. Modern machines are capable of working with letters of the alphabet and numbers when they are expressed as electrical signals or other physical states representing those alphabetical letters or numbers. This physically encoded expression of the alphanumeric characters is called "machine language." The machine languages require the automatic or manual transcription of the conventional alphanumeric symbols into a coded form which may or may not be legible to the human eye. The coded form may be a specific pattern of holes in one column of a punched card; other forms of coding may be utilized in punched tape, edgenotched cards, optical spots, or magnetic cards, tape, or drums.

\footnotetext{
${ }^{130}$ Patrick and Black, 1964 [450], p. 46.

${ }_{140}$ Patrick and Black, 1964 [450], p. 48.

141 Wright, 1956 [655], p. 33.
}

To date, there are three principal ways to obtain or record information in machine language form: (1) actual language or by-product recording at point of origin as in tape typewriters or typesetting paper tape; (2) manual keyboard operations; or (3) automatic character recognition, not yet developed to the point of feasibilty for general purpose text reading. This machineusable text may be regarded as the representation of the alphanumeric symbols constituting a message or messages in the machine languages directly usable both in specific input-output devices and media and in the internal memory and processing units of computers and similar data processing equipment. Material can be considered machine usable whenever it may be processed directly by machine without manual intervention, even though it may be automatically converted from one machine language to another during processing.

The first method is exemplified by the Inforonics studies previously mentioned, by new developments in computer-related automatic type-composing equipment such as GRACE in the MEDLARS System, and by the availability of paper tapes used to drive more conventional typesetting equipment, such as Monotype. Up to the present, however, the potential attraction of the availability of machine-usable text in the form of Monotype tape has been almost universally disappointed by the lack of suitable conversion equipment to rerecord the information given in a 30-column layout to 6-, 7-, or 8-channel tape usable by computer, or to punched cards or to magnetic tape. Another distinct problem is that of detecting corrections that have been made and handwritten indicia for changes of type style, font, and the like.

Some text is already available, whether obtained by this method or by manual keystroking operations with a tape typewriter or a keypunch for punched cards. The National Science Foundation announced in 1963 the awarding of a contract to Thompson Ramo Wooldridge, for a feasibility study of a "center for text in machine-usable form," the center to collect and make available machine-usable texts for documentation research. ${ }^{142}$ A report as of February 1964 (Mersel and Smith [379]) gives a total figure of approximately 50,000,000 words of text so available, but this includes a large proportion of nonscientific text, such as newspaper and popular magazine materials.

In terms, then, of material now available and the fact that the new type-composing equipment developments can operate only on future materials, not the present store, the principal method for preparing machine-readable material remains that of manual keyboard operation.

In this second method of preparing machineusable input, the typist or keypunch operator transcribes indicated copy into a desired machine p. 1. 
language form on punched cards, on punched paper tape, or directly to magnetic tape. The underlying difficulties here are time, cost, and availability of skilled operators.

"Punched cards must be produced manually from data in the source document and here lies the first and major input problem. The fact that the card must be produced manually limits the speed of the system to the speed of the staff operating the card punch equipment regardless of the fact that cards can be read at the rate of 1000 to 2000 per minute ... The average key punch operator works at a speed of 8000 strokes per hour . . . Verification cuts the production speed exactly in half and thus the net punched and verified card production is 50 cards per hour per card-punch machine." ${ }^{143}$ Since a single card contains only the number of symbols or words that can be accommodated in the space of 72-80 characters, it is obvious that preparation of even bibliographic citations alone can be a slow and costly business.

As noted in section 3.6.5 of this report, the tape typewriter is one of the devices that has been suggested for cooperative interlinkage between the document centers and between the centers and their customers at remote locations as in the "Reactive Typewriter" Plan (Mooers, 1960 [393]). Tape typewriters are also claimed by Horty and Walsh to be more economical of key-stroking time, such that "Flexowriter operators can produce between 1400 and 1800 lines per day of statutory text," whereas "key punch operators used in previous experiments could punch approximately 100 lines per hour of alphabetic materials, but could not maintain this rate for a sustained period of time." 144

Bernstein (1962 [57]) and Bernstein and MeyerUhlenried (1963 [58]) have made surveys of keyboard devices suitable for recording bibliographic data for documentation activities at EURATOM. They conclude:

"For recording bibliographical data card punching typewriters should be used if: the cards are directly fed into EDPM, the cards directly serve as storage and retrieval medium on conventional punched card machines, the initial document has no more importance than a proof reading sheet. Tape punching typewriters under program control should be applied if: trained typists are available, repeated duplication with putting as heading of filing criteria is wanted, an easy tapeto-card-conversion is to be used. Tape punching typewriters without program control should be used if: the recording and correction process is to be kept as simple as possible, repeated duplication without selection of filing criteria is wanted, the less expensive recording equipment is to be used." 145

In any case, intermediate transcription and conversion operations may be required in addi-

${ }_{144}$ Cornelius, 1962 [136], pp. 44-45.

144 Horty and Walsh, 1963 [273], p. 259

145 Bernstein and Meyer-Uhlenried, 1963 [58], pp. 75-76. tion to the initial keystroking and verification. A particular application may require a sequence of keyboard-to-punched-tape, tape-to-card, and card-to-magnetic-tape operations. Here also is a problem to be faced in the preparation of material in machine-usable form: the question of availability and cost of suitable conversion equipment, and whether it can handle, for example, 5-, 6-, 7-, and 8-channel tape produced by different varieties of tape typewriters.

Similarly, in the Flexowriter preparation of the texts of statutes at the Health Law Institute, University of Pittsburgh, the records themselves might be of indefinite length, but "since the punched paper tape is being prepared for conversion to cards before being placed on tape, each flexowriter line corresponds to one punched card and is limited to 75 of the 80 possible characters. The last five spaces on each card are reserved for a machine code." 146

This raises the general question of whether or not the machine-usable record or storage media is physically compatible with the machine processing equipment available. The most obvious example is that Remington-Rand punched cards, with 90 round hole columns which may or may not be punched, cannot be read with equipment designed for handling 80 rectangular hole columns on IBM cards, and vice versa. The possibility for compatibility is nil. Convertibility might be achieved if suitable conversion equipment were available and if the economics of using such equipment were better than those of interpreting the information from one card set and rekeypunching it into the other type of cards.

A more recent example, involving the general question of intra-Government and Governmentto-non-Government cooperation and with regard to the problems of machine compatibility is that of the MEDLARS system. To facilitate use by other centers and libraries of materials in the MEDLARS files, it is planned to deposit copies of the tape files in various decentralized locations for easier access on a regional basis. Following a presentation of this system (Taine, 1964 [552]), R. T. Esterquest made the following remarks: "But there are more problems to a decentralized MEDLARS than meet the eye. In the first place, MEDLARS in Bethesda is centered in a Honeywell 800 computer. The computers locally available to my library happen not to be Honeywell machines and cannot read Honeywell's tape." 147

To which the speaker replied: “. . . Honeywell is not alone among the computer manufacturers in being incompatible with the other computers. In fact, there is even a considerable degree of incompatibility between different computers from the same company. However, this is not a serious obstacle to the effective distribution of duplicate MEDLARS tapes to outside computer centers.

${ }^{146}$ Horty and Walsh, 1963 [273], p. 259.

147 Taine, 1964 [552], p. 130. 
The conversion of $\mathrm{M}-\mathrm{H} 800$ magnetic tapes to other tape formats is economically and technically feasible at the present time." 148

A case in point is the Biomathematics Division at Ft. Detrick, Maryland, which has the Honeywell tapes converted to its own UNIVAC System tapes, via an intermediate conversion to IBM tapes, in order to incorporate MEDLARS material into its own search files. But, as Esterquest further remarked, "even if Honeywell's tapes were to be converted, there is still noncompatibility at the systems or operational level." 149

The possibilities for machine convertibility between systems have been little explored. The few exceptions have mostly been limited to mechanical transcriptions and transliterations, resortings and reassemblies, often accomplished by slow and cumbersome auxiliary equipment. For example, although a UNIVAC tape version of 400,000 words of Webster's 2d International Dictionary was available to RCA researchers, it was not usable with any of the computers to which they had access. Accordingly, it was necessary to reprocess the hundreds of thousands of the original punched cards to produce another magnetic tape acceptable to the 301 .

More important from the standpoint of future compatibility and interchangeability of machineusable products, however, are those problems which arise with respect to "format control, questions with respect to the conventions to be used in keypunching, and problems of preediting." 150 These problems in turn are closely related to the possibilities of standardization of codes and conventions for recording, keypunching, transliteration, and transcription.

The variety of input characters where texteven if only text of authors' names, titles, and other elements of the typical descriptive cataloging record is involved - adds significantly to time and cost of preparation. Thus manual editing, transliteration, encoding and simplification before input is typically required, in accordance with rules and conventions such as for the spelling out of chemical symbols or Greek letters and for consistent practice with respect to format indicators and font change designators.

Nugent (1959 [431]) and Ray (1962 [471]) have pointed out some of the requirements and some of the difficulties in providing a manual for keypunching of natural language texts. Newman, Swanson and Knowlton provide (1960 [428]) an even more complicated notation-transliteration scheme necessary for keypunching of patent disclosures in which a wide variety of boldface, italic and special symbol inserts have been accounted for.

Patrick and Black have recently suggested that "in the following rather simple way, a catalog card could be easily punched: start with a modechange character that set[s] the mode to bold-face

\footnotetext{
148 lbid, p. 131 .

149 Taine, 1964 [552], remarks of R. T. Esterquest.

150 Stevens, 1962 [543], p. 63-64.
}

alphabetic; following this would come the author's name; following the trailing punctuation would be a mode-change character that specified the mode as numeric; the author's year of birth would follow; whenever this line was complete, an end-ofthe-line symbol would establish the format for the title line; and so on down the card, with the changes of font, capitalization, intervening punctuation, through the end of the recorded information. If the card were multilingual ... a mode-change character would indicate this fact. . . ." 151

Font designators available in one experimental program for the "extraction of significant information items to be used in the automatic production of secondary publications from a formatted, punched tape manuscript" include signals for changes from Roman to Greek alphabets, subscript or superscript, italics, bold, sans serif. ${ }^{152}$

We note, however, that the number and identity of these mode-change characters must be established and their usage for a particular application must be defined. This requirement raises the next specific problem, that of character sets for input, internal processing, and output.

\subsubsection{Character Sets for Machine Processing}

The present disparity between the very large character sets which typically can appear on the printed page or even on the catalog card and the size of the character sets available on typical typewriter, keypunch and console keyboards creates a dilemma. Either much of the information conveyed by typestyle changes, bold face, superscripts and subscripts, special symbols and the like must be eliminated as part of the input process or it may be preserved by spelling out, encoding, and the use of special clue symbols, sometimes amounting to three or four for each "text" character. If the information is eliminated, then its restoration is generally not feasible, so that the output character set will usually be limited to not more than 64 letters, numbers and symbols, printed in upper case. Yet what is desired is "legibility to permit the rapid scanning of the printed product [which] is an important requirement that implies a capability for printing in a variety of type fonts and sizes ... A variety of type styles, weights, and sizes are needed to meet the standards of Library publication." 153

The present alternative, however, pending the development of automatic, multifont, page reading devices, is likely to increase the already staggering costs of input data preparation severalfold. "Obviously, direct conversion of data by machine scanning would be infinitely superior." 154 Unfortunately, the third possible method of input of bibliographic and textual information mentioned earlier, that of the use of automatic char-

\footnotetext{
${ }^{151}$ Patrick and Black, 1964 [450], p. 41.

${ }^{352}$ Lund $y_{,} 1963[361]$, p. 115.

153 King, 1963 [318], p.9.

154 U.S. Senate, 1960 [592], p. 38.
} 
acter recognition techniques, is not yet feasible. In general, a summary appraisal of the state of the character reading art made in 1961 is still applicable: "With character recognition equipment, the printed or typed page would be inserted into the reader, which would scan each line, converting each letter recognized into the appropriate machine code language equivalent. Reader output might be punched cards, punched tape, magnetic tape, or directly to computer. Prototype page readers for good quality printed text in one or several different type fonts are already undergoing active development and testing. . . .

"The feasibility of machine reading of good quality printed, typed or, in some cases, even handprinted characters, has been successfully demonstrated. However, there is little operational experience to date except with limited vocabularies of specially designed characters and questions of equipment cost and confidence in performance have so far precluded general use of readers for preparing texts in machine-usable form. In addition, if the source material contains graphic material, equations, and formulas as well as text, it may be necessary to perform extensive manual editing and masking out before input to a reader." 155

More recent developments involving design proposals and demonstrations of page-readers with some multifont capability are still far below the character set size required for most scientific and technical literature. Shaw reports, for example: "To get an indication of the number of difficult alphabetical characters that may be used in a single scholarly book, I asked Mr. Theodore Besterman to count the different pieces of type used in his World Bibliography of Bibliographies. This he did, and as shown in the preface to the third edition of this work, he used approximately 1950 different pieces of monotype ... There are a number of alphabets that are not included in Besterman, as well as mathematical symbols, etc." 156

Even for the case of catalog cards only, the severe problems of machine-reading are those of mixed-font, mixed-weight and size, mixed alphabets and formats, and varying conventions of abbreviation, punctuation, and representation which have been adopted to differentiate the various types of selection, locator or reference clues in a manner that would be convenient for the human eye in scanning and filing. This is why it is only reasonable to conclude as of today that"

The automatic conversion of files, such as the $\mathrm{Na}$ tional Union Catalog, which contain considerable heterogeneous symbolism, is not likely in the near future." 157

The question of how large input and output character vocabularies should be is further illustrative of the ramifications, in a specific problem sense, of the general problem areas, including

\footnotetext{
$15 i$ Stevens, 1962 [543], pp. 61, 63.
}

158 Shaw, 1962 [518], p. 268 .
157 King, 1963 [318], p. 20. those of problem definition (especially, of "seeing the problem and seeing it whole"), languages, and user acceptance. Clapp has spoken to the problem of the so-called "upper-case limitation" as follows: "As long as Mr. Watson would only give us a character font in capital letters there could not be any great fervor to load. If I may say so, the whole picture of automation in libraries from the thirties right down to the present date has been controlled by that uppercase limitation." 158

Regardless of the size and contents of input and output character sets, however, there are additonal special problems of the internal character set which will affect planning for sorting, ordering, filing, and interfiling. "Even though we have not yet agreed on a standard character set for our data processing computers, each computer has a single set built into it. This set is the 'natural' set of that computer, and all other sets are defined in relation to this built-in character set. The character set is extremely important in file definition since the character set defines the order of a file once it is sorted." 159

An example involving computer maintenance of a thesaurus in the Public Health Service uses machine-generated line numbers for each dictionaly line because "filing of terms cannot be done in a strictly alphabetical manner. For example, $\mathrm{X}-\mathrm{RAY}$ is filed under $\mathrm{X}$, while D-GLCCTTOL is filed under G." 160

The effect of the particular internal set in a particular computer on filing and ordering also points up the importance of either exact compatibility in input material exchanged between organizations or the availability of carefully programmed conversion capabilities. For example, in certain computers, sequences of information recorded in punched paper tape must be interrupted at arbitrarily fixed intervals by a special symbol such as the carriage retum in order to prevent shifting in input so that one or more bits are deleted or added to the original bit pattern. If in the tapes received from another installation there is any deviation in position or bit pattern of the interrupt indicia, such shifting may occur in any case.

This will result in garbling of the encoded text. Thus, for example, a one-bit shift of the text of the title: "Real-Time Data," with upper and lower case as recorded in ASCII code might result in the following message being actually read by the machine: ") 206 (SYNC) : 462 ..." If and only if such shifts were consistently made for all inputs and a compensating shift made on output, could such messages be used for file posting, file maintenance, or retrieval purposes.

\subsubsection{Internal Processing and Programming Languages}

Specific questions of internal processing language and programming language are interrelated

\footnotetext{
158 Clapp, 1964 [114], p. 54-55.

159 Patrick and Black, 1964 [450], p. 31.

160 MeGee et al., 1963 [377], p. 348 .
} 
with those of internal character set, fixed versus variable word length allowed in internal memory, and compatibility, or interchangeability. For the 21 different information retrieval languages and systems listed by Grems in 1961 ([227]), 11 different computers are used. Some use a binary internal language, some a binary-coded decimal, some a full binary-coded-alphanumeric. Special programming languages are used, for example, in BASEBALL (an experimental question-answering system), for the ACSI-MATIC intelligence processing system, and for linguistic data processing programs at the System Development Corporation.

A computer program to produce printed book catalogs at Boeing Research Laboratories, for another example, has the following features which illustrates some of the problems of compatibility: (1) it is written in FAP language for an IBM 7094-1401 intsallation but because it uses only three index registers, it can be "directly adapted to IBM 7090 or 709 with only minor revision"; (2) it provides subject entries, conventional title entries and permuted title entries, but the latter are based on manually preselected key words and "a nonprinting symbol entered on input copy causes rotation of the title about the normal indexing locus, the left margin, with no loss of context, whatever its length"; (3) input can be either from the preferred form, Flexowriter tape, or from standard punched cards; (4) "sorting is accomplished in a manner analogous to Library of Congress rules, as commas and dashes in subject headings are used as control characters to permit the necessarily unique subject-title intermix." 161 "Program revision" however minor, "nonprinting. symbols," "control characters," "normal indexing locus" are all clues to difficulties of interchangeability even with organizations having a closely similar equipment configuration.

In general, with respect to computerized documentation operations little or none of the input, intermediary, or output products are directly usable in any other system whatsoever. Apparent exceptions, such as the distribution through the SHARE system of various KWIC index preparation programs, require innumerable compromises between what-is-desired and what-can-beobtained both cheaply and expeditiously. Even for the case where the standard Luhn KWIC format is only slightly modified, input copy is generally not interchangeable today.

Two additional examples of related problems might be mentioned here. The first has to do with the wide variations in length and contents of the stop lists used to delete from indexing consideration the common and insignificant words in KWIC and similar type machine-prepared indexes. The length and contents of stop lists used directly affect the number of pages compiled, and hence both the costs and the usability

161 Weinstein and Spry, 1963 [638], p. 233. of the printed indexes produced. Changes in stop lists over time in a single organization, which is quite common practice, will seriously impair the prospectives for cumulative indexes of this type.

The seconc' example also relates to computer production of permuted entry indexes, but in this case subject indexes involving a classification scheme. Mills says: "The wide use of the UDC in published indexes and bibliographies as well as by journals and abstracting services makes consistency between these in the use of UDC desirable. To assist this, some users have advocated the extensive use of the colon device in place of special (and even common) auxiliaries in order to facilitate the routine production of permuted entries, e.g., 669.295: 669.018.5 ... would be preferred to 669.295 .018 .5 ... There is no general agreement on this however." 162

For another example, Wofsey in his analysis of four COBOL compilers for four different computers (1962[651]) found an average of more than 21 variations which would necessitate changes if a source program from one machine were processed on another. These differences involved compiler restrictions in one system but not the otlier, options available in one and not the other, failure to accommodate changes in COBOL specifications (1960 as versus 1961) and variations in the equipment.

Further, at a seminar on the prospects for an information retrieval programming language, the chairman summarized the consensus as follows: "The wide divergency of basic file layouts, indexing techniques, etc., make the development of a 'standard' IR language impractical at this time. Thus, the answer . . . is to encourage the development of special-purpose IR languages to meet individual needs, even though this complicates the translation problems enormously . . . " 163

\section{Implications for Further Progress}

Observations that may be made as a result of this literature review are as follows: certainly in the United States, cooperation has long been evident among librarians since the establishment of the American Library Association in 1876. International aspects of such cooperation are evidenced by such widely separated events as the 1908 AngloAmerican rules for cataloging author and title entries and the 1961 International Conference on Cataloging Principles, sponsored by the International Federation of Library Associations.

Cooperation is also evident among those active in the development of new and less conventional procedures and equipment, especially since World War II. Examples of this interest may be seen in the development of a standard for the descriptive cataloging of government reports under the sponsorship of the present Committee on Scientific and

\footnotetext{
I62 Mills, 1964 [388], p. 47.
}

163 Sammet, 1962 [503], p. 8. 
on [echnical Information, in the NASA, AEC, and OOD microfiche agreement and in the approval sy the American Standards Association of an American Standard Code for Information Intershange (ASCII).

Most of these examples of cooperation are conserned either with physical aspects of the exchange of information or with the identification and description of documents. Cooperation in the "tagging" of the subject content has not been so prevlent. The COSATI standard, for example, makes compatibility possible among several agencies in describing bibliographic items. The achievement of compatibility among three Federal agencies (AEC, DDC, and NASA) for processing these reports has been difficult to attain, even the achievement of convertibility among the terms used for indexing content proving elusive despite investigations such as the Datatrol studies which look toward a scheme of generic subject categories that will subsume the composite subject content of the research reports dealt with by these agencies.

Major deterring factors in this area of potential compatibility or convertibility appear to be those of achieving consistency of human indexing and of bridging the unfortunate gap which still appears to exist between librarians and "information scientists," between traditional libraries and information centers dealing primarily with the report literature.

While the original impetus for this review was with respect to the implications that might be found regarding machine language compatibility, it appears that very little helpful precedent is available. The history of both early and current activities point to a serious question of prematurity of compatibility efforts in this area, much less efforts directed toward standardization. It would appear that firm standards for report numbering compatible with an identification system for the journal literature, for descriptive cataloging embracing both the traditional and the more recent types of publication and disclosure, and for subject cataloging and abstracting at least to the extent of minimum classificatory schemes or indexing vocabularies, are all prerequisite to efforts in the machine language area other than those of agreeing upon such detail matters as the common coding of a minimum character set (ASCII).

"For the past ten or so years, we have been preoccupied with the development of new techniques, few, if any, of which have yet proven themselves to the exclusion of others. Now, with small chance of consensus as to the best approach for a single situation, talk of compatibility emerges with standardization looming as its ultimate manifestation. Premature standardization on a large scale to systems which are not the best is entirely possible." I

Y. S. Touloukain stated at Congressional hearing in 1963 that "one cannot be against standardi-

IAnderson, 1962 [29], p. 116. zation, the question is what it is that we want to standardize. . . . Industrial compatibility in nuts and bolts and machine threads is one thing, and compatibility of coding intellectual information which may be in numerical form, pictorial form, quite often in the form of opinion and judgment, is another." 2

The problems and difficulties include, as we have attempted to illustrate, those of defining requirements throughout the entire cycle of information processing from generation of basic data to use of recorded knowledge, those of language at many levels, those of human consistency and human acceptance. Problems raised by prospects of mechanization include: (1) the physical characteristics of storage and recording media, (2) layout and format of storage and recording media, (3) selectivity as to units-of-information to be handled and items to be recorded, (4) layout and format of identificatory indicia, (5) coding required and conventions used for abbreviations, variant spellings, and transliterations, (6) code symbol vocabularies, (7) machine language variations, and (8) programming language variations.

Each of these problems obviously has impact on the underlying intellectual, organizational, and systems problems, reaching back into traditional library practice and conventional interlibrary cooperative activities. In the 1961 report on Senate hearings with respect to the coordination of scientific information, continuing and intensified efforts were recommended in such areas as "(1) Formulating a thesaurus of index titles for classifying research and development on a Government-wide and national basis; (2) Developing standardization and compatibility of data processing systems, at least for all Government agencies; (3) Correlating a central project registry with the indexes maintained by different agencies, with information and data centers, with research documentation and with the NSF Register of Scientific and Technical Personnel." 3

These objectives remain worthy long-range goals, but there are many practical difficulties which must be faced. Thus, Wall in commenting upon the implications raised by the above three points suggests:

"Specifically, $a$ thesaurus for government wide application would seem to be useful as an interagency communication vocabulary standing for concepts of interagency interest ... but each agency would need its own thesaurus, consistent with the interagency one, to cover its own unique terminology plus that of the interagency thesaurus which may be of interest to the individual agency. An interagency organization thesaurus such as this for government-wide and national application is out of the question, I believe, until government and non-government organizations involved have first created their own thesauri, thus creating a base

${ }^{2}$ D.S. House, 1963 [582], p. 191.

3 U.S. Senate, 1961 [593], p. 4. 
for common agreement and resolution of individual disagreements.

"Standardization of all government data processing systems might well turn out to be a will-ofthe-wisp-at least for a number of years. There are such tremendous problems involved, especially considering all the levels at which standardization may be striven for. At what levels is standardization to be achieved and with what economic justification (bit structure, collating sequence, character sets, word length, programming language, record length, record format, media, etc., etc.) ?

"Finally, as for 'correlation' of project data and information, we can see the possibility of SIE (or equivalent) and similar agency indexes being coordinated, but it seems to us that beyond that the 'implication balloons to a gargantuan tasknamely, correlation with information centers' and with 'research documentation. . . ." " 4

Under these circumstances, as Fussler said a decade or so ago, "the conditions for successful cooperation are both limited and important." 5

It should, of course, be noted that many of the recommendations of the Crawford and Weinberg panels, of Congressional committees and subcommittees, of the Science Information Advisory Council, FASCI, COSATI, the DOD-wide documentation coordination program, the Clearinghouse for Federal Scientific and Technical Information and others which have been put into effect will have a continuing impact on increased cooperation, compatibility, and convertibility. The COSATI task groups on technical vocabulary compatibility, on conspicuity, on descriptive cataloging standards, on a national inventory of journal literature, on a single Government depository system and on research and development in the information sciences all point in helpful directions.

Nevertheless, a variety of questions and provocative suggestions are implied by the reports in the literature of prior experience, failures and shortcomings, the lack of extensive examples and the recognition of new challenges and new opportunities. First and foremost of the implications is that: ". . While the theoretical recognition of the advantages for co-operation can be taken for granted, it is a much more difficult thing to achieve real and helpful co-operation . . . ." 6

Honest differences of opinion have existed and continue to exist with regard to centralization and decentralization, mission versus disciplinary orientation, Governmental coordination and private initiative, prematurity or belatedness of standardization, precoordination or postcoordination in indexing, down to details of physical characteristics of storage media and the like. For example, Agard Evans has noted that despite an international agreement for cooperative abstract-

\footnotetext{
4 Eugene Wall, private communication, March 30, 1965.

5 Fussler, 1953 [208], p. 222.

${ }^{6}$ Readett, $1960[472]$, p. 155.
}

ing in building documentation, only nine of the 1 . participating countries conformed to the agreed upon standards, even in such details as physica characteristics of products. He reports, for ex ample, that in France "the abstracts are produced in the prescribed form but printed on thin pape] and not on cards." " Nevertheless, "if informa tion systems are to succeed they must be uniform enough to serve the common needs of various cate gories of users yet flexible enough to contribut to specialized needs." 8

Compliance with standards, or agreed-upor conventions of practice, is also difficult to achieve For example, the Unesco recommendation, "Guid, for the preparation and publication of Synopses' has been "officially adopted by the Internationa Council of Scientific Unions but seems to have had little publicity judging by its slowness tc take effect." 9

As another example, Cady (1950 [92]) reports on the survey of 40 general periodicals and 25 scientific journals with respect to their compliance with "An American Standard Reference Data ane Arrangement of Periodicals, Z 39.1-1943", which was intended to prescribe a standard location in journals for the date, volume issue, page numbers table of contents, authors and titles of pages. For the general publications, it appeared evident either that the editors had never heard of the standard or were ignoring it, and, while the technica journals adhered in some cases, considerable improvement was indicated.

Provocative suggestions have been made with respect to a variety of new and specialized types of clearinghouse, directory, and exchange services, and for the extension of existing services. Guides or directories to sources of information have been advocated at least as early as the Royal Society Conference on Scientific Information in 1948. ${ }^{\text {ic }}$ Directories of specialized information centers and services for both the physical and biological sciences (National Science Foundation 1961 [419]) and of the information resources of the United States (Library of Congress, 1964 [339]) are examples of recent approa ches to one aspect of this problem. However, although "we have information about information centers in the United States ... we do not have adequate information about centers in other countries that might well provide service to us." 11

Closely related, as anticipating new services for continuing systems design, systems evaluation, and systems improvement is Bourne's suggestion for a "documentation census": "One approach that would be very useful would be to establish a permanent mechanism for obtaining current and accurate information about the parameters of the literature problem-that is, a continuing docu-

\footnotetext{
"Agard Evans. 1959 [8], n. 493. U.S. Senate, 1961 [590], p. XVI.

9 Craig. 1964 [146]. pp. 4-14.

${ }^{10}$ Urquhart, $1952[604]$, p. 236

${ }^{11}$ Heumann, 1962 [258], p. 122
} 
mentation census that keeps a finger on the pulse of the literature flow to note the volume, characer, and trends of the various mixes in the low ...."12

Another suggestion is for the provision of photooopies for all items covered by a given abstracting or indexing service, or for an entire broad field of science. Wilkinson and Waldo ask: "Couldn't someone assume the responsibility to provide photocopies of any article which has been abin stracted in C.A.? . . . What we really need is ere a sort of clearing house to which we could send orders for copies of any articles which have ap"peared in the chemical literature. The clearing house would be able to provide copies immediately from its own holdings or forward the order to a osource which they know can definitely provide it immediately." 13

Taylor, writing in 1963 with respect to increased cooperative action among Federal libraries, suggested that among the particularly timely joint measures that might be undertaken would be the establishment of a clearinghouse on bibliographical projects and a review of translation services: "demand, cost, speed, method of reproduction, and indexing." 14

Also, with respect to technical translations, the general suggestions find echo in a specific case of mechanization: "One of the noteworthy features of the French system is the recent introduction of a Selecto-Cordounier mechanical selector, which enables translations to be traced even from incomplete data such as only the author's name, subject of the article, title, or date of periodical from which the article was taken." 15

In the area of translations, it has also been suygested that directories or records of holders of copyright should be established, especially with respect to obtaining authorizations for translation to be made. Reed says, further: "I think we should explore the possibility of more frequent recourse to owners. . . . It might be well worth while considering the establishment of some focal point at which experience of owner approach could be ac- cumulated and advice given." 16

A more general approach to the copyright owner clearinghouse has been reported. "A grant has been made by the Council on Library Resources for a feasibility study of a clearinghouse which would serve as an intermediary between owners of copyrighted material and scientists and others wishing to make one or more photocopies of it. The study is being conducted by the Committee to Investigate Copyright Problems Affecting Communication in Science and Education." 17

Another example of a specific suggestion or question is whether a "Current Contents" project

12 Bourne, 1962 [73] p. 162

13 Wilkinson and Waldo, 1962 [646], p. 175. Note that VINITI does provide such services, see p. 49 of this report.

14 Taylor, 1963 [565], p. 77.

${ }^{15}$ Liebesny, 1960 [340], p. 150.

${ }^{16}$ Reed, 1960 [475], p. 166.

17 Scientific Information Notes 5, 4, 12 (1963). can be estabilished for multisubject technical reports, especially consolidated progress reports of major research laboratories?

The idea of a central clearinghouse for "field-ofinterest" registers extends itself quite logically into the idea of one or more relatively centralized and specialized selective dissemination operations. New machine possibilities for the production of special-purpose and 'tailored' bibliographies on demand raise the further intriguing prospect of demand specified in advance, of "profile bibliographies" as a further extension and development of selective dissemination.

It has recently been recommended, for example, that pilot trials be conducted for "screening computer tapes of current references to bio-medical literature, such as those produced in the MEDLARS program, to provide individual bio-medical scientists with a current awareness service specially tailored to their interests, habits and preferences." 18

Fundamental questions that are raised, however, go to matters of bridging gaps between libraries and report handling centers, of maintaining proper balance between requirements of large-scale or centralized services and local needs, of developing systems with sufficient flexibility and provision for the incorporation of user feedback and usage data.

In the area of U.S. Government responsibilities, for example, has enough attention been given to departmental and agency libraries - their policies, procedures and problems? The Brookings survey suggests not: ". . It is fair to say that, taken as a group, the libraries of executive departments and agencies have received little concentrated attention either from government policy-making officials or from students of government. No general policy regarding their functions has been enunciated; no standing body of administrators or librarians is concerned with their problems; and no current and comprehensive statistics have been available on the magnitude of their holdings, the cost of their operations, or the range of their services." 19

What measures of compatibility can be assured in planning or implementing improved and increased Government-wide services in terms of accessibility and costs of suitable equipment for the use of mechanized records, microforms, and other products available only in machine-usable form? Priorities of access to centralized services? Compatibility or at least convertibility of physical form and medium, content, and format of bibliographic control information with specialpurpose needs and local secondary handling costs? The latter may include, for example, the human costs involved in scanning indexes, abstracts, and announcement bulletins which are too lengthy, too cumbersome and which have poor readability because of "upper-case limitation."

18 "Communication Problems in Biomedical Research" 1963 [403], p. 21

19 Orlans, $1963[434]$, p. v. 
In this connection, the specific question of the availability of inexpensive microform readers also arises. As Becker points out: "Little information on machines and other equipment was collected in Dr. Evans' survey. In their questionnaire replies a few librarians did report the presence of microfilm reading machines and photoduplicating equipment, but the data were too sketchy to permit significant conclusions. Conspicuous by its absence in their comments, however, is any widespread concern about equipment and the impact which automation is apt to have on their libraries. If the federal library system is to be strengthened this certainly is one area that needs detailed attention and helpful support." 20

Turning, then, to the more specific area of present and future prospects for mechanization, we find suggestions for the provision of basic tools such as the National Union Catalog in "machinelanguage form, periodically updated and maintained," 21 for "a systematic program of training and education in documentation [which] should be developed by federal libraries to encourage the automation of their activities, whenever practical," ${ }^{22}$ and for the encouragement and support of cooperative experimentation in mechanized documentation.

Among the improved clearinghouse and exchange services which might be set up for the mechanization area would be exchanges of indexing and cataloging information tapes, exchanges of computer programs for listings and selective assemblages of such information, exchanges of programs for conversion of one machine language to another or to provide magnetic tape images of punched paper tapes so that information in various formats can be "unpacked" and reformatted by computer, and exchanges of machine-usable texts, records, stop lists, word lists, dictionaries and thesauri.

We note, however, in this last example, some warnings of possible prematurity. For example, in House hearings on research in mechanized translation the following exchange occurred: (The Chairman) "Each group doing research in this field builds its own dictionary. Why can't the research work on dictionaries be exchanged?"

(Mr. Dostert.) "We should perhaps make a distinction between 'word lists' and 'dictionaries.' There seems to be no complication in providing for the reciprocal exchange of word lists developed by the various groups. It seems to me also that some coordination and standardization could be arrived at in regard to keypunching procedures and format. However, if by 'dictionary' we mean the lexical materials plus the codes for the analytical operations, this would seem less feasible, since the codes are devised on the basis of the particular

\footnotetext{
${ }_{21}^{20}$ Becker, 1963 [46], p. 92.

21 Swanson, 1964 [549], p. 87 .

22 Becker, 1963 [46], p. 92 .
} philosophy and techniques pursued by the several

Similarly, King says: "It is too dangerous to insist upon or freeze on a 'programming language' for lexical material, but some sort of clearinghouse will soon be essential in view of the manpower requirements." 24

Another aspect of possible prematurity with respect to mechanized systems relates to the more general question: Should a uniform system for at least minimal subject content indication be based: upon a universal classification system, facetted classification schedules, alphabetized subject headings, thesauri of descriptors, Uniterms with scope notes, "free indexing" (largely of words derived from text), or mechanical derivative indexing by automatic extraction of keywords or words occurring with significant frequencies in a text? An example of desirable research in this area might be the project in which "AEC . . . cooperated with the National Science Foundation in the development of an experimental classification and coding system for AEC documents. The ultimate purpose is to develop a coding scheme which can be utilized by a small digital computer which would be economically feasible for smaller libraries." 25

Further, is the code or notation scheme by which the classification or indexing terms are recorded sufficiently flexible for multipurpose use? It should be remembered that the major criteria for notation schemes are "usually judged to be hospitality (the ability to incorporate new classes in their correct, logical place . . .), simplicity (the ease with which symbols convey position) and brevity (a central element in simplicity)." 26

Here the problem of possible prematurity relates the evidence, on the one hand, of the serious lack of consistency between human indexers, even when they are using the same controlled indexing or classificatory vocabulary, to that of the, at the least, provocative results from automatic assignment indexing and automatic classification experiments, on the other. While in the latter case the experimental data available to date have been limited to very small test samples, to a very small number of subject headings or indexing terms to be assigned and to quite carefully selected pseudocollections within highly specialized fields, within these limitations the results do suggest a level of indexing such that users, or indexers, would agree as to the relevance of terms assigned by machine about as frequently as they now agree with each other. ${ }^{27}$ This is at about the 50 percent level, or less, for routine mass-production indexing operations, although it may rise considerably higher for a carefully trained, highly motivated staff as at

\footnotetext{
23 U.S. House, 1960 [588], p. 107.

$24 \mathrm{King} 1964$ [319], p. 241 .

25 U.S. Senate, 1960 [592], p. 37

${ }^{26}$ Mills, 1964 [388]

27 For a review of some of these experiments see Schultz, 1964 [510]. A state-of-the-art review of automatic indexing developments is also in process of publication as an NBS monograph
} 
Chemical Abstracts or among those participating in the Cranfield experiments.

It is clear that any successful interchange of compatible or convertible materials with respect to subject cataloging or content analysis must be dependent upon a very high level of intrasystem consistency as is, of course, optimal use of the individual systems. To date there is hardly a system that has approached the degree of consistency which will provide such optimal use of its own facilities or of the export of its products to other systems. Further, as Painter points out (1963 [445]), convertibility between indexing systems is highly dependent upon a high degree of consistency within each system. Perhaps only by mechanized processes of indexing and classification can results be replicated and, hence, consistency achieved. This area, therefore, certainly appears to be one in which future research should be encouraged and supported.

"Research should be expanded as to how far individual systems-manual or mechanized-may vary one from the other (as they do vary at present) while still offering reasonable opportunity for compatibility." 28

Other research areas in which greater cooperation, coordination and encouragement would appear indicated are those of systematic attack on the bottleneck problems of input and of the development of remote consoles and other means for man-machine interaction in the information system. The first requires further research and development in the field of automatic character recognition, with emphasis on multifont pagereaders and other alphabets than the Roman.

As noted previously, the cost of converting the present union catalog information of the Library of Congress, assuming keystroking of the information for each entry, would be not less than $\$ 7,500$,000 , and in the case of Federal Departmental Libraries the sheer costs of transcribing to punched cards merely the descriptive cataloguing information for these holdings would exceed, at minimum, $\$ 10,000,000$. Pending development in character recognition, therefore, it has also been suggested that the possibilities for machine processing of stenotyped copy should be further explored. ${ }^{29}$

A somewhat similar question of adequate character vocabularies also arises in the research area of man-machine interface.

"Machine methods of editing, spelling correction, type selection, page formatting, and line justification have all been demonstarted. Stress must be placed on software techniques for editing and page composition. Computer graphic composing equipments must be made capable of providing high quality, reproducible copy at rates of several hundred characters per second with a large

${ }^{28}$ Cahn, 1962 [94], p. 27.

${ }^{29} \mathrm{King}, 1963$ [318], p. 9 ; Patrick and Black, 1964 [450], p. 43 . repertory of symbols, characters, and type sizes. .. There should also be some means, whether at the console or central processor, of automatic format control and a means of automatic transliteration of words in digital storage to the Roman alphabet, regardless of the source language alphabet." 30

The King report also emphasizes some of the benefits to be gained by the development of adequate user consoles as follows: "users" annotations of subject classification or assignment of subject headings could be accepted as input at the console, subjected to further review and editing by a librarian and then incorporated, as desirable, in the system. Users could also comment on the similarity or relatedness of specific papers, reports, or books which they utilize." 31

"A capability for browsing by use of the console should be of even greater significance. The opportunity to examine statistical data on the number of entries in a bibliography, the bibliography itself, and then selected pages of particular items which may include title pages, tables of content, and indexes, all on a successive rapid response basis and coupled with subject access to whatever depth economics permits, will provide a far more flexible intellectual interaction between the user and the collection than occurs in wandering through the stacks as though one were shopping in a supermarket." 32

A final further example of needed research is in the area of programs and programming languages for index compilation, linguistic data processing and automatic content analysis. Is it feasible to develop a general purpose compiler to cover a variety of output formatting requirements, including those for various automatic photocomposition systems? Is it possible to develop a problemoriented interpretative language to do for information selection and retrieval what ALGOL and COBOL offer other types of computer applications? Can Federal support as well as encouragement be provided to those who are capable of determining answers to these questions?

"The federal library community offers an ideal setting for the establishment of a cooperative automation program involving education, research, and experimentation. No effective means exists today for federal librarians to exchange and evaluate their knowledge and experience of mechanization, or to pursue broad, government-wide mechanization programs.... The value of cooperative experimentation in library automation should be emphasized in order to minimize cost, avoid duplication, and ensure widespread dissemination of results." 33

However, notwithstanding the probable results of further research, the problems of the handling of scientific and teclinical information are urgent

\footnotetext{
so King, 1963 [318], p. 20.

si Ibid., p. 11.

33 Becker, 1963 [46], p. 93.
} 
today. While information handling of the scientific and technical literature was principally a matter of manual typing, scanning, labelling, recording, storing and searching, the questions of compatability and convertibility arose only as a matter of avoidance of duplication of effort. Cooperation was and is still predominantly concerned with the sharing of information about holdings, availabilities, exchange of hard copy items and records such as catalog cards. The efforts are collaborative actions of libraries and information centers (as organizations) and of librarians and documentalists (as individuals or as members of professional groups).

With the introduction of machine techniques, however, cooperation in the conventional sense acquires one or both of two prerequisites-those of compatability and/or convertibility.

What, then, are some of the practical steps which can be taken today, without unnecessary prejudice to future developments with respect to the intellectual organization of subject content analysis, automatic content analysis, machine search and retrieval, man-machine interaction during search and selection processes, and interlocking communication networks?

First and foremost, as we have seen, is to work for mutually acceptable conventions and standards with respect to journal abbreviations, transliterations of proper names, ordering and coding of corporate authors, form, order, and content of entries in biblographic citations.

From the point of view of potential mechanization and of interchange of programs for, and products, of machine compilations can agreement be reached with respect to the number of characters per line to be reserved for identifactory purposes so as to minimize, on the one hand, "double lookups," and yet not to jeopardize contradictory requirements for multipurpose identifiers?

Will it be possible to arrive at a Governmentwide report numbering system? If so, can it be such as to incorporate security classification information? Can it include an error-detecting or error-correcting digit? At the very minimum, there should be concern for machine transliteration possibilities from one coding, cataloging, or indexing system into another.

More significantly, every effort should be made to provide systems interface byproducts, such as minimum version catalog cards, including subject cards, that will be adaptable to less sophisticated equipment in smaller organizations and even to manual filing as suggested by Altman (1963[12]).

The latter point raises certain further possibilities with respect to which an organization such as COSATI might provide leadership and initiative, at least for Govermment, by virtue of its influence and position. The first is to encourage the use of Federal procurement authority in such way as to promote greater compatibility in the equipment produced by various manufacturers and to insist, for example, not only for at least one input and output facility for handling ASCII and for punched card input and output capabilities as well.

Somewhat less obvious, but equally pertinent to the elimination and reduction of barriers to scientific communication, would involve promotion of policy leading to more favorable copyright conditions, to push the "preparation, elaboration, and revision of classification systems in neglected fields," "34 and to press for changes in editorial, page makeup, and even typographical practice that will make typed and printed text more amenable to reading and processing by machine.

A responsible, far-seeing coordinating body (even if its functions are advisory only) should, it is suggested, direct attention to problems and possible solutions in the area of present barriers to scientific communication.

Elimination or reduction of major barriers to more effective communication and use of scientific and technical information will first of all broaden the bases for cooperation as such. Second, such elimination or reduction of the communication barriers contributes directly to improved problem definition, determination of requirements, system design, and practical implementation. Finally, without such reduction, compatibility and/or convertibility within and between isolated subsystems cannot improve the overall situation and may in fact make it worse.

We are especially indebted to those members of the Ad Hoc Committee who have forwarded comments and criticisms, many of which have been reflected in revisions to the earlier draft of this publication. In particular, we are indebted to Scott Adams, Deputy Director of the National Library of Medicine, and Ann F. Painter, and other reviewers not only for detailed and cogent criticisms but also for access to private files or personal recollections.

The cooperation and assistance of Josephine I. Walkowicz and her staff in checking the bibliographic references and of Betty Anderson, Catherine Bailey, Helen Grantham, Norma Lupowitz, and Anna K. Smilow in the preparation and proofreading of the manuscript are also gratefully acknowledged.

\section{Appendix. List of References Cited and Selected Bibliography}

[1] Abelson, P. H., Information transfer and retrieval, Science 141, 319 (1963).

[2] Adams, S., Discipline- and Mission-Oriented Science in Relation to the Abstracting Problem, in R. A. Jensen [ed]. Proceedings of Sixth Annual Meeting, 1963, pp. 15-24.

[3] - Information-A national resource, Amer. Documentation 7, 71-75 (1956).

s4 Oellrich, 1963 [435], p. 72. 
[4] Adkinson, B. W., ADI-Past, Present and Future, in P. C. Janaske [ed]. Automation and Scientific Communication, Pt. 3, 1964, pp. 387-388.

[5] Adkinson, B. W., The Federal Government and U.S. Scientific Information, J. Chem. Documentation 2, 48-50 (1962)

[6] - Trends in Library Applications of Data Processing, in H. Goldhor [ed.] Proceedings of the 1963 Clinic in Library Applications of Data Processing, pp. 1-8, 1964.

[7] Aerospace abstracts and indexes, Special Libraries 54, 117 (1963).

[8] Agard Evans, A. B., International Cooperative Abstracting on Building: An Appraisal, in National Academy of Sciences-National Research Council, "Proceedings of the International Conference on Scientific Information, Vol. 1, 1959, pp. 491-495.

[9] Alexander, S. N., 'Federal Activities in Information Interchange, in R. H. Jensen [ed]. Proceedings of Sixth Annual Meeting', 1963, pp. 67-72.

[10] Alexander, S. N. and S. M. Newman, Interim Report of the Ad Hoc Interagency Study Group on Language Compatibility in Mechanized Storage and Retrieval Systems, unpublished, mimeo, June 30, 1963, $29 \mathrm{pp}$

[11] Allen, C. G., The Russian transcription of Chinese names, J. Documentation 16, 80-91 (1960).

[12] Altmann, B., The Medium-Sized Information Service: Its Automation for Retrieval, Rept. No. TR1192, Harry Diamond Laboratories, Army Materiel Command, Washington, D.C., Dec. 30, 1963, $26 \mathrm{pp}$.

[13] American Association for the Advancement of Science, Information Systems-Essential Tools in Engineering Application of Science for the Needs of Society (Proceedings of a Panel Program jointly sponsored by Engineers Joint Council and Section M (Engineering) AAAS 129th Annual Meeting, Philadelphia, 1962), Engineers Joint Council, New York, 1963, 28 pp.

14] American Council of Learned Societies, Planning For Scholarly Photocopying, Preprint, Publications of the Modern Language Association of America, Vol. 79, No. 4, Part 2 (Sep 64) 14 pp.

[15] American Documentation Institute, Parameters of Information Science (Proceedings of Annual Meeting. Philadelphia, October 5-8, 1964), Vol. 1, Washington, D.C., 1964, 521 pp.

[16] (American Federation of Information Processing Societies) * Proceedings of the Western Joint Computer Conference, 1961, Vol. 19, Western Joint Computer Conference, Glendale, Cal., 1961, 661 pp.

[17] American Federation of Information Processing Societies, Spring Joint Computer Conference, 1963, AFIPS Conference Proceedings, Vol. 23, Spartan Books, Baltimore, Md., 1963, 413 p.

[18] American Institute of Chemical Engineers, Chemical Engineering Thesaurus; A Wordbook for Use with the Concept Coordination System of Information Storage and Retrieval, New York, 1961, $175 \mathrm{pp}$.

[19] American Library Association, ALA Cataloging Rules for Author and Title Entries' 2d ed., Chicago, 1949, $265 \mathrm{pp}$.

[20] American Meteorological Society, Boston, Mass., Meteorological and Geoastrophysical Titles, Vol. 2, No. 1, Jan 1962, 55 pp. (An experimental subject, author and key word index to titles listed in Part III, of Meteorological and Geophysical Abstracts, Vol. 13, No. 1, Jan 1962.)

"Note that although proceedings of the Joint Computer Conerence were not published by the American Federation of Inormation Processing Societies prior to Volume 20 , they are ;ouped here in accordance with the volume series numbers.
[21] American standard code for information interchange, Comm. Assoc. Computing Machinery 6, $422-126$ (1963).

[22] American Standards Association, Inc., American Standard: Basic Criteria for Indexes, ASA Z39.4-1959, approved May 5, 1959. New York $1959,11 \mathrm{pp}$.

[23] - American Standard Code for Information Interchange, ASA X3.4-1963, approved June 7, 1943. New York, 1943, 11 pp.

[24] - American Standard for Periodical Title Abbreviations, ASA Z39.5-1963, approved Nov. 20, 1963. New York, 1964, $19 \mathrm{pp}$.

[25] - American Standard: Reference Data and Arrangement of Periodicals, ASA Z39.1-1943, approved June 7, 1943. New York, 1913, 4 pp. (Supersedes Z29.1-1935.)

[26] - American Standard: Signaling Speeds for Data Transmission, ASA X3.1-1962, approved Aug. 8, 1962. New York, 1962, 5 pp.

[27] - American Standard: Specifications for $16 \mathrm{~mm}$ and $35 \mathrm{~mm}$ Microfilms on Reels or in Strips, ASA PH5.3-1958, approved Oct. 16, 1958. New York, $1959,8 \mathrm{pp}$.

[28] American University, Machine Indexing: Progress and Problems (Papers presented at the Third Institute on Information Storage and Retrieval, Feb. 13-17, 1961), Washington, D.C., 1962, 354 pp.

[29] Anderson, H. T., Compatibility of Information and Data Systems Within a Company, in L. H. Hattery and E. M. McCormick [eds.], Information Retrieval Management, 1962, pp. 111-116.

[30] Andrews, D. D., Cooperative Information-Patents, in J. H. Shera et al., [eds]. Documentation in Action, 1956, pp. 297-300.

[31] Andrews, D. D. and S. M. Newman, Storage and Retrieval of Contents of Technical Literature: Nonchemical Information, Preliminary Report. Patent Office Research and Development Rept. No. 1, Washington, D.C., May 15, 1956, 12 pp. See S. M. Newman, Storage and Retrieval ... for Supplementary Reports.

[32] Angell, R. S., The Need for a New United States Code, Library Quarterly 26, 318-330 (1956).

[33] - Standards for subject headings : A national program, J. Cataloguing and Classification 10, 191197 (1954).

- Armed Services Technical Information Agency, Arlington, Va., see Defense Documentation Center.

[34] Aronson, E. J., Cataloging in a large reports organization, Amer. Documentation 3, 114-117 (1952).

[35] Artandi, S. and T. C. Hines, Roles and links ... or forward to Cutter, Amer. Documentation 14, 74-77 (1963).

[36] Artelt, W., The problem of abbreviating the titles of medical periodicals, Bull. Med. Lib. Assoc. 43, 52-57 (19555).

[37] Ashworth, W. [ed]., Handbook of Special Librarianship and Information Work, ASLIB, London, 1955,387 pp. 2d ed. (completely revised), 1962, $508 \mathrm{pp}$. ASLIB Handbook 2d ed. ASLIB London, $1962,508 \mathrm{pp}$.

[38] Association of Scientific Libraries and Information Bureaus, Looking Forward in Documentation (Papers and Discussions, ASLIB 38th Annual Conference), London, 1964, $107 \mathrm{pp}$.

[39] Atherton, P., A Collection of Remarks About Citation Indexes, American Institute of Physics, New Iork, Apr 1962, 6 pp.

[40] - International conference on cataloguing principles : an observer's report, Spec. Libraries 52, 583-584 (1961).

[41] BA and Psychological Abstracts Commence a Program of Cooperative Abstracting, Biological Abstracts 31, x (1957). 
[42] Bagg, T. C. and M. E. Stevens, Information Selection Systems Retrieving Replica Copies: A Stateof-the-Art Report, Tech. Note 15i, National Bureau of Standards, Washington, D.C., 1961, $172 \mathrm{pp}$.

[43] Baker, D. B., G. M. Conrad, J. C. Green, M. Hoseh, and R. A. Jensen, Some Counterparts in Perspective-a Report on Research Data Processing and Information Retrieval in Other Countries including Poland and the Soviet Union, in U.S. Congress, House Committee on Education and Labor, National Information Center. Hearings ... on H.R. 1946, Appendix to Vol. 1, GPO, Washinton, D.C., 1963, pp. 155-372. Also available as Some Counterparts in Perspective: a Detailed Report on Visits Oct. 20 to Nov. 5, 1959, National Federation of Science Abstracting and Indexing Services, Washington, D.C., 1960, 1v.

[44] Ball, N. T., Research or available knowledge: a matter of classification, Science 105, 34-36 (1947).

[45] Bar-Hillel, Y., Is information retrieval approaching a crisis? Amer. Documentation 14, 95-98 (1963).

[46] Becker, J., Machines and Equipment, in H. Orlans [ed], Federal Departmental Libraries: a Summary Report of a Survey and a Conference, 1963, pp. 87-93.

[47] - Some Approaches to Mechanization of Technical Information Processing Systems, in D. E. Cetone [ed]. Proceedings of the March AFBMD Conference on Scientific and Technical Information, 1960, pp. 9-20.

[48] Becker, J. and R. M. Hayes, Information Storage and Retrieval: Tools, Elements, Theories, 448 pp. (John Wiley \& Sons, New York, N.Y., 1963), $448 \mathrm{p}$.

[49] Bemer, R. W., The American standard code for information interchange, parts 1-2, Datamation 9, 32-36 (Aug. 1963) and 9, 39-41, 44 (Sep. 1963).

[50] - The Present Status, Achievement and Trends of Programming for Commercial Data Processing, in W. Hoffmann [ed]. Digital Information Processors, 1960 , pp. 312-405.

[51] - Survey of coded character representation, Comm. Assoc. Computing Machinery æ3, 639-642 (1960).

[52] Bennington, J., The integration of report literature and journals, Amer. Documentation 3, 149-152 (1952).

[53] Bernal, J. D., Provisional Scheme for Central Distribution of Scientific Publications, in Royal Society of London, Royal Society Scientific Information Conference, London, June 21-July 2, 1948, pp. 253-258.

[54] - The Transmission of Scientific Information: a User's Analysis, in National Academy of SciencesNational Research Council, International Conference on Scientific Information, Vol. 1, 1959, pp. $77-95$.

[55] Bernier, C. L. and E. J. Crane, Correlative indexes, part VIII. Subject-indexing versus word-indexing, J. Chem. Documentation 2, 117-122 (1962).

[56] Bernier, C. L. and K. L. Heumann, Correlative indexes, part III. Semantic relations among semantemes-the technical thesaurus, Amer. Documentation 8, 221-220 (1957).

[57] Bernstein, H. H., The use of flexowriters in documentation centers and libraries, UNESCO Bull. Libraries 16, 79-85 (1962).

[58] Bernstein, H. H. and K. H. Meyer-Uhlenried, Recording Bibliographical Data by Punching Typewriters-A Survey, in H. P. Luhn [ed]. Automation and Scientific Communication, Pt. 1 1963 , pp. $75-76$.

[59] Berry, M. M. and J. W. Perry, Notational systems for structural formulas, Chem. Eng. News 30, 407 (1952).
[60] Bessinger, J. B. Jr., S. M. Parrish, and H. F. Arader [eds], Literary Data Processing Conference Proceedings September 9, 10, 11, 1964, IBM, White Plains, N.Y., 1964, 329 pp.

[61] Better Information Coordination Urged, Chem. Eng. News 42, 27 (1964).

[62] Bishop, C., An integrated approach to the documentation problem, Amer. Documentation 4, 54 65 (1953).

[63] Biunno, V. P., Cooperative Information Processing-Patents, in J. H. Shera et al. [eds], Documentation in Action, 1956, pp. 359-364.

[64] Blegen, T. C., The scholar looks at inter-library cooperation, Lib. Quarterly 22, 13-17 (1952).

[65] Bliss, H. E., The Organization of Knowledge and the System of the Sciences, 433 pp. (Holt, New York, 1929).

[66] Boaz, M. [ed], Modern Trends in Documentation 108 pp. (Pergamon Press, New York, 1959).

[67] Bohr, P. G. and K. C. Owen. A cooperative project in new drug reporting, J. Chem. Documentation 3, 201-205 (1963).

[68] Bonn, G. J., Training for Activity in Scientific Documentation Work, 1959 , pp. 1441-1488, in National Academy of Sciences-National Research Council, Proceedings of the International Conference on Scientific Information, Vol. 2, 1959, pp. 14411488.

[69] Born, L. K., The Literature of Microreproduction 1950-1955, Amer. Documentation 7, 167-187 (1956).

[70] - Universal Guide to catalogs of manuscripts and inventories of archival collections : a proposal for cooperative listing, College and Research Li braries $17,322-329$ (1956).

[71] Bourne, C. P., The historical development and present state-of-the-art of mechanized information retrieval systems, 241 pp. Amer. Documentation 12, 108-110 (1961).

[72] - Methods of Information Handling (John Wiley \& Sons, New York, N.Y., 1963).

[73] - The world's technical journal literature: an estimate of volume, origin, language, field, in dexing, and abstracting, Amer. Documentation 13, 159-168 (1962).

[74] Boutry, G. A., Abstracting Board of International Council of Scientific Unions, Science 123, 423-424 (1956).

[75] Boyd, J. P., A landmark in the history of coopera. tion, College and Research Libraries 8, 101-108 $(1947)$.

[76] Bralove, A. L., Concept, Specifications, Dissemina tion, and User Acceptance Study of the NASA Microform, in H. P. Luhn [ed], Automation ano Scientific Communication, Pt. 1, 1963, pp. 77-78

[77] Brandhorst, W. T., Corporate author cataloging anc the technical report literature, Amer. Documenta tion $15,35-46$ (1964).

[78] Brenner, C. W. and C. N. Mooers, Case History of Zatocoding Retrieval System in R. S. Casey et al [eds], Punched Cards: Their Application to Sci ence and Industry, 1958 , pp. 340-356.

[79] Brenner, E. H., B. H. Weil and N. E. Rawson, A Ner Centralized Information-Retrieval System for the Petroleum Industry Including a Computer Searcl System and Two Manual Indexes, in H. P. Luhr [ed], Automation and Scientific Communication Pt. 2, 1963, pp. 291-292.

[80] A Brief Description of Viniti (with illustrations)the Soviet Union's All Union Institute of Scien tific and Technical Information, located ir Moscow, May 1963, in U.S. Congress, House Com mittee on Education and Labor, National Infor mation Center. Hearings . . . on H.R. 1946 Appendix to Vol. 1, 1963, pp. 373-409.

[81] British Standards Institution, Guide to the Uni versal Decimal Classification (UDC), B.S. 1000C London, 1963, 128 pp. (F.I.D. No. 345). 
[82] - Universal Decimal Classification. Abridged English edition, B.S. 1000A, London, 1961, 254 pp. (F.I.D. No. 289).

[83] Browne, C. A. and M. E. Weeks. A History of the American Chemical Society, American Chemical Society, Washington, D.C., 1952, $526 \mathrm{pp}$.

[84] Brownson, H. L., Current United States Research on Topics Related to the Conference, in International Federation for Documentation, Proceedings of the International Study Conference or. Classification for Information Retrieval, 1957, pp. 99-100.

[85] - Documentation Needs of Scientists, in L. H. Hattery and E. M. MeCormick [eds], Information Retrieval Management, 1962, pp. 76-82.

[86] - Recommendations and results of international conferences on scientific information and bibliographic services, Amer. Documentation 3, 29-55 (1952).

[87] Buckland, L. F., Recording Text Information in Machine Form at the Time of Primary Publication, in H. P. Luhn [ed], Automation and Scientific Communication, Pt. 2, 1963, pp, 309-310.

[88] Burnett, M. M., The Interservice Data Exchange Program as a Specialized Approach, in D. E. Cetone [ed], Proceedings of the March AFBMD Conference on Scientific and Technical Information, 1960, pp. 31-34.

[89] Burns, L. R., Automation in The Public Libraries of Lake County, Indiana, in H. Goldhur [ed], Proceedings of the 1963 Clinic on Library Applications of Data Processing, 1964, pp. 9-17.

[90] Bush, V., As we may think, Atlantic Monthly 176, 101-108 (1945).

[91] - Science the Endless Frontier, A Report to the President on a Program for Postwar Scientific Research, U.S. Government Printing Office, Washington, D.C., July 1945, 184 pp.

[92] Cady, W. H., An examination of scientific periodicals, Standardization 21, 11-12 (1950).

[93] Cahn, J. N., A B.I.T.S.-Bureau of Information for Technology and Science proposed as Key Station of Federal Network of Information Services to U.S. Free Enterprise Systems, in Engineers Joint Council, Proceedings of the EJC Engineering Information Symposium, 1962, pp. 45-50.

[94] - A System of Information Systems, in L. H. Hattery and E. M. McCormick [eds], Information Retrieval Management, 1962, pp. 21-30.

[95] Cambridge Language Research Unit, England, Report on Research, Mech. Translation 3, 36-37 (1956).

[96] Canter, L., Factors restricting the availabilty of Government research reports, Amer. Documentation 3, 133-138 (1952).

[97] Carlson, I. G., Cataloging of technical reports in a Military Research Library, Amer. Documentation 3, 119-122 (1952).

[98] Carlson, W. M., Information Resources for Tomorrow's Engineers, in American Association for the Advancement of Science, Information SystemsEssential Tools in Engineering Application of Science for the Needs of Society, 1963, pp. 21-28.

[99] - Proposed EJC Course of Action in Field of Information Systems, Engineers Joint Council, New York, 21 Sep. 1962, 13 pp., appendices.

[100] Casey, R. S., J. W. Perry, M. M. Berry, and A. Kent [eds], Punched Cards: Their Applications to Science and Industry, $697 \mathrm{pp}$. (Reinhold Publishing Corp., New York, N.Y., 2nd ed., 1958).

[101] Cataloging-in-Source-a Symposium, Library Res. Tech. Services 4, 269-284 (1960).

[102] Center for Documentation and Communication Research, Western Reserve University, Information Retrieval in Action (Proceedings of Conference on Research in Progress 1962), The Press of Western Reserve University, Cleveland, Ohio, 1963,323 p.
[103] Center for text in machine-usable form, Scientific Information Notes 5,1 (1963).

[104] Centralized register of microfilms, Library of Congress Inf. Bull. 22, 593-594 (1963).

[105] Cetone, D. E. [ed], Proceedings of the March AFBMD Conference on Scientific and Technical Information, Rept. No. AFBNID TR-60-143, Air Force Ballistic Missile Division, Air Research and Development Command, Washington, D.C., 1960, 134 pp.

[106] Chamberlin, W., An International Institute for Scientific Information, in National Academy of Sciences-National Research Council, Proceedings of the International Conference on Scientific Information, Vol. 2, 1959, pp. 1523-1534.

[107] Chaplin, A. H., Co-operative cataloging, Library Assoc. Record 55, 275-278 (1953).

[108] - International Conference on cataloguing principles. I. Organization, J. Documentation 19, 4146 (1963).

[109] - A universal cataloging code, Lib. Quarterly 26, $337-347$ (1956).

[110] Chemical Center. Clearing House will screen all organic compounds to aid in research for new drugs, insecticides, Federal Science Progress 1, 15 (1947).

[111] Cheydleur, B. F., Information retrieval-1966, Datamation 7, 21-25 (1961).

[112] Chollar, R. G., Standards in computers and information processing, J. Data Management 1, 38-42 (1963).

[113] Clapp, V. W., Cooperative Acquisitions, College and Research Libraries 8, 99-100 (1947).

[114] - Libraries and the 'Uppercase Limitation', in B. E. Markuson [ed], Libraries and Automation, 1964 , pp. 54-55.

[115] - The purchase of books in Europe, College and Research Libraries 7, 127-134 (1946).

[116] - Research in Problems of Scientific InformationRetrospect and prospect, Amer. Documentation 14, 1-10 (1963).

[117] - The Role of Bibliographic Organization in Contemporary Civilization, in J. H. Shera and M. E. Egan [eds], Bibliographic Organization, 1951, pp. 3-23.

[118] - Standards in Photographic Reproduction of Documents, Library of Congress Inf. Bull. 12, 1213 (1953).

[119] — Subject controls-Nature and levels of controls, Amer. Documentation 3, 11-15 (1952).

[120] - UNESCO's Program: Libraries, Bibliographic Services, Documentation, A Catalog of Principal Activities, Amer. Documentation 7, 127-134 (1956).

[121] Clapp, V. W. and F. B. Rogers, Responsibilities of Government Professional Societies, Universities, and Industry for Improved Information Services and Research, Summary of discussion for Area $\tau$, in National Academy of Sciences-National Research Council, Proceedings of the International Conference on Scientific Information, Vol. 2,1959 , pp. $1535-1545$.

[122] Cleverdon, C. W., The ASLIB Cranfield Research Project on the Comparative Efficiency of Indexing Systems, ASLIB Proc. 12, 412-431 (1960).

[123] - The Evaluation of Systems Used in Information Retrieval, in National Academy of Sciences-National Research Council, Proceedings of the International Conference on Scientific Information, Vol. 1, 1959, pp. 687-698.

[124] - Report on the Testing and Analysis of an Investigation into the Comparative fifficiency of Indexing Systems, College of Aeronautics, Cranfield, England, Oct. 1962, 311 pp.

[125] Cleverdon, C. W., F. W. Lancaster and J. Mills, Uncovering some facts of life in information retrieval, Spec. Libraries 55, 84-91 (1964). 
[126] Cleverdon, C. W. and J. Mills, The Analysis of Index Language Devices, in P. C. Janaske [ed], Automation and Scientific Communication, Pt. 3, 1964 , pp. $451-454$.

[127] - The Testing of Index Language Devices, ASLIB Proc. 15, 106-130 (1963).

[128] Coblans, H., International and Local Information Services, in Library Association, Gt. Britain, Scarborough Conference, Proceedings . . . Discussions, 1960 , pp. $67-73$.

[129] Collison, R. L., Bibliographical Services Throughout the World 1950-59, UNESCO, Paris, 1961, $228 \mathrm{pp}$.

[130] - The Continuing Barrier. Translations as a Factor of East-West Communications : an Analysis of the Index Translationum, UNESCO Bull. Libraries 16, 296-300 (1962).

[131] - Indexes and Indexing: Guide to the Indexing of Books, and Collections of Books, Periodicals, Music, Gramaphone Records, Films, and Other Material, with a Reference Section and Suggestions for Further Reading, 200 p. (de Graff, New York, 1959).

[132] Compton, A. H., UNESCO and science, Federal Science Progress 1, 21-23 (1947).

[133] Conferences on Science and World Affairs. Statements by Participants at the 7 th and 8 th Conferences, at Stowe, Vt., in September. Science 194, 984-991 (1961).

[134] Connor, J. M., The need for documentation to Government specifications, Spec. Libraries 47, 152155 (1956).

[135] Cook, C. D., The Farmington plan and the select list of unlocated research books, College and Research Libraries 15, 281-284, 312 (1954).

[136] Cornelius, M. E., Machine Input Problems and Machine Indexing Alternatives and Practicalities, in American University, "Machine Indexing: Progress and Problems", 1962, pp. 41-49.

[137] Costello, J. C. Jr., Computer requirements for inverted coordinate indexes, Amer. Documentation 13, 414-419 (1962).

[138] - Uniterm indexing principles, problems and solutions, Amer. Documentation 12, 20-26 (1961).

[139] Council on Library Resources, Inc., First Annual Report for the period ending June 30, 1957, Washington, D.C., 1957, 28 pp.

[140] - Second Annual Report for the period ending June 30, 1958, Washington, D.C., 1958, 43 pp.

[141] - Third Annual Report for the period ending June 30, 1959, Washington, D.C., 1959, 63 pp.

[142] - Fourth Annual Report for the period ending June 30, 1960, Washington, D.C., 1960, 44 pp.

[143] - Fifth Annual Report for the period ending June 30, 1961, Washington, D.C., 1961, $66 \mathrm{pp}$.

[143] - Fifth Annual Report for the period ending June 30,1961 , Washington, D.C., 1961, 66 pp.

[144] Council on Library Resources, Inc., Library of Congress Sponsors Experimental Demonstration Involving Use of Tape-Producing Typewriter for Versatile Automated Printing, Recent Developments No. 129, Washington, D.C., May 4, 1964, 3 pp.

[145] Cox, G. J., C. F. Bailey and R. S. Casey, Punch Cards for a Chemical Bibliography, Chem. Eng. News 23, 1623-1626 (1945).

[146] Craig, G. Y., Abstract Cards in Scientific Journals, in Association of Scientific Libraries and Information Bureau, Looking Forward in Documentation, 1964 , pp. 4-12 to $4-14$.

[147] Crane, E. J. and C. L. Bernier, Indexing and Index Searching, in R. S. Casey et al. [ed], Punched Cards . . . 1958, pp. 510-527.

[148] Creating order out of confusion, Business Automation 11, 22-26 (July 1964).

[149] Crestadoro, A., The Art of Making Catalogues of Libraries: A Method to Obtain in a Short Time a Most Perfect, Complete, and Satisfactory Cata- logue of the British Museum Library, By a Reader Therein, The Literary, Scientific and Artistic Reference Office, London, $1856,60 \mathrm{pp}$.

[150] Crowther, B. M., International Cooperation in Physics Abstracting, in National Academy of Sciences-National Research Council, Proceedings of the International Conference on Scientific Information, Vol. 1, 1959, pp. 481-489.

[151] Croxton, F. E., Identification of Technical Reports, in B. M. Fry and J. J. Kortendick [eds], The Production and Use of Technical Reports, 1955, pp. 121-135.

[152] Cunningham, R., International Congress of Libraries and Documentation Centers, Spec. Libraries 47, 32-34 (1956).

[153] Cutter, C. A., Rules for a Dictionary Catalog, 4th ed., U.S. Government Printing Office, Washington, D.C., 1904.

[154] Danton, E. M., [ed], The Library of Tomorrow : a Symposium, American Library Association, Chicago, 1939, $191 \mathrm{pp}$.

[155] Datatrol Corp., Common Vocabularly Approaches for Government Scientific and Technical Information Systems, Technical Rept. No. IR-10, Contract NSF C-342, Silver Spring, Md., 1963, 108 pp.

[156] Davies, D. W., Rev. Int. Doc. 29, 66-68 (1962).

[157] Davis, D. D., Subject Indexing for Nuclear Science Abstracts, in Atomic Energy Commission, in U.S. Atomic Energy Commission, The Literature of Nuclear Science: Its Management and Use, 1962, pp. 209-214.

[158] — The Use of Punched-Tape Typewriters and Computers in the Centralized Information Processing at the USAEC Division of Technical Information Extension, in H. P. Luhn [ed], Automation and Scientific Communication, Pt. 2, 1963, pp. 237-238.

[159] Davis, W., Need information center, Science News Letter 84, 70-71 (1963).

[160] Day, M. S., The Scientific and Technical Information Program of the National Aeronautics and Space Administration, in U.S. Atomic Energy Commission, The Literature of Nuclear Science: Its Management and Use, 1962, pp. 361-377.

[161] Day, M. S. and I. Lebow, New indexing pattern for nuclear science abstracts, Amer. Documentation $11,120-127$ (1960).

[162] Defense Documentation Center, ASTIA Chemical Thesaurus, Alexandria, Va., Dec. 1962, 34 pp.

[163] — ASTIA Guidelines for Cataloging \& Abstracting, Alexandria, Va.. June 1962, 29 pp.

[164] - Radiology, Information Service Series, Vol. 2 , No. 1, Alexandria, Va., Apr. 1963, 255 pp.

[165] - Technical Abstracts Bulletin Cumulative Index, Jan.-June 1962, Alexandria, Va., 1962, 1007 pp.

[166] — Technical Abstract Bulletin Cumulative Index, July-Dec. 1962, Alexandria, Va., 1963, 805 pp.

[167] - Thesaurus of ASTIA Descriptors, 1st ed. Alexandria, Va., May 1960, 328 pp., 2d ed., Dec. $1962,673 \mathrm{pp}$.

[168] Defense research reports indexed. Scientific Information Notes $\mathbf{5}, 13$ (Dec. 1963-Jan. 1964).

[169] De Grolier, E., Problems in scientific communication, IBM J. Res. Dev. 2, 276-281 (1958).

[170] - A Study of General Categories Applicable to Classification and Coding in Documentation, UNESCO, Paris 1962,248 pp.

[171] Deignan, S. L. and E. Miller, The support of research in medical and allied fields for the period 1946 through 1951, Science 115, 321-343 (1952).

[172] Dennis, B. K. Financing a Technical Information Center, in L. H. Hattery and E. M. McCormick [eds], Information Retrieval Management, 1962, pp. 61-75.

[173] Dewey, H., Punched card catalogs-theory and technique, Amer. Documentation 10, 36-50 (1959).

[174] Dewey, M., Dewey Decimal Classification and Relative Index, 16th ed., Lake Placid Club, New York, Forest Press, 1958, 2 v., 2439 pp. 
[175] Distribution, Federal Science Progress 1, 10 (1947).

[176] Donker Duyvis, F., Standardization as a tool of scientific management, Library Trends $\mathbf{2}, 410-427$ (1954).

[177] Dougherty, R. M., The Scope and Operating Efficiency of Information Centers as Illustrated by the Chemical-Biological Coordination Center of the National Research Council, Ph. D. Dissertation, Rutgers-The State University, New Brunswick, N.J., May 1963, 241 pp.

[17s] Downs, R. B., Latin American union catalogs, College and Research Libraries 7, 210-213 (1946).

[179] — One for All: a Historical Sketch of Library Co-operation, 1930-1970, in E. M. Danton [ed], The Library of Tomorrow: a Symposium, 1939, pp. $60-67$.

[180] - Wartime cooperative acquisitions, Lib. Quarterly 19, 157-165 (1949).

[181] Dubester, H., The Role of the American Documentation Institute in International Documentation, Amer. Documentation 13, 115-117 (1962)

[182] Dyson, G. M. and J. E. L. Faradane, The aims of the Institute of Information Scientists Ltd., J. Chem. Documentation 2, 72-74 (1962).

[183] Edwards, P. I., Information Retrieval in the Biological Sciences, in Association of Scientific Libraries and Information Bureaus, Looking Forward in Documentation, 1964, pp. 4-15 to 4-18.

[181] Electronic and other equipment for chemical information work, Chem. Eng. News 27, 2911 (1949).

[185] Engineers Joint Council, Proceedings of the EJC Engineering Information Symposium, New York, 1962, $95 \mathrm{pp}$.

[186] — Study of Engineering Terminology and Relationships Among Engineering Terms, Final report on NSF Grant G 24836, New York, Aug 1963, 16 pp.

[187] Evans, L. H., History and the problem of bibliography, College and Research Libraries 7, 195-205 (1916).

[188] — Survey of Federal Departmental Libraries, in H. Orlans [ed], Federal Departmental Libraries: A Summary Report of a Survey and a Conference, 1963 , pp. $3-54$.

[189] - UNESCO work and method illustrated by the librairy programs, Lib. Quarterly 24, 92-100 (1954).

[190] Fagerhough, K. H., Availability of industrial research reports, Amer. Documentation 3, 143-145 (1952).

[191] Fairthorne, R. A., Implications of Test Procedures, in Center for Documentation and Communication Research, Information Retrieval in Action, 1963, pp. 109-113.

[192] Fall, J., Problems of American libraries in acquiring foreign publications, Lib. Quarterly 24, 101113 (1954).

[193] Farradane, J., Introduction, Inf. Storage and Retrieval 1, 1 (1963).

[194] -Relational indexing and classification in the light of recent experimental work in psychology, Inf. Storage and Retrieval 1, 3-11 (1963).

[195] Federal Council for Science and Technology. Committee on Scientific Information, Standard for Descriptive Cataloging of Government Scientific and Technical Reports, Washington, D.C., Dec 1963, $21 \mathrm{pp}$.

[196] - Status Report on Scientific and Technical Information in the Federal Government, Washington, D.C., June 18, 1963, 18 pp.

[197] Field, H. W., A Centralized Abstracting Service for the Petroleum Industry, in J. H. Shera et al. [eds], Documentation in Action, 1956, pp. 269-278

[198] Focke, H. M., Cooperative Information ProcessingDocumentation, in J. H. Shera et al. [eds], Documentation in Action, 1956 , pp. 355-358.

[199] Foskett, D. J., The Classification Research Group, 1952-1962, Libri 12, 127-138 (1962).
[200] Frank, O., Cooperation and Coordination in Abstracting and Documentation, in National Academy of Sciences-National Research Council, Proceedings of the International Conference on Scientific Information, 1959, Vol. 1, pp. 497-510.

[201] Frarey, C. J., The role of research in establishing standards for subject headings, J. Cataloging and Classification 10, 179-190 (1954).

[202] — Subject Headings, in R. R. Shaw [ed], The State of the Library Art, Vol. 1, Pt. 2, 1960, pp. 5-67.

[203] Freeman, M. E., Technical information for research program management, J. Chem. Documentation 3, 217-220 (1963).

[204] Freeman, R. R., Computers and Classification Systems, J. Documentation 20, 137-143 (1964).

[205] Frontard, R., Transliteration codes and their international standardization, UNESCO Bull. Libraries 15, 78-82 (1961).

[206] Fry, B. M., and J. J. Kortendick [eds], The Production and Use of Technical Reports, (Proceedings of the Workshop on the Production and use of Technical Reports, Conducted at the Catholic University of America, 13-18 Apr 1953), The Catholic University of America Press, Washington, D.C., $1955,175 \mathrm{pp}$.

[207] Fussler, H. H., The Problems of Physical Accessibility, in J. $H$. Shera and M. E. Egan [eds], Bibliographic Organization, 1951, pp. 163-186.

[208] - Readjustments by the librarian, Lib. Quarterly 23, 216-229 (1953).

[209] Gardin, J. C., Document analysis and information retrieval, UNESCO Bull. Libraries 14, 2-5 (1960).

[210] Garfield, E., Citation indexes for science: A new dimension in documentation through association of ideas, Science 122, 108-111 (1955).

[211] - A Unified Index to Science, in National Academy of Sciences-National Research Council, Proceedings of the International Conference on Scientific Information, Vol. 1, 1959, pp. 461-474.

[212] Gelberg, A., W. Nelson, G. S. Yee, and E. A. Metcalf, A program retrieval of organic structure information via punched cards, J. Chem. Documentation 2, 7-11 (1962).

[213] General principles of cooperation on biological abstracting, Science 123, 578 (1956). Also in Biological Abstracts 30, viii (1956).

[214] Genereaux, R. P., Technical information needs of the chemical processing industry, J. Chem. Documentation 2, 40-45 (1962).

[215] Gibb, I. P., Foreign book procurement: the decennial Farmington plan survey and afterwards, J. Documentation 16, 1-9 (1960).

[216] Gillett, H. W., Metallurgical Research as a National Resource, in National Resources Planning Board, Research-A National Resource II. Industrial Research, 1941, pp. 2S9-305.

[217] Gingold, K., Translation Pools-ideal and reality, J. Chem. Documentation 1, 14-19 (1961).

[218] Goldhor, H. [ed], Proceedings of the 1963 Clinic on Library Applications of Data Processing, Graduate School of Library Science, University of Illinois, Champaign, Ill., 1964, 176 pp.

[219] Government microfiche programs now shifting into high gear, Systems 4, 26-2S (1963).

[220] Gray, B. S., Automatic typing of literature searches, J. Chem. Documentation 1, 71-73 (1961).

[221] Gray, D. E., An experiment in standardization, Physics Today 4, S-9 (1951).

[222] - Office of Technical Services of the Department of Commerce, Physics Today 4, 24-26 (1951).

[223] - Practical experience in microfacsimile publication, Amer. Documentation 3, 58-61 (1952).

[224] Green, J. C., Last call for Germany, Federal Science Progress 1, 24-25 (1947).

[225] - The Role of the Department of Commerce, J. Chem. Documentation 3, 223-226 (1963). 
[226] - Statement, in U.S. Congress, House Committee on Science and Astronautics, Dissemination of Scientific Information, 1959, pp. 116-122.

[227] Grems, M., Survey of Languages and Systems for Information Retrieval, IBM Research Center, Yorktown Heights, New York, 1961.

[228] Gull, C. D., Automatic documentation, current systems and trends in the USA, Rev. Int. Doc. 29, $57-62$ (1962).

[229] - Guidelines to Mechanizing Information Systems, in L. H. Hattery and E. M. McCormick [eds], Information Retrieval Management, 1962, pp. 101-110.

[230] - The Impact of Electronics Upon Cataloguing Rules, in International Federation of Library Associations, "International Conference on Cataloguing Principles: Report”, 1963, p. 281-290.

[231] - Seven Years of Work on the Organization of Materials in the Special Library, Amer. Documentation 7, 320-329 (1956).

[232] Günther, A., Microphotography in the Library, UNESCO Bull. Libraries 16, 1-22 (1962).

[233] Hall, J. H., The Idea: 'The Dissemination Management Concept, in D. E. Cetone [ed], "Proceedings of the March AFBMD Conference on Scientific and Technical Information", 1960, p. 61-63.

[234] Halliday, M. A. K., The Linguistic Basis of a Mechanical Thesaurus, Mech. Translation 3, 81-88 (1956). (Paper presented at the Second International Conference on Machine Translation, held at the Massachusetts Institute of Technology, Cambridge, Mass., Oct 16-20, 1956).

[235] Hammond, W., Convertibility of Indexing Vocabularies, in U.S. Atomic Energy Commission, The Literature of Nuclear Science: Its Management and Use, 1962, p. 223-234.

[236] Hammond, W. and S. Rosenborg, Experimental Study of Convertibility Between Large Technical Indexing Vocabularies, Technical rept. no. IR-1, Contract no. NSF C-259, Datatrol Corp., Silver Spring, Md., Aug 1962, 297 p.

[237] Hamrick, L. A., The Role of the Office of Technical Services in the Interchange of Documents, in H. P. Luhn [ed], Automation and Scientific Communication, Pt. 2, 1963, p. 219-220.

[238] Hanson, C. W. and M. Janes, Coverage by Abstracting Journals of Conference Papers, J. Documentation 17, 143-149 (1961).

[239] Haskins, S. M., Moving Toward International Cataloging Agreement, ALA Bull. 54, 197-201 (1960).

[240] Hattery, L. H. and E. M. McCormick [eds], Information Retrieval Management, (Papers adapted from Proceedings of the American University Fourth Institute on Information Storage and Retrieval 1962), American Data Processing, Inc. Detroit, Mich.. 1962, $151 \mathrm{p}$.

[241] Hayes, R. M., The Integrated Systems Approach, in D. E. Cetone [ed], Proceedings of the March AFBMD Conference on Scientific and Technical Information, 1960 , p. 5-7.

[242] Heald, J. H., ASTIA and the Information Revolution, Spec. Libraries 54, 40-44 (1963)

[243] - Project MARS, Spec. Libraries 51, 115-121 (1960).

[244] - The Reports Librarian and National Security, Amer. Documentation 3, 138-143 (1952).

[245] - Some Search Strategy Factors in Automated Searches of Technical Reports at DDC, in H. P. Luhn [ed], Automation and Scientific Communication, Pt. 2, 1963, p. 159-160.

[246] Heilprin, L. B., Communication Engineering Approach to Microforms, Amer. Documentation 12, 213-218 (1961).

[247] - On the Information Problem Ahead, Amer. Documentation 12, 6-14 (1961)

[248] Heising, W. P., FORTRAN : Compatibility and Standardization, Datamation 10, 24-25 (Aug 1964).
[249] Heller, Robert \& Associates, Inc., Cleveland, Ohio, A National Plan for Science Abstracting and Indexing Services, National Federation of Science Abstracting and Indexing Services, Washington, D.C., NSF Grant G22594, Mar 15, 1963, 38 p. Also in R. A. Jensen [ed], "Proceedings of Sixth Annual Meeting", 1963, Appendix A, 38 p.; and U.S. Congress, House Committee on Education and Labor, "National Information Center, Hearings ... on H. R. 1946", Appendix to Vol. 1, 1963, p. 109-153.

[250] Henkle, H. H., The Natural Sciences: Characteristics of the Literature, Problems of Use, and Biblographic Organization in the Field. in J. H. Shera and M. E. Egan [eds], Bibliographic Organization, 1951 , p. 140-160.

[251] Henriques, V., The Urgent Quest for Standards, Business Automation 11, 22-27 (1964).

[252] Hensley, C. B., Selective Dissemination of Information (SDI): State of the Art in May 1963, in American Federation of Information Processing Societies, Spring Joint Computer Conference 1963, p. 257-262.

[253] Herbert, E., "Finding What's Known", International Science and Technology, No. 1, Jan. 1962 p. 14-23.

[254] Herner, M. and S. Herner, "The Current Status of the Government Research Report in the United States of America", UNESCO Bull. Lib. 13, 187196 (1959)

[255] Herner, S., Methods of Organizing Information for Storage and Searching, Amer. Documentation 13 , 3-14 (1962).

[256] - "The Role of Theasuri in the Convergence of Word and Concept Indexing", in H. P. Luhn [ed], "Automation and Scientific Communication, Pt. 2, 1963, p. 183-184.

[257] - The Storage and Housing of Unpublished Research Reports, Amer. Documentation" 3, 110 114 (1952).

[258] Heumann, K. F., International Activities in Documentation, in L. H. Hattery and E. M. McCormick [eds], "Information Retrieval Management", 1962, p. 120-122.

[259] - The Program of the United States National Committee for FID, Amer. Documentation 14, 7881 (1963).

[260] Hicks, M. S., Government-Sponsored Research Reports in Three Areas of Physical Chemistry, J. Chem. Documentation 3, 144-148 (1963).

[261] Hillier, J., Neasuring the Value of Information Services, J. Chem. Documentation 2, 31-34 (1962).

[262] Hilsenrath. J., The Utility of Technical Reports, in B. M. Fry and J. J. Kortendick [eds], The Production and Use of Technical Reports, 1955, p. 104-110.

[263] Hilty, D. C., Cooperative Information ProcessingMetals, in J. H. Shera et al. [eds], "Documentation in Action", 1956, p. 341-342.

[264] Hines, T. C. The Collectanea as a Bibliographic Tool, PhD. Thesis (Rutgers) 1961, University Microfilms, Ann Arbor, Mich., 1961, 233 p.

[265] - Machine Arrangement of Alphanumeric Concordance, Thesaurus, and Index Entries : the Need for Compatible Standard Rules, in H. P. Luhn [ed], Antomation and Scientific Communication, Pt. 1, 1963 , p. $7-8$.

[266] Hoffmann, W. [ed], Digital Information Processors, Interscience, New York, 1962, $740 \mathrm{p}$.

[267] Holloway, A. II., The Price of Co-operation, ASLIB Proc. 13, 15-25 (1961).

[268] Holm, B. E., Information Retrieral-a Solution, Chem. Eng. Progress 57, 73-78 (1961). Also in Engineers Joint Council, "Proceedings of the EJC Engineering Information Symposium", 1962, p. $85-90$.

[269] Holmes, D. C., Photoduplication of Technical Reports, in B. M. Fry and J. J. Kortendick [eds], 
The Production and Use of Technical Reports, 1955 , р. $50-59$.

[270] Holstrom, J. E., How Translators Can Contribute to Improving Scientific Terminology, Babel 1, 7379 (1955).

[271] Hooker, R. M., Manual System at NRL Works Well, Survey Advises Against Mechanization, Navy Management Review 6, 10-11, 17 (1962)

[272] Horecky, P. L., Government Publications, American Association for the Advancement of Slavic Studies, Newsletter, Fall 1960, p. 17-18.

[273] Horty, J. F. and T. B. Walsh, Use of Flexowriters to Prepare Large Amounts of Alphabetic Legal Data for Computer Retrieval, in H. P. Luhn [ed]. Automation and Scientific Communication, Pt. 2, p. $259-260$.

[274] Howerton, P. W.. Status of Technical Information Centers, in L. H. Hattery and E. M. McCormick [eds], Information Retrieval Management, 1962, p. 31-33.

[275] Humphrey, H. H., Defense Information on Science and Technology; Key to Progress in National Research, Congressional Record 109, 18124-18129 (1963).

[276] Humphrey, R. A., The Department of State and the Acquisition of Research Materials of Foreign Origin, College and Research Libraries 7, 99-104, 108 (1946).

[277] Hutchisson, E., Cooperative Information Processing -Science Abstracting, in J. H. Shera et al. [eds], Documentation in Action, 1956, p. 279-282.

[278] Hrslop. M. R.. A Compatibility Study of Two Information Systems, Amer. Documentation 14. 292-298 (1963).

[279] - Conperative Information Processing in Metals, in J. H. Shera et al. [eds]. "Documentation in Action", 1956, p. 257-266.

[280] - International Cooperation in Metallurgical Literature Classification, Amer. Documentation 4, 1-3 (1953).

[281] Intermittent Publications, Science 125, 487-4S8 (1957)

[282] International Conference on Science Abstracting, 1949, Final Report, UNESCO, Paris, 1949, 1 v.

[283] International Congress on Medical Librarianship. 1st, London, July $20-25,1953$, Proceedings, Libri 3, 9-16, 258-278, 285-294, 402-418 (1954).

[284] International Federation for Documentation. Modern Documentation and Information Practices, The Hague, 1961, 225 p.

[285] International Federation for Documentation, Proceedings of the International Study Conference on Classification for Information Retrieval, ASLIB, London; Pergamon, New York, 1957, $151 \mathrm{p}$.

[286] International Federation of Library Associations, International Conference on Cataloguing Principles: Preliminary Official Report, UNESCO Bull. Libraries 16, 53-63 (1962).

[287] - International Conference on Cataloguing Principles: Report, (held in Paris, Oct 9-18, 1961), London, 1963, $293 \mathrm{p}$.

[288] Intermational Organization" for Standardization, Standardizaton in the Domain of Documentation, The Hague, $1954,60 \mathrm{p}$.

[289] International Union of Pure and Applied Chemistry, A Proposed Interuational Chemical Notation, Tentative Version Subject to Revision, Longmans, Green, New York, 1958, $165 \mathrm{p}$.

[290] Italy-United States Exchange Manuscripts on Paper Tapes, Scientific Information Notes 5, 1 (1963).

[291] Jackson, E. B., Acquisitions: Sources and Techniques, Amer. Documentation 3, 94-100 (1952).

[292] - The NACA Classification System-a Case History, ASLIB Proc. 5, 215-234 (1953).

[293] Jacoby, J. and V. Slamecka, Indexer Consistency Under Minimal Conditions, Contract AF 30 (602)
2616, Documentation, Inc., Bethesda, Md., Nov $1962,1 \mathrm{v}$.

[294] Janaske, P. C. [ed], Automation and Scientific Communication, (Proceedings of the 26th Annual Meeting of the American Documentetis Institute, Oct 6-11, 1963), American Documentation Institute, Washington, D.C., 1964, Pt. 3, p. 385-489.

[295] Jaster, J. J., A Note on Descriptors, Amer. Documentation 13, 433-434 (1962).

[296] - Subsumption Scheme for Dictionary of Indexing Equivalents, Technical rept. No. IR-3, Contract NSF C-259, Datatrol Corp., Silver Spring, IId., Feb $1963,1 \mathrm{v}$

[297] Jaster, J. J., H. R. Murray and M. Taube, The State of the Art of Coordinate Indexing, Contract NSF C-147, Documentation, Inc., Bethesda, Md., Feb. $1962,256 \mathrm{p}$.

[298] Jensen, R. A. The Function of the National Federation of Science Abstracting and Indexing Services, Spec. Libraries 52, 555-557 (1961).

[299] - A National Plan for Science Abstracting and Indexing Services, in H. I'. Luhn [ed], Automation and Scientific Communication, Pt. 2, 1963, p. $339-342$.

[300] - [ed], Proceedings of the Annual Meeting 1962 , National Ferleration of Science Abstracting and Indexing Services, Washington, D.C., $1963,110 \mathrm{p}$.

[301] - Proceedings of Sixth Annual Meeting, National Federatiou of Science Abstracting and Indexing Services, Washington, D.C., 1963, $1 \mathrm{v}$.

[302] A Joint College/Industry Library with Automata, prepared for Harvey Mudd College, Science and Engineering, Claremont, Califoruia, reprinted by the Council on Library Resources, Ine., Washington, D.C., $1964,35 \mathrm{p}$.

[303] Jolley, L., International Conference on Cataloguing Principles II. Thoughts After Paris, J. Documentation 19, 47-62 (1963).

[30t] Jumpelt, R. W., Towards a FIT-Policy in Scientific and Technical Translation, Babel 1, 21-25 (1955).

[305] Kaiser, F. E., Translators and Translations: Services and Sources, Special Libraries Association, New York, 1959.

[306] Kelsey, F. E., A National Drug Information Clearinghouse, in R. A. Jensen [ed]. Proceedings, of Sixth Annual Meeting, 1963 , p. 67-72.

[307] Kenney, B. L., Cooperative Centralized Processing, A Report of the Establishment and First Year of Operation of the Southwest Missouri Library Service, Inc., American Library Association, Chicago, 1959, 98 p.

[308] Kent, A., Cooperative Information Processing, in J. H. Shera et al. [eds], Documentation iu Action, $1956, \mathrm{p}, 27-41$.

[309] - Digital Computer Use in Medical Bibliography, Methods of Information iu Medicine 1, 109-120 (1962).

[310] - [ed], Information Retrieval and Machine Translation (Part I), (Based on the International Conference for Standards on a Common Language for Machiue Searching and Translations, Cleveland, Ohio, Sep 6-12, 1959), Interscience Publishers, New York, 1960, 686 p.

[311] - Information Retrieval-Review and Prospectus, in C. M. Popplewell [ed], Information Processing 1962,1963 , p. 267-272.

[312] - Textbook on Mechanized Information Retrieval, Interscience, New York, 1962, $268 \mathrm{p}$.

[313] — Their Own Devices, Wilson Library Bull. 37, 276-277, 291 (1962).

[314] Kent, F. L., Periodica Abbreviata and International Standardization, J. Documentation 10, 59-64 (1954).

[315] Kilgour, F. G., R. T. Esterquist and T. P. Fleming, Computerization of Book Catalogues at the Columbia, Harvard and Yale Medical Libraries, in H. P. Luhn [ed], Automation and Scientific Communication, Pt. 2, 1963, p. 299-300. 
[316] King, A., The Work of International Organizations and Foreign Documentation Centers, ASLIB Proc. 7, 3-14 (1955).

[317] King, E. F., Electronic Transmission for Interlibrary Loans, Amer. Documentation 11, 32-39 (1960).

[318] King, G. W. [ed], Automation and the Library of Congress, (a survey sponsored by the Council on Library Resources, Inc.), Library of Congress, Washington, D.C., 1963, 88 p.

[319] - The Automation of Library Systems, in B. E. Markuson [ed], Libraries and Automation, 1964, p. 233-244.

[320] Knox, W. T., How Much Information Service, J. Chem. Documentation 2, 27 (1962).

[321] Kochen, M., Toward Document Retrieval Theory: Relevance-Recall ratio for Texts Containing One Specified Query Term, in P. C. Janaske [ed], Automation and Scientific Communication, Pt. 3, 1964, p. 439-442.

[322] Koelewijn, G. J., Recent Developments in Western Europe in the Field of the Automation of Document Retrieval Systems, Rev. Int. Doc. 29, 42-48 (1962).

[323] Kraft, D. H., Application of IBM Equipment to Library Mechanization, Keyword-in-Context (KWIC) Indexing and the Selective Dissemination of Information, in H. Groldhor [ed], Proceedings of the 1963 Clinic on Library Applications of Data Processing, 1964, p. 133-156.

[324] Kuentzel, L. E. [ed], Coden for Periodical Titles, ASTM Special Technical Publication No. 329, American Society for Testing and Materials, Philadelphia, 1963, 426 p.

[325] Kyle, B. R. F., Information Retrieval and Subject Indexing: Cranfield and After, J. Documentation 29, 55-69 (1964).

[326] Ladd, D. L., ICIREPAT 1963-Progress, Pitfalls, and Prospects, (Press release of address for the third annual meeting of the Committee for International Cooperation in Information Retrieval among Examining Patent Offices (ICIREPAT) at the Patent Office of the Federal Republic of Austria, Vienna), Department of Commerce, Washington, D.C., 1963, 7 p. See also Keynote Address in $\mathbf{H}$. Pfeffer [ed], Information Retrieval among Examining Patent Offices, 1964, p. 11-17.

[327] Landau, T., [ed], Encyclopedia of Librarianship, Hafner Publishing Co., New York, 1958, 334 p.

[328] Langenbeck, E. H., NOL Suggests Cooperative Cataloging. Plan to Reduce Information Costs Includes All Defensive Activites, Navy Management Review 6, 12-23, 17 (1962).

[329] - A Plan to Reduce Costs of Technical Library Operations in the Department of Defense, Amer. Documentation 13, 295-300 (1962).

[330] Larkey, S. V., The Army Medical Library Research Project at the Welch Medical Library, Bull. Med. Lib. Assoc. 37, 121-124 (1949).

[331] - Cooperative Information Processing-Prospectus-Medicine, in J. H. Shera et al, [eds], Documentation in Action, 1956 , p. 301-306.

[332] - The Welch Medical Library Indexing Project, Bull. Med. Lib. Assoc. 41, 32-40 (1953).

[333] Lee, M. O., Responsibilities for Scientific Information in Biology: Proposal for Financing a Comprehensive System, in National Academy of Sciences-National Research Council, Proceedings of the International Conference on Scientific Information, Vol. 2, 1959, p. 1417-1427.

[331] Library Association, Gt. Britain, Searborough Conference, Sep. 13-16, 1960. Proceedings, Papers and Summaries of Discussions, Iondon 1960, $79 \mathrm{p}$.

[335] - Southport Conference, Sep 19-23, 1955. Proceedings, Papers and Summaries of Discussions, London, 1955, $101 \mathrm{p}$.

[336] Library of Congress, Automation and the Library of Congress, Washington, D.C., 1963, 88 p.
[337] - The Cataloging-in-Source Experiment, Wash. ington, D.C., 1960, 199 p.

[338] - Subject Headings Used in the Dictionary Catalogs of the Library of Congress, 6th ed., Wash. ington, D.C., $1957,1357 \mathrm{p}$.

[339] - National Referral Center for Science and Tech. nology, A Directory of Information Resources in the United States, GPO, Washington, D.C., 1965, $352 \mathrm{p}$.

[340] Liebesny, F., Co-operative Action: What Can Be Learned from Abroad, ASLIB Proc. 12, 149-151 (1960). Conference on Technical Translation London, 15 January 1960.

[341] - International Co-operation in Abstracting: An Experiment, in Association of Scientific Libraries and Information Bureaus, Looking Forward in Documentation, 1964, p. 4-19 to 4-21.

[342] - Lost Information: Unpublished Conference Papers, in National Academy of Sciences-Nationa] Research Council, Proceedings of the Interna tional Conference on Scientific Information, Vol. 1,1959, p. $475-479$.

[343] Lipetz, B. A., Labor Costs, Conversion Costs, anc Compatibility in Document Control Systems Amel. Documentation 14, 117-122 (1963).

[344] Little, Arthur D., Inc., Centralization and Documentation, Final report to the National Science Foundation, C-64469, Cambridge, Mass., July 1963, 70 p., and Appendix, 1 v.

[345] - Appendices to Final Report, Cambridge, Mass., July 1963, 178 p.

[346] Lloyd, G. A., Select List of Standards and Other Aids for Editors and Publishers of Technical Literature, ASLIB Proc. 6, 282-286 (1954).

[347] - Members' Forum : Standards in Documentation, ASLIB Proc. 7, 49-54 (1955).

[348] Lockheed Aircraft Corp., An Evaluation of Information Retrieval Systems, Rept. no. 7170, Burbank, Cal., Sep. 30, 1959, 114 p.

[349] Lubetzky, S., Code of Cataloging Rules: Author and Title Entry, American Library Association, Chicago, 1960, 86 p.

[350] Luckett, G. R., Partial Library Automation with the Flexowriter Writing Machine, Lib. Res. Tech Services 1, 207-210 (1957).

[351] Ludington, F. B., The American Contribution to Foreign Library Establishment and Rehabilitation, Lib. Quarterly 24, 192-204 (1954).

[352] Luhn, H. P., Auto-Encoding of Documents for Information Retrieval Systems, in M. Boaz [ed], Modern Trends in Documentation, 1959, p. 45-58.

[353] - Automated Intelligence Systems, in L. H. Hattery and E. M. Mccormick [eds], Information Retrieval Management, 1962, p. 92-100.

[354] - [ed], Automation and Scientific Communication, (Short Papers contributed to the Theme Sessions of the 26th Annual Meeting of the American Documentation Institute, October 6-11, 1963 ), American Documentation Institute, Washington, D.C., 1963, Part 1, p. 1-128, Part 2, p. 129384.

[355] - A Business Intelligence System, IBM J. Res. \& Dev 2, 314-319' (1958).

[356] - The IBM Electronic Information Searching System, IBM Research Center, Yorktown Hights, N.Y., 1952, 1 v.

[357] - Keyword-in-Context Index for Technical Literature (KWIC Index), Rept. no. RC-127, IBM, Yorktown Heights, N.Y., Aug 31, 1959, 16 p. Also in Amer. Documentation 11, 288-295 (1960).

[358] - A New Method of Recording and Searching Information, Amer. Documentation 4, 14-16 (1953).

[359] - Selective Dissemination of New Scientific Information with the Aid of Electronic Processing Equipment, IBM Research Center, Yorktown Heigths, N.Y., Nov 30, 1959, 19 p. Also in Amer. Documentation 12, 131-138 (1961). 
[360] - A Statistical Appraoch to Mechanized Encoding and Searching of Literary Information, IBM J. Res. \& Dev. 1, 309-317 (1957).

[361] Lundy, J. T., Representation of Complex Character Sequences on an Expandable Input Keyboard, in H. P. Luhn [ed], Automation and Scientific Communication, Pt. 1, 1963, p. 115-116.

[362] Lunin, L. F. and M. Stovall, Theasurus for Literature Analysis in a Cancer Research Institution: Construction and Correlation with Three National Thesauri, in H. P. Luhn [ed], Automation and Scientific Communication, Pt. 2, 1963.

[363] Maass, W. G., New Information Services from a Not-So-Old Publishing House, J. Chem. Documentation 2, 46-48 (1962).

[364] MacDonald, M. R., Cataloging at the Armed Forces Medical Library, 1945-1952, J. Cataloging and Classification IX, 58-78 (1953).

[365] MacPherson, J., World Communications: The Impact of Speed, Nature 168, 446-448 (1951).

[366] MacWatt, J. A., Improving Scientific Communication: Reprints Directly Available From The Publisher at a Reasonable Fee Could Supplement Today's Journals, Science 134, 313-316 (1961).

[367] Mahany, P. R., W. A. Creager and S. Herner, Functional Symbols Currently in Use in Government Reports, Final report on Contract NSF213, Herner and Co., Washington, D.C., Dec $1962,121 \mathrm{p}$.

[368] Maloney, C. J., Abstract Theory of Retrieval Coding, in National Academy of Sciences-National Research Council, Proceedings of the International Conference on Scientifie Information, Vol 2,1959 , p. $1365-1282$.

[369] Maloney, C. J. and H. W. Batchelor, Tentative Principles of Information Retrieval in H. P. Luhn [ed], Automation and Scientific Communication, Pt. 1, 1963, p. 107-108.

[370] Marden, E. and H. R. Koller, A Surrey of Computer Programs for Chemical Information Searching, NBS Technical Note 85, office of Technical Services, Washington, D.C., Feb 1961, 84 p.

[371] Markus, J., State of the Art of Published Indexes, Amer. Documentation 13, 15-30 (1962).

[372] Markuson, B. E., [ed], Libraries and Automation, (Proceedings of the Conference on Libraries and Automation held at Airlie Foundation, Warrenton, Virginia, May 26-30, 1963, under sponsorship of the Library of Congress, National Science Foundation, Council of Library Resources, Inc.), Library of Congress, Washington, D.C., 1964, 268 p.

[373] Martin, B., JPRS: Largescale Government Translation Service, Linguistic Reporter 4, 1-2 (1962).

[374] Masterman, M., Potentialities of a Mechanical Thesaurus, Mech. Translation 3, 36 (1956). (Paper presented at the Second International Conference on Machine Translation. Held at the Massachusetts Institute of Technology, Cambridge, Mass., on Oct 16-20, 1956).

[375] - The Thesaurus in Syntax and Semantics, Mech. Translation 4, 35-43 (1957).

[376] Mattson, L., UNESCO Science Cooperation Office for Southeast Asia and its Activities, Amer. Documentation 13, 328-333 (1962).

[377] McGee, L. L., W. J. Holliman, Jr., A. Z. Loren and G. D. Adams, Compilation and Computer Updating of a Medical Sciences Thesaurus, in H. P. Luhn [ed], Automation and Scientific Communication, Pt. 2, 1963, p. 347-348.

[378] Menzel, H., Planned and Unplanned Scientific Communication, In National Academy of SciencesNational Research Council, Proceedings of the International Conference on Scientific Information, Vol 1, 1959, p. 199-243.

[379] Mersel, J. and S. B. Smith, Center for Text in Machine-Usable Form, a feasibility study under contract NSF-C 320, TRW Computer Division, Thompson Ramo Wooldridge, Inc., Canoga Park, Cal., Feb. 28, 1964, 103 p.

[380] Metcalf, K. D., J. Doe, T. P. Fleming, M. L. Marshall, L. Q. Mumford and A. D. Osborn, The National Medical Library Report of a Survey of the Army Medical Library, American Library Association, Chicago, 1944, $94 \mathrm{p}$.

[381] Metcalfe, J. W., Information Indexing and Subject Cataloging: Alphabetical, Classified, Coordinate, Mechanical, Scarecrow Press, New York, 1957,338 p.

[382] - Subject Classifying and Indexing of Libraries and Literature, Scarecrow Press, New York, 1959, $347 \mathrm{p}$.

[383] Microfiche Standards Adopted, Chem. \& Eng. News 42, 54-55 (1964).

[384] Mikhailov, A. I., On the Functioning of the AllUnion Institute for Scientific and Technical Information of the USSR Academy of Sciences, in National Academy of Sciences-National Research Council, Proceedings of the International Conference on Scientific Information, Vol. 1, 1959, p. 511-521.

[385] - Problems of Mechanization and Automation of Information Work, Rev. Int. Doc. 29, 49-56 (1962)

[386] Miller, E. E., The Genesis and Characteristics of Report Literature, Amer. Documentation 3, 91-94 (1952).

[387] Miller, T., Six Minneapolis "Insiders" Build Unique Cooperative, Spec. Libraries 54, 295-297 (1963).

[388] Mills, J., The Universal Decimal Classification, Vol. I of the Rutgers series on Systems for the Intellectual Organization of Information, S. Artandi [ed], Graduate School of Library Science, Rutgers University, New Brunswick, N.J., 1961, 132 p.

[389] Minder, T. and G. Lazorick, Automation of the Penn State University Acquisitions Department, in P. C. Janaske [ed], Automation and Scientific Communication, Pt. 3, 1961, p. 455-459.

[390] Moffit, A., Punched Card Records in Serials Acquisition, College and Research Libraries 7, 10-13 (1946).

[391] Mohrhardt, D. E., Statement, in U.S. Congress, House Committee on Science and Astronauties, Dissemination of Scientific Information, 1959, $p$. $27-40$.

[392] Mooers, C. N., The Indexing Language of an Information Retrieval System, in W. Simonton [ed] Information Retrieval Todav, 1963. p. 21-36.

[393] - The Tape Typewriter Plan: a Method for Cooperation in Documentation, Rept. no. ZTB-137, Contract AF49 (638) 376, Zator Co., Cambridge, Mass., July 1960, 22 p. Also in ASLIB Proc. 12, $277-291$ (1960).

[394] - The Zator-A Proposal, A Machine Method for Complete Documentation. Technical Bulletin no. 65, Zator Co., Boston. Mass., 1951, 20 p.

[395] Morris, J. C., The Duality Concept in Subject Analysis, Amer. Documentation 5, 117-146 (1954).

[396] - Evolution or Involution? Notes Critical of the Uniterm System of Indexing. J. Cataloging and Classification 10, 111-121 (1954).

[397] Morris, M. E. L., From One to Two Fifty: The Economics of Low Cost Bookshelf Replenishment In Association of Special Libraries and Information Bureaus, Looking Forward in Documentation, 1964 , p. $3-1$ to $3-4$.

[398] Morse, R. D., A. I. Ch. E. Information-Retrieval Activities, Amer. Documentation 13, 69-70 (1962)

[399] - Information Retrieval, Chem. Eng. Progress 57, 55-58 (1961). Also in Engineers Joint Council, Proceedings of the E.JC Information Symposium, 1962 , p. 81-84. 
[400] Mumford, L. Q., Statement, in U.S. Congress, House Committee on Science and Astronautics, Dissemination of Scientific Information, 1959, p. $1-16$.

[401] Murra, K. O., History of Some Attempts to Organize Bibliography Internationally, in $J$. H. Shera and M. E. Egan [eds], Bibliographic Organization, 1951, p. 24-53.

[402] - [ed], International Scientific Organizations : a Guide to their Library, Documentation, and Information Services, Library of Congress, Washington, D.C., 1962, $794 \mathrm{p}$.

[403] National Academy of Sciences-National Research Council, Communication Problems in Biomedical Research, Report of a Study by the Division of Medical Sciences National Academy of SciencesNational Research Council in cooperation with the Federation of American Societies for Experimental Biology and with the Institute for Advancement of Iedical Communication, Washington, D.C., Oct 31, 1963. $24 \mathrm{p}$.

[404] - Proceedings of the International Conference on Scientific Information, (held at Waslington, D.C., November 16-21, 1958), Washington, D.C., 1959, Vol. 1, p. 1-813, Vol. 2, p. 817-1635.

[405] National Aeronautics and Space Administration, Scientific and Technical Aerospace Reports, Cumulative Indexes, Jan-Mar 1963, $1 \mathrm{v}$.

[406] National Agricultural Library, Subject Heading List, Washington, D.C., July 1963, 4 v.

[407] National Bureau of Standards, National Standard Reference Data Program: Background Information. NBS 'Technical Note 194, Washington, D.C., June 1963, $18 \mathrm{p}$.

[408] National Federation of Science Abstracting and Indexing Services, A Guide to U.S. Indexing and Abstracting Services in Science and Technology, NFSAIS rept. no. 101, Washington, D.C., '1960, $79 \mathrm{p}$.

[409] - A Guide to the World's Abstracting and Indexing Services in Science and Teclinology, NFSAIS rept. no. 102, Washington, D.C., 1963, $183 \mathrm{p}$.

[410] National Federation of Science Abstracting and Indexing Services. Transliteration of the Modern Russian Alphabet, NFSAIS Standard no. 63-1, Washington, D. C. $1963.1 \mathrm{p}$.

[411] National Library of Medicine. Medical Subject Headings: Main Headings and Cross References Used in Index Medicus and National Library of Medicine Catalog, 2nd ed., Part 2 of Index Medicus, Vol. 4, no. 1, Jan. 1963.317 p.

[412] - The MEDLARS Story at the National Library of Medicine, Washington. D. C.. 1963, $74 \mathrm{p}$.

[413] - The National Library of Medicine Index Mechanization Project, Part 2 of Bull. Med. Lib. Assoc., Vol. 49, no. 1, Jan. 1961, $96 \mathrm{p}$.

[414] National Microfilm Association, Basic Standards and Specifications of the Department of Defense Fngineering Data Microreproduction System, NMA informational monograph No. 1, Annapolis, Md.. 1963. $151 \mathrm{p}$.

[415] National Resources Committee, Research-a National Resource. I. Relation of the Federal Government to Research, U.S. Government Printing Office, Washington, D.C.. 1938, 255 p.

[416] National Resources Planning Board, Research-a National Resource. II. Industrial Research, T.S. Fovernment Printing Office, Washington, D.C. $1941,370 \mathrm{p}$.

[417] The National Science Foundation ...., Library of Congress Inf. Bull. 22, 545-546 (1963).

[418] National Science Foundation. Current Research and Derelopment in Scientific Documentation, No. 11, NSF-63-5, Office of Technical Services, Washington, D.C., Nov. 1962, 440 p.

[419] — Specialized Science Information Services in the United States, A Directory of Selected Special- ized Information Services in the Physical and Biological Sciences, NSF-61-68, U.S. Government Printing Office, Washington, D.C., Nov. 1961, $528 \mathrm{p}$.

[420] The Need for a Faceted Classification as the Basis of All Methods of Information Retrieval, Library Assoc. Record 57, 262-268 (1955).

[421] Neiswender, R., Russian Transliteration-Sound and Sense, Spec. Libraries 54, 37-41 (1962).

[422] New ASA Standard Offers Coding Uniformity for Data Interchange, IBM Data Processor 7, Aug. 7, 1963,12 p., special issue.

[423] New Tools for the Resurrection of Knowledge, Chem. \& Eug. News 32, 866-869 (1954).

[424] Newnan, S. M., Classified Patent Search Files, a Proposed Base for Technical Information Centers, Amer. Documentation 12, 206-209 (1961). Also in J. Pat. Off. Society 43, 418-434 (1961).

[425] - Information Retrieval Research in the U.S. Patent Office, MULL (Modern Uses of Logic in Law ) 1, 45-55 (1960). Also in J. Pat. Off. Society 42, 731-741 (1960).

[126] Newman, S. M., Storage and Retrieval of Contents of Technical Literature: Nonchemical Information. First Supplementary Report, Patent Office Research and Development rept. No. 4, Washington, D.C., 195\%, 16 p. See Andrews, D. D. and S. M. Newman for original report.

[427] - Second Supplementary Report, Patent Office Research and Development rept. No. 12, Washington, D.C., 1958, 12 p.

[428] - R. W. Swanson and K. C. Knowlton, A Notation System for Transliterating Technical and Scientific Texts for Use in Data Processing Systems, in A. Kent [ed], Information Retrieval and Machine Translation (Part I), 1960, p. 345-376.

[428] Newman, S. M., R. W. Swanson and K. C. Knowlton, A Notation System for Transliterating Technical and Scientific Texts for Use in Data Processing Systems, in A. Kent [ed], Information Retrieval and Machine Translation (Part I), 1960, p. 345376 .

[429] Niwa. Y. X., Present State of Mechanization of Documentation in Japan, Rev. Int. Doc. 29, 63-65 (1962).

[430] Nugent, iv. R., The Automated Editing of Text via Computer and Off-Line Devices, in H. P. Luhn [ed], Automation and Scientific Communication, Pt. 1. 1963, p. 125-126.

[431] - A Machine Language for Document Transliteration, preprint, 14th National Conference of the Association for Computing Machinery, Cambridge, Iass. Sep 1959, $33 \mathrm{p}$

[432] Oak Ridge National Laboratory, Key Word Index : Laboratory Reports Received, Semiannual index, Jan-June 1963, Oak Ridge, Tenn., 89 p.

[433] O'Brien, I. C., Recent Activities in Foreign Exchanges, in H. P. Luhir [ed], Automation and Scientific Communication, Pt. 2, 1963, p. 203-204.

[434] O'Donnell, T. R., J. L. Lewis and J. I. Glendinning, Federal Government's System for Distributing Its Unclassified R \& D Reports, Contract NSF C-224, Joln I. Thompson Co., Washington, D.C., June 20, 1962. $1 \mathrm{v}$.

[435] Oellrich, G. L., Cataloging and Classification, in H. Orlans [ed], Federal Departmental Libraries: a Summary Report of a Survey and a Conference, 1963 , p. $67-72$.

[436] Orlans, H., [ed], Federal Departmental Libraries: A Summary Report of a Survey and a Conference, Brookings Institute, Washington, D.C., 1963, $150 \mathrm{p}$.

[437] Orne, J., Resources of Foreign Scientific Literature: Acquisition on a National Scale, Amer. Documentation 14, 229-233 (1963)

[438] Ornsen, K. C. and R. L. Paddock, Industry-Committee Guidance of a Centralized Abstracting Service, J. Chem. Documentation 1, 45-47 (1961). 
[439] Orr, R. H., Letter to the Editor, Amer. Documentation 14, 330-331 (1963).

[440] Orr, R. H., G. Abdian, C. P. Bourne, E. B. Coyl, A. A. Leeds, and V. M. Pings, The Biomedical Information Complex Viewed as a System, Federation Proceedings 23, 1133-1145 (1964).

[441] Orr, R. H. and V. M. Pings, Document Retrieval: The National Biomedical Library System and Interlibrary Loans, Federation Proceedings 23, 1155-1163 (1964).

[442] Orr, R. H., V. M. Pings and A. A. Leeds, Reference Retrieral Tools: Biomedical Abstracting and Indexing Services, Federation Proceedings $\mathbf{2 3}, 1164$ 1176 (1964).

[443] Osborn, A. D., Cataloging and Cataloging Codes in Other Countries Today, Lib. Quarterly \$6, 276285 (1956).

[444] - The Future of the Union List of Serials, College and Research Libraries 15, 26-28, 118 (1954).

[445] Painter, A. F., An Analysis of Duplication and Consistency of Subject Indexing Involved in Report Handling at the Office of Technical Services, Contract CC-4753. Office of Technical Services, Washington, D.C., Mar. 1963, 135 p.

[446] Parker-Rhodes. A. F., Mechanical Translation Program Utilizing an Interlingual Thesaurus. Mech. Translation 3, 36 (1956). (Paper presented at the Second International Conference on Machine Translation, held at the Massachusetts Institute of Technology, Cambridge, Mass., on Oct. 16-20, 1956).

[447] Parkins, P. Y. New Section on Communication, Science 135, 535-536 (1962).

[48] Parthasarathy, S., INSDOC (Indian National Scientific Documentation Centre) and Its Regional Activities, Amer. Documentation 13, 334-337 (1962).

[449] Patrick, L. G., Experience of Co-operation in Translation Work, ASLIB Proc. 12, 131-135 (1960). Conference on Technical Translation, London, 15 Jan. 1960.

[450] Patrick, R. L. and D. V. Black. Index Files: Their Loading and Organization for Use, in B. E. Markuson [ed], Libraries and Automation, 1961, p. $29-53$.

[451] Pearl, R., Some Contributions of Dr. John Shaw Billings to the Derelopment of Vital Statisties, Bull. Inst. History of Medicine 6, 35 $\mathbf{7}-393$ (1938).

[452] Peiss, R.. Report on Europe, College and Research Libraries 8, 113-119 (1947).

[453] Perez-Vitoria, A.. Docmment UNESCO NX 177-a Code of Good Practice for Scientific Publications, Amer. Documentation 14, 241-243 (1963).

[454] Perry, J. W., Cooperative and Centralized Information Processing-Dream or Reality? in J. H Shera et al. [eds], Documentation in Action, 1956, p. $27-41$.

[455] Perry, J. W., A. Kent and M. M. Berry, Machine Literature Searching, Interscience, New York, 1956, $162 \mathrm{p}$.

[456] Pfeffer, H., [ed], Information Retrieval Among Examining Patent Offices, (Third Annual Meeting of the Committee for International Cooperation Among Examining Patent Offices (ICIREPAT) at the Patent Office of the Federal Republic of Austria, Vienna, September 17th through 26th, 1963), Spartan Books, Baltimore, Md., 1964, $347 \mathrm{p}$.

[457] Phelps, R. H. and J. P. Herlin, Alternatives to the Scientific Periodical: a Report and a Bibliography, UNESCO Bull. Libraries 14, 61-75 (1960)

[458] Pings. Y. M., Tniversal Classification-T'ntenable, Library Res. Tech. Services 4, 5-13 (1960)

[459] Poindron, P., Arailability of Scientific Conference Papers and Proceedings, UNESCO Bull. Libraries 16, 165-176 (1962).

[460] - La Conference Internationale sur les Principes de Catalogage, Rev. Int. Doc. 29, 18-22 (1962).
[461] - The Content, Influence and Value of Scientific Conference Papers and Proceedings, UNESCO Bull. Libraries 16, 113-126 (1962) .

[462] Popplewell, C. M., [ed], Information Processing 1962, (Proceedings of IFIP Congress, Munich. Aug 27-Sep. 1, 1962), North-Holland Publishing Co., Amsterdam, 1963, $780 \mathrm{p}$

[463] President's Science Advisory Committee, Improving the Availability of Scientific and Technical Information in the United States, White House Press Release for Dec 7, 1958, 9 p.

[464] - Science, Government, and Information, (WVeinberg report) U.S. Government Printing Office, Washington, D.C., 1963, 52 p. Also in U.S. Congress, House Committee on Education and Labor, National Information Center, Hearings ... on H.R. 1946, Appendix to Vol 1, 1963, p. 453-508.

[465] - Scientific and Technological Communication in the Government, (Crawford Task Force on Federal Scientific and Technological Information Problems), Washington, D.C., Apr 1962, 81 p. Also in U.S. Congress, House Committee on Education and Labor, National Information Center, Hearings . . on H.R. 1946, Appendix to Vol 1, 1963. p. 21-107.

[466] Proceedings of the Librarians' Convention held in New York Cits, September 15, 16, and 17, 1853, Reprinted for William H. Murray, The Torch Press, Cedar Rapids, Iowa, 1915. $63 \mathrm{p}$.

[467] Randall, G. E., Man is Measured by His Horizons, Spec. Libraries 53, 380-381 (1962).

[468] Ranganathan, S. R., Colon Classification and Its Approach to Documentation, in J. H. Shaer and II. E. Egan [eds], Bibliographic Organization, 1951, p. 94-105.

[469] - Prolegomena to Library Classification, 2nd ed., Library Association, London, 1957.

[470] - Why "Documentation"?, ASLIB Proc. 4, 105-108 1952).

[471] Ray, L. C., Keypunching Instructions for Total Text Input, in American University, Machine Indexing: Progress and Problems, 1962, p. 50-37.

[472] Readett, A. G., The Benefits of Co-operation, ASLIB Proc. 12, 152-157 (1960). Conference on Technical Translations. London, 15 January 1960.

[473] Recent Actions of the FCST Committee on Scientific Information, Scientific Information Notes 5, 2-3 (1963).

[474] Redman, H. F. and L. E. Godfrey [eds], Dictionary of Report Series Codes, Special Libraries Association, New York, 1962, 618 p.

[475] Reed, J. B., Some Impediments to Co-operation in Translations: Copright and Other Matters, ASLIB Proc. 12, 158-166 (1960). Conference on Technical Translation. London, 15 January 1960.

[476] Regional Technical Report Centers Established, Scientific Information Notes 4, 1-2 (1962).

[477] Reiteration of ACM[ Policy Toward Standardization. Comm. Assoc. Computing Machinery (1962).

[478] Reynolds. W. L., The Senate Committee on Government operations and Documentation, Amer. Documentation 12, 93-97 (1961).

[479] Rhees, W. J. [ed], The Smithsonian Institution: Documents Relative to Its Origin and History, 1835-1899, Smithsonian Institution Publications 1035 and 1036, U.S. Government Printing Office, Washington, D.C., 1901, 2 v. 1938 p.

[480] Richardson, E. C.. Some Aspects of International Library Cooperation, F. S. Cook \& Son, Yardley, Pa., 1928, $168 \mathrm{P}$.

[481] Richardson, H. G.. The Proposed Houston Technical Information Center, Spec. Libraries 54, 297-299 (1963).

[482] Richmond, P. A., Reriew of the Cranfield Project, Amer. Documentation 14, 307-311 (1963). 
[483] Richter, A. J., Z-39 Today: Its Work and Its Subcommittees, Spec. Libraries 54, 107-109 (1963).

[484] Ridenour, I. N., R. R. Shaw and A. G. Hills, Bibliography in An Age of Science, Univ. of Illinois Press, Urbana, 1951, $90 \mathrm{p}$.

[485] Rider, F., The Possible Correlation of All Forms of Microtext, Amer. Documentation 2, 152-157 (1951).

[486] - The Scholar and the Future of the Research Library: a Problem and Its Solution, Hadham Press, New York, 1944, 236 p.

[187] Roberts, M. A., The Library of Congress in Relation to Research, in National Resources Committee, Research-A National Resource. I. Relation of the Federal Government to Research, 1938, p. 235-255.

[4S8] Rogers, F. B., Facilities and Services of the National Library of Medicine, Bull. Millard Fillmore Hospital, Buffalo, N.Y., 7, 32-38 (1960).

[489] — Stresses in Current Medical Bibliography, New England J. Medicine 267, 701-708 (1962) .

[490] - and S. Adams, The Army Medical Library's Publication Program, Texas Reports on Biology and Medicine 8, 271-300 (1950).

[491] Rolling, L., A Keyword Index for Machine Documentation in the Nuclear Field, EUR/CID/4213/ 10/62/e, EURATOM, Brussels, Aug. 1962, 1 v.

[492] Rolling, L., Un Repertoire de Mots-Cles pour la Documentation Mechanisee dans le Domaine de la Technique Nucleaire, Bull. Bibliotheques de France 8, 11-25 (1963).

[493] Ross, H. McG., Considerations in Choosing a Character Code for Computers and Punched Tapes, The Computer Journal 3, 202-210 (1961).

[494] - Current Position on Standards Work Relating to Computers, The Computer Bulletin 6, 133-135 (1963).

[495] Rossheim, R. J., Report on Proposed American Standard Flowehart Symbols for Information Processing, Comm. Assoc. of Computing Machinery 6, 599-604 (1963).

[496] Rothgeb, C. L., Centralized Processing of Technical Information at the Scientific and Technical Information Facility, in H. P. Luhn [ed], Automation and Scientific Communication, Pt. 2, 1963 p. $277-278$.

[497] Rothstein, S., The Development of the Concept of Reference Service in American Libraries, 1850-1900, Lib. Quarterly 23, 1-15 (1953).

[498] Royal Society of London, Royal Society Scientific Information Conference, London, June 21-July 2, 1948 (Report and Papers Submitted), London, $1948,723 \mathrm{p}$.

[499] Rubenstein, A. H., Timing and Form of Researchers' Needs for Techical Information, J. Chem. Documentation 2, 28-31 (1961).

[500] Rubinoff, M.. Data Retrieval, text of a presentation at the Technical Forum of the Insitute of Electrical and Electronies Ingineers, Toronto, June $18,1963,4 \mathrm{p}$.

[501] Runge, G. E., [ed], Correlation Index: Document Series and PB Reports, Special Liblaries Association, New York, 1953, $271 \mathrm{p}$.

[502] Salton, G., [ed], Information Storage and Retrieval, Scientific rept. no. ISR-3, Computation Laboratory, Harvard University, Cambridge, Mass., 1 Apr $1963,1 \mathrm{v}$.

[503] Sammet, J. E., H. Ohlman and H. G. Bohnert Discussing Pros and Cons of a Special IR Language, Comm. Assoc. Computing Machinery b, 8-10 (1962).

[504] Savage, T. R., Is Yehoshua Bar-Hillel Approaching a Crisis?, Amer. Documentation 14, 331 (1963).

[505] Schuchmann, M., Bibliography of Standards on Documentation, FID publication no, 303, International Federation of Documentation, The Hague, 1961, 107 p. ; supplement, 1961, 11 p.
[506] Schuller, J. A., Experience with Indexing and Retrieving by UDC and Uniterms, ASLIB Proc. 12, $372-359(1960)$.

[507] Schullian, D. M. and F. B. Rogers, The National Library of Medicine, Lib. Quarterly 28, 1-17, 95-121 (1958).

[508] Schultheiss, L. A., D. S. Culbertson and E. M. Heiliger, Advanced Data Processing in the University Library, Scarecrow Press, New York, $1962,388 \mathrm{p}$

[509] Schultz, C. K., Editing Author-Produced Indexing Terms and Phrases Via a Magnetic-Tape Thesaurus and a Computer Program, in H. P. Luhn [ed], Automation and Scientific Communication, Pt. 1, 1963 , p. 9.

[510] - An Imaginary Panel Discussion About Indexing, in American Documentation Institute, Parameters of Information Science, Vol. 1, 1964, p. 437452 .

[511] - and C. A. Schwartz, A Generalized Computer Method for Index Productions, Amer. Documentation 13, 420-432 (1962).

[512] - and C. A. Shepherd, The 1960 Federation Meeting: Scheduling a Meeting and Preparing an Index by Computer, Federation Proceedings 19, $682-699(1960)$.

[513] Schwegmann, G. A., Jr., The Bibliographical Control of Microforms, Library Trends 8, 380-390 (1960).

[514] Sectional Committee Z39, J. Chem. Documentation 3, 123 (1963).

[515] Senders, J. W., Information Storage Requirements for the Contents of the WVorld's Libraries, Science 141,1067-1068 (1963).

[516] Sewell, W., Cooperative Information ProcessingPharmaceuticals (Summary), in J. H. Shera et al [eds], Documentation in Action, 1956, p. $267-268$.

[517] Shachtman, B. E., Documents and Information Exchange, in H. P. Luhn [ed], Automation and Scientific Communication, Pt. 2, 1963, p. 257-258.

[518] Sliaw, R. R., Documentation and the Individual, Science 137, 409-411 (1962).

[519] - Information Retrieval, Science 140, 606-609 (1963).

[520] - Parameters for Machine Handling of Alphabetic Information, Amer. Documentation 13, 267-269 (1962).

[521] - The Publication Board, College and Research Libraries 7, 105-108 (1946).

[522] - [ed], The State of the Library Art, Rutgers University Press, New Brunswick, N.J., 1960-61, 5 v.

[523] Shera, J. H., Classification as the Basis of Bibliographic Organization, in J. H. Shera and M. E. Egan [eds], Bibliographic Organization, 1951, p. $72-93$.

[524] - and M. E. Egan [eds], Bibliographic Organization (Papers presented before the Fifteenth Annual Conference of the Graduate Library School July 24-29, 1950), The Univ. of Chicago Press, Chicago, Ill., 1951, 275 p.

[525] - A. Kent and J. W. Perry [eds], Documentation in Action, (Proceedings of Conference on the Practical Utilization of Recorded Knowledge Present and Future), Reinhold Publishing Corp., New York, 1956, 471 p.

[526] - Information Resources: A Challenge to American Science and Industry, (Based upon the Proceedings of a Special Meeting of the Council on Documentation Research. February 3-4, 1958, Western Reserve University), Western Reserve University Press, Cleveland, Ohio, 1958, 214 p.

[527] Sherrod, J., Feasibility Criteria for Establishing Specialized Information Centers, in H. P. Luhn [ed], Automation and Scientific Communication, Pt. 2, 1963, p. 221. 
[528] - Functions of a Technical Information Center, in L. H. Hattery and E. M. McCormick [eds], Information Retrieval Management, 1962, p. 3436.

[529] - A Progress Report on an Experiment in Semiautomatic Indexing Conducted by the AEC Division of Technical Information Extension, in H. P. Luhn [ed], Automation and Scientific Communication, Pt. 2, 1963, p. 215 .

[530] Shilling, C. W., Requirements for a Scientific Mission-Oriented Information Center, Amer. Documentation 14, 49-53 (1963).

[531] - Status Report on the Biological Sciences Communcation Project (BSCP), in H. P. Luhn [ed], Automation and Scientific Communication, Pt. 2, 1963 , p. 205-206.

[532] Shipman, F. W., Weeding, in H. Orlans [ed], Federal Departmental Libraries: A Summary Report of a Survey and a Conference, 1963 , p. $62-66$.

[533] Simonton, W. [ed], Information Retrieval Today (Papers presented at the Institute, conducted by the Library School and the Center for Continuation Study, University of Minnesota, September 19-22, 1962), University of Minnesota, 1963, $176 \mathrm{p}$.

[534] Slamecka, V., Classificatory, Alphabetical, and Associative Schedules as Aids in Coordinate Indexing, Amer. Documentation 14, 223-228 (1963).

[535] - and J. Jacoby, Effect of Indexing Aids on the Reliability of Indexers, Final Technical note, Contract AF30(602)-2616, Documentation, Inc., Bethesda, Md., June 1963, 1 v.

[536] Smith, A., Substantive Changes in the Draft Code, June 1960-July 1961, Library Res. Tech. Services 5, 341-342 (1961).

[537] Smith, W. A., Locating Periodicals. I. The World List of Scientific Periodicals, Library Assoc. Record 55, 245-247 (1953).

[538] Smithsonian Institution, Report on the International Exchange Service for the Year Ended June 30, 1963, U.S. Government Printing Office, Washington, D.C., 1964, p. 64-73 from the Smithsonian Report for 1963.

[539] Special Librarians and the Weinberg Report, Spec. Libraries 54, 325-332 (1963).

[540] Special Libraries Association. Guide to the SLA Collection of Classification Schemes and Subject Heading Lists on Deposit at Western Reserve University as of March 20, 1961, B. R. Barden and B. Denison [comp], New York, 1961, 104 p.

[541] Sprenkle, P. M. and F. G. Kilgour, A Quantitative Study of Characters on Biomedical Catalogue Cards-A Preliminary Investigation, Amer. Documentation 14, 202-205 (163).

[542] Stanford Research Institute, A Draft Program for a National Technical Information Center Prepared by Stanford Research Institute, in U.S. Congress, House Committee on Education and Labor, National Information Center. Hearings . . . on H.R. 1946, Appendix to Vol. 1, 1963, p. $1-20$.

[543] Stevens, M. E., Availability of Machine-Usable Natural Language Material, in American University, Machine Indexing Problems and Progress, 1962 , p. 58-75.

[544] - and E. De Grolier, Summary of Discussion. Area 4, Organization of Information for Storage Search. Comparative Characteristics of Existing Systems, in National Academy of SciencesNational Research Council, Proceedings of the International Conference on Scientific Information, 1959, Vol. 1, p. 803-812.

[545] Stiles, H. E., The Association Factor in Information Retrieval, J. Assoc. Computing Machinery 8, 271279 (1961).

[546] Strieby, I. M., Cooperative Information Processing - Pharmaceuticals, in J. H. Shera et al [eds], Documentation in Action, 1956, p. 341-347.
[547] Structures of Standards-Processing Organizations in the Computer Area, Comm. Assoc. Computing Machinery 6, 294-305 (1963).

[548] A Subcommittee on Classification, Library of Congress Inf. Bull. 22, 630 (1963).

[549] Swanson, D. R., Design Requirements for a Future Library, in B. E. Markuson [ed], Libraries and Automation, 1964, p. 11-21.

[550] - Information Retrieval; State of the Art, in Proceedings of the American Federation of Information Processing Societies, Joint Computer Conference 1961, p. 239-246.

[551] - Library Goals and the Role of Automation, Spec. Libraries 53, 466-471 (1962).

[552] Taine, S. I., Bibliographic Data Processing at the National Library of Medicine, in H. Goldhor [ed], Proceedings of the 1963 Clinic on Library Applications of Data Processing, 1964, p. 109-132.

[553] - The Future of the Published Index, in American University, Machine Indexing Problems and Progress, 1962, p. 144-149.

[554] Talmadge, R. I., The Farmington Plan Survey : an Interim Report, Coll: Res. Libraries 19, 375-383 (1958).

[555] Tareev, B. M., Methods of Disseminating Scientific Information, and Science Information Activities in the USSR, Amer. Documentation 13, 338-343 (1962).

[556] Taube, M., The Cataloging of Publications of Corporate Authors, Lib. Quarterly 20, 1-20 (1950).

[557] - Experiments With the IBM-9900 and a Discussion of an Improved Comac as Suggested by These Experiments, J. Chem. Documentation 2, 22-76 (1962).

[558] - Extensive Relations as the Necessary Condition for the Significance of Thesauri for Mechanized Indexing, J. Chem. Documentation 3, 177-180 (1963).

[559] - Functional Approach to Bibliographic Organization: a Critique and a Proposal, in J. H. Shera and M. E. Egan [eds], Bibliographic Organization, 1951 , p. 57-71.

[560] - Possibilities for Cooperative Work in Subject Controls, Amer. Documentation 3, 21-28 (1952).

[561] - Storage and Retrieval of Information by Means of the Association of Ideas, Amer. Documentation 6, 1-18 (1955).

[562] Taube, M. and Associates, Studies in Coordinate Indexing, Documentation, Inc., Washington, D.C. Vol. 1, 1953; Vol. 2, 1954; Vol. 3, 1956; Vol. 4, 1957 ; Vol. 5, 1959.

[563] Tauber, M. F., Cataloging and Classification, in R. R. Shaw [ed], The State of the Library Art, Vol. 1, part 1, 1960, p. 167-251.

[564] Tauber, M. F. and Associates, Technical Services in Libraries, Columbia University Press, New York, 1954, p.

[565] Taylor, K. L. Reader Services, in H. Orlans [ed], Federal Departmental Libraries: A Summary Report of a Survey and a Conference, 1963, p. $73-77$.

[566] Technical Translation: Co-operative Action, ASLIB Proc. 12, 129-168 (1960). ASLIB Conference, London, 15 January 1960.

[567] Technical Reparations, Federal Science Progress 1, no. 3, 8-9 (1947).

[568] "There'll Be More Microfilming Soon North of the Border", Systems Management 3, 47-48 (1962).

[569] Thompson, E., [ed], A.L.A. Glossary of Library Terms with a Selection of Terms in Related Fields American Library Association, Chicago, $1943,159 \mathrm{p}$.

[570] Thompson, M., Automatic Reference Analysis, in G. Salton [ed], Information Storage and Retrieval, Scientific rept. no. ISR-3, 1963, p. II-1-II-27.

[571] Towner, I. L., [comp.], Directory of Special Libraries, Special Libraries Association, New York, 1953,297 p. 
[572] True, W. P., The First Hundred Years of the Smithsonian Institution 1846-1946, [Smithsonian Institution], Washington, D.C., Aug. 10, 1946, 46 p.

[573] Union List of Serials in Libraries of the United States and Canada, W. Gregory [ed], 2nd ed., H. W. Wilson, New York, 1943, 3063 p.

[574] - Supplement to the 2nd ed., Jan. 1941-Dec. 1943, G. E. Malikoff [ed], H. W. Wilson, New York, $1945,1123 \mathrm{p}$.

[575] - Second Supplement to the 2nd ed., Jan. 1944Dec. 1949, M. Franck [ed], H. W. Wilson, New York, 1953, 1365 p.

[576] United Nations Educational, Scientific and Cultural Organizations, Information Processing, (Proceedings of the International Conference, Paris, 15-20 June 1959), Oldenbourg, Munich; Butterwortlis, London, 1960,520 p.

[577] U.S. Air Force, Air Force Technical Objective Document [TOD] Release Program, 1964, 7 p.

[578] U.S. Atomic Energy Commission, The Literature of Nuclear Science: Its Management and Use, (Proceedings of conference held at Division of Technical Information Extension, Oak Ridge, Tenn., Sep. 11-13, 1962), TID-7647, Oak Ridge. Tenn., 1962, $398 \mathrm{p}$.

[579] - Research and Development Abstracts of the USAEC, RDA-3, Oak Ridge, Tenn., July-Sep 1962, and RDA-4, Oct.-Dec. 1962. Issues contain an experiment in automatic indexing).

[580] - Subject Headings Used by the USAEC Technical Information Service, TID-5001, 3rd ed., Oak Ridge, Tenn., 1960, $476 \mathrm{p}$.

[5S1] - Subject Headings Used by the USAEC Division of Technical Information, TID-5001, 4th ed., Oak Ridge, Tenn., 1962, 375 p.

[582] U.S. Congress, House Committee on Education and Labor, National Information Center. Hearings on H.R. 1946, S8th Cong., 1st sess., U.S. Goverument Printing Office, Washington, D.C., Vol. 1, 1963, 679 p., Appendix to Vol. 1, 1963, $508 \mathrm{p}$.

[583] - House Committee on the Judiciary, Copyright Law Revision. Report of the Register of Copyrights on the General Revision of the U.S. Copyright Law, House committee print, 87th Cong., 1st sess., U.S. Government Printing Office, Washington, D.C., 1961, $160 \mathrm{p}$.

[584] - House Commitee on Post Ofice and Civil Service, Interim Report on the Use of Electronic Data Processing Equipment in the Federal Agencies, House rept. no. 627, 88th Cong., 1st sess., U.S. Government Printing Office, Washington, D.C., 1963, 4 p.

[585] - Use of Electronic Data Processing Equipment. Part 1-Comptroller General and Department of Defense, Hearings, 88th Cong., 1st sess., U.S. Government Printing Office, Washington, D.C. 1963, $194 \mathrm{p}$.

[586] - House Committee on Science and Astronautics, Dissemination of Scientific Information, Hearings, 86th Cong., 1st sess., U.S. Government Printing Office, Washington, D.C., 1959, 182 p.

[587] - Dissemination of Scientific Information, Report of the Committee, House rept. no. 1179, 86th Cong., 1st sess., U.S. Government Printing Office, Washington, D.C., 1959, 12 p.

[588] - Research on Mechanical Translation, Hearings, 86th Cong., 2nd sess., U.S. Government Printing Office, Washington, D.C., 1960, 183 p.

[589] - House Select Committee on Government Research, Documentation and Dissemination of Research and Development Results, Study No. IV, 88th Cong., 2nd sess., U.S. Government Printing Office, Washington, D.C., 1964, 148 p.

[590] - Senate Committee on Government Operations, Coordination of Information on Current Federal Research and Development Projects in the Field of Electronics, Committee print, 87th Cong., 1st sess., U.S. Government Printing Office, Washington, D.C., 1961, 292 p.

[591] - Coordination of Information on Current Scientific Research and Development Supported by the United States Government, Report no. 263, 87th Cong., 1st sess., U.S. Government Printing Office, Washington, D.C., 1981, 286 p.

[592] - Documentation, Indexing, and Retrieval of Scientific Information. A Study of Federal and Non-Federal Science Information Processing and Retrieval Programs, Senate document no. 113, 86th Cong., 2nd sess., U.S. Government Printing Office, Washington, D.C., 1960, 283 p.

[593] - Addendum to Senate document no. 113, Senate document no. 15, 87th Cong., 1st sess., U.S. Government Printing Office, Washington, D.C., 1961, 22 p.

[594] - Sellate Committee on Government Operatons, Interagency Coordination of Information. Federal Plans for Improvement and Use of Scientific, Engineering and Other Information Systems. Hearings, 87th Cong., 2d sess., Part 1 of 2, U.S. Government Printing Office, Washington, D.C., 1962,242 p.

[595] - Senate Committee on the Judiciary, U.S. Patent Office Research and Development Program, Comgram, Committee print, 88th Cong., 1st sess., U.S. Government Printing Office, Washington, D.C., $1963,55 \mathrm{p}$.

[596] U.S. Department of Commerce, Report of the Advisory Committee on Application of Machines to Patent Office Operations, (Vannevar Bush, chairman), Washington, D.C., Dec. 22, 1954, 76 p.

[597] - Office of Technical Services, U.S. Government Research Reports, Vol. 37, Cumulative Index, Semi-annual issue, Jan.-June 1962, $590 \mathrm{p}$; JulyDec. 1962, 409 p., U.S. Government Printing Office, Washington, D.C.

[598] - Non-Military and Older Military Research Reports, Vol. 37, Cumulative Index, Issues 1-24, Jan.-Dec. 1962,150 p., U.S. Government Printing Office, Washington, D.C. (The Jan.-June 1962 cumulation is bound with its counterpart above and consists of 77 pages.)

[599] U.S. Department of the Interior, Bureau of Reclamation, Thesaurus of Descriptors : a List of Keywords and Cross-References for Indexing and Retrieving the Literature of Water Resources Devolopment, tentative edition, Denver, Colo., Oct. $1963,140 \mathrm{p}$.

[600] U.S. Nary Department, Bureau of Ships, Thesaurus of Descriptive Terms and Code Book, Ruth D. Camp [comp], 1st ed., NAVSHIPS-250-210-1, Washington, D.C., Dec. 1963,878 p.

[601] U.S. Patent Office, Guide for Patent Draftsmen, U.S. Government Printing Office, Washington, D.C., May 1961, $16 \mathrm{p}$.

[602] - 125th Anniversary of the United States Patent Act of 1836. Part II : Proceedings of the International Patent Office Workshop on Information Retrieval, U.S. Government Printing Office, Washington, D.C., 1963, p. 77-231.

[603] U.S. Public Health Service, Medical and Health Related Sciences Thesaurus, PHS publication no. 1031. Washington, D.C., Mar. 1963, 213 p.

[604] Urquhart, D. J., A Review of the Results of the Royal Society Scientific Information Conference, 1948, ASLIB Proc. 4, 233-240 (1952).

[605] Utman, R. E., Standards for Information Processing: a Progress Report, Computers and Automation 12,9-12 (1963).

[606] Vann, J. O., Defense Documentation Center (DDC) for Scientific and Technical Information, J. Chem. Documentation 3, 220-222 (1963). 
[607] Veilleux, M. P., Permuted Title Word Indexing: Procedures for Man/Machine System, American University, Machine indexing: Progress and Problems, 1962, p. 77-111.

[608] Veronese, U. H., UNEsco's Future Programme in the Field of Libraries, Libr : 10, 1-9 (1960).

[609] Vertanes, C. A., Automation Raps at the Door of the Library Catalog, Spec. Libraries 52, 237-242 (1961).

[610] Vickery, B. C., Classification and Indexing in Science, Butterworth Scientific P'ublications, London, 1958, 185 p., 2nd ed. $235 \mathrm{p}$.

[611] - Machines and Indexes, UNESCO Bull. Libraries 13. 249-252 (1959).

[612] - On Retrieval System Theory, Butterworths, London, 1961, $159 \mathrm{p}$.

[613] — Subject Analysis for Information Retrieval, in Proceedings of the International Conference on Scientific Information, National Academy of Seiences-National Research Council, 1959, Vol. 2, p. $855-865$.

[614] - Thesaurus-a New Word in Documentation, J. Documentation 16, 181-189 (1960).

[615] - The Tower of Babel: the Language Barrier in Science, in Library Association, Southport Conference, Sep. 19-23, 1955. Proceedings, Papers and Summaries of Discussions, 1955 , p. 76-84

[616] - The Universal Decimal Classification and Technical Information Indexing, UNESCO Bull. Libraries 15, 126-147 (1961).

[617] Visscher, M. B., The Interdependence of Knowledge and Information in the World Today, Lib. Quarterly 24, 81-91 (1954).

[618] Wagner, F. S., Jr., A Dictionary of Documentation Terms, Amer. Documentation 11, 102-119 1960).

[619] Wahlin, E., Principles for a [niversal System of Classification Based on Certain Fundamental Concepts and an Outline of a Variant Adapted to Technology, J. Documentation 19, 173-186 (1963).

[620] Wall, E., An Action Plan for the Engineering Profession, in American Association for the Adrancement of Science, Information Systems-Essential Tools in Engineering Application of Science for the Needs of Society, 1963, p. 16-20

[621] - Action Plan for Improved Dissemination of Engineering Information, Progress rept. No. 1 (rev), Grant NSF-G-24836, Engiweers Joint Council, New York, Nov. 23, 1962, 17 p.

[622] - First Revision of the Thesaurus of ASTIA Descriptors, Final rept. on Contract AF 18(600) 1944, Engineers Joint Council, New York, Aug. 6, 1962, 19 p.

[623] - Information Retrieval Thesauri, Engineers Joint Council, New York, Nor. 1962, 17 p.

[624] - A Practical System for Documenting Building Research, in U.S. Congress, Senate, Committee on Government Operations, Documentation. Indexing, and Retrieval of Scientific Information, 1961, p. $180-203$.

[625] - A Unified Engineering Vocabulary for Use in Information Dissemination Indexing, Storage, and Retrieval, in H. P. Luhn [ed], Automation and Scientific Communication, Pt. 1, 1963, p. $37-38$.

[626] Walton, T. S., A Formal Indexing Language for Automated Document Retrieval Systems, in H. P. Luhn [ed], Automation and Scientifie Communication, Pt. 1, 1963, p. 21-22.

[627] Warheit, I. A., Bibliographic Identification and Organization, Amer. Documentation 3, 105-110 (1952)

[628] - Evaluation of Library Techniques for the Control of Research Materials, Amer. Documentation 7,267-275 (1956).

[629] - Review of Centralization and Documentation, (Little, Arthur D.. Inc report), Documentation Progress 6, 3-4 (1963).
[630] Waterman, A. T., The Future of Report Literature, in B. M. Fry and J. J. Kortendick [eds], The Production and Use of Technical Reports, 1955, p. 3-S.

[631] Weber, D. C., A Quagmire of Scientific Literature? College and Research Libraries 18, 103-106, 118 (1957).

[632] - The Road to a Bibliographic Utopia, D.C. Libraries, 27, 2-6 (1956).

[633] Weik, M. H. and V. J. Confer, Survey of Scientific and Technical Information Retrieval Schemes Within the Department of the Army, BRL rept. no. 1169, Ballistic Research Labs., Aberdeen Proving Ground, Md., July 1962, 95 p.

[634] Weil, B. H., Cooperative Information ProcessingPetroleum, in J. H. Shera et al [eds], Documentation in Action, 1956, p. 34S-354.

[635] Weil, B. H., E. H. Brenuer, K. Ornsen, R. Paddock, J. Raymond and S. Winn, Coordination of Documentation Research and Information Services by the American Petroleum Institute, Amer. Documentation 12, 56-60 (1961).

[636] Weinberg, A. M., The Government Looks at Science Abstracting and Indexing Services, in B. A. Jensen [ed], Proceedings of Sixth Annual Meeting, 1963, p. 1-14.

[637] - Scientific Communication, International Science and Technology, No. 16, Apr 1963, p. 65, 67-68, $71-72,74$.

[638] Weinstein, E. A. and J. B. Spry, Boeing SLIP : Computer Maintained Printed Book Catalogs, in H. P. Luhn [ed], Automation and Scientific Communication, Pt. 2, 1963, p. 233-23!.

[639] Wellisch, H., New Publication Methods for the UDC, A Proposal, Rev. Int. Doc. 97, 145-148 (1960).

[610] Welt, I. D., A Combined Indexing-Abstracting System, in Proceedings of the International Conference on Scientific Information, National Academy of Sciences-National Research Council, 1959, Vol. 1, p. $449-459$.

[641] - Indexes aud Index Mechanization in Biomedicine, J. Chem. Documentation 3, 169-174 (1963).

[642] Wessel, C. J. and W. M. Bejuki, Evaluation of Document Control in a Materials Deterioration Information Center, in National Academy of Seiences. National Researeh Council, Proceedings of the Internatonal Conference on Scientific Information, Vol 1, 1959, p. 731-761.

[613] Where the Computer Fits in Command and Control, Armed Forces Management 8, 22-24 (1962).

[614] Whitby, T. J., National Bibliography in the U.S.S.R., Lib, Quarterly 23, 16-22 (1963).

[645] Wichers, E., The Role of the Internatioinal Union of Pure and Applied Chemistry, J. Chem. Documentation 3, 7-11 (1963).

[616] Wilkinson, W. A. and W. H. Waldo, New Information Services-A Practical Approach, J. Chem. Documentation 2, 175-177 (1962).

[617] Williams, E. E., Farmington Plan Handbook, Assoc. of Research Libraries, Harvard Printing Office, Cambridge, Mass. 1953.

[618] Williams, T. M., Translating from Ordinary Discourse into Formal Logic-a Preliminary Systems Study, rept. on Contract AF 19 (604)1582, ACF Industries Inc., Alexandria, Va., Sep.-Nov. 1956, $110 \mathrm{p}$.

[649] Wilson, C. D., and G. A. Hamel, Developments in the European Translations Centre, Rev. Int. 30, 51-54 (1963).

[650] Winchell, C. M., Guide to Reference Books, th ed., American Library Association, Chicago, 1951, $645 \mathrm{p}$.

[651] Wofsey, M. M., An Analysis of Four COBOL Specifications, bulletin no. 5, Center for Technology and Administration, American Univ., Washington, D.C., Mar 1962, 21 p. 
[652] World List of Scientific Periodicals Published in the years 1900-1950, W. A. Smith and F. L. Kent [eds], 3rd ed., Academic Press, New York; Butterworths, London, 1952, $1058 \mathrm{p}$.

[653] Wright, M., The British Iron and Steel Industry Translation Service, ASLIB Proc. 12, 136-143 (1960). Conference on Technical Translation, Iondon, 15 January 1960.

[654] Wright, P., U. S. Computer Industry Can Capture European Market, Electronies Weekly, No. 156, Aug 28, 1963, p. 10.

[655] Wright, W. E., A Report on Progress on Catalog Code Revision in the United States, Lib. Quarterly 26, 331-336 (1956).

[656] — Standards for Subject Heading: Problems and Opportunities, J. Cataloging and Classification 10, 175-178 (1954).
[657] Wyart, J., Scientific Documentation in France, in National Academy of Sciences-National Research Council, Proceedings of the International Conference on Scientific Information, Vol. 1, 1959, p. $605-611$.

[658] Wyllys, R. E., Letter to the editor, Amer. Documentation 14, 330 (1963).

[659] Yerkes, C. P., Microfiche, a New Information Media, in H. P. Luhn [ed], Automation and Scientific Communication, Pt. 2, 1963, p. 129.

[660] Zusman, T. S., M. S. Thompson, J. B. Wilson, L. S. Rotolo and T. D. Gomery, Selected Bibliography of the International Geophysical Year: An Example of Tabledex Formats, National Biomedical Research Foundation, NBR and the Library of Congress, Rept. No. 62071/18100, Washington, D.C., July 1962, 109 p. 

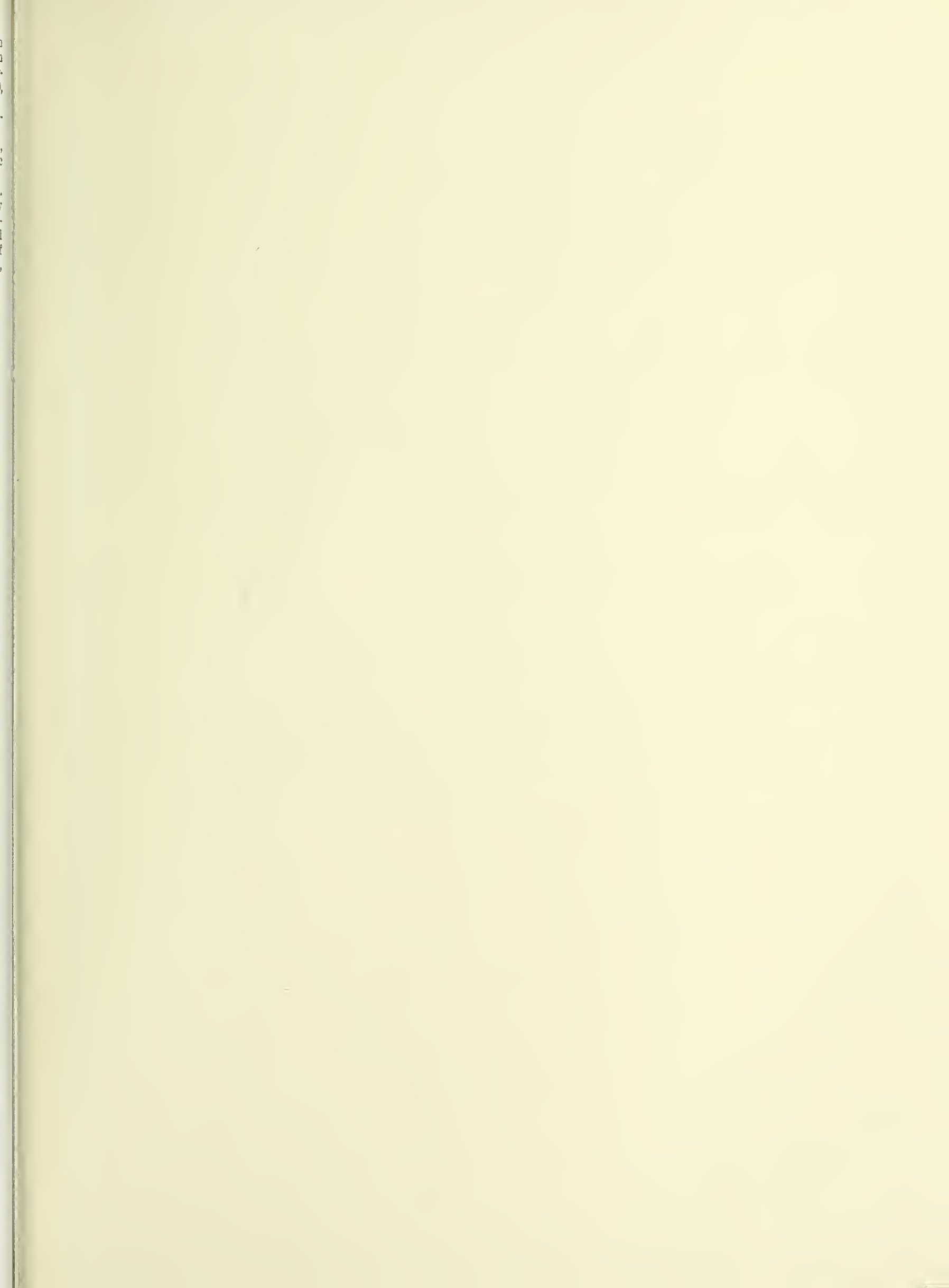


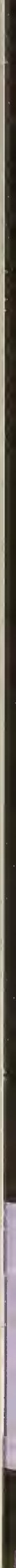

